Aus dem pathologisch-anatomischen und bakteriologischen Institut der k. k. Krankenanstalt Rudolfstiftung in Wien (Vorstand: Hofrat Prof. Dr. R. Paltauf).

\title{
Klinische und experimentelle Untersuchungen über die Einwirkung von Anilinfarbstoffen auf die menschliche und tierische Haut. $\left.{ }^{1}\right)$
}

\author{
Von Dr. Otto Sachs. \\ (Hiezu Tat. XXIX-XXXII.)
}

\section{Einleitung.}

Das große Gebiet der unter dem Sammelnamen der Gewerbekrankheiten zusammengefaßten Erkrankungen ist mit der Zunahme der industriellen Unternehmungen, ihren komplizierten Technizismen in steter Erweiterung begriffen. Es besteht wie bei allen Erkrankungen bekanntlich auch bei den Gewerbekrankheiten ein inniger Kausalnexus zwischen bedingenden Schädlichkeiten und bedingten Schädigungen. Außer diesen kommt noch ein Faktor in Betracht, der auch bei dieser Gruppe von Erkrankungen nicht vernachlässigt werden kann: es ist dies die individuelle Dispositjon.

Weder die klinische Beobachtung, noch das Tierexperiment geben uns darüber Aufschluß, warum in dem einen Falle bei längerer Dauer der Finwirkung z. B. von pulverförmigen Anilinfarbstoffen auf die menschliche Haut völliges Intaktbleiben derselben $z u$ konstatieren ist, in einem anderen ein Ekzem oder papillomatöse Exkreszenzen auftreten. Trotz dieser offenkundigen Lücke in der Pathogenese dieser Erkrankungen lassen sich im Anschlusse an klinische Beobachtungen besonders ïber die Einwirkung von pulvertörmigen Anilinfarbstoffen auf die menschliche Haut, sowie auf Grundlage experimenteller Untersuchungen auf die tierische mit den in verschiedenen Betrieben verwendeten Anilinfarbstoffen eine Reihe von Tatsachen konstatieren, die, auf pathologisch-anatomischer Basis gestützt, die

1) Die vorläufige Mitteilung zu dieser Arbeit ist in der Wiener klin. Wochensohrift, 1911, Nr. 45, erschienen. 
komplizierten Vorgänge der Genese solcher Erkrankungen unserer Erkenntnis ein wenig näherzubringen geeignet sind.

Meine klinischen, experimentellen und tberapeutischen Untersuchungen über die Einwirkung von Anilinfarbstoffen auf die menschliche und tierische Haut bilden gleichzeitig Beiträge zur Ätiologie der Dermatitis arteficialis, des Eccema verrucosum, sowiezur Geneseron Hautpapillomen.

Diese in der vorliegenden Arbeit zu erörternden Fragen beanspruchen nicht nur für den Patbologen und Dermatologen, sondern auch für den Chemiker und den Gewerbehygieniker weitgehendstes Interesse, und gewinnen dadurch für manche Gebiete der sozialen Medizin eine praktische Bedeutung.

Die vorliegende Arbeit zerfällt in folgende drei Teile:

I. Klinische Beobachtungen über die Einwirkung von Anilinfarbstoffen a d die menschliche Haut.

II. Experimentelle Untersuchungen über die Einwirkung von Anilinfarbstoffen auf die tierische Haut.

III. Therapeutische Anwendung von Anilinfarbstoffen in Form von Streupulvern, Salben, zur Behandlung von granulierenden Wuaden, Ulcera cruris etc.

Herrn Hofrat Prof. Paltauf bin ich für die außerordentliche Förderung meiner Arbeit und die vielen Ratschläge, Herrn Dozenten Dr. Maresch für seine liebenswürdige Unterstützung zu besonderem Danke verpflichtet.

\section{Teil.}

\section{Klinische Beobachtungen über die Einwirkung von Anilin- farbstoffen auf die menschliche Haut.}

1. Bisherige klinische Beobachtungen aus der Literatur. gemengt.

2. Einwirkung von Anilinfarbstoffen mit Terpentin, Firnis etc.

3. Einwirkung von mit Anilinfarbstoffen gefärbter Wolle.

4. Einwirkung von trocknen, pulverförmigen Anilinfarbstoffen.

5. Zusammenfassung der Resultate und Epikrise.

6. Literatur.

Bevor ich meine eigenen klinischen Beobachtungen, die sich einerseits auf Fälle von Einwirkung von pulverförmigen Anilinfarbstoffen, andererseits von mit Firnis, Terpentin etc. vermengten auf die menschliche Haut beziehen, mitteile, möchte ich einige Angaben aus der Literatur, soweit dieselben unmittelbar oder mittelbar mit dieser Frage in Zusammenhang stehen, erwähnen. 
Zur besseren Orientierung einiger oft sich wiederholender Fachausdrücke chemischer oder chemisch-technischer Natur wird es angezeigt sein, zunächst die Darstellung ron Anilin und Teerfarbstoffen, sowie Einteilung und Eigenschaften derselben einer kurzen Besprechung zu unterziehen.

Diese entnehme ich den Arbeiten von Goldschmidt, Heinzerling, Helbig, Roth, Weyl über die Hygiene der chemischen Großindustrie aus dem Handbuch der Hygiene, ferner den Arbeiten ron $\mathrm{H}$ of fmann-Halle, Weber, Grandhom $\mathrm{me}^{1}$ ), Eulenburg u. a.

Der Teer wird aus den Leuchtgasfabriken, Kocksanstalten und den sonstigen Gewinnungsplätzen in die chemischen Fabriken geliefert und von diesen in die Rohstoffe, Zwischenprodukte und Farbstoffe verwandelt. Das bei der trocknen Destillation von Steinkohlen oder durch Reduktion von Nitrobenzol mit Zink und Salzsäure oder anderen Reduktionsmitteln entstehende Anilin (Amidobenzol) ist in reinem Zustande eine farblose, aromatisch riechende, etwa $\mathrm{zu} 3 \%$ in Wasser lösliche, bei $184^{\circ}$ siedende Flüssigkeit. Gewöhnliches, zur Farbenbereitung verwertetes Anilin ist ein wechselndes Gemisch von Anilin und Tolujdin, mitunter auch Xylidin. Das Anilin bildet gut kristallisierende Salze. Vergiftungen damit kommen bei Arbeitern durch Inhalation vor, selten bei der medizinalen äuberen oder innerlichen Anwendung des Mittels und bisweilen auch durch Aufnahme von Anilinfarbstoffen in Fruchtsäften, Konditoreiwaren, sowie durch Bekleidungsgegenstände.

Die Grundlage sämtlicher Fabrikationszweige bilden erstens das Benzol und dessen Homologe, zweitens das Naphthalin und drittens das Anthrazen. ${ }^{2}$ ) Aus diesen Rohmaterialien werden die Farbstoffe dargesteilt.

Unter Farbst offen versteht man diejenigen Stoffe, welche mehr oder weniger Verwandtschaft zu der tierischen oder pllanzlichen Faser haben und sich mit derselben unmittelbar oder mittelbar fest verbinden. Dazu sind meist schwach basische oder schwach saure Eigensehaften erforderlich. Ein Farbstoff ist echt, wenn er durch äußere Einflüsse unverändert bleibt. Man unterscheidet Licht-, Wasch-, Dampf-, Walkecht-

1) Der Aktien-Gesellschaft Farbwerke vorm. Meister Lucius \& Brünning in Höchst a. M. danke ich bestens für die freundlịche Überlassung eines Sep.-Abdr. von Sanitätsrat Dr. Grand hom $\mathrm{me}$ : „Über die Fabriken der Aktien-Gesellschaft Farbwerke vorm. Meister Lucius \& Brünning zu Höchst a. M. in sanitärer und sozialer Beziehung." 4. Auflage 1896.

2) Alizarinfarbstoffe leiten sich vom Anthrazen ab. Anthrazen ist ein Bestandteil des Steinkohlenteers. Die genaueren Details über die Farbenfabrikation finden sich in oben genannten Arbeiten. (Grandhomme, Weyl etc.) 
heit, ferner Echtheit gegen Seifen, Säuren und Alkalien. Die Farbstoffe kommen in den Handel als Pulver oder Paste, sind dann häufig mit Dextrin, schwefelsaurem Natron, Soda oder Salmiak versetzt. Die Coupage ist notwendig, um den Kousumenten stets die gleiche Nuance des Farbstoffes zu liefern, da dieser bei der Fabrikation nicht immer dieselbe Schattierung erhält. Sie sind im festen Zustande anders gefärbt als in Auflösung, in welcher sie mit derselben Farbe erscheinen wie auf Geweben.

Die Farben. färben entweder direkt und heißßen dann substantive, oder mit Hilfe von Beizen und heißen dann adjektive Farben.

Als Beizen dienen die essigsauren Salze von Blei, Eisenoxyd und Chromoxyd, ferner Alaun, Chlorzinn, Brechweinstein, Tannin, Stärke und Eiweiß.

Die Farbstoffe teilt man nach der Muttersubstanz, aus der sie hervorgingen, in drei $\mathrm{Ha}$ a $\mathrm{ptg} \mathrm{r}$ ppen ein:

1. Benzol-Farben, 2. Azo-Farbstoffe, 3. Alizarin-Farben. Die Benzol-Farben zerfallen wiederum in zwei Gruppen, in die der Anilin- und die der Resorzin-Farben. Nach ihren Eigenschaften kann man die Farbstoffe einteilen in: 1. Säuren (saure Farbstoffe, die nitrierten und sulfonierten Farben, wie Pikrinsänre, Orange, Ponceau und Nitrofarbstoffe), 2. Basen (die salzartigen Verbindungen von Farbbasen mit Säuren, wie Fuchsin, Methylenblau, Gentiana etc.), 3. indiffer en te $\mathrm{K}$ örper (Indigo).

Diese Einteilung ist verlassen und gegenwärtig ist für dieselbe die relative Lagerung der Atome und Atomgruppen im Farbstoffmolekü], ihre chemische Konstitution maßgebend.

Die Anilinfarben (Tryphenylmethan- oder Rosanilin-Farbstoffe) leiten sich ab vom Rosanilin, einer farblosen Base: deren Salze prächtig rote Farbstoffe lieferu. Unter seinen Salzen ist das Fuchsin (RosanilinChloralhydrat) das wichtigste. Über die toxischen Eigenschaften des Fuchsins ist unendlich viel geschrieben und gestritten worden. Fuchsin ist ein Salz des ungiftigen Rosanilins. Weyl sagt auf Grund zahlreicher experimenteller Arbeiten, klinischer Beobachtungen und kritischer Beurteilungen des vorliegenden literarischen Materiales: „Reines Fuchsin ist ungiftig; die Vergiftungen durch Fuchsin sind Arsen-Vergiftungen."

Die Gruppe der A zofarben ist ungemein artenreich und spielt zur Zeit eine große Rolle. Zur Färbung von Wolle und Baumwolle, aber auch von Nahrungs- und Genußmitteln finden die Azofarben Anwendung.

Obgleich manche der zur Darstellung benützten Ausgangsmaterialien, z. B. Anilin und Naphthol, giftige Eigenschaften besitzen, sind die mit Hilfe der giftigen Körper dargestellten Azofarben nach $\mathrm{Th}$. Weyl zumeist ungiftig oder doch erst in größerer Dosis schädlich. $\mathrm{Zu}$ den Azofarben gehören z. B. Echtgelb oder Säuregelb, Ponceau und Orange-G.

Der Kohlenwasserstoff-Anthrazen wird durch Oxydation in Anthrachinon, dieses durch Schmelzen mit Ätznatron in Alizarin verwandelt. Die Metallverbindungen des Alizarins bilden äußerst wertvolle und zugleich nngiftige Farbstoffe (Farblacke). 
Das Arbeiten mit den fertigen Farbstoffen, das Trocknen, Zerschlagen, Mahlen, Pulvern und Verpacken derselben gibt die Möglichkeit zu allerlei Gesundheitsschädigungen.

Es muB hier nochmals wiederholt werden, dab das Experiment und die Erfahrung, nicht zum wenigsten auch die Statistik der Erkrankungen bei den Arbeitern in Teerfarbenfabriken die Ungiftigkeit der meisten Teerfarben erwiesen hat. Wir wissen, $d a B$ diese Farben im allgemeinen ungiftig sind, aber giftig werden können, wenn sie als Verunreinigung noch diejenigen giftigen Stoffe enthalten, welche zu ihrer Herstellung notwendig waren, oder wenn siezum Färben mit giftigen Beizen behandelt wurden.

Daß die meisten Anilinfarben bei Einnahme per os keine Giftwirkung äußern, schließt noch nicht aus, daß dieselben auch sonst nicht zu Gesundheitsschädigungen Anlaß geben könnten.

Nach Blaschkos Ansicht kann man nun nicht alle diese Farben ohne weiters als giftige bezeichnen; wenn sie auch bei einzelnen Arbeitern als exquisit giftige Substanzen, Hautgifte oder besser gesagt als Hautgefäßgifte wirken, so wirken sie nur bei wenigen Personen, bei denen man eine Idiosynkrasie gegenüber den betreffenden Körpern annehmen muß. Es mögen einige unter diesen Farben sein, welche für eine größere Anzahl von Menschen schädlich sind, die also als allgemein giftig gelten können; wieder andere, denen gegenüber nur einige wenige Menschen eine derartige Empfindlichkeit zeigen. Immerhin gestattet die gelegentlich beobachtete Giftwirkung eines solchen Farbstoffes keinen Schluf auf den allgemein gültigen Giftcharakter desselben, auch muB man bedenken, daß eine Substanz sehr wohl ein Hautgift sein kann, ohne sich allgemein, z. B. bei innerlicher Wirkung, als giftig zu erweisen.

Nach Blaschko ist das Auftreten derartiger Hautentzündungen nach dem Tragen neuer gefärbter und nicht gewaschener Strümpfe oder Unterkleider wahrscheinlich ebenfalls auf eine derartige Idiosynkrasie des Trägers, nicht auf eine allgemein giftige Wirkung der betreffenden Farbe zurückzuführen.

Bei den Arbeitern in den Anilinfabriken kommen häufig Hautkrankheiten vor, welche in verschiedenen Intensitäts- und Extensitätsgraden auftreten und verlaufen, sowobl bei solchen, die mit den fertigen Farbstoffen, giftigen oder ungiftigen, als mit deren Vorstufen oder mit Beizen zu tun haben. Es zeigt sich, daß dieselben Farben bei dem einen Arbeiter eine Hautkrankheit hervorrufen, bei dem andern nicht, daß also zweifellos eine gewisse Disposition dazu existieren muh, und daß für gewisse Farbstoffe bei vereinzelten Arbeitern Idiosynkrasien 
bestehen. Um die Kenntnis dieser gewerblichen Hautkrankheiten haben sich Blaschko, K. Herxheimer u. a. große Verdienste erworben.

BI aschko versteht unter diesen nicht die in den Farbfabriken so häufig naturgemä $B$ auftretende Färbung der Haut, Haare und Nägel mit Teerfarben, nicht die zyanotische Verfärbung der Haut bei Anilin-, Nitrobenzol- und Dinitrobenzol-Vergiftung, auch nicht die unabhängig von der Berufsbeschäftigung vorkommenden vielgestaltigen Hautkrankheiten, sondern er bezeichnet als solche nur diejenigen Hautaffektionen, welche sich direkt auf die Beschätigung der Anilinarbeiter zurückführen lassen und ihren Ursprung in dem Kontakt der Haut mit den fertigen Farbstoffen - in flüssig-breiiger oder in Pulverform - haben.

$\mathrm{Blaschko}$ teilt diese gewerblichen Hautaffektionen in zwei große, wesentlich voneinander verschiedene Gruppen, von denen die eine den Charakter einer mehr akuten erythematösen Hantentzündung trägt, welche durch Einwirkung eines Giftes durch die intakte Epidermis hindurch auf die tieferen Hautschichten hervorgerufen wird, während die andere in ihrem klinischen Bilde dem gewöhnlichen Ekzem sehr nahe steht. Die Ähnlichkeit dieser Affektionen in allen ihren einzelnen Formen und Faktoren mit dem gewöhnlichen Ekzem ist nicht von der Hand zu weisen.

Drei Momente spielen nach diesem Autor bei beiden die Hauptrolle: die Stärke und die Natur der äuBeren Reize, die Widerstandsfähigkeit, bzw. die Anpassung der Epidermis der einzelnen Individuen und die sekundäre Infektion mit ekzemerregenden Organismen (Unna). Letzterem gegenüber vertritt Blaschko die Ansicht, daB es sich dabeinicht um eine Autoinfektion handelt.

Nicht nur in Farbenfabriken, sondern auch bei allen jenen gewerblichen Berufsarten, bei denen pulverförmige Farben, insbesondere Teer- oder Anilinfarben verarbeitet werden, kommen nahezu die gleichen Erkrankungsformen der Haut zur Beobachtung, wenngleich die Art des Berufes, sowie der verschiedenartigen Bearbeitung gewisse, jedoch unbedeutende Unterschiede im Krankheitsbilde erkennen lassen.

Aber auch nichtgewerbliche, nicht durch Berufsa r beit beding te $\mathrm{H}$ a u terkrankungen können bei längerer Anwendung von Anilinfarbstoffen bei disponierten Individuen den Gewerbeerkrankungen der Haut ähnliche Bilder erzeugen.

Nach Grandhommes Beobachtungen in den Höchster Farbwerken waren die Ekzeme nicht so häufig und nicht so hartnäckig, auch nicht mit ödematösen Schwellungen oder Blasenbildungen kompliziert, wie 
dies Blaschko in Verbindung mit Erythemen bei Anilinarbeitern behauptet.

Ähnliche gewerbliche Hauterkrankungen wie Ekzeme, Dermatitiden, Akne etc., kommen auch bei Malern, Anstreichern und Lackierern vor. Die trockenen Farbstoffe, welche in den Malberufen Verwendung finden, kommen als außerordentlich feine Pulver in den Handel (meist in Fässern).

Die pulverförmigen Farbstoffe müssen fein zerteilt, wie in einer Emulsion, von einem flüssigen Menstrum aufgenommen werden. Je nach der Art der verwendeten Flüssigkeiten unterscheidet man: Ölfarben mit Leinöl, Terpentinöl, Lackfarben (Lacke plus Farbstoff), und zwar mit Leinöl, Terpentinöl, Lackharzauflösungen (in Weingeist) etc.; W a sserfarben mit Leim, Gummi arabicum, Stärke etc. Das Farbpulver muß möglichst fein sein. Farbstaub wird aus diesem Grunde sehr lange in der Luft schwebend erhalten. Früher wurden viele Farben in Stücken geliefert. Jetzt liefern die Fabriken das Farbstoffpulver, meist jedoch die bereits eingeweichte Farbe.

Weyl, Roth $u$, a. beschreiben Hautkrankheiten der chemischen Arbeiter, Leiser die der Steindrucker und Lithographen, Silberstein Hautkrankheiten der Buchdrucker, Netolitzky die der Textilarbeiter.

Unter den Hautkrankheiten dieser Berufsarten ist das Ekzem als die häufigste zu erwähnen, deren Entstehung durch die Beschäftigung mit den Farben, Säuren, Ölen usw. begünstigt wird. Nach dem Urteil dieser Autoren ist das Ekzem dieser Berufsarten oft recht hartnäckig.

Da auch bei Arbeitern anderer Berufsweige, z. B. bei Pecharbeitern, ähnliche Dermatosen beobachtet werden wie bei Arbeitern, die einerseits mit der fabriksmäßigen Herstellung von Anilin- und Teerfarbstoffen, anderseits der technischen Verwertung der bereits fertigen Farben in den verschiedensten Berufen, wie in der Buch- und Steindruckerei, der Lithographie, beschäftigt sind, ist es angezeigt, in Kürze die sogenannte ${ }_{2} \mathrm{Pechhaut}$ e als Gewerbedermatose zu besprechen. Die Beobachtungen beziehen sich auf Arbeiter verschiedener Berufe, die mit der Verarbeitung ron Pech (Steinkohlenpech) zu tun haben. Bei der gewerblichen Schädigung durch Pech handelt es sich sowohl um Pechstaub als auch um Pechdämpfe. Die Erscheinungsweise der Pechhaut setzt sich typisch aus drei Faktoren zusammen: 1. Pechbräunung der Haut (Indianer- 
haut) und Vergilbung (Verschmutzung) des Skleraweiß am Auge. 2. Pechkomedonenbildung. 3. Hyperkeratotische Bildungen, wie verruköse Papillome, Verrucae, verruköse Hyperplasien der palmae manuum (palmare Keratosen). Die näheren klinischen Details der Pechhaut werden beim Kapitel der bei den verschiedenen Berufsarten oft zur Beobachtung gelangenden Papillomen beschrieben werden.

Zu den häufigsten und gewöhnlichsten Erkrankungsformender Haut durch Anilinfarbstoffe gehören die Dermatitis, das Ekzem, die akneartigen Ausschlagsformen, ferner die Papillome und Epitheliome, letztere allerdings nicht in der Häufigkeit wie die ersteren.

Was das Bild der Dermatitis anlangt, so liegen eine Reihe von Beobachtungen vor, welche das Auftreten derselben in direktem Zusammenhang mit der Beschäftigung mit Anilinfarbstoffen oder mit dem Tragen von Kleidungsstücken, die mit soichen gefärbt sind, bringen.

Wils on bericntet aus dem Jahre 1869 über 3 Fälle von Vergiftung und Hautentzündungen mit Anilinfarben, welche darch Tragen von mit Korallin gefärbten Strümpfen veranlafit wurden. Wilson meint, es gehe aus diesen Fällen hervor, daß3 das Gift in der Schweibflüssigkeit löslich sei, und $d a B$ es, sobald die Resorption erfolgt ist, zuerst die Gewebe und dann die Nerven reize.

Bemerkenswert ist eine hieher gehörige Beobachtung vout Balzer und Gaucher. Ein 39jähriger Beamter zeigte eine heftige ekzematöse Hautentzündung beider Füße bis an die Knöchel, in parallelen Streifen angeordnet. Die Effloreszenzen waren regelmäßig angeordnet und entsprachen genau den Stellen, an denen die schwarzen und grünen Streifen die Haut bedeckt hatten. Überall, wo die gelben und roten Streifen aufgelegen hatten, selbst wo sie nur $2 \mathrm{~mm}$ breit waren, fand sich ein entsprechender Streifen gesunder Haut. Die Untersuchnag der Strümpfe ergab, daß die grüne und schwarze Farbe von Anilinfarbstoffen herrührte. Diese hatten die Gelegenheitsursache für die Entstehung der ekzemartigen Dermatit is abgegeben.

Eine ähnliche Beobachtung machten Landouzy und Brouardell bei Kindern nach dem Tragen von Lederstiefeln, die mit anilinhaltiger Farbe geschwärzt waren. Die lokalen Erscheinungen, die als Dermati i is anzusprechen waren, wurden von allgemeinen, die in Zyanose, Asphyxie und Pulsschwäche bestanden, begleitet.

Feilchenfeld berichtet über eine durch Tragen gelb gefärbter, wildlederner Handschuhe hervorgerufene Hautentzündung. 
White beobachtete, daß die Mannschaft der Bostoner Feuerwehr Dermatitis am Stamm bekam, wahrscheinlich durch das Tragen von Hemden, die mit Anilinschwarz gefärbt waren.

Th. W e yl erkrankte mehrmals hintereinander an a kuter Dermatitis mit folgender Abschuppung - jedesmal nach Darstellung von Buttergelb, einem A z of arbstof $f$, im Laboratorium.

Die von Bosellini beobachteten und beschriebenen Fälle von chronischer, zirkunskripter, verrukoider Dermatitis der Hände sind in ihrer Ätiologie unklar.

Das Krankheitsbild des Ekzems tritt bei mit pulverförmigen Farben beschäftigten Arbeitern in den mannigfaltigsten Formen auf. Nicht alle in einem derartigen Beruf beschäftigten Arbeiter erkranken an Ekzem; ein mehr oder minder großer Bruchteil bleibt dauernd verschont, wohl iu Folge einer geringeren Empfindlichkeit resp. Widerstandsfähigkeit der Epidermis gegenüber den einzelnen Schädlichkeiten. Diese Widerstandsîähigkeit wird erworben durch die Anpassung oder Akkommodation. Zu der Finwirkung des äußeren Reizes, sei es nun auf physikalischem Wege (Hitze, Kälte, Druck, Reibung) oder durch differente chemische Mittel, welche eine mehr oder minder ausgedehnte Zerstörung von Epidermissubstanz bewirken, kommt dann noch die Einwirkung von Mikroorganismen, welche zuweilen das von den äußeren Reizen begonnene Zerstörungswerk in Gemeinschaft mit ihnen fortsetzen und so die gewöhnlichen Ekzemformen zustande bringen.

Es hat sich ferner gezeigt, daß die Krankheit in der Regel nicht sofort, sondern nach längerer, manchmal mehrjähriger Beschäftigung auftritt. Handelt es sich um stärker wirkende Reize, so zeigen sich wohl bei allen Arbeitern anfangs leichte Erkrankungsgrade; bei den meisten tritt jedoch bald Gewöhnung der Haut an die schädlichen Einflüsse (Abhärtung) ein. Beim Aussetzen der schädlichen Beschäftigung heilen in der Regel die Ekzeme ab, um bei Wiederaufnahme derselben entweder überhaupt nicht, sofort oder gelegentlich aus nicht immer ersichtlichen Ursachen zu rezidivieren. Meist bleiben kleine, sichtbare oder latente Reste der Erkrankung bestehen, von denen die Rezidive ausgehen. Anamnese und Untersuchung ergibt bei den Patienten nicht selten frïhere ekzematöse Erkrankungen, namentlich in den Kinderjahren, und ferner das 
gleichzeitige Bestehen ekzematöser Herde örtlich und ursächlicb, unabhängig von dem schädlichen Agens. Die Ekzeme gleichen in allen ihren Einzelheiten den verschiedenen bekannten Formen des Ekzems.

Blaschko, Grandhomme, K. Herxheimer beschreiben eine große Reihe von gewerblichen Ekzemen, deren Entstehung in ursächlichen Zusammenhang gebracht wird mit der Beschäftigung mit den verschiedenartigsten pulverförmigen Anilinfarbstoffen, von denen eine Anzahl sich der menschlichen Haut gegenüber völlig indifferent verhält, andere sehr leicht Veranlassung zu Elzzemen abgeben, und auch in diesen Fällen in individuell verschiedenem Grade.

Eccemaverrucosum warde von Morton, Pringle, Dabreuilh, Gebert u. a. beobachtet, ohne für das Auftreten desselben eine äuBere Schädlicbkeit angeben zu können. Gelegentlich der. Demonstration des Gebertschen Falles in der Berliner Dermatologischen Gesellschaft erinnert Pinkus an den Gassmannschen Fall aus der Klinik Jadas. sohn (Bern), bei welchem auf eìne Chrysarobin-Dermatitis bei Psoriasis vulgaris eine allgemeine Warzen-Eraption stattgefunden hat.

Sehr häufig kommen akneartige Ausschläge zur Beobachtung, sie zeigen das Bild der Acne vulgaris, der Follikulitis suppurativa, entweder allein oder vergesellschaftet mit Ekzem, mit Papillomen. Häufiger als in Farbenfabriken werden diese Formen bei Teer- und Pech-Arbeitern usw. beobachtet.

Der von Mackenzie beschriebene Fall eines 60jährigen Teerarbeiters zeigt an den Vorderarmen der Dorsalflächen der Hände und Finger die Haarfollikelmündungen mit einer schwarzen Kruste verstopft. An einigen Stellen sieht man erbsengroße Erhabenheiten der Haut von warziger Beschaffenheit.

Der von Balban ans Oppenheims Ambulatorium in der Wiener dermalologischen Gesellschaft am 8. Nov. 1911 demonstrierte Fall von Teerhaut wäre hier za erwähnen.

In der Literatur ist eine recht große Anzahl von Mitteilungen über Papillombildungen der Haut, sei es allein oder in Kombination mit Ekzem oder auf der Basis eines solchen, beschrieben worden.

Bei Ulcera cruris, bei stark irritierten Wundflächen kommen oft derartige papillomähnliche Wucherungen vor. Elliot, Notin, Nobl, Pecirka, Alessandro, Du Castel, Biedermann beschreiben solche Fälle. Wahrscheinlich hängt diese Tendenz zur Wucherang der Kutis und Epidermis in begrenzten Hautbezirken, zum Beispiel beim Ulcus cruris mit Varizen, oder bei Elephantiasis teils mit dem durch diegeänderten 
Zirkulationsverhältnisse nichtnormal sich involvierenden Granulationsgewebe, teils mit auf die Umgebung sich erstreckende Proliferation des Gewebes zasammen.

Leichter verständlich wird die Entwicklung von Papillomen auf der Haut bei Einwirkung von irritierenden Schädlichkeiten, wie bei Teer- und Pecharbeitern. Solche Fälle beschreiben Mackenzie, Blaschko, K. Herxheimer, Oskar Ehrmann u. a. Der letztgenannte Autor weist darauf hin, daß bei Pecharbeitern das Eigenartige des Krankheitsbildes in meist multiplen Warzengebilden auf der pechexponierten Haut besteht.

Die Härafigkeit derselben unter der Zahl von Ehrmanns Beobachtungen und die spezifische Lokalisation gerade an den exponierten Stellen der Haut (entblößte Teile, wie Gesicht und Hände, ja sogar Befallensein nur rechter und linker Hand bei Bearbeitung des Materiales mit Bevorzugung einer Hand, ferner die nur während der Arbeit entblößten Hals-, Nacken-, Rücken- und Brusthautpartien) beweist deren Spezifizität als "Pechwarze" gegenüber etwaigen akzidentellen Befunden von Verrucae vulgares. Die Warzengebilde hatten teils den Charakter gewöhnlicher Warzen, teils waren sie gelappt wie Condylomata accuminata. Vielfach waren es mehrere kleine, weiße Wärzchen, meist in Gesicht (Nase, Ginn usw.). Im Schnurrbartgebiet, am oder im Naseneingang usw. fanden sich ebenfalls Warzen. Die Vorliebe tür das Gesicht ist durch ihre Entstehung infolge verdampfenden Pechs erklärt.

Derville und Guermonprez, Blaschko, K. Herxheimer, K. Ullmann u. v. a. beschreiben solche warzige papillomatöse Wucherungen. bei Arbeitern in Petroleum-Raffinerien. Solche Wucherungen gehen stets von den Haarbälgen aus. Um die punktförmigen schwarzen Follikel bildet sich unter Ausfallen des hornigen Zentrums ein glatter Tumor, der sekundär rauh und zerklüftet wird. Histologisch finden sich in der Tiefe solcher Papillome häufig Epithelperlen, in allen Teilen entzündliche Veränderungen. Die Tumoren ähneln den EpithelKankroiden. Durch Einreibung mit Rückständen der Petroleum-Destillationen konnten die Veränderungen bei Tieren nicht erzeugt werden, ebenso wenig durch Impfung mit Geschwulstteilchen.

Die oben beschriebenen Papillomebei Teer-, Pech- und Petroleum-Arbeitern bilden den Übergang zu den durch die genanten Schädlichkeiten sich entwickelnden Karzinomen. ${ }^{1}$ ) Nach ihrer Lokalisation unterscheidet man solche an der äußeren Hautdecke, Gesicht, Skrotum und solche der Blase.

Wie als reizende Agentien fürdie Entstehung multipler Hautkarzinome Teer, Paraffin und RuB genannt werden, so wäre auch der Tabak als reizende Substanz für die Bildung von Krebsen (Esmarch, Tillmanns) anzuführen.

1) Arnstein Alfred: Der Krebs als Berufskrankheit (Sammelreferat), Arbeiten aus dem Gebiete der sozialen Medizin. Herausgegeben im Verlage von A. Hölder in Wien von Privatdozenten Dr. L. Teleky. 1912. 2. Heft. 
Ludwig $Z_{w}$ ig $^{1}$ ) beschreibt in seiner Inaugural-Dissertation (1909) ausführlich einen Fall von multiplen Hautkarzinomen bei einem Brikettarbeiter.

Hoffmann (Halle), Mackenzie, Kirk, Karl Ullmannu. a. teilen Beobachtungen vou multiplen Karzinomen an der Haut und besonders am Skrotum bei Arbeitern in Petroleum. raffinerien, in Paraffinfabriken nsw. mit. Karl Ullmann hat in der Wiener dermatologischen Gesellschaft (3. November 1909) einen 45jährigen Paraffinarbeiter mit multiplen Karzinomen am Skrotum demonstriert.

Aber nicht nur bei Teer- und Paraffinarbeitern, sondern auch bei den im Destillierraume von Anilinfabriken beschäftigten Arbeitern treten durch Inhalation von Anilindämpfen nicht gar zu selten Karzinome auf, und zwar insbesondere Blasenkarzinome.

Huldschiner, Leichtenstern, Jores, Straus berichten über Fälle von Blasentumoren, insbesondere Karzinomen bei Arbeitern in Anilinfabrike $\left.\left.n^{3}\right)^{4}\right)$. Besonders interessant sind die Beobachtungen von Rehn, welcher bei Fuchsinarbeitern außer Zystitis auch Blasentumoren auftreten sah, deren Bildung in ursächlichem Zusammenhang mit den bei der Fuchsinfabrikation entstehenden chemischen Substanzen za bringen war, welche Befunde durch Leichtensterns Mitteilungen bestätigt wurden.

Rehns Beobachtungen beziehen sich auf 23 Fälle von Blasentumoren, besonders Karzinomen, bei Fuchsinarbeitern, deren Entstehung nach diesem Autor zweifellos auf einen längere Zeit einwirkenden entzündlichen Reiz wahrscheinlich chemischer Natur zu beziehen ist.

Im Jahresbericht der preußischen Regierungs und GewerbeRäte des Jahres 1909 "Zur Erkrankung der Arbeiter in Anilinfabriken an Blasenleiden" ist folgende bemerkenswerte Mitteilung enthalten. Durch eine Rundfrage in 18 Anilinfabriken wurden nur 38 Fälle von derartigen Biasen-Geschwülsten bekannt, von denen 18 tödlich verlaufen

1) In der sehr interessanten Arbeit von Ludwig Zweig ist die Geschichte des Teer-oder Paraffin-Krebses ausführlich beschrieben.

2) Nach Abschluß meiner Arbeit ist eine Publikation von Ka rl Ullmann über "Dermatosen bei Erdölgewinnung und Paraffinfabrikation", Arbeiten aus" dem Gebiete der sozialen Medizin, herausgegeben im Verlage von A. Hölder in Wien vom Privatdozenten Dr. L. Teleky. :912. 2. Heft, erschienen.

3) Nach Abschluß meiner Arbeit erschien eine Publikation von S. G. Le u enberger "Die unter dem Einfluß der synthetischen Farbenindustrie beobachtete "Geschwulstentwicklung." Beiträge zur klinischen Chirurgie 1912. Bd. LXXX, p. 208.

4) Lewin, Arthur. Blasengeschwülste bei Arbeitern in Anilinfabriken. Zeitschrift für Urologie. 1913. Bd. VII. p. 282 und Diskussion in der Berliner urolog. Geselschaft. 28. Jan. 1913. 
waren, während 17 operiert werden konnten. Die Mehrzahl der Geschwülste war bei solchen Arbeitern zu finden, die längere Zeit mit Anilin, Naphthylamin und homologen Basen zu tun batten; in 7 Fällen waren die betreffenden Arbeiter mit Benzidin allein beschäftigt. Die Erkrankung konnte nicht beobachtet werden bei Arbeitern, die erst liurze Zeit im Anilinbetriebe tätig waren, oder bei solchen, die nur mit Nitrokörpern $\mathrm{za}$ tun hatten. ${ }^{1}$ )

Alexander Fraenkel hat in seinem in der Festsitzung der österreichischen Krebs-Gesellschaft am 5. März 1911 gehaltenen Vortrag das "Problem der Krebskrankheit" aller jener Momente Erwähnung getan, die drastische Hinweise für die pathogenetische Bedeutung lokaler chronischer Reizzustände für die Entwicklung der Krebskrankheit bieten.

Außer lokal disponierenden, gleichsam einleitenden und vermittelnden Prozessen muß auch allgemein disponierenden, konstitutionellen Momenten eine bestimmte pathogenetische Bedeutung für die erworbene Krebsbildung zugeschrieben werden. Im weiteren Verlaufe seines Vortrages bemerkt Fraenkel, daß unter Eliminierung des kausal schädigenden Momentes allen diesen chronisch entzündlichen Zuständen schon frühzeitig alle notwendige therapeutische Sorgfalt zuzuwenden ist. Namentlich der Gewerbehygiene und sozialen Medizin fällt dabei ein dankbares Feld der Tätigkeit zu, da nicht so selten der Krebs als ausgesprochene Berufskrankheit auftritt.

Anhangsweise seien auch die durch Anilinfarbst offe oder deren $\mathrm{Z}$ wischenprodukte bedingten Schädigungen oder Erkrankungen der A ugen kurz angeführt.

Senn beobachtete bei Anilinfärbern auf der Hornhaut im Bereicbe des Lidspaltbezirkes eine Trübung, die bedingt war durch die aufsteigenden Dämpfe von Anilinschwarz.

Über eine ähnliche Veränderung der Hornhaut, bedingt durch Nitrouaphthalin, berichtet Hanke aus der Augenklinik Fuchs in Wien. Vogt, Gräflin hatten Gelegenheit, Arbeiter der Baseler Farbfabriken zu untersuchen, bei denen infolge von Eindringen von pulverförmigen Farbstoffenoder Farblösungen in den Konjunktivalsack mehr oder weniger schwere Konjunktivitis und oft sogar mit Kornealerkrankung zu beobachten waren. Um sich von der Schädlichkeit oder Unsehädlichkeit einiger Anilinfarben zu überzeugen, haben die genannten Autoren deren Einfluß experimentell am KaninchenAuge erprobt. Das Resultat der Versuche (Einstauben der Farbstoffe in den Konjunktivalsack von Kaninchen) zeigt, daß sich die Farben in bezug

1) Weyl, Th.: Zur Revision des Reichsgesetzes betreffend die gesundheitsschädlichen Farben. Berl. med. Gesellsch. vom 1. März 1911. 
auf ihre Schädlichkeit oder Unschädlichkeit auf die Konjunktiva sehr verschieden verhalten. In die Gruppe der am stärksten reizenden Farben gehören: Kristallviolett, Viktoriablau und Malachitgrün. Der Endausgang des durch diese drei Farben hervorgerufenen Entzündungsprozesses war jedesmal $\mathrm{Pan}$ ophthalmie. Die klinischen Befunde zeigen eine volle Übereinstimmung mit den experimentellen.

Nach Vogts experimentellen und klinischen Untersuchungen ergibt sich unzweideutig, daß alle basischen Anilinfarben auf die Konjunktiva des Kaninchenauges schädlich einwirken, während die sauren keine oder höchstens sehr geringe (mechanische) Reizerscheinungen machen. Vogts Versuche am Kaninehenauge ergaben, daß durch die Spülung des Konjunktivalsackes mit 5-10\% Tanninlösung die Giftigkeit aller, auch der schädlichsten Anilinfarben ganz oder zum größten Teile aufgehoben wird, während die Fälle, wo der Konjunktivalsack unter sonst gleichen Bedingungen mit Wasser oder Lösungen von Kochsalz, Borsäure, Sublimat oder Natr. bicarbonicum ausgespült wird, eher schwerer verlaufen, als sich selbst überlassene.

Kuwahara stellte Versuche mit Anilinfarbstiften, sogen. Kopierstiften, auf das Kaninchenange an. Die Anilinfarbstifte wirken nicht nur anf die Konjunktiva, sondern auch auf die Kornea ein. Das mechanische Moment spielt keine Rolle, sondern nur eine chemische Einwirkung gibt den Anstoß zur Entzündung.

Fassen wir die in der Literatur bekannten, hier in Frage kommenden schädlichen Agentien zusammen, so sindesdie Teer-oder Anilin-Farben und ihre Zwischenprodukteoder die Bestandteile, aus denen die betreffenden Anilinfarben hergestelltwerden. Anhangsweise wurden auch jene Irritantien besprochen, die in Teer- und ParaffinFabriken, bei Pech-, Brikett- und Petroleum-Arbeitern Veranlassung zur Entwicklung der mannigfaltigsten Schädigungen der Haut sowiedes Auges, der Harnblase abgeben.

So mannigfaltig auch die verschiedenen Stoffe sein mögen, verschieden in ihrer Darstellung, Anwendungsart, chemischen Konstitution - ein gemeinsames Moment zeigen alle diese Stoffe in ihrer Wirkung bei dazu disponierten Individuen: sie rufen die Schädigungen größtenteils - wenn nicht ausschließlich durch eine spezifisch chemische Komponente herror, die $\mathrm{mechan}$ is che spielt bei dieser Gruppe von Erkrankungen wohl auch eine nicht zu unterschätzende, jedoch viel kleinere Rolle als die chemische. Es ist ja, wie A. Fraenkel ausführt, 
hinlänglich bekannt, daß bei all' diesen und den früher erwähnten Prozessen in Betracht kommenden lokal wirkenden Reizen nicht nur solche rein chemischer oder mechanischer Natur zu erwähnen sind, sondern auch solche thermischer, aktinischer und infektiöser Natur. Schon die Mannigfaltigkeit dieser verschiedenen Einflüsse läßt es nahezu ausgeschlossen erscheinen, daß der Spezifizität des Reizes hiebei eine entscheidende Bedeutung zukommt.

Meine eigenen Beobachtungen sind nach mehrfacher Richtung hin geeignet, die vorhin skizzierten Krankheitsbilder, hervorgerufen durch die mannigfaltigsten, größtenteils chemischen Irritantien, nicht nur durch gleichartige Bilder zu vermehren, sondern auch durch neue zu bereichern. Die Einteilung der von mir gewonnenen Beobachtungen kann verschiedenartig vorgenommen werden, je nach dem Prinzip, welches der Einteilung zugrunde gelegt wird; je nachdem wir die verwendeten Agentien oder Berufszweige zunächst ins Auge fassen oder die daraus resultierenden Schädigungen der Haut. Nach der Art des Krankheitsbildes setzen sich meine Beobachtungen aus Fällen von Dermatitis, Ekzem und Papillomen zusammen. Bei Besprechung der einzelnen Krankheitsgruppen werden auch die sie hervorrufenden Agentien, ihre Verwendung in den betreffenden Berufszweigen entsprechend gewürdigt werden. Eine recht bedeutende Anzahl von Dermatitiden, Ekzemen, konnte ich bei dem relativ großen Krankenmaterial meines Ambulatoriums seit mehreren Jahren bei Malern, Anstreichern, Buchdruckern, Seidenfärbern, Blumenfärbern, Federnschmückern usw. beobachten, bei Berufen, die die verschiedenartigsten Farben, wie Erdfarben, Anilinfarbstoffe verwenden und verarbeiten. Von diesen Dermatosen, die sich wohl auf viele Hunderte von Fällen belaufen, will ich nur die klinisch interessantesten besonders besprechen.

Fall I. F. F., 53 Jahre alt, Buchdrucker, verheiratet, suchte am 27. Juli 1908 (Protokoll-Nr. 1361/08) das Ambulatorium auf.

Pat. ist in einer Buchdruckerei mit Terpentin- und Anilinfarbstoffen beschäftigt. Über die Natur der Anilinfarbstoffe konnte ich vom Patienten keine näheren Angaben erlangen. 
Die klinische Diagnose lautete: Eccema arteficiale madidans dorsi manus utriusque et inter digitos. Eccema verrucosum. Onychogryphosis digiti III. man. dextri.

Auf dem Rücken beider Hände finden sich zerstreut zablreiche warzige Exkreszenzen von Kleinlinsengröße, nicht von dem Aussehen der Verrucae vulgaris. Die warzigen Exkreszenzen gehören mit zum Bilde des artefiziellen Ekzems. Dieses verdankt seine Entstehung größtenteils der Einwirkung des Terpentins, zum kleinen Teile der der Anilinfarbstoffe auf die Handrücken. Die Anilinfarbstoffe sind jedoch mit großer Wahrscheinlichkeit für das Auftreten der verrukösen Fixkreszenzen verantwortlich zu machen.

$\mathrm{Zu}$ bemerken ist ferner, daB Pat. schon zu wiederholten Malen Rezidive der gleichen Erkrankungen aufwies, nur waren die verrukösen Exkreszenzen nicht so stark ausgebildet wie dieses Mal.

Fall II. G. W., $45 \mathrm{~J}$. alt, verheiratet, $\mathrm{T}$ is chle $\mathrm{r}$, sucht am 30. August 1908 das Ambulatorium anf (Pr.-Nr. 1560/08).

Dieser Pat. bietet das gleiche Krankheitsbild wie Fall I. Außer den Zeichen einer artefiziellen Dermatitis finden sich auf beiden Handrückenverstreutzahlreiche, warzige, maulbeerähnliche Exkreszenzen.

Die Beschäftigung des Patienten besteht im Anstreichen von Jalousiebrettern. Diese werden mit grünen oder gelben Farben, mit Firnis oder Terpentin verrieben, angestrichen. Nach den Angaben des Patienten werden folgende Farben verwendet: 1. Chromgrü n, Ockergelb; gelber Ocker ist bergmännisch gewonnenes Eisenoxydhydrat, durch Tongehalt heller gelb, durch Erhitzen in rotes Eisenoxyd verwaudelt. 3. Lithopon-WeiB, besteht aus $30 \%$ Zinksulfid und $70 \%$ Schwerspat, d. i. $\mathrm{BaSO}_{4}$. Diese Farben werden in nachbenannten Vehikeln verrieben: 1. Wiener Neustädter Terpentin, 2. Doppelfirnis, 3. Kopallack. (Heiß gewonnene Lösung von Kopal [Caesalpinenharz] oder Bernstein in Terpentinöl und Leinölfirnis.)

Die Dermatitis ist wohl hauptsächlich auf die Einwirkung von Terpentin, La ck etc., die Entstehung der verrukösen Exkreszenzen mit größter Wahrscheinlichkeit auf die Einwirkung von Chromgrün zurückzuführen. Es entspricht dieses Bild vollkommen dem vorhin geschilderten und reiht sich demselben als zweiter Fall von Eccemaverrucosum an.

Pat. hat schon wiederholt mit der gleichen Erkrankung das Ambulatorium aufgesucht und führt die Entstehung dieser warzigen Gebilde auf seine Beschäftigung mit Anilinfarbstoffen ( $\mathrm{Ch} \mathrm{rom} \mathrm{gr} \mathrm{ün)} \mathrm{zurück.}$ Eine spontane Involution solcher warziger Exkreszenzen wurde weder von mir, noch vom Patienten selbst beobachtet.

Zum Zwecke der histologischen Untersuchung wurde eine warzige Exkreszenz exzidiert, in Alkohol fixiert und gehärtet. Als Färbemethoden wurden die gebräuchlichen angewendet. 
Entsprechend dem makroskopischen Aussehen der verrukös-papulösen Exkreszenz vom linken Handrücken findet sich auch mikroskopisch bei schwacher Vergrößerung ein dem verrukösen Bau entsprechendes Knötchen. Deutlich ausgesproshen ist die Hyperkeratose, noch viel mehr die Akanthose der Epidermis. Die akanthotischen Reteleisten repräsentieren sich als lange und breite, je nach der Schnittrichtung, auch miteinander in Zusammenhang stehende Zapfen. Entsprechend diesen sind auch die Papillen beträchtlich verbreitert und verlängert. Die Verbreiterung und Verlängerung des Papillarkörpers sowie der Retezapfen gehen Hand in Hand.

Die obersten Lamellen der Hornschichte sind aufgelockert, an einzelnen Stellen auseinander gerissen und mit dem bei der Exzision austretenden Blute bedeckt. An anderen Stellen wiederum ist das Stratum corneum von der Stratum granulosum-Reteschicht losgerissen. Die Lamellen des Strat. corneum zeigen eine deutliche Parakeratose. Außerdem fallen im Strat. corneum zahlreiche, verschieden große, runde oder ovale Hohlräume auf, die teils isoliert, teils miteinander in Kommunikation sind. Diese Hohlräume sind mit einer klaren, homogenen (bei HämalaunEosinfärbung), rötlich blau gefärbten F'lüssigkeit erfüllt; dem blasigen Inhalt sind vereinzelte Lymphozyten beigemischt.

In den Retezapfen sind die Interspinalräume durch ö dem erweitert, in denselben und auch auf den Zellen finden sich zahlreiche polynukleäre Leukozyten oder auch in die Länge gezogene, spindelig aussehende Lymphozyten in Durchwanderung begriffen. In den Retezellen selbst sind deutlich Mitosen zu erkennen. Sowohl im Strat. corn., als auch im Rete Malpighii zeigt das histologische Bild den Charakter der spongoiden Umwandlung, die ihren Höhepunkt in der Bildung blasiger Hohlräume im Stratum corn. findet. Das Stratum granulosuma ist ebenfalls verbreitert.

Im Papillarkörper sind die GefäBe stark erweitert, ihre Wandung verdickt, die Endothelzellen gequollen und vorspringend. Die Bindegewebsbündel sind gleichfalls gequollen. Um diese erweiterten Gefäße lagert sich ein dichtes, diffuses, zelliges Infiltrat, oder es bildet knötchenförmige Anhäufungen und setzt sich vorwiegend aus Lymphozyten, polynukleären Leukozyten, Mastzellen, weniger Plasmazellen, ferner aus gewucherten fixen Bindegewebszellen zusammen. Das Zellinfiltrat ist in den obersten Schichten des Papillarkörpers eingelagert, in den tieferen findet es sich nicht in dieser diffusen Form, sondern meistens als vereinzelte Zellen, und zwar vorwiegend Mastzellen.

Im Bindegewebe des Papillarkörpers sieht man freies, braungelbes Pigment in Form von Körnchen. Außerdem lassen sich noch im Papillarkörper vereinzelte pigmentführende Zellen, Chromatophoren, nachweisen. An den Stellen des Infiltrates fehlen die elastischen Fasern, dort, wo dieselben erhalten sind, kann man sie als feinste Ausläufer bis in die Papillen verfolgen. Qualitativ sind die elastischen Fasern njcht verändert, quantitativ nur an den Stellen des Infiltrates reduziert oder vollständig fehlend. 
Nach dem histologischen Befunde handelt es sich um eine papulös-verruköse Exkreszenz, wiesolche im Verlaufe eines chronisch-rezidivierenden Ekzems nach Einwirkung von irritierenden Substanzen, wie Terpentin, Anilinfarbst offen, rechthäufig zubeobachten sind. Bemerkenswert ist ferner, dak anch diese papulös-verrukösen Gebilde in ihren Schichten die Charaktere des Ekzems in deutlicher Weise manifestieren.

Fall III. O. A., 29 J. alt, verh., Teppicharbeiterin, sucht am 21. März 1909 das Ambulatorium (Pr.-Nr. 493/09) auf.

Die klinische Diagnose lantet gleichfalls:

Eccema verncosum. Auf den ekzematös veränderten Fingerund Handrủcken finden sich zahlreiche, ungefähr linsengroße, warzige Exkreszenzen.

Patientin istals Teppicharbeiterin mit dem Knüpfen der mit Anilinfarbstoffen gefärbten Wolle beschäftigt. Hauptsächlich werden beim Darübergleiten der Wolle äber die Finger diese am meisten in Mitleidenschaft gezogen.

Nach den mir von der Fabriksfirma mitgeteilten Angaben werden in der Färberei folgende Farbstoffe verwendet: 1. Anilinfarbstoffe: a) Sauerziehende Farbstoffe: Chinolingelb, Naphtholgelb, Wollgrün, Ponceau, Säurerot. Diese Farbstoffe werden unter Zusatz von Schwefelsäure und Glaubersalz zum Färben benützt. b) B a s ische Farbst offe: Auramin, Rhodamin, Chrysoidin, Safranin, Fuchsin, Kristallviolett, Baumwollblau, Brillantgrün. Diese Farbstoffe werden unter Zusatz von Alaun gefärbt. 2. A lizarinfarbst of fe: Gebeizt oder nachbehandelt mit Kalium bichromat, Weinstein, Kupfervitriol. Außerdem Behandlung mit Natronlauge, Natriumnitrit, Fluorchrom und Chlorkalk.

Differentialdiagnosisch käme in diesem Falle noch Tuberculosis verrucosa cutis in Betracht, doch ist letztere schon ex juvantibus (Behandlung mit Burrowumschlägen und Rückgang der Affektion) auszuschließen.

Die Therapie der Fälle I, II und III ist die bei Ekzem übliche. Die erste und wichtigste Bedingung ist natürlich das Aussetzen der das Ekzem provozierenden Schädlichkeiten. Wenn auch die Patienten aus der Behandlung geheilt entlassen werden, so treten in den meisten Fällen, wenn sie zu ihrer früheren Beschäftigung zurückkehren, Rezidiven des Hautleidens ein.

Besonderes Interesse beansprucht der von mir beobachtete Fall IV. Soweit ich in der Lage war, die einschlägige Literatur zu verfolgen, ist dieser Fall der erste, bei dem sich die papillomähnlichen Gebilde im Gesichte sowie an der Beugefläche der rechten oberen Extremitäta f einelängere Einwirkung von pulverförmigen Anilinfarbstoffen auf die Haut zurückführen las sen. 
Fall IV. P. E., 22 Jahre alt, Lithograph, suchte am 30./XII. 1907 mein Ambulatorium auf (Pr.-Nr. 419/07).

Pat. beobachtet seit ungefähr 10 Tagen an der rechten Gesichtsbälfte, wie der Beugefläche des rechten Vorderarmes einen Ausschlag, den er mit seiner Beschäftigung, dem Verreiben von Anilinfarbst offen und Erdfarben in ursächlichen Zusammenhang bringen zu sollen glaubt.

Der aus den Farbenfabriken bezogene Farbstoff besteht aus verschieden großen Stücken, die in der betreffenden Buch- und Steindruckerei in einem besonders dazu bestimmten Raume, dem sog. An reiberaume, so lange verrieben werden, bis ein ganz feiner Farbstaub daraus resultiert. Bei dieser Prozedur fliegt der Farbstaub in der Luft, er schwebt gleichsam in derselben, so daß die in diesem Raume beschäftigten Arbeiter von diesem Farbstaub getroffen werden.

Pat. war in diesem Anreiberaum $3 / 4$ Jahre beschäftigt. Dieser Farbstaub wird zur weiteren technischen Verwendung mit Firnis, ${ }^{1}$ ) Sikkativ, Terpentin versetzt und dann in dieser Form in der Buch- und Steindruckerei verwendet. Nicht nur im Anreiberaum wird fast kontinuierlich Farbstaub entwickelt, sondern auch die bereits zum Drucken fertige, mit Terpentin versetzte Farbe sprizt in feineren oder gröberen Tröpfehen.

Die in der betreffenden Buchdruckerei in Gebrauch stehenden Farben und Anilinfarbstoffe haben folgende ehemische Konstitution:

1. Weiß (BleiweiB), das bekannte basische Bleikarbonat, bei interner Einverleibung giftig.

2. Zinnober, rotes Schwefelquecksilber ( $\mathrm{HgS})$, nicht giftig.

3. Miloribla u (B erlinerbla a): $\left.:^{\mathbf{2}}\right)$ Ferrum ferro-cyanatum, Eisenzyanürzyanid, nicht giftig.

4. Sienna, Erdfarbe, eisenoxydhaltiger Ton, nicht giftig.

5. Krapplack, ein synthetisch dargestellter Farbstoff, ein bleihaltiger Alizarintonerdelack, ist nicht giftig, gehört in die Gruppe der Anthrazen-(Alizarin-)Farben, wurde früher aus der Färberröte, Rubia tinctoria, dargestellt. Krapplack, synthetisch dargestellt, ist ein Antrachinonfarbstoff. Alizarinfarbstoffe leiten sich vom Anthrazen ab, Anthrazen ist ein Bestandteil des Steinkohlenteers.

6. Gelblicht, ein tonerdehaltiger Säuregelbbariumlack (Azofarbe) ist ungiftig (Säuregelb-Naphtholgelb S).

7. Grünerlack, ein tonerdehaltiger Säuregrünbariumlack, ist ein ungiftiger Anilinfarbstoff. Grünerlack, unter dem Namen Säuregrün bekannt, ist seiner chemischen Zusammensetzung nach als Triphenyl-

1) Firnisse sind fette öle, besonders Leinöl, welche kochend mit Substanzen gemischt werden, die schnelles Trocknen der Mischung bewirken sollen. Als solche "Sikkative" dienen hauptsächlich Bleiglätte (Bleioxyd), Mennige, borsaures oder harzsaures Manganoxydul, Braunstein. Zusatz von Firnissen zu Farbstoffen dient zum Binden der Farbstoffemulsion.

2) Mierzinski, Stanislaus. Handbuch der Farbenfabrikation. 1898. II. Bd. p. 551 . 
methanfarbstoff anzusprechen. Fuchsin gehört in dieselbe Gruppe. In dieser Gruppe sind noch nie giftige Farbstoffe konstatiert worden.

8. Brillantrot ist ein tonerdehaltiger Azofarbbariumlack (ungiftig). Es enthält anßer Tonerdehydrat und Bariumsulfat (Blanc fixe) neben geringen Mengen Kochsalz (Chlornatrium) den Barytlack des Azo-. farbstoffes: Litholrot R. Dieser Barytlack ist also das Bariumsalz des A zofarbstoffes: 1. 2 Naphthylaminsulfosäure-azo- $\beta$-Naphthol.

Die drei letztgenannten Farbstoffe (Gelblicht, Grünerlack, Brillantrot) sind Teerfarbst offe, die künstlich, d. h. fabriksmäßig aus Teerbestandteilen bergestellt werden. Gelblicht und Brillantrot sind Azofarbstoffe, die bei innerer Darreichung als Gifte wirken können. Basische, saure Beizfarbstoffe enthalten Säuregruppen, welche sich mit Metalloxyden zu La a ken vereinigen. Krapplack, Gelblicht, Grünerlack, Brillantrot sind Lacke von schwach sauren Farbstoffen. In den genannten Anilinfarbstoffen ist weder Arsen, noch Anilin enthalten.

Die Farbstoffe Krapplack, Gelblicht, Grünerlack sind in Wasser und Alkohol leicht löslich, Brillantrot in Wasser schwer und in Alkohol leicht löslich, enthalten das Tonerdehydrat als Beize, resp. Bindungsmittel; das BIanc fixe (Bariumsulfat) als Beschwerungsmittel.

Das Tonerdehydrat (gefälltes $\mathrm{Al}(\mathrm{OH})_{3}$ besteht ausschließlich aus doppelbrechenden, dem hexagonalen System angehörenden Kristallen (Prismen, wetzsteinförmigen Kristallen etc.), ist in Wasser unlöslich, in dünnen Säuren in Spuren löslich, wirkt im tierischen Gewebe nur mechanisch and entfaltet außerdem auch eine geringe chemische Wirkung. Das $\mathrm{Blanc}$ fixe (Bariumsulfat $\mathrm{BaSO}_{4}$ ) enthält neben zahlreichen kristallinischen Bestandteilen auch amorphe, ist in Wasser und Säuren unlöslich, wirkt im tierischen Gewebe nur mechanisch. Blanc fixe ist ein durch Fällung von Bariumchlorid mit Natriumsulfat künstlich hergestelltes Bariumsulfat. ${ }^{\text {) }}$

Status praesens vom 30./XIL. 1907. Bei dem gesund aussehenden, kräftig gebauten Patienten finden sich ausschließlich auf der rechten Stirnund Gesichtshälfte, sowie der Beugefläche des rechten Vorderarmes in Gruppen angeordnete, stecknadelkopf-, hanfkorn- bis linsengroße, wachsartigglänzende, hellrote Knötchen, die von einem ganz kleinen, zarten, roten Hof umgeben sind. Bei Kompression eines solchen Knötchens erhält man einen gelblichen Farbenton, die Konsistenz

1) Herrn Prof. Dr. Paul Friedlaender in Darmstadt, seinerzeit an der k. k. Staatsgewerbeschule in Wien-Hernals, danke ich bestens für seine mir in chemischen Fragen erteilten Ratschläge; Herrn D o z e n ten Dr. Ludwig Teleky für seine liebenswürdige Unterstützung in zahlreichen, die Gewerbekrankheiten betreffenden Fragen.

Ebenso danke ich der Druckerei- und Verlags-Aktiengesellschaft vorm. R. v. Waldheim, Josef Eberle \& Comp. in Wien, ferner der Farbenfabrik Michael Huber in München für die freundliche. Überlassung der Farbstoffe zu Versuchszwecken, sowie der chemischen Analyse derselben. 
ist derb. Beim Anstechen eines Knötchens mit der Sonde entleert sich keine Flüssigkeit.

Außer diesen Knötchen finden sich zahlreiche maulbeerähnliche Knötchen, von gleichfalls hell- bis gelblich-roter Farbe, kleinlinsengroß und von mäBig derber Konsistenz. Diese beiden Arten von Knötchen, die klein-papulösen und die maulbeerähnlichen, sind nicht ausschließlich auf die Follikeln beschränkt, sondern auch an anderen Stellen der Haut lokalisiert. Weder auf den kuötehenförmigen, noch den maulbeerähnlichen Effloreszenzen ist makroskopisch Farbstoff zu erkennen.

Subjektiv verursacht dieser Ausschlag dem Patienten nur geringen Juckreiz. Im Urin wurde weder Albumen noch Saccharum gefunden.

Patient erhielt therapeutis $\mathrm{ch}$, da die histologische Untersuchung eines exzidierten Knötchens noch nicht abgeschlossen war, Natrium salicylicum (täglich $4 \mathrm{mal}$ je eine Messerspitze voll nach dem Essen).

Der weitere Krankheitsverlauf gestaltete sich folgendermaßen:

31./XII. 1907. Die Darreichung von Natr. salic. hatte zunächst den - allerdings nicht erwarteten - Effekt, daß die Mehrzahl der Effloreszenzen, sowohl die knötchenförmigen, als auch die maulbeerähnlichen, an ihrer Kuppe eine bläschenförmige Abhebung ihrer Epidermis zeigten. Beim Anstechen einer solchen bläschenförmigen Effloreszenz entleert sich eine gelblich-seröse Flüssigkeit. Natr. salicyl. wird fortgesetzt.

2./I. 1908. Die Mehrzahl der Blasen ist geplatzt, das heraussickernde Serum zu einer gelbbräunlichen Kruste eingetrocknet. Einzelne von den Knötchen sind flacher geworden, in Involution begriffen. Therapie: Umschläge mit Burrowscher Lösung.

3./I. 1908. An Stelle der früheren Knötchen, die ohne Narben ausheilten, sieht man nunmehr rote Flecken. Therapie: Lassars Zinkpaste. Pat. wird geheilt entlassen.

Zum Zwecke einer histologischen Untersuchung wurde ein maulbeerähnliches Knötchen vom rechten Vorderarm exzidiert. Dieses Knötchen ${ }^{1}$ ) wurde in Alkohol fixiert und gehärtet. (Fig. 1.)

Entsprechend dem makroskopischen Aussehen des Tumors zeigt auch das mikroskopische Bild schon bei scliwacher Vergrößerung (Ok. 2, Obj. A. A. nnd Übersichtsfärbung mit Hämalaun-Eosin, Van Gi es on) den papillären Bau. Es erhebt sich aus dem Nivean der Haut ein etwa linsengroßes Knötchen von papillärer Struktur. Außer einer Hyperkeratose mäßigen Grades ist die Akanthose besonders stark ausgesprochen. Beim Vergleich mit den Randpartien, an denen das Rete Malpighii nur wenig oder in mäßigem Grade verbreitet ist, läßt sich dieses Verhalten am besten konstatieren. Infolge der Verbreiterung und Verlängerung der Reteleisten sind selbstverständlich auch die Papillen ver-

1) Eine Hälfte des Knötchens wurde in Serienschnitte zerlegt, die andere zur Färbung der Schnitte mit den üblichen Färbemethoden verwendet. Als Färbemethoden kamen in Betracht: Hämalaun.Eosin, V a n Gieson, polychromes Methylenblau, Methylgrün-Pyronin, Pranters Methode zur Darstellung der elastischen Fasern. 
längert und verbreitert. In den Vertiefungen, Buchten und Falten des maulbeerähnlichen Knötchens sehen wir außer dem von der Exzision desselben stammenden Blute zahlreiche schwarz-grünlich bis schmutziggelblich gefärbte Häufchen. Diese erweisen sich bei starker Vergrößerung, insbesondere bei Untersuchung im polarisierten Lichte, als ein $\mathrm{Konglo-}$ merat von bellglänzenden, doppelbrechenden Kristallen von Wetzstein-Würfelform, von sechssejtigen Doppelpyramiden, von Bariumsulfat und Tonerdehydrat, denen amorphe schmutzig-grünlichgelbe, staubförmige Farbstoffpartikel beigemischt sind. Nicht in allen Buchten und Falten sind Farbstoffpartikel und Kristalle nachweisbar. An einzelnen Stellen des Stratum corneum sind die Lamellen durch die bei der Exzision des Knötchens entstandene Blutung auseinandergedrängt. Der dem Rete Malpighii angrenzende Teil des Stratum corneum steht mit demselben in fester Verbindung. Den durch Exsudat aufgelockerten Lamellen der Hornschichte liegen vereinzelte, doppelbrechende Kristalle von Tonerdehydrat und Blanc fixe (Bariumsulfat) auf. An den Stellen der dichtesten Farbstoffansammlung sind die Lamellen der Hornschichte von feinsten Farbstoffkörnchen bedeckt, sie sehen wie bestäubt aus. Im auffallenden Licht erscheint die Epidermis hauptsächlich durch Farbstoff resp. Kristallauflagerung stark weiß glänzend. Der Farbstoff selbst erscheint bei Untersuchung im polarisierten Lichte als dunkle amorphe Masse, während die doppelbrechenden Kristalle dem Tonerdehydrat und Bariumsulfat angehören. An einzelnen Stellen des Strat. corn. sind in den Lamellen deutlich Kerne zu sehen, also ein geringer Grad von Parakeratose.

In dem beträchtlich verbreiterten Rete Malpighii sind die Retezellen durch ein interspinales ödem auseinandergedrängt, in den erweiterten Interspinalräumen finden sich außer Farbstoffpartikeln, je nach der. Lage, langgestreckte, spindelig ausgezogene, oftmals kolbig angeschwollene Zellen, die wahrscheinlich als Leukozyten (mechanisch gezerrte) anzusprechen sind, neben diesen mononukleäre, weniger polynukleäre Leukozyten. Solche Zellen sind häufig den Retezellen aufgelagert. Die obersten Schichten des Rete sind ebenso wie die Lamellen der Hornschichte mit dunkelgrünen Farbstoffpartikelchen bestaubt.

An Stelle von Retezellen sehen wir recht häufig runde oder ovale Hohlräume, welche mit Exsudat und nahezu homogen mit Eosin rot gefärbtem Inhalt erfüllt sind. Diese Hohlräume sind als intraepidermoidale $Z y$ sten anzusprechen. Das Rete erscheint durch diese Hohlräume zerklüftet, diese werden durch Brücken, den Resten der Retezellen, in größere und k]einere, in ein- und mehrkämmerige geteilt. Dem Exsudat in den Hohlräumen sind polynukleäre Leukozyten, manchmal auch rote Blutkörperchen beigemischt.

Man gewinnt hier den Eindruck einer blasigen Abhebung der obersten Reteschichten mit dem Strat. corneum zusammen von den untersten Reteschichten. Oftmals sieht man auch das Strat. corneum 
allein vom Rete blasig abgehoben. Diese Hohlräume sind spindelig ausgezogen, oft auch unregelmäBig gestaltet und durch senkrecht verlaufende Reteleisten in mehrere Hohlräume geteilt. In manchen Präparaten kann man die Umwandlung einer mehrkämmerigen in eine einkämmerige sehr gnt verfolgen, indem die die Hohlräume trennenden Leisten einschmelzen.

In zahlreichen Zellen des Rete Malpighii sind nicht vollständig ausgebildete Mitosen nachweisbar. Viele Retezellen zeigen einen Hohlraum, als ob der Kern ausgefallen wäre, manchmal ist der Kern geschrumpft. In den untersten Schichten des Rete, besonders in der Basalzellenschichte zeigen die Retezellen kerniges, grünlich-gelbes $\mathrm{Pigment}$, aber nicht in allen Basalzellen.

Der Papillarkörper ist, wie ich bereits erwähnte, durch die verbreiterten und verlängerten Retezapfen gleichfalls in seinen Dimensionen entsprechend vergrößert. Er ist auch der Hauptsitz der entzündlichen Veränderungen, desgleichen die GefäBe, sowohl die Blutals auch die Lymphgefäße.

Die kollagenen Kutisfasern sind durch Ödem etwas aufgelockert und auseinandergedrängt. Die elastischen Fasern sind weder qualitativ noch quantitativ verändert, lassen sich als feinste Fasern bis in die Papillen verfolgen.

Das Z ellinfiltrat ist entsprechend dem papillomähnlichen Tumor, sowohl in den einzelnen Papillen, als auch den tieferen Schichten des Stratum papillare, ziemlich stark entwickelt; es besteht (Färbung mit Methylgrün-Pyronin) aus gewucherten Bindegewebszellen, Lymphozyten, polynukleären Leukozyten, Mast- und Plasmazellen, letztere besonders zahlreich um die erweiterten Gefäße. Letztere sind nicht nur erweitert, sondern ein wenig verdickt und von einem dichten Zellmantel eingescheidet. In den erweiterten Gefäßen sind die Endothelien etwas gequollen, in einzelnen Blut- und Lymphgefäßen sind gleichfalls Kristalle zu sehen. In den tiefsten Schichten des Papillarkörpers, oft auch im subkutanen Fettgewebe, finden sich vereinzelte Mastzellen, sowie spärliche Farbstoffkristalle. Letztere sind oft so klein, dah sie sich nur mit der Immersionslinse nachweisen lassen.

So wie die Lamellen des Stratum corneum, die Retezellen, sind auch die Bindegewebsfasern und die Zellen des Infiltrats im Papillarkörper an manchen Stellen mit Farbstoffkristallen gleichsam imprägniert und zeigen einen bräunlichen Farbenton. Diese Tatsache läbt sich jedoch nicht an allen Präparaten konstatieren. In den tieferen Schichten der Kutis ist kein Zellinfiltrat nachweisbar.

Dort, wo wir an der Oberfläche Farbstoffniederschläge finden, ist eine starke Akanthose vorhanden, mit einem im Papillarkörper lokalisierten, entsprechend dichten Zellinfiltrat.

Der in einem Präparate seiner größten Länge nach getroffene Schwei $B$ dr üsena $u$ f ü hrungsgang ist erweitert, in seinen Wandungen verdickt und gleichfalls von zelligen Elementen umgeben. Der Schweißdrüsenausführungsgang ist an einzelnen Stellen spindelig ausgebuchtet. 
In der Subkutis finden sich Querschnițte von Schweißdrüsenlumina, die gleichfalls erweitert sind.

Fassen wir das Resultat unserer histologischen Untersuchung zusammen, so ergibt sich im Zusammenhalten mit dem klinischen Aussehen, daß der Tumor als ein Papillom, im Sinne ron Auspitzund Unna als Akanthom anzusprechen ist. Das Überwiegen der zelligen Elemente, Lymphozyten, polynukleäre Leukozyten, Plasma- und Mastzellen deutet auf einen éntzündlichen Prozeß im Papillarkörper hin. Außer diesen entzündlich-zelligen Elementen konnte auch $d$ er Nachweis des Farbstoffes, sowie der ihm beigemengten Kristalle in einer großen Reihe ron Präparaten erbracht werden. Der Farbstoff fand sich sowohl in den Buchten und Falten des papillomähnlichen Tumors, der Hornschichte aufgelagert, als auch in den Retezellen, den mit Exsudat gefüllten Hohlräumen der Reteschichte (sog. intraepithelialen Zysten, richtiger blasigen Abhebungen der Reteschichte), ferner in den Bindegewebsfasern und Infiltrationszellen des Papillarkörpers, in den Blut- und Lymphgefäßen. Der Nachweis der Kristalle im Gewebe, auch wenn sie spärlich vorhanden sind, gelingt ganz leicht. Bemerkenswert ist ferner die außerordentlich starke Erweiterung des Schweißdrüsenausfiuhrungsganges. Das entzündliche Infiltrat lokalisiert sich im Papillarkörper, sowie an den darin verlaufenden Blut- und Lymphgefäßen, entsprechend dem von den Anilinfarbstoffen getroffenen Hautbezirke.

Was nun die Frage anlangt, ob aus dem histologischen Befund ein ursächlicher Zusammenhang zwischen Einwirkung von Anilinfarbstoffen und Entstehung dieser papillomähnlichen Gebilde erschlossen werden kann, so ist diese Frage ohne weiters zu bejahen. Für die Genese derartiger Wucherungen kommen außer einer individuellen Disposition sicherlich zwei Momente in Betracht: 1. das mechanische, 2. das chemische Moment. Es unterliegt wohl keinem Zweifel - die experimentellen Untersuchungen bestätigen dies -, daß die in den Farbstoffen enthaltenen Kristalle (Tonerdehydrat und Bariumsulfat), sowie der Farbstoff selbst ihre mechanische Komponente entfalten, indem sie die oberflächlichen Schichten der Epidermis lädieren. Auf einer 'solchen durch längere Zeit präparierten 
Haut kann dann um so intensiver die chemische Komponente einwirken. Vielleicht genügt der chemische Reiz allein ohne mechanische Komponente, um solche papillomähnlichen Gebilde hervorzurufen. Da die Knötchen nur an den Stellen sich entwickelt haben, auf welche der Farbstoff von außen eingewirkt hat, so ist nur der exogene Entstehungsmodus für die Entwicklung der papillomähnlichen Knötchen verantwortlich zu machen und jeder andere, zum Beispiel der durch Inhalation der Farbstoffe und durch Resorption derselben, mit absoluter Sicherheit auszuschließen.

Nach der mikroskopischen Untersuchung sind es mit der größten Wahrscheinlichkeit die Anilinfarbstoffe Säuregelb und Säuregrün, welche ätiologisch für die Entwicklung der papillomähnlichen Knötchen verantwortlich zu machen sind.

Vom pathologisch-anatomischen Standpunkte handelt es sich um eine entzündliche Neubildung, die sich so. wohl durch Proliferation der Epidermis, als auch des Bindegewebes entwickelt und alspapillomatöse Wucherung anzusprechen ist.

Was die Diagnose anlangt, so besteht nach der histologischen Untersuchung nicht der mindeste Zweifel, daß es sich um papillomartige Gebilde handelt. Sowohl mit Rücksicht auf das Resultat der histologischen Untersuchung, als auch den Nachweis des Farbstoffes, sowie der Kristalle in den einzelnen Schichtendiesespapillomartigen Gebildes, au Berdem noch die anamnestischen Angaben, ist die Diagnose einer durch den Anilinfarbstoff entstandenen Papillomatosis cutis zu stellen.

Wollen wir diese Dermatose in das System der Hautkrankkeiten einreihen, so wird sie nach ihren morphologischklinischen Charakteren noch am ehesten unter die hyperkerat o t is chen Bild ungen, wie Verrucae oder Papillome etc., einzuordnen sein.

Mit Rücksicht auf diese Tatsache sind in unserem Falle differential-diagnostisch allenfalls in Betracht kommende Formen wie kongenitale Papillome, 
Verrucae juveniles, sowie papillomatöse Wucherungen, wie solche bei Lupus vulgaris papillaris, bei Lues framboësiformis vorkommen, oder Acne arteficialis mit absoluter Sicherheit auszuschließen.

Die Prognose dieser Erkrankung ist als eine günstige zu bezeichnen, zumal diese gewerbliche Dermatose in überraschend kurzer Zeit unter einer wenig eingreifenden Therapie abheilt und für den Patienten keine wie immer gearteten nachteiligen Folgen, wie die wiederholte nachfolgende Beobachtung und Untersuchung des Patienten lehrte, zurückgeblieben waren.

Die Therapie bestand in der Darreichung von Natrium salicylicum. Nach dieser Medikation wandelten sich die papulösen sowie die papillomatösen Effloreszenzen in Blasen um, die nach Applikation von Umschlägen mit verdünnter Burrowscher Lösung abheilten. Ob die diaphoretische Wirkung des Natrium salicyl. allein im stande war, die Umwandlung der Knötchen in Blasen zu veranlassen, oder ob die erst histologisch nachweisbaren kleinen Hohlränme im Rete die Blasenbildung begünstigten, oder die Blasenbildung, die im Rete präexistent war, auch spontan ohne interne Medikation von Natrium salicyl. erfolgt wäre - kann ich nicht entscheiden.

Für die Prophylaxe solcher Hauterkrankungen, die auf die äußere Einwirkung von Anilinfarbstoffen auf die Haut von in derartigen Betrieben beschäftigten Arbeitern zurückzuführen sind, haben sich einige wichtige Anhaltspunkte aus der $\mathrm{Be}$ handlung des exzidierten Hautstiuckchens mit Alkohol zum Zwecke der histologischen Untersuchung ergeben. Das in Alkohol fixierte und gehärtete Hautstückchen enthält, wie die mikroskopische Untersuchung ergeben hatte, in seinen Falten und Buchten Anilinfarbstoff. Dieser warde rom Alkohol zum großen Teile ausgelaugt, daher konnte die Natur und Art des im Schnitte vorhandenen Farbstoffes nur per exclusionen aus der Farbenreaktion bestimmt werden.

Als prophylaktische Maßnahmen sind, abgesehen von der nach dem Verlassen des Betriebes unbedingt notwendigen und eigentlich selbstverständlichen Reinigung mit Seife und Wasser, Eintupfen der unbekleideten Körperteile mit $70-80 \%$ Alkohol, um die Reste des in den Hautporen und 
auf der Haut befindlichen Farbstoffes zu entfernen. ev. aufzulösen, zu empfehlen. Bei Beginn der Arbeit in dem Anreiberaum ist das Einfetten des Gesichtes mit Vaselin anzuraten.

Die Untersuchung der übrigen in demselben Betriebe beschäftigten Arbeiter, meistens älterer Leute - unser Patient war der einzige im jugendlichen Alter befindliche - ergab in bezug auf eine ähnliche oder gleichartige Dermatose ein negatives Resultat. Diese Tatsache findet auch in den experimentellen Untersuchungen am Kaninchen, über die ich im zweiten Teile meiner Arbeit berichten werde, ihre teilweise Bestätigung. Ich möchte gleich jetzt hervorheben, daß die Mitteilung eines einzelnen Falles noch nicht genügt, um von einer Gewerbedermatose sui generis zu sprechen. Dazu gehören eine größere Reihe von gleichen Erkrankungsbildern, die bei Leuten auftreten, die den gleichen gewerblichen Schädlichkeiten ausgesetzt sind. $\mathrm{Da}$ ich nur über einen einzigen derartigen Fall verfüge, so liegt die Annahme einer besonderen individuellen Disposition sehr nahe. Der jugendliche, 22 Jahre alte Arbeiter hat eine zarte Haut, erkrankt unter der äußeren Einwirkung der Anilinfarbstoffe an diesen papillomähnlichen Gebilden nur an solchen Stellen seines Körpers, die der Farbstoffeinwirkung am meisten ausgesetzt sind; er bedient nämlich die Maschine in einer solchen Körperstellung, daß die rechte Hälfte seines Gesichtes und seines rechten Vorderarmes dieser fast ausschließlich zugekehrt sind. Die älteren Arbeiter dagegen, mit einer resistenteren und derberen Haut, haben keinerlei auf die Einwirkung von Anilinfarbstoffen zu beziehenden Hauterkrankungen dargeboten. Die Frage, ob hier ein bloßer Zufall obwaltet, daß die älteren Leute völlig frei bleiben, ein junger Arbeiter dagegen nach Einwirkung von pulverförmigen Anilinfarbstoffen mit der Bildung von papillomähnlichen Exkreszenzen reagiert, läßt sich nach den Resultaten meiner experimentellen Untersuchungen (II. T'eil) dahin beantworten, daß abgesehen vom chemischen Reiz des schädlichen Agens, d. i. der Anilinfarbstoffe, die individuelle Disposition eine große Rolle spielt.

Anhangsweise seien noch zur Gegen überstellung der Ekzemfälle, hervorgerufen durch Anilinfarbstoffe, zwei Fälle angeführt, ein Fall von Eccema sebor- 
rhoicum mit Warzenbildungen im Gesichte, ein zweiter von Eccema verrucosum der kleinen Zehe des rechten FuBes, das wahrscheinlich auf ein lange Zeit einwirkendes Trauma, z. B. Schuhdruck, zurückzuführen ist.

Bei dem zu beschreibenden Falle $\mathrm{V}$ entwickelten sich im Verlaufe eines seborrhoischen Ekzems des Gesichtes, hauptsächlich in den nasolabialen Furchen, wa r zige Gebild e, sogenannte seborrhoische Warzen, die mit zum Bilde des seborrhoischen Ekzems gehören und nicht auf die Einwirkung von Anilinfarbstoffen zu beziehen sind.

Fall V. N. F., 57 J. alt, verheiratet, suchte am 6. September 1909 das Ambulatorium auf, nachdem er schon früher wiederholt mit Rezidiven der gleichen Dermatose in ambulatoriseher Behandlung stand (Pr.-Nr.183/07).

Pat. ist in einer Hutfabrik als Hilfsarbeiter bei der Hutfärberei beschäftigt, kommt nach den Angaben des Fabriksdirektors mit den in Verwendung stehenden Anilin- und Alizarinfarben nicht in direkte Berührung, sondern ist nur den Wasser- und Säuredämpfen ausgesetzt.

Die klinische Diagnose lautet: Eccema crustosum et rhagadiforme manus utriusque. Verruköse (seborrhoische) Exkreszenzen in der linken Nasolabialfalte auf Basiseines seborrhoischen Ekzems des Gesichtes und der Stirne.

Die histologische Untersuchung eines von der linken Nasolabialfalte entfernten Knötchens ergibt das dem makroskopischen Aussehen entsprechende Bild einer seborrhoischen Warze. Starke Hyperkeratose und Parakeratose mit beträchtlicher Akanthose, so daß die Retezapfen sowohl in die Länge, als auch in die Breite wuchern. Die Lamellen des Stratum corneum sind fettig imbibiert, außerdem sind ibnen schollige, fettige Massen anfgelagert. In der akanthotischen Reteschichte finden sich zahlreiche Mitosen. Im Papillarkörper sind die Gefäße erweitert and um dieselben ein geringes zelliges Infiltrat. Die elastischen Fasern sind weder qualitativ noch quantitativ verändert.

Ich habe diesen Fall nur zum Vergleiche angeführt, um zu zeigen, daß auch chemische Reize anderer Art, zum Beispiel das Sekretbei seborrboischem Ekzem, verruköse Exkreszenzen zu produzieren imstande sind. Die warzigen Gebilde, die seborrhoischen Warzen in der linken Nasolabialfalte, gehören zum Bilde des seborrhoischen Ekzems und haben mit der Einwirkung der Anilinfarbstoffe auf die Haut direkt nichts zu tun. Das rhagadiforme und krustöse Ekzem an beiden Händen ist sicherlich auf die Beschäftigung des Patienten als Hilfsarbeiter in der Hutfärberei zu beziehen.

Aber auch langeinwirkende mechanische Schädlichkeiten, wie z. B. Schuhdruck, können mit dazu 
beitragen, die Entwicklung von verrukösen Exkreszenzen (Eccema verrucosum) bei geeigneter Disposition zu fördern.

F all VI. R. F., 52 J. alt, verheiratet, Tischler, suchte das Ambulatorium am 11. September 1910 auf. (Pr.-Nr. 1122/10.)

Die klinische Diagnose lautet: Eccema chron. dorsi pedis dextriet Eccemaverruc. digiti V. ped. dextri.

Es ist wahrscheinlich, daß das auf den Rand der kleinen Zehe des rechten Fulies einwirkende Trauma (Sehuhdruck) in dem chronischen Ekzem ein geeignetes Terrain zur Entwicklung des verrukösen Ekzems gefunden hat. $\mathrm{Ob}$ nicht außer dem mechanischen Moment noch andere Momente für die Entwicklung des verrukösen Ekzems verantwortlich zu machen sind, kann ich nicht entscheiden.

Die histologische Untersuchung bestätigte vollkommen die Diagnose des Eccema verrucosum.

Bei Fall V handelt es sich um seborrhoische Warzen des Gesichtes, wie solche ja häufig im Gefolge von seborrhoischen Ekzemen, namentlich im Gesicht vorkommen; im Falle VI um das Bild des Eccemaverrucosum der rechten kleinen $\mathrm{Zehe}$, als dessen Ursache, wie gesagt, wahrscheinlich ein langdauerndes Trauma anzusehen ist.

Zusammenfassung: Es zeigten uns die Fälle I und II daß sich das Krankheitsbild als Dermatitis mit papulösverrukösen Exkreszenzen entwickelt, wenn durch längere Zeit Anilinfarbstoffe mit Terpentin, Firnis etc. gemengt auf die menschliche Haut einwirken, oder wenn - wie im Falle III - die Ursache des Eccema verucosum auf die Beschäftigung mit dem Knüpfen der mit Anilinfarbst offen gefärbten Woll e zurückzuführen ist.

Der Fall IV präsentiert den Typus, wie sich nach Einwirkung von pulverförmigen Farbstoffen auf die menschliche Hautpapillomatöse Exkreszenzen entwickeln, und daß diese klinisch feststehende Tatsache durch den Nachweis der Anilinfarbstoffe in Gewebe auch histologisch erbracht und der genetische Zusammenhang von ursächlicher Wirkung der chemischen Noxen, der Anilinfarbstoffe, und Entwicklung solcher papillomatöser Gebilde mit großer Wahrscheinlichkeit nahegelegt wurde.

Im Falle $V$ handelt es sich um seborrhoische Warzen auf Basis eines seborrhoischen Ekzems des Ge- 
sichtes, im Falle VI um ein wahrscheinlich auf mechanische Ursachen zurückzuführendes Eccema verrucosum der kleinen Zehe des rechten Fußes. Die beiden letzten Fälle sollen nur zum Vergleich angeführt werden, daß andere chemische Ursachen als Reizung durch Anilinfarbstoffe, wie z. B. das Sekret des seborrhoischen Ekzems oder auch mechanische Ursachen gleichfalls papillomatöse oder verruköse Ezkreszenzen zu produzieren im stande sind.

\section{Literatur.}

1. A lessandro. Ein Fall von Elefantiasis des Beines mit Papillombildung am Fuß infolge von Erysipel. Il Policlinico. 1896. $\mathrm{Nr}$. 4. Ref. Monatsh. f. pr. Dermatol. 1897. I. p. 49. - 2. A u s pitz, H. System der Hautkrankheiten. Wien 1881. p. 147. Verlag Wilh. Braumüller. - 3. Balzer et $\mathrm{Gau}$ cher. Dermite eczématiforme des pieds provoquée par la teinture des chaussettes. Annales de dermat. et de Syph. 1899. X. 7 . p. 683. Ref. Schmidts Jahrbücher 1900. Bd. CCLVIII. p. 39. - 4. B arthéle my. Des verrues séborrhéiques ou verrues de la vieilesse. Annales de dermatol. 1881. p. 535. - 5. B el1. I. Paraffin-Epithelioma am Skrotum. Edinburg. med. Journal. 1876. CCLIV. Ref. Arch. f. Derm. u. Syph. 1877. p. 267. - 6. B ergman n, E. v. Diskussion zu Volkmanns Vortrag. Verhandlungen der deutschen Gesellsch. f. Chir. Berlin 1874. Ref. Berl. klin. Wochenschr. 1874. Ref. Berl. klin. Wochenschr. 1874. p. 228. - 7. B ernatzik, W. und Vogel, A. E. Lehrbuch der Arzneimittellehre. Wien und Laipzig. Urban \& Schwarzenberg. 1891. - 8. Bi e d erm a n n, Robert. Über einige papillär gebaute Tumoren der Haut (Papillome). Inaug.-Diss. Zürich 1895. - 9. Bla s c h k o, A. Die Hauterkrankungen der Anilinarbeiter. Deutsche med. Wochenschr. 1891. Nr. 45 u. 46. - 10. Derselbe. Gewerbliche Hautkrankheiten. Deutsche med. Wochenschr. 1892. Nr. 7. 11. Ders el be. Gewerbliche Hautkrankheiten. Weyl, Handbuch der Arbeiterkrankheiten. 1908. p. 765 ff. und 771. - 12. Bosellini, P. L. Über eine chronisuhe, zirkumskripte, verrukoide Dermatitis der Hände. Giorn. ital. d. Malattie veneree e della pelle. 1906. H. 5. Ref. Arch. f. Derm. u. Syph. Bd. LXXXIII. p. 275. - 13. Derselbe. Über eine chronische verrukoide Dermatitis der unbedeckten Körperteile. Arch. f. Derm. u. Syph. 1909. Bd. XCVI. p. 229. - 14. D u Caste l. Papillomatöse Ulzerationen des Beines. Pariser Gesellschaft für Derm. u. Syph. Sitzung vom 9. Dez. 1897. Ref. Monatsh. f. prakt. Derm. 1898. Bd. I. p. 101. - 15. Derville und $G$ uermonprez: Das Papillom der Petroleumraffineure. Journ. des sciences médic. de Lille. 1892. IV. Ref. Monatsh. f. prakt. Dermat. 1893. p. 195. - 16. D u bre uil h. De l'eczema hyperkératosique interdigital. Annal. de dermat. 1899. Dez. - 17. E hrmann, Oskar. Die "Pechhaut", eine Gewerbedermatose. Monatsh. f. prakt. Derm. 1909. Bd. XLVIII. p. 18. 18. Eliot, G. T. Papilloma ani, perinaei et penis, post ekzem. chron. Journ. of cut. and genito-urin. dis. New-York 1888. Ref. Arch. f. Derm. u. Syph. 1890. p. 251. - 19. Esmarch. Diskussion zu Volkmanns Vortrag. Verhandlungen der deutsch. Gesellsch. f. Chir. Berlin 1874. Ref. Berl. klin. Wochenschr. 1874. p. 228. - 20. E u l e $\mathrm{b}$ b u rg, A. Über Anilinfarben. Realenzyklopädie der ges. Heilkunde. Urban und Schwarzenberg. 1907. Berlin und Wien. p. 552. - 21. Feilchenfeld, Leopold. Über eine durch Handschuhfarbe hervorgerufene Hautentzündung. Deutsche med. Wochenschr. 1909. Nr. 47. p. 2065. - 22. Finger, E. Die Hautkrank- 
heiten. Leipzig und Wien. Franz Deuticke. 1907. p. 103. - 23. Fleck. Albert. Die Krankheiten der Maler, Anstreicher und Lackierer. W eyl, Handbuch der Arbeiterkrankheiten. p. ó14. - 24. Ge hert. Ekzem mit warzenartigen Effloreszenzen. Berliner derm. Ges, vom 3. März 1903. Ref. Arch. f. Derm. u. Syph. 1903. Bd. LXVI. p. 218. - 25. Gold s chmidt, F., Heinzerling, Chr., Helbig, Roth, E., Weyl, Th. Handbuch der Hygiene. Bd. VIII. Gewerbehygiene mit besonderer Rücksicht auf Fabrikgesetzgebung, Unfallschutz- und Wohlfahrtseinrichtungen. Jena. Verlag v. Gustav Fischer. 1897. p. 629 ff. und p. 839. - 26. Gräfflin, Artur. Experimentelle Untersuchungen über den schädlichen Einfluß von pulverförmigen Anilinfarben auf die Schleimhaut des Kaninchenanges. Zeitschr. f. Augenheilkunde. 1903. Bd. X. p. 193. - 27. Grandhomme. Die Fabriken der Aktiengeselllschaft Farbwerke vorm. Meister, Lucius und Brüning zu Höchst a. M. IV. Auflage. Frankfurt a. M. Verlag von Mahlau und Waldschmidt. 1896. p. 87. - 28. Guy. Ein Fall von generalisierter pruriginöser Papillomatose (Lichen planus papillomatosus). Journ. des mal. cut. es syph. 1899. Nr. III. p. 129. Ref. Dermatol. Zeitschr. Bd. VI. p. 810. - 29. Hanke, Viktor. Die Nitronaphthalin-Trübung der Hornbaut - eine Gewerbekrankheit. Wiener klin. Wochenschr. 1899. p. 725. 30. Hebra-Kaposi. Lebrbuch der Hautkrankheiten. Erlangen. Ferd. Enke. 1874. - 31. Herxheimer, Karl. Über die gewerblichen Erkrankangen der Haut. Deutsche med. Wochenschr. 1912. Nr. 1. - 32. H offmann (Halle a. S.). Die Krankheiten der Arbeiter in Teer- und Paraffinfabriken in medizinisch-polizeilicher Hinsicht. Vierteljahrschr. f. gerichtl. Medizin u. öffentl. Sanitätswesen, herausgegeben von A. Wernich. Dritte Folge. V. Band. Berlin 1893. p. 358 (mit ausführlicher Literatur). - 33. $\mathrm{Huber}$, Alfred. Perifolliculitis suppurativa und framboesiforme Vegetationen im AnschluB an Ekzem. Arch. f. Derm. $u$. Syph. Bd. XLIX. p. 57. - 34. HuIdschiner. Zur Ätiologie der Blasengeschwülste bei Anilinarbeitern. Ärztl. Verein in Hamburg. Sitzung vom 1. November 1898. Ref. Münch. med. Wochenschr. 1898. p. 1452. - 35. Jaris ch, A. Hautkrankbeiten. Alfred Hölder. 1908. 2. Aufl. p. 271 und 311 ff. - 36. Jess ner, S. Diagnose und Therapie des Ekzems. p. 31. Würzburg. Kurt Kabitzsch. (A. Stubers Verlag.) 1909. - 37. Derselbe. Kompendium der Hautkrankheiten. Würzburg 1906. - 38. J ores, L. Pathologie und patholog. Anatomie der Harnorgane in Lubarseh und Ostertag. 1899. Bd. VI. p. 804. - 39. Ka posi. Pathologie und Therapie der Hautkrankheiten. Urban und Schwarzenberg. 1899. - 40. Kirk. Paraffincancer. The British med. Journal. 1903. 12. Dez. p. 1528. Ref. Arch. f. Derm. u. Syph. Bd. LXXIII. p. 466. - 41. Kreibich, K. Lehrbuch der Hautkrankheiten. Moriz Perles. Wien 1904. - 42. Kuwahara, Y. Experimentelle und klinische Beiträge über die Einwirkung von Anilinfarben auf das Auge. Arch. f. Augenheilk. 1903. p. 157. - 43. Landonzy, E. und Brouardel, G. Empoisonnements non professionnels par l'auiline. Annal d'Hygiene etc. Bd. XLIV, II. p. 137. Ref. Schmidts Jahrbücher 1901. Bd. CCLXIX, p. 174. - 44. Langenbeck, v. Diskussion za Volkmanns Vortrag. Verhandlungen der deutschen Ges. f. Chirurgie. Berlin 1874. Ref. Berl. klin. Wochenschr. 1874. p. 228. - 45. L e fe b u e. Contribution à l'étude des dermites professionnelles. De l'ekzéma, des fileurs et varouleurs de lin. Thèse de Doktorat. Lille 1888. Annales d. dermat. 1888. p. 824. - 46. L ei ch tenstern, 0 . Über Harnblasenentzündung und Harnblasengeschwülste bei Arbeitern in Farbfabriken. Deutsche med. Wochenschr. 1898. Bd. XXIV. p. 709. - 47. Derselbe. Über Zysten und Harnblasengeschwülste bei Arbeitern in Farbwerken. Allg. ärztl. Verein zu Köln. Sitzung v. 17. Okt. 1898. Ref. Münch. med. Wochenschr. 1898. II. p. 1453. - 48. Lei s er, Georg. Die Krankheiten der Steindrucker und Lithographen. W ey l, Handbuch d. Arbeitenkrankheiten. p. 337. - 49. Léloir. Dermite profes- 
sionelle spéciale. (Ekzema des fileurs et varouleurs de lin.) Ann. de derm. et syph. März 1885. Ref. Monatshefte f. prakt. Derm. 1886. p. 253. 50. Lesser, E. Lehrbuch der Hautkrankheiten. Leipzig 1904. - 51. Derselbe. Enzyklopädie der Haut- und Geschlechtskrankheiten. Leipzig 1900. - 52. Liebe, P. Ein Fall von Paraffinkrebs. Ref. in Schmidts Jahrbücher. 1892. p. 325. - 53. L i p p an n. Diskussion zum Falle Gebert. Berl. dermat. Ges. März 1903. - 54. Ludwig, Ernst. Über einige Bestandteile des Tabakrauches. Arch, f, klin. Chirurgie. Bd. XX, p. 363. 55. Mackenzie, St. Demonstration eines. Falles von Teerausschlag. Londoner dermat. Ges.-Sitzung v. 12. Okt. 1898. The British Journ. of dermat. Nov. 1898. Ref. Monatsh. f. prakt. Dermat. 1899. I. p. 254. 56. Morton. Demonstration eines Falles von Eccema verrucosum. Brooklyn dermatological and genito-urinary society. Sitzung v. 10. Febr. 1893. Ref. Monatsh. f. prakt. Dermat. 1893. Bd. II. p. 131. - 57. M r a ček, Franz. Handbuch der Hautkrankheiten. Wien. Alfred Hölder. 1902. - 58. N e is s e rJad a s s o hn. Hantkrankheiten. Sonderabdruck aus Fipstein-Schwalbes Handb. d. prakt. Medizin. 1901. - 58a. N etolitzky. Hygiene der Textilindustrie. W e y ls Handbuch der Hygiene. Bd. VIII. p. 1163. - 59. N o bl, G. Der variköse Symptomenkomplex (Phlebktasie, Stauungsdermatose, Uleus cruris), seine Grundlage und Behandlung, Urban und Schwarzenberg. 1910. p. 98 u. ff. p. 110 . - 60. Notin, E. Etudes sur les papillomes simples. Annal. de dermat. 1885. p. 696. - 61. Pinkus, F. Diskussion zum Falle Gebert. Berl. dermat. Ges. 3. März 1903. - 62. Derselbe. Die Pathologie des Ekzems in Lubarsch-Ostertag: Ergebnisse der allg. Pathologie und patholog. Anatomie des Mensehen und der Tiere. X. Jahrg. Ergänzungsband 1907. p. 143. Wiesbaden. Verlag v. I. F. Bergmann. 63. Pecirka. Über Hautpapillome. Ref. Monatshefte f. prakt. Dermat. 1891. II. p. 170. - 64. Pollitzer, S. (New-York). Die seborrhoische Warze. Monatsh. f. prakt. Dermat. 1890. II. p. 145. - 65. Pratique dermatologique von Besnier, Brocque, Jacquet. - 66. Pringle. Ein Fall von ulzerierendem, hypertrophischen Eccema verrucosum. Londoner dermat. Ges. Sitz. v. 10. März 1897. Ref. Monatsh. f. prakt. Derm. 1897. II. p. 130. - 67. Purdon, H. S. Die akneartigen Ausschläge von Arbeitern in Flachsspinnereien. British med. Journ. 13. Sept. 1902. Ref. Monatsh. f. prakt. Dermat. 1903. I. p. 279. - 68. Rehn, L. Blasengeschwülste bei Fuchsinarbeitern. Arch. f. klin. Chir. von B. v. Isangenbeck. Bd. I. p. 588. - 69. Dersel be. Über Harnblasengeschwülste bei Anilinarbeitern. 34. Kongreß der deutschen Ges. f. Chir. p. 220. - 70 . Riecke, E. Lehrbuch der Haut* und Geschlechtskrankheiten. Jena 1909. Verlag von G. Fischer. - 71. Rill e. Demonstration einer Moulage; darstellend eine besondere Form von Akne arteficialis. Versamml. deutscher Naturforscher u. Ärzte. Braunschweig 1897. Ref. Arch. f. Derm. u. Syph. Bd. XLII. p. 111. - 72. Rosenthal, 0. Diskussion zum Falle Gebert. Berl. derm. Ges. vom 3. März 1903. - 73. Roth, E. Kompendium der Gewerbekrankheiten. 1904. p. 50. - 74. Sa alfeld. Diskussion zum Falle Gebert. Berl. derm. Ges. vom 3. März $1903-75$. S a chs, Otto. Diskussionsbemerkung zum Falle Ullmanns (Multiple Paraffinkarzinome am Skrotum). Wiener derm. Ges. v. 3. Nov. 1909. - 76. Schamberg, Jay Frank. Krebs bei Teerarbeiten. The Journ. of cutan. diseases includ. syphilis. Dez. 1910. - 77. S \& bu chard t, Karl. Beiträge zur Entstehung der Karzinome aus chronisch entzündlichen Zuständen der Schleimhäute und Hautdecken. Volkmanns Sammlg. klin. Vorträge. 1885. Nr. 257. Leipzig. Breitkopf \& Härtel. - 78. Senn, A. Typische Hornhauttrübungen bei Anilinfärbern. Korrespondenz-Bl. f. Schweizer Ärzte. Ref. VirchowHirch. 1897. Bd. II. p. 437. - 79. Silberstein, R. Die Krankheiten der Buchdrucker. W eyl, Handbuch der Arbeiterkrankheiten. p. 272. 80. Straus s, Friedrich. Über Anilintumoren. 34. Kongreß d. deutschen 
Ges. f. Chirurg. p. 226 . - 81. Tillmanns, H. Über Teer-, Ruß- und Tabakkrebs. Zeitschr. f. Chir. 1880. Bd. XIII. p. 519. - 82. Török, L. Spezielle Diagnostik der Hautkrankheiten für prakt. Ärzte und Studierende. Wien 1906. Alfred Hölder. - 83. Ullm a n n, K. Demonstration eines Falles von multiplen Paraffinkarzinomen am Skrotum. Wiener derm. Ges. v. 3. Nov. 1909. - 84. Un n a, P. G. Histopathologie der Hautkrankheiten. Berlin 1894. Verlag von August Hirschwald. - 85. Vogt, A. Weitere experimentelle und klinische Untersuchungen über den schädlichen Einfluß von künstlichen Anilinfarben auf das Auge. S.-A. aus der Zeitschr. f. Augenheilk. 1905. Bd. XIII. p. 226 ff. Ref. in $\mathrm{Sebmidts}$ Jahrbücher. Bd. CCLXXXIX. p. 210. - 86. Derselbe. Experimentelle Untersuchungen über die Bedeutung der chemischen Eigenschaften der basischen Anilinfarbstoffe für deren schädliche Wirkung auf die Augenschleimhaut. Zeitschr. f. Augenheilk. 1906. XV. 1. Ref. in S $\mathrm{chm}$ idts Jahrbücher. 1906. Bd. CCXCII. p. 96. -87 . Volkman n, R. Über den Teer- und Rußkrebs. Verhandl. der deutschen Ges. f. Chir. Berl. klin. Wochenschr. 1874. p. 218. - 88. Ders el be. Beiträge zur Chirurgie, anschlielsend an einen Bericht über die Tätigkeit der chirurgischen Universitätsklinik zu Halle 1873. Breitkopf \& Härtel. Leipzig 1875. - 89. W e b e r, Karl. Über Anilinfarben. Monatshefte f. praktische Dermatologie. Bd. 1886. p. 230. - 90. Wils on, Erasmus. Über Hautentzündungen durch Anilinfarben. Journ. of Cut. Med. April 1869. Ref. Arch. f. Dermat. u. Syph. 1869. p. 464. - 91. Weyl, Th. Handbuch der Hygiene. Bd. VIII. Gewerbehygiene mit besonderer Rücksicht auf Fabrikgesetzgebung. Unfallschutz und Wohlfahrtseinrichtungen. Jena. Verlag von G. Fischer. 1897. p. 839. 92. Weyl, Th. Handbuch der Arbeiterkrankheiten. Krankheiten der chemischen Arbeiter. 1908. p. 206. - 93. Derselbe. Zur Revision des Reichsgesetzes betreffend die gesundheitsschädlichen Farben. Berl. med. Ges. v. 1. März 1911. Ref. Deutsche med. Wochenschr. 1911. Nr. 11. 94. White, James C. Notes on dermatitis venenata. Boston med. and surg. Journ. 1897. CXXXVI. 4. p. 77. Ref. in $\mathrm{S} \mathrm{ch} \mathrm{midts} \mathrm{Jahrbücher} 1897$. Bd. CCLV. p. 18. - 95. Z weig, Ludwig. Über einen Fall von multiplen Hautkarzinomen bei einem Brikettarbeiter (Fall von Teer-, resp. Paraffinkrebs) und einiges über die ̈̈tiologie dieser sogenannten Berufskarzinome. Inang.-Diss. Berlin 1909. Verl. v. S. Karger. - 96. Z u r Erkrankung der Arbeiter in Anilinfabriken an Blasenleiden. Zeitschrift f. Gewerbehygiene 1910. p. 157. Ref. in Jahresbericht der preuBischen Regierungs- und Gewerberäte. p. 390 und 391.

\section{Teil.}

\section{Experimentelle Untersuchungen über die Einwirkung von Anilin- farbstoffen und chemischen Agentien auf die tierische Haut (innere Ohrfläche von Kaninchen).}

\section{Einreibungsversuche:}

1. Einreibung mit Bleiweiß, Miloriblau, Sienna, Zinnober. Grünerlack

2. Einreibung mit Scharlachrot, Brillantrot, Krapplack, Gelblicht,

3. Einreibung mit Farbstoff-Lanolinsalben, Tonerdehydrat, Bariumsulfat (Blane fixe).

4. Histologische Untersuchung.

5. Zusammenfassung der Versuchsresultate. 
II. Injektionsversuche:

1. Bisherige experimentelle Untersuchungen aus der Literatur.

2. Injektion von Emulsionen der Anilinfarbstoffe (Scharlachrot, Brillantrot, Krapplack, Gelblicht, Grünerlack) in Olivenöl, von Suspensionen dieser Farbstoffe in destilliertem Wasser, von reinem sterilisierten und nicht sterilisierten Olivenöl.

3. Histologische Untersuchung.

4. Epikrise.

5. Zusammenfassung der Versuchsresultate.

6. Literatur.

Nach den klinischen Beobachtungen war der Gedanke naheliegend, mit den bereits genannten Stoffen: BleiweiB, Berlinerblau (Miloriblau), Sienna, Zinnober; mit den Anilinfarbstoffen: Scharlachrot, Brillantrot, Krapplack, Gelblicht, Grünerlack, ferner Tonerdehydrat und Bariumsulfat unter möglichster Einhaltung des Entstehungsmodus der im ersten Teile dieser Arbeit von mir beschriebenen gewerblichen Hauterkrankungen, die Einwirkung der genannten Agentien auf die tierische Haut innere Ohrfläche des Kaninchens - experimentell zu prüfen.

Im Anschlusse daran wurden die bekannten Versucbe B. Fischers mit subkutanen Injektionen von Scharlachölundanalogemit den oben genannten Anilinfarbstoffen am Kaninchenohr wiederholt.

Bevor ich die Resultate meiner experimentellen Untersuchungen, sowie die der sich daran schließenden histologischen Ergebnisse derselben mitteile, möchte ich zunächst nur auf die in der Lehre von den Entzündungen und den Geschwülsten seit langem in der Pathologie bekannten und allgemein anerkannten ursächlichen Beziehungen zwischen Reiz und Entzündung hinweisen.

Wir unterscheiden bekanntlich Entzündungen 1. aus mechanischen, 2. aus physikalischen, 3. aus chemischen Uraachen. $\mathrm{Zu}$ den letzteren sind die rein urtikariellen Dermatosen, die einfachen, oberflächlichen Nekrosen, die meisten tiefgehenden Ätzungen durch konzentrierte Säuren und Alkalien nach Unna nicht zu rechnen. Auch nach Abzug dieser Gruppen bleibt nach Unnas Ausführungen noch eine Fülle von krankhaften Erscheinungen übrig, die wir den Entzündungen hinzurechnen müssen und „es ist - nach den Worten dieses Autors -nur zu beklagen, dal unsere histologischen Kenntnisse in diesem Kapitel nicht entfernt unseren klinischen nahekommen. Es ist sicher zu hoffen, $\mathrm{da} \beta$ gerade diese Lücken in nicht zu ferner Zeit ausgefüllt werden, da kein anderes Kapitel so sehr der experimentellen Bearbeitung zugänglich 
ist und kaum eines so fruchtbar für die Erweiterung unserer pathologischen Anschauungen zu werden verspricht".

Mit den folgenden experimentellen Untersuchungen - Einwirkung von chemischen Agentien, insbesondere Anilinfarbstoffen - die in Form von Einreibungen auf die innere Ohrfläche von Kaninchen appliziert wurden, sowie den histologischen Untersuchungen glaube ich einen kleinen Teil zur Ausfüllung dieser Lücken beitragen zu können.

\section{Einreibungsversuche.}

Die Versuchsanordnung gestaltete sich folgendermaßen: Die chemischen, in einer Buchdruckerei verwendeten Agentien Bleiweiß, Miloriblau, Sienna, Zinnober, sowie die zum Dreifarbendruck gebrauchten, bereits des öftern genannten Anilinfarbstoffe wurden in einer trockenen, sterilen Glasschale mit sterilem Pistill möglichst fein zerrieben, dieses fein verriebene Pulver wurde mit dem kolbigen Ende einer Eprouvette auf die innere Ohrfläche von verschieden alten Kaninchen in der Dauer von 5-10 Minuten unter möglichst leichtem Druck eingerieben. Die Einreibungen wurden entweder täglich oder mit 2-3tägiger Pause vorgenommen, im ganzen 2-13. Die histologische Untersuchung erfolgte in den verschiedensten Stadien. Es wurden Fälle nach zwei, vach sechs, nach zehn, nach dreizehn Einreibungen der histologischen Untersuchung zugefülrt. Die exzidierten Hantstücke wurden in Alkohol oder in $10 \%$ igem Formol fixiert und in steigendem Alkohol gehärtet. Die Einbettung erfolgte in Paraffin, in manchen Fällen wurden Gefrierschnitte angefertigt. Als Färbemethoden kamen als die gebräuchlichsten und für unsere Zwecke am geeignetesten folgende zur Anwendung: HämalaunEosin, van Gieson, polychromes Methylenblau, Methylgrän-Pyronin, Pranters Färbung auf elastische. Fasern.

Fünf Einreibungsversuche $(1-5)$, bei denen wiederholt 2-6mal auf die Innenflächedes Ohres Bleiwei $B$, Miloriblau (Berlinerblau), Sienna und Zinnober eingerieben wurden, sind vollständig negativ ausgefallen. Die Obrinnenfläche blieb glatt und glänzend. Es erscheint doch auffallend, daß trotz der oft wiederholten Einreibungen mit chemisch für die Haut mehr oder minder indifferenten Agentien, bei einer Einreibungsdauer von 5-6 Minuten, kaum eine ganz oberflächliche Dermatitis aufgetreten war.

Es ist nun die Frage zu beantworten, auf welche Momente das Ausbleiben der Reaktion in dieser Versuchsreihe zurück- 
zuführen wäre. Die zum Versuche verwendeten chemischen Agentien waren so fein verrieben, daß allerdings grob mechanische Läsionen, z. B. ausgedehnte Exkoriationen - zumal bei der mikroskopischen Untersuchung dieser Chemikalien keine Kristalle nachweisbar - a priori nicht zu erwarten waren. Fs dürfte vielleicht daran liegen, daß die chemische Komponente dieser Agentien auch vollständig inaktiv ist, indem diese Stoffe unlöslich sind.

Die folgenden Versuch'e 6-22 beziehen sich auf Einreibungen mit den Anilinfarbstoffen Scharlachrot, Brillantrot, Krapplack, Gelblicht, Grünerlack a uf die Ohrinnenfläche von Kaninchen. Sämtliche zu diesen Versuchen verwendeten Farbstoffe enthalten Tonerdehydrat in Kristallform als Beize und Bariumsulfat (blanc fixe) als Beschwerungsmittel in kristallinischer, resp. Kristallform beigemengt.

6. Versuch mit Scharlachrot (auch Sudan IV genannt, Einwirkungsprodukt des diazotierten Amidoazotoluol auf $\beta \mathrm{Naphthol).}(6 a$ und $6 \mathrm{~b}$.)

14./XII. 1909. Beide Ohrinnenflächen eines weißen, 6 Monate alten Kaninchens werden mit Scharlachrot 5-6 Minuten lang eingerieben. 1. E.) 16./XII. 1909. Nach 1 E. am rechten Ohr keine Erscheinungen, am linken an zahireichen Stellen strichförmige Dermatitis. 2. E. am rechten Ohr, linkes $\mathrm{Ohr}$ wird nicht eingerieben.

17./XII. 1909. Rechtes Ohr deutliche oberflächliche Dermatitis, linkes Ohr strichförmige Dermatitis. Kaninchen sieht elend aus, Speichelflub. Rechtes Ohr 3. E., linkes Ohr 2. E.

20./XII. 1909. Nach 3 E. r. Ohr anßer einer Dermatitis eine Ulzeration von ovaler Form, $3 \mathrm{~cm}$ lang und $2 \mathrm{~cm}$ breit. Nach $2 \mathrm{E}$. linkes Ohr ziemlich ausgedehnte Dermatitis. Ohren welk.

21./XII. 1909. Status unverändert.

23./XII. 1909. Nach 3 E. r. Ohr Dermatitis im Rückgang, Ulzeration abgeheilt. Nach $2 \mathrm{E}$. linkes Ohr Dermatitis im Rückgang.

28./XII. 1909. Rechtes Ohr 4. E., linkes Ohr 3. E.

31./XII. 1909. Rechtes Ohr nach 4 E. deutliche Dermatitis, linkes Ohr nach 3 E. streifenförmige Dermatitis. Tier munter.

7./I. 1910. Krusten der Dermatitis in Abstoßung begriffen. R. Ohr 5. E., linkes Ohr 4. E.

10./I. 1910. Nach 5 E. sieht man am r. Ohr, nach 4 E. am linken $\mathrm{Ohr}$ außer der Dermatitis Follikel mit Farbstoft gefüllt, stark hervorspringend. An Stelle der früheren Dermatitis glatte Stellen ohne Follikel. Rechtes Ohr 6. E., 1. Ohr 5. E.

13./I. 1910. Nach 6 E. r. Ohr und 5. E. l. Ohr treten außer der Dermatitis die Follikel deutlich hervor, weil dieselben mit Farbstoff gefüllt sind. Rechtes $\mathrm{Ohr}$ 7. E., linkes Ohr 6. E.

20./I. 1910. Nach $7 \mathrm{E}$. rechtes $\mathrm{Ohr}$ und $6 \mathrm{E}$. linkes $\mathrm{Ohr}$ der gleiche Befund, Follikel stark hervortretend. Rechtes Ohr 8. E., linkes Ohr 7. E.

1) Der Kürze halber wird statt Einreibung E. geschrieben. 
28./I. 1910. Rechtes $\mathrm{Ohr}$ nach $8 \mathrm{E}$., linkes $\mathrm{Ohr}$ nach $7 \mathrm{E}$, außer einer Dermatitis stark vorspringende, reibeisenförmige Follikel. Am rechten Auge eitrige Konjunktivitis infolge Reizung von Farbstoffen. Rechtes Ohr 9. E., linkes Ohr 8. E.

31./I. 1910. Der gleiche Befund.

10./II. 1910. Der gleiche Befund. Rechtes Ohr 10. E., linkes Ohr 9. E.

15./II. 1910. Exzision der Hautstäcke und Fixierung in 10\% Formol.

Die Versuchsdauer beträgt nahezu 2 Monate, die Einreibungen wurden anfangs täglich, dann in 3-4-5tägigen Intervallen vorgenommen. Makroskopisch sieht man a Ber einerDermatitis starkvorspringende Follikel, die der inneren Ohrfläche ein reib. eisenähnliches Aussehen verleihen. Die histologische Untersuchung wurde 5 Tage nach der letzten Einreibung vorgenommen. Da die Resultate der E. mit Scharlachrot an der inneren Ohrfläche beider Ohren eines 6 Monate alten Kaninchens $(10$ E. rechtes $\mathrm{Ohr}, 9 \mathrm{E}$. linkes $\mathrm{Ohr}$ ) die gleichen waren, so werden sie gemeinsam besprochen.

Diewesentlichsten Merkmale der histologischen Untersuchung bestehen in folgenden Punkten: Verbreiterung des Stratum corneum mit zahlreichen Hornperlen, die Reteschicht ist stark proliferiert, besonders entsprechend den vergrößerten Talgdrüsen und Follikeln. In diesen findet man den bei $\mathbf{E}$. eingepreßten Farbstoff. Nur an diesen Stellen erfolgt eine Wucherung des Rete Malpighii und der Talgdrüsen. Die Zellen des Rete Malpighii sind lang und schmal und haben eine gewisse Ähnlichkeit mit gewucherten Retezellen bei Psoriasis vulgaris. In der Kutis selbst lassen sich Epithelinseln, die abgeschnürten Teilen der proliferierten Retezapfen entsprechen, nachweisen. Zwischen den Bindegewebsbündeln finden wir ödem und ein mäßig reichliches Zellinfiltrat, das hauptsächlich aus Rundzellen, polynukleären Leukozyten, gewucherten fixen Bindegewebszellen und spärlichen Plasinazellen besteht. Die entzündlichen Vorgänge sind im Abklingen begriffen. Blut- und Lymphgefäße erweitert, die elastischen Fasern gut tingiert, weder qualitativ noch quantitativ verändert, fehlen nur an den Stellen des Infiltrates. Die wichtigsten Veränderungen beziehen sich auf die Wucherung des Stratum corneumsud Rete Malpighii, ferner auf eine Vergrößerung der Talgdrüsen und Erweiterung der Follikel. Manche Präparate machen durch das Vorkommen von Epithelinseln, die tief in das Kutisgewebe eingesenkt erscheinen, den Eindruck einer epitheliomähnlichen Veränderung. Dazu kommt noch das Auftreten von Hornperlen in den Epithelinseln, die geringen, bereits im Abklingen begriffenen entzündlichen Erscheinungen der Kutis, die den Eindruck eines epitheliomähnlichen Bildes noch erhöhen.

\section{Versuch mit Scharlachrot. (Fig. 2.)}

17./XII. 1909. Beide Ohrinnenflächen eines zwei Jahre alten Kaninchens werden mit Scharlachrot 5-6 Min. lang eingerieben. $1 \mathrm{E}$.

15./II. 1910. Die Versuchsdauer beträgt $z$ wei Monate (vom 17./XII. 1909 bis 15./II. 1910) mit 8 E. bei einem zwei Jahre alten Kaninchen. Die E. wurden in verschieden langen Intervallen vorgenommen. Makroskopisch sehen wir nach 8 E. an der inneren Ohrfiäche reibeisenartig vorspringende Follikel. Nach 8 E. werden die Hautstücke exzidiert und in $10 \%$ igem Formol fixiert. Zwei Hautstäckchen werden zur Granulafärbung in warmes konzentriertes Formalin eingelegt. Die histologische Untersuchung wurde fünf Tage nach der 8. E. vorgenommen. Der Farbstoff Scharlachrot jst in den Präparaten nicht nachweisbar, weil er bei der Fixierung und Härtung der Präparate in Alkohol ausgelaugt wurde. Das Resultat dieses Versuches ist analog dem des Versuches 6.

8. Versuch mit Scharlachrot. 
12./V. 1910. Beide inneren Ohrflächen eines älteren Kaninchens werden mit Scharlachrot 5-6 Minuten eingerieben. $1 \mathrm{~F}$.

20./V. 1910-1./VIII. 1910. Ganz geringe Entwicklung der follikulären Exkreszenzen. 2. E.-8. E.

15./IX, 1910. Vollständige spontane Involution der Exkreszenzen.

Da die klinischen Merkmale der tollikulär entwickelten Exkreszenzen sehr gering waren, wurde von einer histologischen Untersuchung Abstand genommen.

9. Versuch mit Brillantrot (tonerdehaltiger Az of a rbBariumlack. Azofarbenicht giftig.) (Fig. 3.)

4./VII. 1908. Innere Ohrfläche (rechtes Ohr) eines jungen Kaninchens wird mit Brillantrot durch 5-6 Minuten eingerieben. 1. E.

8./VII. 1908. Keine Erscheinungen. 2. E.

11./VII. 1908. Knötchenbildung und Dermatitis. 3. E.

14./VII. 1908. Derselbe Befund. 4. E.

16./VII. 1908. Derselbe Befund.

18./VII. 1908. Dermatitis unverändert, ebenso die Knötchen. 5. E.

20./VIl. 1908. Ziemlich ausgedehnte, mit rotem Farbstoff bedeckte

Dermatitis. 6. E.

22./VII. 1908. Der gleiche Befund. 7. E.

25.VII. 1908. Einlegen des exzidierten Hautmaterials zum Teil in Alkohol, zum Teil in $10 \%$ Formol.

Das gleiche histologische Bild wie die Präparate des 6. Versuches bieten auch die des 9 . Versuches. Die Versuchsdauer beträgt 3 Wochen mit $7 \mathrm{E}$, die in Intervallen von 1-2-3 Tagen wiederholt wurden. Makroskopisch haben wir das Bild einer Dermatitis. Die histologische Untersuchung wurde 3 Tage nach der 7. E. vorgenommen. Auch bei diesem Versuche ist als das wichtigste Moment anßer den entzündlichen Erscheinungen die Verbreiterung und Proliferation des Rete Malpighii und der Talgdrüsen, hervorgerufen durch den chemischen Reizdes Farbstoffes Brillantrot (Azofarbstoff) nach 7 E.za erwähnen. 10. Versuch: mit Krapplack (bleibaltiger AlizarinTonerdelack), nicht giftig. (10a und 10b.)

4./VII. 1908. Die Innenfäche des rechten Ohres eines jungen Kaninchens wird mit Krapplack $5-6$ Minuten lang eingerieben.

8./VII. 1908. Nach der ersten E. mit Krapplack auf der Obrinnenfläche Dermatitis, zum Teil vom Aussehen eines impetiginösen Ekzems. In der Umgebung der Dermatitisherde wird eine 2. E. 5-6 Minuten lang vorgenommen.

11./VII. 1908. Nach der 2. E. tritt wiederum eine starke Dermatitis auf. Die Dermatitisherde vom 4./VII. 1908 und 8./VII. 1908 werden exzidiert und in $10 \%$ Formalin fixiert; ein Teil wird nach 24stündigem Verweilen in $10 \%$ Formol zu Gefrierschnitten verwendet, ein anderer mit Alkohol weiter behandelt und gehärtet.

Schon nach einer Einreibung mit Krapplack trat auf der Ohrinnenfläche eîne Dermatitis auf, eine zweite, nach 4 Tagen wiederholte Einreibung hatte denselben Effekt zur Folge. Die 7 resp. 3 Tage nach der Einreibung erfolgte histologische Untersuchung der betreffenden Hautstïcke ergab folgenden Befund.

An den Gefrierschnitten (Färbung mit Methylgrün-Pyronin, mit Sudan III) ist bei den Versuchen nach einer Einreibung und nach 2 Einreibungen histologis $\mathrm{ch}$ eine mit Farbstoff bedeckte papelartige Erhebung za konstatieren. Diese besteht aus einer Exsudatmasse, entsprechend dieser fehlt das Rete Malpighii oder ist nur als ganz schmale Zone erhalten, im Korium ein reichliches Rundzelleninfiltrat, die Gefäße erweitert. 
In den mit Hämalaun-Eosin gefärbten Präparaten nach Formol-Alkohol-Behandlung findet man entsprechend dem makroskopischen Aussehen auch mikroskopisch ein Knötchen, das sich als eine mit roter Farbe (Krapplack) bedeckte Exsudatmasse erweist. Das Rete Malpighii fehlt an dieser Stelle fast vollständig, ebenso das Stratum granulosum und das Stratum corneum. Dieser Substanzverlust ist ausgefüllt mit einer Exsudatmasse und einer darüber gelagerten Schichte von Krapplack. Das Exsudat setzt sich aus mono- und polynukleären Leukozyten und Fibrin zusammen, in den Spalträumen desselben ist roter Farbstoff in Form von Streifen eingelagert.

Entsprechend der knötchenartigen Erhebung findet man im Papillarkörper ein ziemlich dichtes Rundzelleninfiltrat mit vereinzelten $\mathrm{Pla}$ s maand Mastzellen. Die Gefäße der Kntis sind stark erweitert und strotzend getüllt.

Nach der histologischen Untersuchung besteht das Ergebnis dieses Versuches in einem Substanzverlust, von demaus - wahrscheinlich durch chemische Irritationdes bleihaltigen Alizarins bedingt - eine ziemlich starke Entzündung ihren Ausgangspunkt nimmt. Diese manifestiert sich zunächst in einer beträchtlichen Erweiterung der Blut- und Lymphgefäße der Katis mit nachfolgender proliferierender Entzündung. Das ziemlich reichliche Exsudat füllt nun den Substanzverlust - die ohersten Schichten der Kutis sowie die ganze Epidermis betreffend - vollständig aus und bildet ein mit Krapplack bedecktes, auch makroskopisch sichtbares papelartiges Knötchen. Hier fehlt das Rete Malpighii entweder vollständig oder ist sehr stark verdünnt. Der histologische Befund nach $2 \mathrm{E}$. zeigt die gleichen Bilder wie nach 1 E. Die Gewebsveränderungen spielen sich nur an den Stellen der Farbstoffauflagerung ab.

11. Versuch mit Gelblicht (tonerdehaltiger Säuregelb-Bariumlack), nicht giftig.

Nach 7 E. mit dem Farbstoff Gelblichtwar es möglich, durch seinen chemischen Reiz das Rete Malpighii, sowie die Haarbälge zur Proliferation mit Zapfenbildung und zur Verbreiterung zu bringen. Diesem Vorgang gehen die entzündlichen Erscheinungen, die anfangs einenakuten Charakter haben, voran, klingen aber allmählich ab, während dieverbreiterten und proliferierten Retezapfen und $\mathrm{Haarbälge}$ persistieren.

12. Versuchmit Gelblicht. (Fig. 4.)

20./II. 1909. Beide Ohrinnenflächen (junges Kaninchen) werden mit Gelblicht 5-6 Minuten lang eingerieben. $1 \mathrm{E}$.

Die Versuchsdauer beträgt 14 Tage (vom 20./II. 1909 bis 6./III. 1909) mit $4 \mathrm{E}$., die in Intervallen von $2-3-4$ Tagen wiederholt wurden. Die histologische Untersuchung wurde drei Tage nach der vierten E. vorgenommen. Makroskopisch haben wir das Bild einer Dermatitis vor uns, die manchmal in Form von Knötchen oder warzigen, mit Farbstoff bedeckten Gebilden erscheint. Entsprechend dem makroskopischen Aussehen finden wir auch mikroskopisch ein Knötchen, das die analogen Veränderungen wie bei den Versuchen 6 und 11 zeigt.

13. Versuch mit Säuregelb (Gelblicht ohne Tonerdehydrat und ohne Bariumsulfat).

10./XI. 1909. Die linke Ohrinnenfläche eines $3 / 4$ Jahre alten Kaninchens wird mit Säuregelb 5-6 Minuten eingerieben.

Die Versuchsdauer beträgt 13 Tage (rom 10./XI. 1909 bis 23./XI. 1909) mit $4 \mathrm{E}$., die $\mathrm{E}$. werden in 2-3-4tägigen Intervallen vorgenommen. Die bistologische Untersuchung erfolgt vier Tage nach der 4. E. 
Makroskopisch finden wir auBer einer Dermatitis kleinste, stecknadelkopfgroßeKnötchen an der inneren Ohrfläche. Die histologische Untersuchung bietet nichts Besonderes. Der Epidermis ist eine geringe Exsudatmasse ohne Gewebszerstörung aufgelagert, in der Kutis, entsprechend der Größe der Exsudatmasse, nur ganz geringe entzündliche Erscheinungen.

14. Versuch mit Säuregelb.

19./XI. 1909. Die linke innere Ohrfiäche eines albinotischen, zwei Monate alten Kaninchens wird 5-6 Minuten lang mit Säuregelb eingerieben 1. E.

Die Versuchsdauer beträgt 4 Tage (vom 19./XI. 1909 bis 23./XI. 1909), im ganzen wurde eine $\mathrm{E}$. vorgenommen. Makroskopis ch haben wir das Bild der Dermatitis. Die histologische Untersuchung erfolgte vier Tage nach der ersten E.; sie ergab das gleiche Resultat wie beim Versuche $10 a$ und $10 b$

15. Versuch mit Gränerlack (tonerdehaltiger Säuregrün-Bariumlack [Triphenylmethanfarbstoff], nicht giftig).

Die Versuchsdauer beträgt drei Wochen (vom 4./VII. 1908 bis 25./VII. 1908) mit 7 E., die E. wurden in Intervallen von 2-3-4 Tagen wiederholt. Die histologische Untersuchung wurde drei Tage nach der 7. E. vorgenommen.

Dieser 15. Versuch ist sowohl in seinem klinischen wie histologischen Bilde analog dem 10. Versuch (Einreibung mit Krapplack).

16. Versuch mit Grïnerlack.

5.JI. 1909. Beide inneren Ohrfiächen eines älteren Kaninchens werden mit Grünerlack 5-6 Minuten eingerieben. 1. E.

Die Versuchsdauer beträgt 29 Tage (vom 5./I. 1909 bis 3./II. 1909) mit zwei $\mathrm{E}$, die in Intervallen von 15 Tagen ausgeführt wurden; die histologische Untersuchung wurde 19 Tage nach der 2. E. vorgenommen. Makroskopischsehen wir ein.Knötchen, das einemit grünem Farbstoff bedeckte Kruste trägt, mikroskopisch begegnen wir demselben Bilde wie bei den Versuchen 10a, $10 b$ und 15 .

17. Versuch. Einreibung von Grünerlack auf beide innere 0 hrflächen eines älteren Kaninchens.

Bei diesem Versuchstier (älterem Kaninchen) werden die Einreibungen mit Grünerlack 6 E. nicht mehr fortgesetzt, da das Kaninchen auf dieselben gar nicht oder nur in sehr geringem Maße - im Vergleich zu einem jungen Kaninchen - reagiert. Versuchsdaver vom 18./I. 1909 bis 20./II. 1909 .

18. Versuch. Einreibung beider Obrinnenfläeheneines jungen Kaninchens mit Grünerlack.

12./II. 1909. 1, E.

13./II. 1909. Nach 1 F. an beiden Ohrinnenflächen je ein schmaler, langgestreckter Streifen von Dermatitis.

17./II. 1909. Dermatitis im Abheilen begriffen. 2. E.

18./II. 1909. Keine neuen Erscheinungen.

19. III. 1909. Die streifenförmige Dermatitis besteht noch mit geringem Nässen verbunden. 3. E. Außerdem wird ein Wattebausch mit dem Farbstoff Grünerlack imprägniert, die Ohrränder werden durch zwei Nähte miteinander vereinigt, um das Heraustallen der Wattebauschen zu verhindern.

20./II. 1909. Die Farbe bildet auf der Ohrinnenfläche einen schmierigen Belag.

23./II. 1909. Das in seiner Ernährung sehr stark berabgekommene Tier ist eingegangen. 
19. Versuch mit Gränerlack.

24./II. 1909. Beide Ohrinnenflächen eines älteren Kaninchens werden mit Grünerlack 5-6 Minuten lang eingerieben. 1. E.

Die Versuchsdaner beträgt 36 Tage vom 24./II. 1909-1./IV. 1909 mit $13 \mathrm{E}$., die in Intervallen von $2-3-5-8$ Tagen ausgeführt wurden. Makroskopisch finden wir das Bild einer streifenförmigen Dermatitis, außerdem kleine Knötchen auf der inneren Ohrfläche. Die histologische Untersuchung wurde 2 Tage nach der 13. E, vorgenommen.

Bei diesem Versuche ist das histologische Bild dem der Versuche 9 mit Brillantrot, 11 and 12 mit Gelblicht insofern analog, als es neben den entzúndlich exsudativen Erscheinungen ebenfalls zu einer Verbreiterung und Proliferation des Rete Malpighii, wenn auch mäbigen Grades, kom t. Hervorzuheben wären noch außer der proliferierenden Entzündung in der Kutis die in größerer Zahl vorhandenen Hämorrhagien, abgesehen von den erweiterten Blut- und Lymphgefäßen.

Die Tatsache, daß es hier nur zu einer mäßigen Wucherung der Reteschicht - trotz $13 \mathrm{E}$. mit Grünerlack (Triphenylmethanfarbstoff) gekommen ist, darf uns nicht wundernehmen, da die Resistenz der Gewebe bei einem älteren Kaninchen im Vergleich zu einem jungen sicherlich eine nicht zu unterschätzende Bedeutung für das Maßj der Proliferationsfähigkeit der Reteschicht ceteris paribus besitzt. Ich werde auf diese experimentell wie auch klinisch interessante Tatsache, die einen kleinen Beitrag zu dem Begriff "Disposition" resp. "Resistenz" liefert, noch eingehender zurückkommen.

20. Versuch mit Grünerlack.

26./III. 1909. Beide Ohrinnenflächen eines jüngeren Kaninchens werden mit Grünerlack eingerieben. 1. E.

Die Versuchsdauer beträgt 6 Tage vom 26./III, 1909 bis 1./IV. 1909 mit 2 E., die in einem intervall von vier Tagen ansgeführt wurden. Makroskopisch sind nach 2 E. auf derinneren Ohrfläche zahlreiche, gröBtenteils den Follikeln entsprechende, stecknadelkopfgroße Knötchen nachzuweisen. Die histologische Untersuchung wurde zwei Tage nach der zweiten E. vorgenommen.

Auch hier konnte histologis $\mathrm{h}$ h eine geringgradige Verbreiterung dès Rete Malpighii konstatiert werden, wenngleich die Beobachtungsdauer dieses jungen Versuchstieres nicht länger als sieben Tage betragen hat. Daraus erklärt es sich wohl auch, daß die entzündlichen Erscheinungen im Korium stärker akzentuiert sind als bei den früheren Versuchen.

21. Versuch mit Säuregrün (Grünerlack ohne Tonerdehydrat und ohne Bariumsulfat).

10./XI. 1909. Linke Ohrinnenfiäche eines $3 / 4$ Jahre alten Kaninchens wird mit Säuregrün 5-6 -Minuten eingerieben. 1. E.

11./XI. 1909 bis 10./XII. 1909 2 E.-10 E. Keine Erscheinungen,

keine Dermatitis nach $10 \mathrm{E}$. Einreibungen werden ausgesetzt.

Da nach $10 \mathrm{E}$. mit Säuregrün bei den älteren Kaninchen keine

Erscheinungen aufgetreten waren, so wurden die E. ausgesetzt und der Versuch abgebrochen.

22. Versuch mit Säuregrün.

19./XI. 1909. Albinotisches Kaninchen (Nr. 169), zwei Monate alt.

Die linke innere Ohrfläche wird mit Säuregrün 5-6 Minuten eingerieben. 1. E. 20./XI. 1909. Keine Erscheinungen.

22./XI. 1909. Kleinste, stecknadelkopfgroße, auf die Follikel lokali-

sierte Knötchen.

23./XI. 1909. Exzision der Knötchen und Fixierung in 10\% $\%$ igem Formol. 
Es lassen sich keine Präparate herstellen, weil das Farbstofflknötchen beim Schneiden des Hautstückchens abgesprungen ist.

23. Versuch. Einreiben der Innenfläche des rechten Ohres eines drei Monate alten Kaninchens mit einer $10 \%$ igen Grünerlack-Lanolinsalbe, und der Innenfläche des linken 0 hres mit einer $10 \%$ igen Gelblicht-Lanolinsalbe. $(27 a$ und $27 b$.

26./X. 1908. 1. E.

28./X. 1908 bis 16./XI. 1908. Keine Knötchenbildung, keine Dermatitis, Ieichte diffuse Rötung. 2.-7. E.

Die Versuche mit Einreibungen einer $10 \%$ igen Grünerlack- und einer $10 \%$ igen Gelblicht-Lanolinsalbe auf die innere Ohrfläche der Kaninchen haben keinerlei makroskopisch sichtbare Veränderungen ergeben. Das negative Resultat dieses Versuches dürfte sich vielleichtausdem Umstande erklären, daB das Lanolinden Farbstoff derart gebunden, zum Teil gelöst hält, daßer aufder intakten, mechanisch vorher nicht lädierten Haut nicht zur Wirkung kommen kann. Es wäre auch möglich, daß der Farbstoff ans dem Grunde nicht zur Wirknngelangen kanu, weil das Fett denselben amhüllt. Vielleicht könnte eine $0.9 \mathrm{ClNa-}$ Lösung den Farbstoff aus der Lanolinsalbe extrahierea und der freigewordene die Haut reizen? Diese Frage soll durch einschlägige Versuche geprüft werden.

24. Versuch mit Tonerdehydrat.

10./XI. 1909. Rechte Ohrinnenfläche eines 1/2-3/4 Jahre alten Kaninchens wird mit Tonerdehydrat 5-6 Minuten lang eingerieben, 1. E. 10./XII. 1909. Oberfächliche, bereits im Ausheilen begriffene Fxkoriation. Keine weiteren Erscheinungen nach 10 E. Einreibungen werden ansgesetzt. Die Versuchsdauer beträgt 4 Wochen mit 10 E., die in Intervallen von 2-3-4 Tagen vorgenommen wurden. Eine histologische Untersuchung wurde in diesem Falle nicht ausgeführt, da die Erscheinungen des ganz oberflächlichen Substanzverlustes nach $10 \mathrm{E}$. mit Tonerdehydrat bei dem älteren Kaninchen im Ausheilen begriffen waren. Die Veränderung bestand in einer Abschilferung ganz oberflächlicher Schichten des Stratum corneum.

25. Versuch mit Tonerdehydrat.

19./XI. 1909. Kaninchen Nr. 169, albinotisch, zwei Monate alt, rechte Ohrinnenfläche wird 5-6 Minuten mit Tonerdehydrat eingerieben. 1. E. 23./XI. 1909. Die Versuchsdauer beträgt 4 Tage mit $1 \mathrm{E}$. bei einem zwei Monate alten albinotischen Kaninchen.

Makroskopisch habea wir das Bild einer im Abheilen begriffenen oberflächlichen Exkoriation. Die histologische Untersuchung wird 4 Tage nach der 1. E. vorgenommen. Das Resultat der mikroskopischen Untersuchung besteht in einer Exkoriation, die durch eine Exsudatmasse ausgefüllt wird. Diese hat eine knötchenförmige Konfiguration und reicht bis in die obersten Schichten des Koriums. In der Kutis selbst ist das entzündliche Infiltrat nur mäßig dicht, die Gefäße erweitert.

Ausdiesem. Versuche folgt, daßes schon ach 1 E. mit Tonerdehydrat gelingt, eine Exkoriation mit mäBigen entzündlichen Erscheinungen in der Katis zu erzengen. Allerdings war das Versuchstier ein 2 Monate altes, albinotisches Kaninchen mit wenig widerstandsfähiger Haut.

Dieser Versuch würdebeweisen, dab auch auf mechanischem Wege - abgesehen von der Exkoriation - eine Entzündung des Kutisgewebes provoziert werden kann, und diesum so leichter, je jünger das Versuchstier ist. Viel. 
leichtist bei diesem Versucheauch die Tatsache erwähnenswert, dab es sich um ein junges, albinotisches Kaninchen handelt, das noch weniger widerstandsfähig ist als die pigmentierten. Diese Verhältnisse werden in der Zusammenfassung dieser Versuchedes näheren besprochen werden.

26. Versuch mit Bariumsulfat (Blanc fixe).

10./XI. 1909. Die rechte Ohrinnenfläche eines $8 / 4$ Jahre alten Kaninchens wird 5-6 Minuten lang mit Blanc fixe eingerieben. 1. E.

23./XI. 1909. Bei einem älteren ( $3 / 4$ Jahre alten) Kaninchen treten bei einer Versuchsdaver von 13 Tagen nach $4 \mathrm{E}$. von Bariumsulfat, in 2-3-4tägigen Intervallen ausgeführt, keine makroskopisch sichtbaren Erscheinungen auf, es wird der Versuch nach 4 E. ohne Resultat abgebrochen.

27. Versuch mit (Bariumsulfat) Blanc fixe.

19./XI. 1909. Die rechte innere OhrAläche eines zwei Monate alten, albinotischen Kaninchens wird $5-6$ Minuten lang mit Blanc fixe eingerieben. 1. $\mathrm{E}$.

23./XI. 1909. Nach $1 \mathrm{E}$. bei einem zwei Monate alten, albinotischen Kaninchen waren keine Erscheinungen aufgetreten, auch 4 Tage nach erfolgter E. konnten keine Ver änderungen konstatiert werden.

\section{Epikrise:}

Fassen wir die Ergebnisse dieser Einreibungsversuche zusammen, so können wir folgendes resümieren.

Bei den Versuchen (1-5) mit Bleiweib, Miloriblau (Berlinerblau), Sienna, Zinnober kamen junge albinotische Tiere zur Verwendung. Trotz mehrfacher E. (6), auch bei Wiederholung ein und desselben Versuches, erhielten wir stets ein negatives Resultat. Es erscheint auffallend, daß bei Einreibung dieser mehr weniger chemisch indifferenten Agentien auf die intakte, wenig widerstandsfähige Haut junger Kaninchen nicht mindestens eine stärkere Dermatitis durch eine mechanische Läsion, wenn schon nicht aus chemischen Ursachen sich entwickelt hat. Vielleicht waren die eingeriebenen Agentien so fein pulverisiert, daB bei mäBigem Drucke mit dem Kolbenende einer Eprouvette eine starke mechanische Läsion nicht auftreten konnte. Die genannten Stoffe Bleiweiß, Berlinerblau, Sienna, Zinnober sind im Wasser unlöslich; vielleicht spielt ihre absolute Unlöslichkeit in kochsalzhaltigen Medien, wie es ja die körperlichen Flüssigkeiten sind, mit eine Rolle, daß Reaktionen bei Einreibungen solcher Stoffe auf die Haut ausbleiben. Eine endgültige beweiskräftige Antwort auf diese Frage muß ich schuldig bleiben.

An diese Versuche schließen sich diejenigen mit Tonerdehydrat (Nr. 24 und 25), sowie die mit Barium- 
sulfat (Nr. 26 und 27) an. Bei beiden Versuchen mit Tonerdehydrat entstand ein durch mechanische Läsion der Kristalle hervorgerufener Substanzverlust. Je nach der Größe der mechanischen Komponente, i. e. der Beschaffenheit der Kristalle und der Intensität des Druckes beim Einreiben entsteht eine Erosion oder Exkoriation. Durch das geschädigte Epithel wandern die Leukozyten aus den erweiterten Kutisgefäßen aus, in der Kutis proliferieren die fixen Bindegewebszellen, es entwickelt sich das Bild der proliferierenden Entzündung, im weiteren Verlaufe wird der gesetzte Substanzverlust durch eine Exsudatmasse ausgefüllt. Bei längerer Dauer des Versuches klingen die entzündlichen Erscheinungen in der Kutis ab.

In den Versuchen mit Bariumsulfat sind weder bei einem jungen, noch bei einem älteren Kaninchen makroskopisch sichtbare Veränderungen aufgetreten, weil bei Bariumsulfat weniger Kristalle vorhanden und feine kristallinische Massen überwiegen.

Die Versuche mit Scharlachrot (Nr. $6 a$ und $6 b, 7$ ) und mit Brillantrot Nr. 9 zeigen, daß die Proliferation des Rete Malpighii und der Talgdrüsen deutlich zum Ausdruck kommt und die Beweiskraft der chemisch-proliferativen Komponente der genannten Farbstoffe erhöht. Es liegt hier eine pathologische Epithelproliferation vor, die Epithelzellen zeigen aber kein atypisches Verhalten wie beim Karzinom.

Bei dem Versuch 8 sind nach 8 Einreibungen mit Scharlachrot bei dem älteren Kaninchen die Knötchen spontan involviert.

Der Einreibungsversuch mit Krapplack Nr. 10a und $10 b$ bei einem jungen Tier mit $2 \mathrm{E}$. hat einen durch Exsudatmasse erfüllten Substanzverlust ergeben; wahrscheinlich ist es infolge zu starken Druckes beim Einreiben zur Zerstörung des Rete Malpighii und zur Bildung eines Substanzverlustes gekommen.

Bei einer anderen Versuchsreihe, die sich auf E. mit dem Farbstoff Gelblicht (Nr. 11 und 12) beziehen, erhielten wir nach 4 E. resp. 7 E. bei jungen Tieren eine Verbreiterung und recht starke Proliferation des Rete Malpighii und der Talgdrüsen. Diese starke Proliferation des Rete Malpighii läßt wohl 
keinen Zweifel aufkommen, daß diese Wucherungsvorgänge auf den direkten chemischen Reiz des Anilinfarbstoffes Gelblicht zurückzuführen sind. Beim Versuch 13 erhielten wir nach $4 \mathrm{E}$. mit dem reinen Anilinfarbstoff Säuregelb bei einem älteren Tiere mit resistenterer Haut nur entzündliche Erscheinungen in der Kutis, ferner eine Auflagerung von Exsudatmassen auf der Epidermis ohne Proliferation des Rete Malpighii. In einem anderen Versuche Nr. 14 trat nach einer E. durch mechanische Zerstörung des Rete Malpighii ein Substanzverlust, der durch eine geringe Exsudatmasse ausgefiullt ist, auf. In der Kutis sind verhältnismäßig geringe im Abklingen begriffene, entzündliche Erscheinungen zu konstatieren.

Aus den Einreibungsversuchen mit Grünerlack (Nr. 15, 16, 17, 18,19, 20), mit Säuregrün (Nr. 21, 22), ferner mit einer 10\% igen Grünerlack-Lanolinsalbe (Nr. 23) ergibt sich folgendes:

Bei jungen Tieren genügt eine geringe Anzahl von E., um eine Verbreiterung und Proliferation des Rete Malpighii und der Talgdrüsen zu provozieren. Die in manchen Versuchen zu beobachtenden Substanzverluste sind auf eine mechanische Läsion durch die Kristalle oder kristallinischen Beimengungen zu beziehen. Die konkomitierenden entzündlichen Erscheinungen in der Kutis sind je nach der Dauer des Versuches von verschiedener In- und Extensität. Bei kurzer Versuchsdauer ceteris paribus - sind die akut entzündlichen Erscheinungen ausschließlich in der Kutis lokalisiert, bei längerer in Form einer Exsudatmasse zwischen Rete Malpighii und Stratum corneum, das blasig abgehoben wird. Im letzteren Falle sind dann die entzündlichen Erscheinungen in der Kutis im Abklingen begriffen oder zeigen bereits den Charakter eines jungen Granulationsgewebes. Bei älteren Kanin chen dagegen treten nach wenigen E. mit dem Farbstoff Grünerlack entweder keine Wucherungen des Rete Malpighii, oder erst nach mehreren E. ganz geringgradige auf.

Ein negatives Resultat haben wir mit Säu regrün, dem von Kristallbeimengungen befreiten Farbstoff, erhalten. Allerdings kamen dabei ältere Versuchstiere in Verwendung. Bei jungen Versuchstierengenügt eine geringere Anzahl von 
E., um dieselben Erscheinungen hervorzurufen, wie nach mehrfachen E. bei älteren Tieren mit denselben Farbstoffen.

Die mechanische Läsion tritt stets in Form eines seichten Substanzverlustes auf (Versuch 15 und 16), dieser wird durch eine Exsudatmasse ausgefüllt; bleiben noch einige Retezellen an dieser Stelle erhalten, dann können diese unter der Einwirkung des chemischen Reizes proliferieren. Je nach der Dauer des Versuches, sowie nach dem Zeitpunkt der Untersuchung wird das histologische Bild ein verschiedenes sein, mit verschiedenen Farbstoffen zu gleicher Zeit vorgenommen, stets ein gleiches.

Bemerkenswert ist ferner das negative Resultat mit $7 \mathrm{E}$. einer $10 \%$ igen Grünerlack-Lanolinsalbe bei einem 3 Monate alten Kaninchen. Aus diesem Versuche können wir den Schluß ziehen, daß der fettlösliche Farbstoff auf der intakten Haut keine irritierenden Wirkungen zu entfalten vermag. Die Fettlöslichkeit gewisser Anilinfarbstoffe und in weiterer Folge ihre irritative Unwirksamkeit auf die intakte Haut kann auch praktisch zu prophylaktischen $Z$ wecken insoferne verwendet werden, als Arbeiter in Betrieben, in denen Farbstoffe (Anilin-oder Teerfarbstoffe) verarbeitet werden, Gesicht, Arme und Hände (die unbedeckten Körperstellen) zum Schutze ihrer Hauteinfetten sollen.

Nach den Resultaten dieser Versuchsreihe ist wohl die Annahmeals gerechtfertigtzubetrachten, da $B$ chemisch reizende Stoffe, wie Anilin-und Teerfarbstoffe, imstande sind, eine Verbreiterung und Proliferation des Rete Malpighii, sowie eine Wucherung der Talgdräsen zu erzeugen.

Außer der Annahme einer ausschließlich chemischen Irritation ist vielleicht auch die Vermutung gerechtfertigt, dab auf der Basis der primär durch die Kristalle mechanisch lädierten Hautpartie, sekundär die Wirkung der chemischen Komponente der Farbstoffe in die Erscheinung tritt, die sich zuerst in Form einer akuten Entzündung, die dann im Verlaufe von 2-3 Wochen abklingt, geltend macht, der dann die proliferativen Veränderungen am Rete sowie an den Anhangsgebilden folgen. 
Die chemisch indifferenten, mechanisch wirkenden Kristalle oder kristallinischen Beimengungen der Farbstoffe Tonerdehydrat und Bariumsulfat veranlassen in der Regel nur eine mechanische Läsion des Gewebes, bei der keine Wucherung des Rete zu konstatieren ist. Es unterliegt aber keinem Zweifel, und es ist von allen Autoren anerkannt, daß auch die rein $\mathrm{mech}$ an is $\mathrm{ch}$ e Komponente als Reiz fürdie Proliferation des Rete Malpighii in Betracht gezogen werden muß.

Wichtig ist auch die Dauer des Versuches und der Zeitpunkt der Untersuchung. Bei frischen Fällen mit exquisit chemischer Reizung finden wir oft keine, oder nur eine geringe Proliferation des Rete Malpighii, dafür in der Kutis starke entzündliche Erscheinungen. Dauern die entzündlichen Erscheinungen längere Zeit, etwa $3-4$ Wochen an, so finden wir sowohl in der Kutis, als auch der Epidermis Reste der vorübergegangenen Entzündung.

Hier sei noch erwähnt, daß außer den von mir zu den Einreibungsversuchen verwendeten Farbstoffen es noch eine außerordentlich große Reihe von Agentien gibt, die, in gleicher Versuchsordnung angewendet, ähnliche oder gleiche Resultate geben wïrden.

Mit wenigen Worten sei noch die Resistenz oder Widerstandsfähigkeit der $\mathrm{Haut}$ besprochen. Diese Fähigkeit der Haut läßt sich aus unseren Versuchen recht gut erklären. Es stimmen die klinischen Beobachtungen (Fall 4) mit den Resultaten der experimentellen Untersuchung sehr gut überein. Ein junger Arbeiter, 19 Jahre alt, blond, der ${ }^{3} / 4$ Jahre mit dem Verreiben von Anilinfarbstoffen beschäftigt war, zeigte nach dieser Zeit die im ersten Teil dieser Arbeit genauer beschriebenen maulbeer- und papillomähnlichen Knötchen. Die in der von mir des öfteren erwähnten Buchdruckerei beschäftigten alten Leute boten keinerlei Exscheinungen, außer chronischem Ekzem, Dermatitis infolge von Terpentin, Fett, Öl etc. dar, die somit nicht auf eine direkte schädigende Einwirkung von Anilinfarbstoffen zu beziehen wären.

Gleiche oder ähnliche Beobachtungen konnten wir bei den Tierversuchen machen. 
Hier sei nur festgestellt, daß bei den früheren Versuchen (Versuch $9: 6$ E. mit Brillantrot, Versuch $11: 7 \mathrm{E}$, mit Gelblicht, Versuch 12:4 E. mit Gelblicht) junge Tiere verwendet wurden, während wir beim Versuch 19 ein älteres Kaninchen mit Grünerlack in 13 E. behandelten. Die Verbreiterung und Proliferation des Rete Malpighii in den Versuchen 9,11 und 12 war eineso bedeutend stärkere als beim Versuch 19, daß die Annahme einer verschiedenen Resistenz der Haut nicht von der Hand $\mathrm{zu}$ weisen ist.

Junge, insbesondersalbinotische Tiere bieten schon nach wenigen E. eine recht starke Proliferation desRete Malpighii und derTalgdrüsen dar, während ältere Tiere nach wiederholten Einreibungen mit Anilinfarbstoffen keine oder nur sehr geringere Wucherungen des Rete Malpighii und der Talgdrüsen zeigen.

Vielleicht ist es ein bloßer Zufall, daß der junge Arbeiter ein blondes Individuum ist; diejenigen Versuchstiere, bei denen das Rete am stärksten wucherte, waren jedoch albinotisch oder nur wenig pigmentiert. Nur die Tatsache als solche möchte ich festhalten, ohne daraus irgendwelche Schlußfolgerungen zu ziehen.

\section{Zusammenfassung.}

Die Anilinfarbstoffe Scharlachrot, Brillantrot, Krapplack, Gelblicht, Grünerlack wurden in derersten Versuchsreihe in Form von Einreibungen nit mannigfaltigen Variationen in Anzahl und Zeitintervall auf die innere Ohrfläche ron Kaninchen appliziert. Die histologische Untersuchung solcher durch Einreibungen von Anilinfarbstoffen veränderter Hautstellen ergab in einer großen Anzahl Versuche im wesentlichen stets das gleiche Resultat: das in einer Verbreiterung und Proliferation des Rete Malpighii, sowie in einer Wucherung der Talgdrüsen bestand, häufig verruköse oder epitheliomähnliche Bilder darbot. 
Kontrolluntersuchungen mit BleiweiB, Miloriblau (Berlinerblau), Zinnober, Sienna sind negativ ausgefallen.

\section{Injektionsversuche.}

Im folgenden habe ich die bekannten Versuche B. Fischers mit subkutaner Injektion von Scharlachöl in das Kaninchenohr zur Erzeugung von Epithelwucherungen wiederholt. Daran anschließend wurden auch die zu den Einreibungsversuchen verwendeten Anilinfarbst offe $z u$ gleichen Injektionsversuchen benuitzt, um ihre Wirkung auf das Epithel zu studieren und die Resultate dieser den Epithelwucherungen des Scharlachöls gegeniiberzustellen.

Zunächst möchte ich, bevor ich die Resultate meiner eigenen Untersuchungen mitteile, in Kürze die in der Literarur bereits bekannten Angaben mitteilen. Von einer ausführlichen Wiedergabe kann ich um so eher Abstand nehmen, als Herxheimer und Reinke (konf. Lubarsch-Ostertag, Bd. XIII, II, 1909, p. 393) diese Frage in eingehender und ausgezeichneter Weise behandelt haben.

Bernhard Fischer ging von dem Gedanken Ribberts aus, $\mathrm{da} B$ eine subepitheliale, entzündliche Infiltration bzw. zellige Wucherung des Bindegewebes in der Krebsgenese, speziell der Hautkrebse, eine bedeutsame Rolle spiele, und versuchte durch Einbringen verschiedener, möglichst wenig reizender Fremdkörper unter die Haut des Kaninchenohres eine chronische Entzündung im Bindegewebe hervorzurufen und dann deren Einfluß auf das deckende Epithel zu studieren. Die Fremdkörper, die in Organstückchen bestanden, riefen zwar den gewünschten entzündlichen Prozeßs im Bindegewebe hervor, das Deckepithel verhielt sich aber, abgesehen von einer mäßigen Verdickung, reaktionslos. Weitere Versuche $\mathbf{F}$ is chers, mit Injektion von Agar unter die Haut des Kaninchenohres Epithelwucherungen zu erzielen, waren in einem Falle von dem Erfolge begleitet, daß ausgedehnte Wucherungen des Deckepithels in, sowie um die Agarmassen stattfanden. Fis cher glaubt nun, diese Épithelwucherungen dahin erklären zu können, daß beim Einstich etwas Epithel in die Tiefe verlagert wurde und sich so zu eigenartig modifizierten Epithelzysten umbildete.

Die Injektion von öl hatte den Erfolg, daß das Epithel mit Verdickung und beträchtlichem Aussprossen der Epithelzapfen reagierte, auch konnte er keine epitheliale Wucherung erzeugen, die einigermaßen Ähnlichkeit mit dem exzessiven Wachstum krebsig entarteter Epithelien hatte. 
Durch die Anwendung von Scharlachrot und Sudan III, Fettfarbstoffe (Az of arbst offe) von analoger ehemischer Konstitution, in Öl gelöst, gelang es Fischer, Epithelwucherungen zu erzeugen. Fis cher bezeichnet als wichtigstes, unmittelbares Ergebnis seiner Untersuchungen, da $B$ zum ersten Male der Beweis erbracbt sei, daB es Stoffe gebe, die eine spezifische, starke chemotaktische Wirkung auf eine bestimmte Zellart auf das Epithel ausübten und dieses Epithel dadurch zu raschem, "atypischem" Wachstum veranlaßten. Fischer folgert nun weiter, daß solche Stoffe, sogenannte "Attraxine", vielleicht auch bei der Entstehung der Geschwülste eine Rolle spielen und weist so auf eine ganz neue und eigenartige Auffassung des Entstehens und Wachstums der Geschwülste hin. Weder an der Brustdrüse noch am Magen- oder Darmepithel hat dieser Autor irgendwelche Epithelwucherungen hervorrufen können.

Fischers Versuche wurden von mehreren Seiten nachgeprüft und seine Angaben a. a. von Ritter, Geipel, Seckel bestätigt.

Jores anerkennt die Wirkung des Scharlachöls auf das Eipithel nach Art der Chemotaxis nicht. Er fand, daß die Wucherungen sich aus 2 Komponenten zusammensetzen, ans einer Wirkung auf die oberen Teile der Haarbälge und aus einer Wucherung des Epithels in direkter Berührung mit Öltropfen. Jores fand ferner, daß auch andere Zellen des Kaninchens reagieren; seitens der Endothelien der LymphgefäBe der Haut kommt es zu epithelähnlichen Säumen um die Öltropfen und zur Riesenzellenbildung.

Nach den Untersuchungen Stahrs, der die Versuche Fischers nachprüfte, konnte auch bei anderen Tieren als bei Kaninchen ein positives Resultat erzielt werden. S tahr nimmt für die Proliferation des Plattenepithels nicht nur einen "Reiz", sondern einen Komplex von Ursachen an, unter denen die anatomische Beschaffenheit der Gegend eine große Rolle spielt.

W yss glaubt nach seinen Untersuchungen, die Ursache für die schrankenlose Teilung der Epithelzellen, d. h. für die Entstehung kleiner Hautkarzinome, eine vollständig mangelnde Ernährung einer Epithelzellengruppe mit Blut finden zukönnen. Er erklärt nun die Epithelwucherungen Fischers so, daß durch die pralle Injektion der AusschluB des Epithels von der Blutzirkulation und damit der Ernährung experimentell erzengt und die Proliferatiou des Epithels bervorgerufen werde. Danach müßten, wie Stoeber und Wacker bemerken, aber auch Injektionen von Öl allein, die doch gewiß auch dieselben Ernährungsstörungen seizen müssen wie z. B. das Scharlachöl, ebensolche Wucherungen erzeugen. In früheren Versuchen konnte $S$ to eber, wie auch andere Autoren, ni emals die ausgedehnten Wucherungen des Epithels durch Injektion von öl alle in erreichen; daher dürfte diese Erklärung der Epithelwucherungen nach der Auffassung von Stoeber und Wacker wohl kaum zu recht bestehen. Anch allzu pralle Injektionen in das subepitheliale Bindegewebe des Kaninchenohrs erzeugen eben wegen der zu starken 
Schädigung der Ernährung Nekrose der darüberliegenden Epithelschicht (Stoeber und Wacker).

Stoeber kounte schon in einer früheren Arbeit mitteilen, daß auch die basischen Komponenten von Scharlachrot und Sudan III das Amidoazotoluol und Amidoazobenzol, ferner das Paratoluidin und die Amidoverbindung des Naphthalins, das Naphthylamin, in öliger Lösung ausgedehnte Wucherungen des Plattenepithels am Kaninchenohr hervorrufen, wobei die ausgiebige Beteiligung der Keimschicht der Haarbälge betont wurde. Gleichzeitig konnte die Vermutung $F$ ischers bestätigt werden, daß den von ihm benützten Fettfarbstoffen chemisch verwandte Stoffe in der Ätiologie mancher Geschwülste eine Rolle spielen, indem in Sudan III und Scharlachrot Basen vorhanden sind, bei deren technischer Verwendung Störungen der Blase bei Arbeitern in Form von Geschwülsten beobachtet werden. Für eine chemische Wirkung schienen Stoeber die selbständigen Sprossenbildungen der verdickten Haarbälge und deren unverkennbares Hinstreben zu in der Nähe gelegenen Öltröpfchen zu sprechen. Nach diesem Autor steht es fest, daß die von Fischer benützten Fettfarbstoffe, sowie die von ihm verwendeten Komponenten derselben und chemisch nahe verwandte Stoffe einen entschiedenen Wachstumsreiz auf das Plattenepithel auszuäben imstande sind.

In einer im Jahre 1909 erschienenen Inaugural-Dissertation von A. W. Meyer über „experimentelle Epithelwucherungen" wird die Tatsache konstatiert, $\mathrm{daB}$ die anscheinende Spezifität der Wucherungserregung des Scharlachöls und verwandter Stoffe nicht besteht, sondern daß eine Reihe anderer Substanzen, z. B. Ölsäure, Ruß, Paraffin usw. in gleicher Weise wirkt, wichtiger noch, daß unter ganz bestimmten Bedingungen (chronische Entzündung mit Zirkulationstörung) diese Wirkung zunimmt, ja sich auf Substanzen ausdehnt, die vorher diese Wirkung nicht hatten. $\left.{ }^{2}\right)$ Meyer zieht nun aus seinen Experimenten folgende Schlüsse: $F \ddot{r} r$ das Zustandekommen der Epithelwucherungen ander Kaninchenhautscheinteinechronische Entzündung bei lokaler Zirkulationsstörung die Ursache zu sein." Meyer glaubt nun sagen zu können: "Keine Epithelwacherung obne chronische milde Entzündung mit Bindegewebswucherung, aber auch keine Epithelwucherung bei chronischem Reiz ohne Zirkulationsstörung."

Nach den Ausführungen von Stoeber und Wacker (1910) hat Meyer wohl nachgewiesen, daß auch andere Stoffe und bestimmte MaBnahmen am Kaninchenohr (Zirkulationsstörungen und Entzündung) Epithelwucherungen hervorrufen können, nicht aber daß ein entschiedener

1) Die zufällige Untersuchung Meyers eines durch Milben verursachten seborrhoisehen Ekzems am Kaninchenohr ergab ganz erhebliche epitheliale Verdickungen und Wucherungen, die, wenn sie nicht senkrecht zur Oberfläche im Schnitt getroffen werden, schon ein völlig karzinomähnliches Bild vortäuschen können.

Arch, f. Dermat. u. Syph. Bd. CXVI. 
Wachstumsreiz auf das Plattenepithel durch Fischers Farbstoffe sowie andere chemisch verwandte Stoffe nicht ausgen̈bt wird. Meyer gibt ja selbst zu, dals z. B. nach Injektionen von Öl oder Paraffin oder Gummi arabicum, die doch gewiß dieselben Veränderungen im Sinne einer Entzündung und Zirkulationsstörung setzen, keine Wucherungen auftraten, während das Scharlachöl oder Gummi arabicum mit Scharlachrot die stärksten Wucherungen erzeugten. Damit allein ist, wie Stoeber und W acker ausführen, bewiesen, daB den Farbstoffen doch ein wucherungserregender Einfluß auf das Plattenepithel innewohnen rauß, wenn wir uns auch darüber klar sein müssen, daß die entzündlichen Veränderungen im Bindegewebe durch Auflockerung des Gewebes das Tiefenwachstum des Epitbels auch bei Injektionen von Farbstoffen begünstigen mögen. Stoeber und Wacker weisen im Gegensatz zu Meyer auf das Auftreten von reichlichen Epithelwucherungen auch auf der Außenseite des Kaninchenohres hin.

Weitere Versuche S toe be rs bestätigen, daß das A mid oa zotol u ol die wirksame Komponente des Scharlachrots, die spezifische Scharlachwirkung in bedeutend verstärktem Maße liefert. Weitere Überlegungen veraulaßten Stoeber und Wacker, mit solchen Substanzen am Kaninchenohr Injektionen vorzunehmen, die im tierisehen $\mathrm{Orga}$ nismus unter physiologischen oder pathologischen Verhältnissen eine Rolle spielen. Zu diesem Behufe wurden insbesondere EiweiBspalt- und EiweiBfäulnisprodukte zur Untersuchung herangezogen, darunter solche, welche speziell bei menschlichen Geschwülsten vorgefunden werden. Nach diesen Autoren haben nur organische Substanzen basischen Charakters die gesuchte Eigenschaft, und zwar nur solche, welche fettlöslich sind. Die genannten Autoren erzielten ein positives Resultat: mit Pyridin in $2 \%$ und $5 \%$ Lösung, in Olivenöl, Indol in $5 \%$ Lösung in Kaninchenfettund Skatol in $5 \%$ Lösung in Kaninchenfett.

Die schönsten Wucherungen wurden mit Indol erzielt, wenn mit etwas Skatol nachgespritzt wurde. Die epithelialen Neubildungen mit Pyridin waren weniger charakteristisch als jene mit Indol und Skato Die Bilder, welcheStoeber und Wacker mit Indol und Skatol erzielten, sollen dem Plattenepithelzellenkrebs ähnlich sehen. Stoeber und Wacker suchen die erzielten Versuchsresultate auf die pathologischen Wachstumsprozesse zu beziehen. Die Ursache, welche das Zellsystem aus dem Gleichgewicht bringt, könnte darin zu suchen sein, daB im Überschuß vorhandene, geeignete Eiweißfäulnisprodukte von der wachsenden Zelle verankert werden. Eine solche Zelle mit unechten Eiweibbausteinen könnte die Eigenschaft der Auswahl der Wuchsstoffe, sei es aus dem Transporteiweiß oder aus dem Mutterboden, verloren haben.

Weitere Versuche beim Menschen hat Stoeber ausgeführt, die insoferne bemerkenswert sind, als sie der Erzeugung von Epithel- 
wucherungendurch Injektion von Scharlachrot- und Amidoazotoluol in das subkutane Gewebe dienen.

Die von $\mathbf{F}$ is ch e r angenommene spezifische chemotaktische Wirkung auf das Plattenepithel des Kaninchens kann als sicher erweitert betrachtet werden, nachdem von Jores an der Rückenhaut des Hundes, sowie von Stahr an der Bauchhaut weißer Mäuse mittelst Scharlachölinjektionen Epithelwucherungen erzeugt wurden.

Am Fußrücken eines Patienten injizierte Stoeber Scharlachrot, Amidoazotoluol und $\alpha$-Naphthylamin in öliger Lösung. Die erzielten Epithelwucherungen stehen an Ausdehnung bedeutend hinter den in gleicher Zeit am Kaninchenohr erhaltenen zurück. Stoeber konnte in Übereinstimmung mit Jores als Hauptproduzenten der Epithelwucherungen am Kaninchenohr die dort reichlich vorhandenen Haare, d. h. deren Keimschichten ansprechen. Es finden sich nach Injektionsversuchen am Kaninchenohre außerordentliche Verdickungen der $\mathrm{Ha}$ arbälge, deren Keimschicht breite Ringe und mehr flächenbafte Epithelkomplexe um die Haarschäfte bildet. Die innersten, dem Haarschafte zu gelegenen Zellen sind zu Hornlamellen umgewandelt. Die Talgdrüsen, die anfänglick noch gut zu erkennen sind, gehen allmählich ebexfalls in der Epithelwucherung auf, indem zuerst die Ausf ührungsgänge durch Wucherung des dieselben anskleidenden Epithels zu verdickten, plumpen Epithelzapfen werden, an deren Ende noch gut erhaltene, körnige Zellen des Drüsenkörpers sitzen. Letztere schwinden, wie Stoeber ausführt, auch und gehen in der allgemeinen Wucherung auf, darauf bildet sich in den zentralen Partien Verhornung der Zellen aus, und zuletzt kann eine mit Hornmassen erfüllte $\mathrm{Z} y$ s te resultieren.

Der Ausführungsgang der Schweißdrüsen ist zu einem dicken Epithelzapfen umgewandelt. Außerdem finden sich neben und zwischen den zu einem Knäuel zusammengeballten Enden der Schweißdrüsen teils kleine, teils größere, rundliche Epithelkomplexe, die nach S to eber aus umgewandelten Schweißdrüsenkanälchen hervorgegangen sein sollen. Diese gleichen genau den Kankroidperlen, indem um eine zentrale Hornmasse zwiebelschalenartig geschichtete Plattenepithelzellen liegen. Es handelt sich bei den beschriebenen Veränderungen an den Schweißdrüsen wohl um denselben Vorgang, den B. Fischer nach Injektionen von Scharlachätherindie Brustdrüsen von Kaninchen beobachtete. Nach Stoebers Ansicht muß man für die beschriebene Veränderung der Schweißdrüsen eine direkte Umwandlung des gewucherten, die Drüsenstücke und Ausführungsgänge auskleidenden Epithels zu Plattenepithel annehmen, wobei das neugebildete Epithel eine starke Neigung zur Verhornung zeigt. Ob nun die Umwandlung des Epithels der primäre, die Wucherung der sekundäre Vorgang ist, möchte $\mathrm{S}$ t o e b er nicht entscheiden.

Durch Stoebers Untersuchungen ist festgestellt, daß durch subkutane Injektion von Scharlachrot und Amidoazotoluolinöliger Lösung beim Menschendieselben Epithel. wucherungen entstehen wie am Kaninchenohr. Daß dieselben 
nicht so ausgedehnte Dimensionen annehmen, bat Stoeber mit der anatomischen Beschaffenheit der Gegend, sowie durch das Fehlen von Talgdrüsen und spärlichem Vorhandensein von Haaren erklärt. Be merkenswert ist die Beteiligung der Schweibdrüsen an den Wucherungen, sowie deren Umwandlang zu Plattenepithelkomplexen.

Über Scharlachölversuche beim Affen berichtet K. Wessely (1910) und beschreibt an der Hand von mikroskopischen Präparaten, daß an den verschiedensten Stellen der Haut eines Affen ausgeführte intrakutane Injektionen von Scharlachöl keine Epithelwucherungen, sondern nur Bindegewebsproliferationen im Korium mit Bildung reichlicher epitheloider Zellen zur Folge hatten. Kann es sich hiebei möglichenfalls auch um individuelle Dispositionen handeln, so liegt doch im Zusammenhalt mit den schon nahezu negativen Resultaten an Katzen und Hunden der Gedanke nahe, daß die Scharlachwirkung im wesentlichen auf das Kaninchen beschränkt ist.

Über die Wirkung des Scharlachrotöls auf die menschliche Epidermis (Selbstversuch) berichtet K. Wessely 1910. Er nahm einen Versuch an sich selbst vor, und zwar injizierte er zweimal in Abständen von 8 Tagen an der gleichen Stelle eine kleine Menge gesättigten Scharlachrotöls intrakutan in die Haut des linken Oberarms. Öl und Farbstoff waren vor ihrer Vermischung in trockener Hitze sterilisiert worden. 14 Tage nach der ersten Injektion wurde das etwa markstückgroße Hautstück bis ins Fettgewebe hinein exzidiert.

Es war bis zu dieser Zeit keine makroskopische Geschwulstbildung entstanden, wie wir sie beim Kaninchen zu sehen gewohnt sind, sondern die Haut erschien über der Injektionsstelle lediglich etwas verdickt, ihre Oberfläche kaum merklich uneben. Das Scharlachöl schimmerte rot durch sie hindurch.

Die mikroskopische Untersuchung ergab nun in erster Linie eine Verbreiterung der Epidermis über der ganzen injizierten Stelle, und zwar hauptsächlich des Stratum Malpighii, bis auf etwa das Doppelte der normalen Dicke; desgleichen eine Verbreiterung des Epithels der Ausführungsgänge der Schweiß- und Talgdrüsen und vor allem der Haarwurzelscheiden. Diese zeigten sich auch nach der Tiefe verlängert, verbreitert und an ihrem unteren Ende in oft bedeutende Verzweigungen ausladend, die, wenn im Schnitte tangential getroffen, das Bild großer isolierter Epithelzapfen gaben. Besonders bemerkenswert ist, daß dabei das geschichtete Pflasterepithel die Innenräume der Talgdrüsen vielfach in sich aufgenommen hatte. Hier liegen also nach Wesselys Ansicht diejenigen Punkte vor, von wo man von einer "atypischen" Wucherung des Epithels sprechen kann, während es im übrigen nur hypertrophisch, d. h. nur dem Umfange, aber nicht der Abgrenzung nach, über die normalen Konturen hinansgegangen zu sein scheint. Jedenfalls konnte Wessely eine Verzweigung in die Tiefe, außerbalb der präformierten Einsenkungen an den Haaren 
und Drüsenausführungsgängen bisher nirgends nachweisen, obwohl, wie Untersuchung ungefärbter Gefrierschnitte ergab, die roten Öltropfen überall die Kutis bis direkt an die Epidermis durehsetzten. Die Bindegewebsproliferation war verbältnismäßig nicht mächtig, desgleichen nicht die Bildung epitheloider Zellen.

Es zeigt dieser Versuch, daß auch beim Menschen eine zweifellose Wirkung der Scharlachölinjektionen auf das Epithel besteht, wenn sie auch nicht unwesentlich hinter demzurückbleibt, was wir am Kaninchen, speziell am Kaninchenohr zu sehen gewohnt sind.

Weitere Beiträge zur Frage der experimentellen Erzeugung von Epithelwucherungen brachten Rutschinski und Benthin.

Rutschinski (zit. nach Greischer) sucht den Beweis zu erbringen, daß dem spezifisch chemischen Reiz des Sudan III, Scharlach R und seinen Bestandteilen in der Frzeugung von Epithelwacherungen die Hauptrolle zukommt, die verschiedenen anderen mit der Injektion zusammenhängenden Reize nur eine Nebenrolle spielen. Dieser Autor konnte bei Injektion des $\alpha-N$ aphthylamin in wässeriger Lösung, bei welcher die stärkere mechanische Schädigung der Gewebe durch öl ausgeschlossen war, die gleichen Proliferationserscheinungen beobachten, wie bei Injektionen desselben Stoffes in öliger Lösung. Weiter konnte er zeigen, daß eine Injektion von $\alpha$-Naphthylamin in Verbindung mit Stoffen, welche an sich das Epithel nicht zum. Wachstum anregen, z. B. Krotonöl, keine stärkeren Wucherungen auslöste, ferner daß eine Verstärkung des mechanischen Reizes durch Zusatzes einer Aufschwemmung von KieselguhrInfusorienerde (Podwyssozki) zu den Injektionen das Proliferationsvermögen des Epithels nicht steigerte, sondern hauptsächlich nur entzündliche Erscheinungen veranlaßte.

Rutschinski bestätigte, dab derspezifisch-chemische Reiz allein eine Epithelwucherung erzeugte, der mechanische Reiz aber allein (Injektion am Kaninchenohr der A ufschwemmung von Kieselguhrund Infusorienerde) hauptsächlich entzündliche Erscheinungen und unbedeutende Epithelproliferation hervorrief. Besonders zu erwähnen ist folgendes Experiment des Autors: Rutschinski erzengte nämlich durch einen Hammerschlag am Kaninchenohr im subkutanen Bindegewebe einen Bluterguf und injizierte gleich darauf Sudan III ins Ohr. Bei diesen Versuchen konnte er von 8 Versuchstieren nur bei 2 einen Unterschied in der epithelialen Wucherung im Vergleich mit dem Kontrolltiere konstatieren, und zwar war in diesen zwei Fällen die Epithelwucherung hochgradig, wie er sie in allen seinen anderen Versuchen nie beobachtet hatte.

Benthin untersuchte im Jahre 1911 im Institute von v. Hansemann folgende Stoffe auf ihr spezitisches Vermögen, das Epithel zur Wucherung anzuregen, nämlich: Olivenöl, Agar, Agar mit kohlensaurem Kalk und phosphorsaurem Kalk, Paraffinöl, Sudan III, Scharlach R. 
Indophenol, Amidoazotoluol, Amidoazobenzol, Paratoluidin (Bestandteile des Scharlach R), $x$-Naphthylamin, Indol, Skatol, Paraffinöl mit Ruß, Gummi arabicum allein und mit Sudan III, Ölsäure und Glyzerin. Negativ waren die Versuche dieses Autors mit Agar, Olivenöl und Gummi arabicum. Die schönsten Epithelwucherungen gaben Scharlach R. Auch mit Paraftin und RuB (Meyer) erhielt Benthin Wucherungen, jedoch nicht so ausgedehnt, wie es Meyer angibt. Benthin erhielt nur Epithelzysten, deren epitheliale Auskleidung keine weitere $A b z$ weigung erkennen ließ. Er nimmt an, daß man zur Erklärung der Wucherungen genötigt ist, einen Komplex von Ursachen anzunehmen. Es wirken nebeneinander Entzündung, Gewebsspannung, damit vielleicht auch eine gewisse Zirkulationsstörung, in der Hauptsache aber das Vorhandensein gewisser chemischer Stoffe.

Greischers Versuche wurden zu dem Zwecke unternommen, den Einfluß der Zirkulationsstörung, die nach Meyer im Verein mit Entzündung der wesentliche Faktor in der Erzeugung der Epithelwucherung sein soll, durch besondere Versuchsanordnung zu klären. Die von Greischer verwendeten Substanzen waren folgende: Olivenöl, Paraffinöl ohne Zusatz, 5\% ige ölsäure in Olivenöl (Meyer) und Eiweißfäulnisprodukt, Indol (S toe ber und Wacker), gelöst in Kaninchenfett. Von diesen Substanzen injizierte Greischer sofort nach den Unterbindungen der linken Karotis in die Haut des linken Ohres, sowie in die des rechten Ohres die gleichen Mengen unter demselben Druck. Am 2. Tage nach der Operation erfolgte eine Nachspritzung.

Nach Greischer sind die linksseitigen Nekrosen dadurch zu erklären, daß an dem $\mathrm{Ohr}$ der linken Seite Zirkulationsstörungen infolge der Karotisunterbindung bereits vor der Injektion bestanden; das in seiner Zirkulation gestörte Gewebe vermochte die mit der Injektion verbundene zweite Schädigung der Ernährung nicht auszuhalten und verfiel der Nekrose, während das Gewebe der rechten Seite die mit der Injektion verbundene Schädigung seiner Zirkulation überstand. Daß die Zirkulationsstörung im Sinne der Anämie allein nicht imstande ist, Epithelwucherung auszulösen, dürfte eben aus dem Verhalten der Ohren bei Olivenölinjektionen hervorgehen; wäre diese Zirkulationsstörung der wirklich auslösende Faktor, so hätten an diesem Ohr Epithelwucherungen auftreten müssen. Bei Olivenölinjektion blieb jedoch stets eine Proliferation des Epithels ans. Daß diese Zirkulationsstörung nicht an der Epithelwucherung schuld trägt, wird besonders dadurch bestätigt, daß die Epithelwucherungen nie an der anämischen Seite stärker als an der normalen ausfielen. Beide Ohren verhielten sich bei allen Versuchen Greischers gleich; weder waren am Ohr der unterbundenen, auf die Injektion reagierenden Tiere die Epithelwucherungen stärker, noch fanden sich solche Epithelwucherungen links, wenn rechts keine Poliferationen erfolgt waren. Im Gegensatz zu Tabaksteer und Rohparaffinöl ist es bei Verwendung von Indol nach 
den Erfahrungen dieses Autors notwendig, einmal nachzuspritzen, wenn Wucherungen zustande kommen sollen.

Auf Grund sciner Untersuchungsresultate glaubt $G r$ eischer folgendes sagen zu können: Bei den Epithelwucherungen, welche infolge von Injektionen bestimmter Stoffe am Kaninchenohr auftreten, kommt den injizierten Stoffen die ausschlaggebende Rolle zu; ihre Wirkungsweise ist gebunden an einen längeren Kontakt mit den Epithelien. Bei Änderungen der Zirkulation, welche die Dauer des Kontaktes verkürzen, also bei arterieller Hyperämie, wie in Greischers Experimenten mit Sympathikusdurchschneidung, treten die epithelialen Wucherungen deshalb in geringer Ausdehnung auf, weil durch die flotte Zirkulation die injizierten Substanzen schneller vom Injektionsort fortgeführt werden. Bei Änderungen der ZirkuJation, welche die Blutströmung verlangsamen, also bei venöser Hyperämie, in diesen Versuchen durch Unterbindung der Venen erreicht, ist das Umgekehrte der Fall. Die injizierten Substanzen blieben länger an der Injektionsstelle liegen, die Dauer des Kontaktes mit dem Epithel ist somit verlängert; anf diese Weise sind die auftretenden Epithelproliferationen masiger, intensiver und a usgedehnter. Nach Greischer spielen Zirkulationsänderungen nur insofern bei der Epithelwucherung mit eine Rolle, als sie eine längere oder kürzere Einwirkungsdauer der injizierten Substanzen auf das Epithel des Injektionsortes ermöglichen. Wie wir uns - meint Greischer die Art der Einwirkung der injizierten Substanzen auf das Epithel denken können, scheidet da vorläufig aus der Betrachtung vollständig aus. Diese Frage zu ventilieren, lag auch nicht in der Absicht dieses Autors. Daß spezifische Reize von den einzelnen Stoffen ausgehen, geht ja aus den erhaltenen Resultaten und aus dem Unterschiede der einzelnen zur Injektion verwandten Substanzen, z. B. Olivenöl, Tabaksteer usw. hervor. Dieser Autor wollte eben den Einfluß der Zirkulationsstörungen auf das Entstehen der Epithelwucherungen feststellen.

Bei Versuchen über die experimentelle Erzeugung teratoider Tumoren bei der weißen Ratte wurde von Askanazy eine Behandlang des Embryonalbreis mit Scharlachrot mit negativen Ergebnissen vorgenommen. Er konnte, wie schon früher Petrow (l. cfr. Herxheimer und Reinke), auf verimpftes Embryonalgewebe der Ratte durch Scharlachöl nicht nur keine Steigerung, sondern eher eine Schädigung der Zellproliferation beobachten.

Werner R. berichtet über Versuche über den Einfluß des Scharlachrots a f Mäusetumoren. Die Auslösung der Wucherung durch Scharlachöl erfolgt nicht durch chemotaktische Beeinflußung der Zellen, sondern durch eine Reizung derselben, wie der Effekt der intratumoralen Injektion beweist.

Freund Paula versuchte im Anschlo $B$ an die Stoeber-Wackerschen Feststellungen, von einer besonders starken wachstumsanregenden 
Eigenschaft des Indols Gebrauch zu machen und leitete eine Vorbehandlung des Embryonalbreis mit einer Lösung von Indol, ferner mit Mischungen von Indol und Äther ein, in der Annahme, die wachstumbefördernde Wirkung beider Substanzen könne sich summieren; doch war diese Vorbehandlung des Embryonalbreis, sowie wiederholte Einspritzungen der Flüssigkeiten in die Tumoren für die Größenentwicklung derselben anscheinend ohne Bedeutung.

Bemerkenswerte Versuche liegen ferner von Wacker und Sehmincke vor. Ihreexperimentellen Untersuchungen bilden Beiträge zur kausalen Genese von Epithelwucherungen. Beide Autoren haben sich zwei Fragen allgemeinen Interesses zur Beantwortung vorgelegt: 1. Gibt es besondere Stoffe, welche das Epithel überhaupt und unter allen Umständen zu einem Wachstum anregen? 2. Haben die experimentell erzeugten Epithelwucherungen mit denen des Karzinoms irgendwelche Wesensgemeinschaft, führt daher ihre Erforschung zu einer Erweiterung unserer Kenntnisse über das Wesen des Karzinoms?

Die von den verschiedenen Autoren mit positivem Resultat zur Injektion benützten Stoffe sind ihrer Natur nach ganz verschieden, zeigen jedoch eine gemeinsame physikalische Eigenschaft, die Lipoidlöslichkeit. Die Lipoidlöslichkeit ist gleichbedentend der Lösungsfähigleit in Öl oder Fett. Diese Lipoidlöslichkeit ist als physikalischer Vorgang wohl zn unterscheiden von dem ebemischen Prozeß der Lipolyse oder besser Lipoidolyse (Fettspaltung - Verseifung). (Wacker-Schmincke.) Nach Untersuchungen dieser beiden A utoren ist die Lipoidlöslichkeit aer Substanzen für die wucherungsanregende Wirknng auf das Epithel von ausschlaggebender Bedeutung. Sie benutzten zu ihren Versuchen als Injektionsort gleichfalls das Kaninchenohr. Einspritzungen in die Ohren, sowie in die Subkutis der Rückenhaut eines jungen Schweines ergaben ein negatives Resultat. Die genannten Autoren stimmen mit Stahr ganz überein, wenn er die anatomische Beschaffenheit des Injektionsortes teilweise wenigstens für das Gelingen der Versuche verantwortlich macht. Beim Kaninchenohr sichert die Verbindung des Epithels durch das Bindegewebe mit dem Knorpel, die nur eine geringe Verschiebbarkeit der Teile gegeneinander zuläBt, and die pralle Füllung der straffen subepithelialen Bindegewebsschicht eine langsam erfolgende Resorption der injizierten Substanzen. Wacker und Schmincke haben 49 verschiedene Substanzen (Fette, Öle, Paraffine usw.) zu ihren Versuchen benützt und sind in bezug auf die positiven und negativen Resultate zu dem Ergebnis gekommen, dab Substanzen sauren, basischen und neutralen Charakters bei den Injektionen Wucherungen verursachen.

Die Injektion der Stoffe erfolgte bei einer Temperatur von etwa $37^{\circ} \mathrm{C}$. Die Fette wurden vorher durch Erhitzen auf $100^{\circ}$ sterilisiert. Die Exzision erfolgte nach ca. 10-20 Tagen. Maßgebend für den Exzisionstermin war das Abgeklungensein entzündlicher Erscheinungen. 
Die mit positivem Erfolg verwandten Substanzen zeigen nach Wacker und Schmincke wiederum die gemeinsame Eigenschaft der Lipoidlöslichkeit. Es scheinen alle solche Stoffe das Epithel zum Wachstum anzuregen, welche die lipoide Hülle der Epithelien physikalisch verändern. Eine Ausnahme von dieser Theorie machen nur einige lipoidlösliche Körper, welche nach den Versuchen dieser und anderer Autoren zu keiner Epithelproliferation Veranlassung gaben. Wie a us der Versuchstabelle dieser Autoren hervorgeht, sind dies die flüssigen Öle neutralen Charakters, Olivenöl, Rizinusöl, Leinöl und Paraffinöl. Daß es mit Olivenöl und ähnlichen ölen nicht gelingt, Epithelwucherungen hervorzurufen, hat nach Wacker und Schmincke seinen Grund darin, daß diese öle wegen ihres flüssigen Aggregatzustandes and ihrer geringen Viskosität leicht von der Injektionsstelle weggeführt werden. Injektionen von frischem Kaninchenfett ergaben ein negatives Resultat, bei altem Kaninchenfett war eine lebhafte und ausgedehnte Epithelproliferation zu beobachten. Als Ursache der verschiedenen Resultate bei frischem und altem Fett sprechen sie den "Ranziditätsgrad" an. Bekanntlich erleiden die Fette bei längerer Berührung mit der Luft Veränderungen. Die Summe derselben faßt man unter dem Ausdruck "Ranzigwerden" zusammen. Neben den ausschlaggebenden Veränderungen im Geschmack ist auch eine Erscheinung des "Ranzigwerdens" die Zunahme des Säuregehaltes. Fette von hohem Säuregehalt wirkten also bei diesen Versuchen epithelwucherungsanregend, von niedrigem nicht.

Bei der Einwirkung der Fette auf das Epithelwachstum müssen zwei Faktoren berücksichtigt werden. Einesteils kommt es darauf an, daß das Fett längere Zeit am injizierten Ort liegen bleibt - diese Eigenschaft ist allen Fetten mit höherem Schmelzpunkt gemeinsam -, ferner daß das Fett einen gewissen Säuregrad besitzt. Äther und andere Narkotika wurden mit Bezug auf die Rein keschen Experimente, nach welchen dem Äther und verwandten Substanzen eine wachstumserregende Wirkung zugesprochen wird, zu Versuchen verwandt. Mit Äther in Olivenöllösung gelang es Wacker und Schmincke nicht, Epithelwucherungen hervorzurufen.

Will maneine Substanz nach Wacker und Schmincke aufihreproliferationsanregende Wirkung prüfen, so mu man dieselbe in Olivenöl einspritzen. Im Verlaufe der Besprechung meiner eigenen Versuche komme ich auf diesen Punkt noch besonders zurück.

Von den injizierten Stoffen basischen Charakters ergaben Harnstoff und Guanin als lipoidunlösliche Körper negative, Indol-Skatol (lipoidlösliche Stoffe) positive Resultate. Die von Wacker in Gemeinschaft mit $\mathrm{Stoeber}$ mit Indol und Skatol in Kaninchenfett früher erhaltenen ausgiebigen Wucherungen sind nach den jetzigen Erfahrungen von Wacker und Schmincke als additionelle Wirkungen des Indols-Skatols und Kaninchenfetts 
aufzufassen. Eiweißspaltprodukte amphoterer Reaktion, wie Aminosäuren, gaben negative Resultate. Von den zur Verwendung gekommenen Säuren erhielten die genannten Autoren mit Kohlensäure und Milchsäure keine Wucherung. Harnsäure in öliger Suspension ergab negative Resultate. Mit Tabaksteer und Rohparaffinöl erhält man nach ihren Erfahrungen besonders scböne und ausgedehnte Wucherungen. Besonders auffallend ist nach Wacker und Schmincke die massige epitheliale Proliferation, der Reichtum an Mitosen, die vielfache, bis in die Knorpelnähe reichende, feinwurzlige Verzweigung der gewucherten Epithelzapfen.

Die epithelanregenden Substanzen wirken nach diesen Versuchen in fettiger oder öliger Lösung weitaus besser als in wässeriger. Durch Lösung fremder Stoffe in dem Fett kann somit eine additionelle Wirkang zustande kommen.

Bei den durch Injektionen von verschiedenen Substanzen am Kaninchenohr zustande kommenden Epithelproliferationen sind $\mathrm{zwei}$ F ormen zu unterscheiden: die eine, welche zustande kommt, ohne daß Nekrosen sowie stärkere entzündliche oder eitrige, abszeßähnliche Herde im Gefolge der Injektion im Bindegewebe auftreten - die zweite, die beobachtet wird, wenn im Bindegewebe im Gefolge der Injektion größere oder kleinere, abszeßähnliche Herde zustande gekommen sind. Bei den letzteren erfolgt von den benachbarten Haarbälgen aus eine Wucherung des Epithels, und die Wandung des mit der Abszeßmasse gefüllten Bindegewebshohlraumes wird von dem gewucherten Epithel des Haarbalges aus epithelisiert. Nach vollständiger Epithelisierung resultieren so tief im Bindegewebe gelegene, mit verhornten geschichteten Pflasterepithelien ausgekleidete Epithelzysten. Nach den Untersuchungen von Wacker und Schmincke und anderen Autoren, welche die Erzeugung von Epithelwacherungen zum Gegenstand ihres Studiums machten, rufen nur diejenigen Substanzen ein Epithelwachstum hervor, welche lipoidlöslich sind.

Einen Punkt in der wohl komplexen Ursache der Wachstumanregung glauben die beiden Autoren durch ihre Experimente in der Lipoidlöslichkeit der Substanzen, welche die Epithelproliferation anregen, gefunden zu haben.

Was die eingangs von Wacker und Schmincke gestellten Fragen anlangt, so haben die hier veröffentlichten Untersuchungen nur die erste Frage, ob es besondere, wachstumserregende Stoffe gibt, um ein Stück ihrer Beantwortung näher geführt. Besonderer Beachtung wert scheint nach diesen Autoren das Auffinden von Substanzen, welche in hervorragender Weise das Epithel des Kaninchenohres zum Wachstum anregen, und welche ev. bei dem Karzinom gewisser Berufsklassen eine Rolle spielen; sodann die Tatsache, daß Substanzen, welche beim Stoffwechsel im menschlichen und tierischen Organismus sich bilden, in besonderer Weise eine proliferationsauslösende Wirkung auf das Epithel ausüben. 
Aus dem pathologischen Institute in Göttingen berichtet Takeyoshi Mori (1912) über experimentelle Untersuchungen über die Genese von Epithelwucherungen" und kommt u. a. zu folgendem Schluß:

${ }_{n}$ An der atypischen Epithelwucherung, welche wir am Kaninchenohr als Folge der Injektion auftreten sehen, nahmen das Deckepithel und das versenkte Epithel selbst gar keinen Teil. Sie entsteht immer nur durch die Epithelwucherung an den Haarbälgen. Diese Epithelwucherung entsteht durch einen entzündlichen Reiz, welcher durch die injizierten Stoffe ansgeübt wird. Am Hahnenbart erzielt man durch Injektion derartiger chemischer Substanzen gar keine atypische Epithelwucherung wie beim Kaninchenohr, weil er der Hautanhänge entbehrt."

In einer jüngst erschienenen Arbeit „Über Transplantationen experimentell erzeugter atypischer Epithelwucherungen" kommt von Lamezan') zu dem Ergebnis, daß die subkutanen, teils autoplastischen, teils homoioplastischen Transplantationsversuche der experimentell erzeugten ,atypischen" Epithelwucherungen sich ebenso verhalten, wie die von normalem Epithel. Was gefunden wurde, waren mit Epithel ausgekleidete Zysten in der Art, wie sie bei Verlagerungen von Epithel so häufig beobachtet wurden. Die einzige Beobachtung aus Lamezans Versuchen, welche für die Frage der Transplantation überhaupt eỉn gewisses Interesse beanspruchen dürfte, war die, daß das homoioplastisch transplantierte Epithel früher der Degeneration anheinfällt, wie das autoplastisch transplantierte, ein Befund, wie er mit den Erfahrungen über homoioplastische Transplantation aus neuester Zeit übereinstimmt.

von Hansemann ${ }^{2}$ ) ist zu einem ähnlichen Resultat gekommen wie von Lamezan. Die durch Scharlachöl erzeugten "atypischen" Epithelwucherungen haben sich bei der Transplantation sämtlich zurückgebildet, sie haben also keine Beziehung zur malignen Geschwulstbildung.

Nach Abschluß meiner Arbeit erschien eine Publikation von Ishio $\mathrm{Haga}^{3}$ ) über "Experimentelle Untersuchungen über die Erzeugung atypischer Epithel- and Schleimhatwucherungen“. Haga faßt die Ergebnisse seiner Untersuchungen folgendermaßen zusammen :

1. Einspritzungen von Scharlachöl oder ihm ähnlichen Substanzen rufen nicht nur an der Haut, sondern auch an den Schleimhäuten (z. B. Zunge, Magen), den Endothelien (z. B. der LymphgefäBe) und den Epithelien der Gallengänge und der Ausführungsgänge der Milchdrüsen Wucherungen hervor.

2. Die Fintstehnng dieser Wucherungen dürfte auf einen bestimmten chemischen Reiz des Scharlachrots bzw. der ihm ähnlich wirkenden pag. 389.

1) 1. c. Zeitschrift für Krebsforschung. 1912. XII. Band. 2. Heft,

2) ibidem.

3) ibidem. 1913. XII. Band. 3. Heft, pag. 525. 
Substanzen zurückzuführen sein. Entzündungen, Zirkulationsstörungen usw. wirken dabei unterstützend mit.

3. Für die Entstehung der atypischen Wucherungen spielen die anatomische Beschaffenheit der injizierten Stelle und der Grad der Wucherung die Hauptrolle, daneben kommt sie auch infolge von Zellverschleppung bei der Einspritzung zustande.

4. Die atypische Wucherung an der Magenschleimhaut, welche bei seiner zweiten Einspritzung zustandekommt, scheint ihm für eine Charakterveränderung derjenigen Schleimbautabschnitte zu sprechen, welche durch die Durchbruchstelle des Abszesses oder die Einstichstelle der Spritze hindurchwachsen oder bei der Einspritzung mit der Spritze verschleppt wurden.

5. Der Zusatz von Preßsaft von Karzinom oder Sarkom bringt keine spezifische Wirkung bei der Einspritzung hervor.

6. Transplantation mit Gewebsmaterial, welches aus experimentell erzeugten Tumoren herrührte, konnte von ihm nicht erreicht werden.

7. Die von ihm am Magen experimentell erzengten Tumoren sind keine echten Karzinome, da die Hauptmerkmale der Malignität, schrankenloses Wachstum und Metastasenbildung fehlen, doch scheint ihm die beschriebene Charakterveränderung der Schleimhaut eine gewisse Tendenz zur Malignität zu besitzen.

An diese Untersuchungen schließen sich meine Versuche an.

Diese Versuchsreibe wurde in der Weise ausgeführt, daß Emulsionen von Anilinfarbstoffen Brillantrot, Krapplack, Grünerlack, Gelblicht, sowie eine Reihe anderer chemischer Agentien: Mennige, Alizarin, Azofarbe in Olivenöl, ferner Suspensionen der genannten chemischen Stoffe in destilliertem Wasser, sowie reines sterilisiertes und nicht sterilisiertes Olivenöl subkutan in die innere Ohrfläche von Kaninchen vorgenommen wurden.

Bei vielen Versuchstieren war es nicht zu vermeiden, daß ein Teil, manchmal der größte Teil der Injektionsflüssigkeit in die Ohraußenfläche gelangte, diese an einer zirkumskripten Stelle vorwölbend. Dieses Ereignis kann unter zwei Umständen eintreten, entweder wird bei der Injektion der Ohrknorpel mit der Kanüle durchgestoßen, oder es kann die injizierte Flüssigkeit von der inneren $\mathrm{Ohrfäche}$ durch eine normalerweise im Ohrknorpel vorhandene Lücke an die Ohraußenfläche gelangen. Bei einem Versuchstier wurden an der Ohrwurzel Arterien und Venen durch Ligaturen unterbunden, um den EinfluBder Zir. kulationsstörung (Meyer, Greischer) auf das Epithelwachstum studieren zu können. Um gleichmäBige Quaddeln zu erhalten, ist es notwendig, daß die Emulsionen unter gleichmäßigem Druck subkutan injiziert werden. Die Quaddel darf nicht zu prall sein, soll nicht das Versuchsresultat durch Nekrose gestört werden. Am besten ist es, nach erfolgter Injektion etwas von der Emulsion herauszulassen, so daB 
man die Hautschichte ganz leicht verschieben kann. Eine Nachspritzung der Emulsionen oder Farbstoff lōsungen habe ich nicht vorgenommen. Die Injektionsöffnung verklebt man am besten mit Kolledium, um ein weiteres Herausfließen zu vermeiden. Ferner darf die zu injizierende Emulsion nicht zu konzentriert sein, weil bei solchen Versuchen regelmäßig Nekrose eintritt; bei zu schwachen Emulsionen bleibt manchmal die Epithelproliferation ganz aus, oder sie ist nur in sehr geringem Grade ausgeprägt, so daß für solche Injektionsversuche gesättigte Emulsionen die besten Resultate geben.

Die Emulsionen wurden in der Apotbeke stets frisch hergestellt, das zu den Injektionsversuchen verwendete Olivenöl war stets frisch, rein, sterilisiert oder nicht sterilisiert, die Farbstoffe selbst wurden nicht sterilisiert. Die Injektionen wurden stets bei Zimmertemperatur, die Exzisionen in der Regel in der Zeit nach 2, 3 and 4 Wochen, in einer Versuchsreihe nach 1,2 und 3 Monaten, die Fixierung und Härtung der Hautstücke in 10\% Formol oder Alkohol vorgenommen.

1. Versuch: Subkutane Injektion von Scharlachöl (Scharlachrot 10: Olivenöl 300) in die rechte Ohrinnenfläche eines jungen Kaninchens. Sign. A.

13./I. 1910. In die r. Ohrinnenfläche subkutane Injektion von Scharlachöi an 2 Stellen zu je $3 \mathrm{ccm}$.

20./I. 1910. Auf der rechten Ohrinnenfläche außer Quaddeln keine Erscheinungen. Tier abgemagert.

28./I. 1910. Aus der Iujektionsstelle quillt eine rotgefärbte eitrige Masse hervor.

31./I. 1910. Leichte Andeutung von Knötchenbildung und warzigen Exkreszenzen.

10./1I. 1910. Status idem.

17./II. Anf der Ohrinnenfläche sieht man leicht warzige Erhaben. heiten, die größte Menge der injizierten Flüssigkeit befindet sich an der Ohraußenfläche. An dieser Stelle wird das Ohr halbkugelförmig von der Größe einer Walnuß vorgewölbt, auf der Obertäche dieses Tumors, sowie auf der Ohrinnenfläche warzige, rotgefärbte Exkreszenzen, ähnlich dem Bildeder Keratosis follikularis. Die Versuchsdaner beträgt 25 Tage, die exzidierten Hautstücke wurden in $10 \%$ Formol fixiert und in Alkohol nachgehärtet.

Histologisehe Untersuchung: Bei schwacher Vergröberung (Zeiss Oc. 2, Obj. A. A.) lassen sich folgende Veränderungen an der Ohraußen- und -Innenfläche konstatieren.

Die Epidermis der OhrauBenfläche zeigt in allen ihren Schichten eine beträchtliche Verbreiterung. Das Stratum corneum nimmt ebenso wie das Stratum granulosum an der Proliferation teil. Die Hornschichtlamellen sind vermehrt und aufgelockert. Das Rete Malpighii weist eine beträchtliche Verbreiterung und Proliferation auf, die sich in Form von verschieden langen und verbreiterten, oft unregelmäßig gestalteten Zapfen dokumentiert und das Bild einer pathologisc ben Epithelproliferation präsentiert. In den Zellen des Rete Malpighii finden wir oftmals reichliche Mitosenbildung.

Die Ha a r w urzels cheiden sind bedeutend verbreitert, manchmal quer oder auch schräg getroffen, lassen in ihren zentralen Anteilen deu 
Querschnitt eines Haares erkennen. Die verbreiterten Haarwurzelscheiden berühren sich oft und bilden dann einen breiten Epithelzapfen mit zahlreichen Haardurchschnitten. Diese Epithelzapfen zeigen dann einen Zusammenhang mit der Reteschicht. An dieser Proliferation nehmen die Ha arbalgdrü sen ebenfalls lebhaften Anteil, sie sind beträchtlich vergrößert und verbreitert, ragen als ansehnliches Drüsenkonvolut ins Stratum subpapillare. Oft werden sie durch die gewucherten Epithelzapfen verdrängt, es lassen sich dann in diesen noch Reste von Talgdrüsenzellen nachweisen, oder es finden sich diese gewucherten Talgdrüsen in der. Wand der noch zu besprechenden Epithelzysten und können da ebenso weiterwuchern.

In der Nähe des verbreiterten Rete Malpighii, oft anch weiter entfernt im Stratum papillare oder subpapillare liegend, lagern sich Epithelinseln mit oder auch ohne Hornperlen ein. In den interspinalen Spalträumen dieser Epithelinseln sind polynukleäre Leukozyten und Lymphozyten in Durchwanderung begriffen. Im Zentrum dieser Epithelinseln resp. Epithelzapfen, sowie der Fipithelzysten befinden sich polynukleäre Leukozyten in Haufen angeordnet, als Residuen der abgelaufenen Entzündung. Diese Leukozytenanhäufung wird durch das Vorrücken der Hornschichtlamellen in den Epithelzysten immer kleiner.

In der Kutis der Ohraußenfläche sind Hohlräume zu erwähnen, die durch die Aufnahme der injizierten Emulsion (Scharlachöl) in die Bindegewebsmaschen entstanden und teils ganz frei von Farbstoff sind, teils Residuen von Farbstoftkristallen enthalten. Diese Hohlräume sind kreisrund oder oval, von länglichen, endothelartigen Zellen ausgekleidet.

Außer diesen Hohlräumen, den Depots der Farbstoffemulsion, sind die im Stratum papillare und subpapillare, sowie in den tieferen Schichten der Kutis gelegenen Epithelzysten zu erwähnen. Diese sind von kreisrunder, ovaler oder unregelmäßiger Form, einzeln oder mehrere miteinander kommunizierend. Sie stellen einen von einer ein-oder mehrfachen Epithellage eingesäumten Hohlraum dar, der entweder eine mit Farbstoff vermengte, abszeßähnliche Masse enthält, oder in dessen Inneren sich aufgelockerte Hornschichtlamellen, Farbstoffreste, abgestoßene Epithelien und haufenförmige Ansammlungen von polynukleären Leukozyten befinden. Aus der Wand einer solchen Epithelzyste ragen wiederum versehiedene lange und breite Zapfen, ähnliche Bilder wie das Rete Malpighii darbietend, hervor, außerdem vergrößerte und verbreiterte Talgdrüsen.

An Serienschnitten läßt sich einwandfrei der Beweis erbringen, daß diese Epithelzysten, solange sie in der Tiefe gelegen sind, einen geschlossenen Hohlraum darstellen, im weiteren Verlaufe sich nach außen öffnen, entweder mit den Haarwarzelscheiden, den Haarbalgdrüsen oder den Follikeln im Znsammenhang stehen.

In der Kutis ist, besonders in der Nähe der Farbstoffansammlnng, das entzündliche Infiltrat ziemlich reichlich eingelagert. Es besteht vor- 
wiegend aus gewucherten fixen Bindegewebszellen, polynukleären Lenkozyten, weniger Lymphozyten, vereinzelten Plasma- und Mastzellen.

Einzelne Zellen, sogenannte Fremdkörperzellen, zeigen ovale oder polygonale Form, graugelbliche Farbe sind mit Farbstoffkörnchen oder Farbstoffkristallen vollgepfropft, mit einem großen, exzentrisch gelagerten Kern. Sie kommen vereinzelt oder in Haufen angeordnet vor. Bei starker Vergrößerung (Zeiss Oc. 4, Obj. D. D. oder Ölimmersion) kann man das granulierte Protoplasma dieser Fremdkörperzellen, sowie die Farbstoffkristalle in und zwischen den zelligen Elementen noch deutlicher zur Darstellung bringen. An Gefrierschnitten, die mit Osmium oder mit Hämatoxylin-Sudan gefärbt wurden, lassen sich an vielen Zellen Fetttröpfchen zwischen den Farbstoffkristallen deutlich nachweisen. Außer diesen Fremdkörper-Fettkörnchenzellen finden sich Riesenzellen mit einem vakuolisierten Protoplasma und mehreren, großen, randständig gelagerten Kernen mit spärlichen aufgelagerten Kristallen.

Die Kutis zeigt die entzündlichen Erscheinungen an manchen Stellen im Abklingen begriffen und bereits im Übergang zu einem Granulationsgewebe. Die Bindegewebsbündel sind ödematös, gequollen, zwischen denselben Riesenzellen, Fremdkörperzellen, vereinzelt oder in kleinen, spindelig ausgezogenen Haufen angeordnet. Manche Bindegewebsbündel selbst sind mit Farbstoffkristallen wie bestaubt, die sich auch zwischen diesen Bündeln nachweisen lassen. Die elastischen Fasern sind sowohl quantitativ als auch qualitativ nicht verändert, fehlen fast vollständig im Bereiche des entzündlichen Infiltrates. Die Blut- und Lymphgefäße sind wohl stark erweitert, ihre Endothelien etwas gequollen, die Verdickung der gefalteten Intima ist jedoch nur auf einen Kontraktionszustand der Gefäße zurückzuführen.

Die Ohrinnenfläche bietet besonders schöne Bilder der pathologischen Epithelproliferation mit mächtig verlängerten und verbreiterten Epithelzapfen, mit tief in das Kutisgewebe eingelagerten Epithelinseln, mit vergrößerten Talgdrüsen. Außerdem sind erweiterte Follikel mit vermehrten, konzentrisch angeordneten, aufgelockerten Hornschichtlamellen mit Lanugohaaren, gleich dem Bilde der Keratosis follikularis, zu erwähnen. In der Kutis kommen gleichfalls Epithelzysten mit konzentrisch geschichteten aufgelockerten Hornschichtlamellen zur Beobachtung.

Fasse ich das Resultat der histologischen Untersuchung dieses Versuches zusammen, so komme ich $\mathrm{zu}$ folgendem Ergebnisse :

An der Ohraußenfläche zeigt das histologische Bild der vergrößerten und erweiterten Haarwurzelscheiden eine gewisse Analogie mit dem von J aris ch beschriebenen Bilde des Trichoepithelioma papillosum multiplex. Wie bei letzterem konnte auch bei den von mir experimentell erzeugten Verän- 
derungen ein Zusammenhang der verbreiterten Haarwurzelscheiden sowohl mit dem Deckepithel (Brooke), als auch mit den Bälgen der Lanugohaare (J ar is ch) einwandfrei an Serienschnitten erbracht werden.

Das proliferierte und verbreiterte Epithel der Ohraußenund -innenfläche täuscht auf einzelnen Schnitten das Bild eines epitheliomähnlichen Tumors vor, dem natürlich mit Rücksicht auf seine Genese als rein entzündliches Gewebsprodukt, hervorgerufen durch den chemischen Reiz des injizierten Scharlachöls, sowie wegen des Fehlens einer Anaplasie der Zellen und eines schrankenlosen Wachstums eine Malignität nicht zugesprochen werden kann.

Die erweiterten, mit vermehrten, aufgelockerten, konzentrisch geschichteten Hornschichtlamellen erfüllten Follikeln mit ihren eingepflanzten Lanugohaaren gleichen ihrem histologischen, sowie klinischen Ausseken nach dem Bilde der Keratosis follikularis (Lichen pilaris).

Was die im Gewebe zerstreuten Riesenzellen und Fremdkörperzellen anlangt, so ist ihre Entstehung sowohl auf die in der Farbstoffemulsion (Scharlachöl) dem Scharlachrot beigemengten Kristalle von Bariumsulfat und Tonerdehydrat, als auch, aber zum kleineren Teil, auf das Olivenöl zurückzuführen.

2. Versuch: Subkutane Injektion von Scharlaoböl $\left(1 \cdot 0: 30^{\circ} 0\right)$ in dje rechte Ohrinnenflache eines juggen Kanin. chens (Nr. 481, Sign. B).

Scharlachöl.

20./. 1910. In die rechte Ohrinnenfäche subkutane Injektion von

28./I. 1910. Quaddeln unverändert.

31./I. 1910. Status idem.

10./I. 1910. An der Injektionsstelle ein Ulkus, dessen Ränder verdickt sind. An Stelle der durch die Injektion entstandenen Quaddel fühlt man einen derben Knoten.

17./II. 1910. Im rechten Ohrlappen sind infolge Nekrose zwei wie mit einem Locheisen ausgeschlagene, von kallösen Rändern begrenzte Öffnungen entstanden. An der Obraußenfläche sind ebenfalls warzige Exkreszenzen sichtbar, an dieser Stelle fehlen die Haare. Die Versuchsdaner beträgt 28 Tage, Fixierung der exzidierten Hautstücke in $10 \%$ ig em Formol.

Makroskopisch sind an der Ohraußenfläche warzige Exkreszenzen, entsprechend dem halbkugelig sich vorwölbenden Knoten, sichtbar. Mikroskopischkann man die gleichen histologischen Veränderungen wie bei dem früheren Versuche 1 feststellen.

Die histologische Untersuchung eines in Serienschnitte zerlegten Randstückes von einem den Ohrlappen perforierten Ulkus ergab folgenden Befund: Die Veränderungen an der Epidermis 
sind die gleichen Epithelwucherungen wie bei den früheren Versuchen, die Kutis bestent aus einem sehr dichten, jungen Granulationsgewebe, der Ohrknorpel zeigt Neubildung von jungem Knorpelgewebe in Form von Inseln.

3. Versuch. Subkutane Injektion von Scharlachöl in die rechte Ohrinnenfläche eines jungen Kaninchens (Nr.6).

4. Versuch. Subkutane Injektion von Scharlachöl $3 \cdot 0: 30^{\circ} 0$ in die linke Ohrinnenfläche eines jungen Kaninchens (Nr.6).

17./II. 1910-12/III. 1910. Versuchsdauer 23 Tage. Klinisch und histologisch konnte im dritten und vierten Versuch der gleiche Befund wie im ersten Versuch erhoben werden. Die histologische Untersachung einer durch Nekrose perforierten Quaddel ergab das gleiche Bild wie eine sich nach außen öffnende Zyste; aus der Perforationsöffnung ragen aufgelockerte Hornschichtlamellen und Farbstoffmassen hervor.

5. Versuch: Subkutane Injektion von ScharlachrotOlivenöl (1.0:30'0 öliger Teil) in die rechte Ohrinnenfläche eines vier Monate alten Kaninchens (Nr. 391).

Versuchsdauer 38 Tage vom 2./V. 1910 bis 9./VI. 1910.

Histologische Untersuchung: Die Ohraußenfiäche ist frei von Veränderungen. An der Ohrinnenfläche finden sich entsprechend dem makroskopischen reibeisenähnlichen Aussehen derselben, auch histologisch Keratosis follikularis-ähnliche Gebilde, die in einer Erweiterung der Follikel mit aufgelockerten und konzentrisch geschichteten Hornlamellen bestehen, welch letztere Lanugohaare enthalten und über das Niveau der Haut hervorragen. An zahlreichen Präparaten sieht man perforierte Quaddeln, sowie einen vollständig ausgeheilten, von verbreitertem Epithel überzogenen Substanzverlust.

6. Versuch. Subkutane Injektion von Scharlachöl (1.0:30.0 oliger Teil) in die linke Ohrinnenfläche eines 4 Monate alten Kaninchens (Nr. 391).

Versuchsdauer 38 Tage vom 2./V. 1910-9./VI. 1910.

Makroskopisch entspricht das Bild an der inneren Ohrfläche dem der Keratosis follikularis und weist anch histologisch dieselben Charaktere auf wie beim Versuch 5 .

7. Versuch. Subkutane Injektion von Scharlachöl $(1 \cdot 0: 300)$ in die rechte 0 hrinnenfläche eines 8 Monatealten Kaninchens nach Unterbindung der Arterie und Venedes rechten Ohres (Nr. 12).

13./X. 1910. Injektion.

20./X. 1910. Diffuses Ổdem des r. Ohres (Ohrinnen- und -außenfläche).

11./XI. 1910. Quaddeln mit Perforationen, aus denen kleine, warzige, epithelisierte Exkreszenzen hervorragen. Diese haben das Aussehen von senilen Warzen.

14./XI. 1910. Die exzidierten Hautstücke werden in 10\% Formollösung fixiert. Versuchsdauer 32 Tage.

Histologische Untersuchung: Bei diesem Versuche finden wir die gleichen Veränderungen wie beim Versuch 1; außerdem treten die Veränderungen am Epithel infolge der durch die Unterbindung der Gefäße bedingten Sukkulenz der Gewebe (Ödem) stärker in die Erscheinung als in den Versuchen ohne Gefäßunterbindung. Hervorzuheben wäre noch, dab einzelne Epithelzysten nach auBen durchgebrochen sind; aus 
zahlreichen Perforationsöffnungen ragen epithelisierte, warzenähnliche Exkreszenzen hervor.

8. Versuch. Subkutane Injektion von ScharlachrotAqu. dest. $(0.0: 150)$ in die linke 0 hrinnenfläche eines älteren Kanincbens (Nr. 252).

7./VI. 1910. Injektion.

28./VI. 1910. Quaddeln mit deutlichen Keratosis follicularis-ähnlichen Bildungen.

12./VII, 1910. Status idem.

25./VII. 1910. An einzelnen Quaddeln Nekrosen, mit in Durchbruch begriffenen Wucherungen.

18./IX. 1910. Die exzidierten Hautstücke werden in $10 \%$ Formol fixiert. Versuchsdauer 3 Monate 11 Tage.

Wird destiliertes Wasser und nicht Olivenöl als Vehikel für das Scharlachrot genommen, so ist der Effekt der gleiche. Wir finden histologisch die gleichen Veränderungen, manchmal lassen sich gewisse Unterschiede in der Epithelproliferation nachweisen, die sich auf die Quantität derselben beziehen.

9. 'Versuch. Subkutane Injektion von BrillantrotOlivenöl $(10: 300)$ in die rechte 0 hringenfläche eines jungen Kaninchens (Sign. 0).

13/I. 1910. In die rechte Obrinnenfläche subkutane Injektion an mehreren Stellen von je $3.0 \mathrm{~cm}$.

10./I. 1910. Außer Quaddeln keine Erscheinungen.

Erhabenheiten.

31./. 1910. Auf der rechten Ohrinnenfläche leichte warzige

10./II. 1910. Befund unverändert.

15./II. 1910. Auf der rechten Ohrinnenfläche springen die Follikel stärker vor, man hat beim Darüberstreichen den Eindruck eines Reibeisens. An der entsprechenden Ohraußenfläche ist eine Öffnung za sehen, die unregelmäßig begrenzt ist, und aus welcher warzige, epithelisierte, rotgefärbte Exkreszenzen hervorwuchern. Die Versuchsdauer beträgt 33 Tage, Finlegen der exzidierten Hautstücke in 10\% igen Formol.

Histologische Untersuchung: Das analoge histologische Bild wie nach Injektion von Scharlachöl sehen wir auch nach Injektion von Brillantrot-0livenöl.

An der Ohrinnenfläche finden wir, abgesehen von den entzündlichen Veränderungen im Bindegewebe, als bemerkenswerte Befunde pathologische Epithelproliferationen (vgl. Tafel.... Fig. 5), wie die Verbreiterung des Stratum corneum und granulosum, insbesondere des Rete Malpighii mit verschieden breiten und langen Zapfen, mit epitheliom-nudKeratosis follicularis-ähnlichen Bildungen. In die Kutis sind ferner vergrößerte Talgdrüsen, sowie verschieden große Epithelzysten, im Innern mit aufgelockerten Hornschichtlamellen, Leukozyten, Farbstoffresten und uekrotischen Massen erfüllt, eingelagert. Die vergrößerten Talgdrüsen hängen an manchen Epithelzapfen, sowie an der Epithelzystenwand gleichsam als Appendix.

An der Ohraußenfläche fallen wiederum trichoepitbeliomsowie Keratosis follicularis-ähnliche Bilder auf (vgl. Tafel .... Fig. 6 u. 7). Im Zellinfiltrate der Kutis, insbesondere in 
der Nähe der Farbstoffdzpots, sowie der Epithelzysten sind außer Riesenzellen Haufen von Fremdkörperzellen (vgl. Tafel..... Fig. 8) besonders za erwähnen. Diese Fremdkörperzellen unterscheiden sich durch ihre größere Anzahl von den spärlichen bei den Seharlachölversuchen beschriebenen. Sie kommen einzeln zwischen den ödematös gequollenen Bindegewebsbündeln vor, meistens aber in Haufen ange. ordnet. Sie haben eine rnde, ovale oder auch polygonale Form, das Stroma ist von graugelber Farbe, mit einem großen randständigen Kern. Bei Untersuchung mit der Immersionslinse lassen sich die Granula des Zellprotoplasmas als Farbstoffkristalle, sowie die an manchen Zellen deutlich ausgesprochene honigwabenähnliche Struktur ganz leicht erkennen. In vielen dieser Zellen färben sich im Gefrierschnitt die Fetttröpfchen mit Sudan III, geben auch mit Osmium die Schwarafärbung. Bei den Versuchen mit Brillantrot-Olivenölinjektionen sind die Riesenund Fremdkörperzellen in größerer Menge vorhanden als bei den Ver. suchen mit Scharlachöl. Der Grund davon liegt in der größeren Kristallbeimengung bei Brillantrot als bei Scharlachrot.

Außer den Epithelzysten haben wir auch hier sowohl an der Ohraußen- als auch an der Ohrinnenfläche $\mathrm{H}$ ohlräume, entstanden durch die Aufnahme der Farbemulsion, die von endothelähnlichen Zellen ausgekleidet sind. Die elastischen Fasern, die Blut- und LymphgefäBe zeigen das gleiche Verhalten wie beim 1. Versuche.

10. und 11. Versuch. Subkutane Injektion von Brillantrot-Olivenöl 3.0:300 in die rechte und linke (11. Versuch) Ohrinnenfläche eines jug gen Kaninchens (Nr. 21).

Versuchsdauer 23 Tage vom 17./II. 1910-12./III. 1910.

Die klinische und histologische Untersuchung ergab bei diesen Versuchen das gleiche Resultat wie beim Versuch 9.

12. Versuch. Subkutane Injektion von BrillantrotOlivenöl (30:800) in die rechte Ohrinnenfläche eines jungen Kaninohens (Nr. 4).

13. Versuch. Subkutane Injektion von BrillantrotOlivenöl $(3 \cdot 0: 300)$ in die linke Ohrinnenfläche eines jungen Kaninchens (Nr. 4).

Versuchsdauer 23 Tage vom 17./II. 1910 bis 12./III. 1910.

Die Versuche Nr. 12 und 13 ergeben in ihrem klinischen und histologischen Verhalten das gleiche Resultat wie der Versuch Nr. 9.

14. Versuch. Subkutane Injektion von BrillantrotOlivenöl $(3 \circ 0: 30 \cdot 0)$ in die rechte Ohrinnenfläche eines 4 Monate alten Kaninchens (N r. 267).

2./V. 1910. Injektion.

$12 /$ V. 1910. An zahlreichen Quaddeln ist die Haut nekrotisch, zum Teil in Durchbruch begriffen und mit schmierigen Massen bedeckt. Einzelne Quaddeln intakt.

20./ V. 1910. Der gleiche Befund.

9./VI. 1910. AuBer Knoten und nekrotischen Stellen finden wir anf der Ohrinnenfläche warzige, follikulär angeordnete Exkreszenzen (Keratosis follıcularis). Die exzidierten Hautstücke wurden mit $10 \%$ Formol fixiert. Versuchsdauer 38 Tage.

15. Versuch. Subkutane Injektion von BrillantrotOlivenöI (30:30.0) in die linke Ohrinnenfläche eines 8 Mo- 
nate alten Kaninchens nach Unterbindung der Arterie und Vene des linken Ohres (Nr. 12).

13./X. 1910. Injektion.

11./XI. 1910. Knoten mit und ohne Perforationen, aus denen war-

20./10. 1910. Diffuses Ödem des linken Obres an der Innen- und. zige Exkreszenzen zum Vorschein kommen.

14/XI. 1910. Die exzidierten Hantstücke werden in $10 \%$ Formol fixiert. Versuchsdauer 32 Tage. Nach Unterbindung der Arterie und Vene des linken Ohres eines 8 Monate alten Kaninchens treten nach subkutaner Injektion von Brillantrot-Olivenöl die gleichen Veränderungen wie beim Versuche Nr. 9 auf, vielleicht aurch das Ödem etwas stärker ausgesprochen. Wir finden auch hier epitheliom-, trichoepitheliomähnliche Bildungen, Keratosis follicularis-ähnliche Wucherungen, ferner eine geringe Vergrößerung der Talgdrüsen.

16. Versuch. Subkutane Injektion von BrillantrotAqua dest. $(0 \cdot 5: 150)$ in die rechte 0 hrinnenfläche eines äl teren Kaninchens (Nr. 252). 18./IX, 1910 .

Versuchsdauer 3 Monate and 11 Tage vom 7./VI. 1910 bis

Klinisch und histologisch finden wir bei diesem Versuche die gleichen Veränderungen wie beim Versuch 9 (Brillantrot-Olivenöl), nur sind die Epithelproliferationen bei Injektion von Brillantrot-Aqua dest. etwas geringer ausgesprochen.

17. Versuch. Sabkutane Injektion von KrapplackOlivenöl $(3 \cdot 0: 300)$ in die rechte Ohrinnenfläche eines älteren Kaninchens (Nr. 18).

19./III. 1910. Injektion.

22./III. 1910. Beginnende Nekrose an einzelnen Quaddeln.

tische Herde. $12 . /$ 1V. 1910. Die nekrotischen Stellen sind in Ausheilung begriffen.

25./IV. 1910. Exzision der Hautstücke und Fixierung in $10 \%$ igem Formol. Versuchsdauer 37 Tage.

Histologische Uatersuchung: Die wichtigsten Veränderungen spielen sich an der Ohrinnenfläche $a b$, im Ohrknorpel befindet sich eine Lücke. Die Injektionsmasse reicht nicht bis an das Rete Malpighii, sie befindet sich in den untersten Schichten der Kutis, es sind deshalb auch hier die wichtigsten Gewebsveränderungen zu beobachten. Es überwiegen die entzũndlichen Erscheinungen der Kutis gegenüber den proliferierenden der Epidermis. Neben geringer Verbreiterung des Rete Malpighii und Epithelzystenbildung, mäßiger Vergrößerung der Talgdrüsen, erscheinen die Blut- und Lymphgefäße stark erweitert. Die elastischen Fasern sind durch das entzündliche Infiltrat größtenteils zugrundegegangen.

In der Tiefe der Kutis lassen sich vereinzelte Epithelinseln nachweisen. Die entzündlichen Erscheinungen in der Kutis sind im Abklingen begriffen und geben das Bild eines jungen Granulationsgewebes mit reichlicher Bildung von Fremdkörper- und Riesenzellen und reichlicher 
Ansammlung von Farbstoff in diesen, sowie in und zwischen den Bindegewebszellen. Ferner findet sich Farbstoff in größerer Menge um die Lücken und Maschen, die durch Farbstoffinjektion entstanden sind und Farbstoff-Depots enthalten.

Die Verbreiterung und Proliferation des Rete Malpighii ist nichtsostark wiebei den Injektionsversuchen von Scharlachrot-oder Brillantrot-0livenöl.

18. Versuch. Subkutane Injektion von KrapplackOlivenöl $\left(3 \cdot 0: 30^{\circ} 0\right)$ in die linke Ohrinnenfläche eines vier Monate alten Kaninchens (Nr. 230).

Versuchsdauer 1 Monat 7 Tage (vom 2./V. 1910 bis 9./VI. 1910).

Das Resultat der histologischen Untersuchung ist das gleiche wie beim Versuch 17. Die Fremdkörper- und Riesenzellen haben dasselbe Aussehen wie beim Versuch mit Scharlachöl.

19. Versuch. Subkutane Injektion von AzofarbeOlivenöl (30:300) in die linke Ohrinnenfläche eines älteren Kaninchens (Nr. 333).

Versuchsdauer 37 Tage (vom 19./III. 1910 bis 25./IV. 1910).

Aus diesem Versuche läßt sich die Tatsache konstatieren, daß; wenn die chemisch irritierende Injektionslösung nicht bis an das Rete Malpighii reicht, die Proliferation hauptsächlich von den Haarwurzelscheiden oder Talgdrüsen ausgeht. Die Epithelzyste bezieht dann ihr Zellmaterial von den Anbangsgebilden der Haut. Wir finden hier keine epitheliom-, keine Keratosis follicularis-ähnlichen Bildungen; im Zellinfiltrat der Kutis zahlreiche Fremdkörper- und Riesenzellen nachweisbar.

20. Versucb. Subkutane Injektion von AlizarinOlivenöl $(3 \cdot 0: 300)$ in die rechte Ohrinnenfläche eines älteren Kaninchens (Nr. 333).

Versuchsdauer 37 Tage vom 19./III. 1910 bis 25./IV. 1910. ändert.

Histologische Untersuchung: Die Ohrinnenfläche ist unver-

Bei diesem Versuche finden wir in der Kutis Abszeßhöhlen, in der Umgebung derselben reichliche Ansammlung von Fremdkörper- und Riesenzellen, keine epitheliom-, keine Keratosis follicularis-ähnlichen Bildungen, keine Epithelzysten. Es überwiegen die reaktiv entzündlichen Erscheinungen im Kutisgewebe, während die epitheliale Proliferation nicht zur Geltung kommt.

21. Versuch. Subkutane Injektion von Mennige 3*0:30.0 0livenöl in die linke 0hrinnenfläche eines älteren Kaninchens (Nr. 21).

Versuchsdauer vom 19./III. 1910 bis 25./IV. 1910 (37 Tage).

Bemerkenswert erscheint bei diesem Versuche die geringe Proliferation des Rete Malpighii, die starken entzündlichen Erscheinungen in der Kutis mit beträchtlicher Fremdkörper- und Riesenzellenbildung im Vergleich zu den Injektionsversuchen mit Anilinfarbstoffen.

22. Versuch. Subkutane Injektion von Säuregelb Olivenöl (1.0:30.0) in die linke Ohrinnenfläche eines jungen Kaninchens (Nr. 481).

Die Versuchsdauer beträgt 28 Tage (vom 20./I. 1910-17./II. 1910). Die exzidierten Hautstücke werden in $10 \%$ Formol fixiert. Das Resultat 
dieses Versuches besteht in einem durch Nekrose resp. Perforation des Ohrlappens entstandenen Ulkus mit kallösen Kändern. Die histologische Untersnchung des kallösen Randes ergab das gleiche Resultat wie beim Versuch 2.

23. Versuch. Subkutane Injektion von SäuregelbOlivenöl $(10: 30 \cdot 0)$ in die linke Ohrinnenfläche eines jungen Kaninchens ( $\mathrm{Nr} .18$ ).

17./I. 1910. Injektion.

28./II. 1910. Zwei Ulzerationen an Stelle der Quaddeln.

9./III. 1910. Status idem.

12./III. 1910. Die exzidierten Hautstücke werden in 10\%igem Formol fixiert. Die Versuchsdauer beträgt 23 Tage.

His tologische Untersuchang: Die Hauptveränderungen spielen sich am Übergang der Ohrinnenfläche in die Ohraubenfläche an einer Falte ab." $\mathrm{Zu}$ dresem histologischen Bilde gehören die pathologische Epithelproliferation mit Epithelzystenbildung, Keratosis follicularis-ähnliche Bildungen, bedeutende Vergrößerung der Talgdrüsen, entzündliches Infiltrat in der Kutis ohne Riesenzellen, besonders in der Umgebung der Farbstoff-Depots, ferner Erweiterung von Blut- und Lymphgefäßen.

24. Versucb. Subkutane Injektion von SäuregelbOlivenöl $\left(1^{\circ} 0: 30^{\circ}(0)\right.$ eines älteren Kaninchens (Nr. 21).

19./III. 1910. Injektion.

22./III. 1910. An einzelnen Quaddeln beginnende Nekrose.

5./IV. 1910. Auf der Ohrinnenfläche oberflächliche Nekrose an Stelle der früheren Quaddeln.

12./IV. 1910. An Stelle der früheren nekrotischen Stellen sieht man drei ausgeheilte Ulzera.

25./IV. 1910. Exzision der Quaddeln und Ulzera, Fixierung in 10\% igem Formol. Versuchsdauer 37 Tage.

Histologische Untersuchung: Die Obraußenfläche ist intakt. An der Ohrinnenfläche ist der Entzündungsprozeß bereits im Abklingen begriffen. Mäßige Epithelproliferation und Epithelzystenbildung, mäßige Vergrößerung der Talgdrüsen. Im Zellinfiltrat keine Plasma- und Mastzellen, spärliche Fremdkörper- and Riesenzellenbildung.

25. Versuch. Subkutane Injektion von Gelblicht Olivenöl $(30: 30 \cdot 0)$ in die innere obrinnenfläche eines vier Monate alten Kaninchens (Nr. 230).

Versuchsdauer 38 Tage (vom 2./V. 1910-9./VI. 1910).

Makroskopisch ist die Ohraubenfläche frei von Veränderungen, während die Ohrinnentäche Quaddeln zeigt, die zum Teil nekrotisch sind, in deren Umgebung follikulär angeordnete, warzige Exkreszenzen unter dem Bilde der Keratosis follicularis auftreten.

Das Resultat der histologischen Untersuchung ist ein ähnliches wiebeim Versuch 1 und 9. Die Epithelproliferationen sind nicht so ausgedehnt wie nach Scharlachöl- und Brillantrotölinjektionen. Die Fremdkörper- und Riesenzellenbildung ist entsprechend dem Gehalt an Farbstoffkristallen ziemlich bedeutend. In der Kutis finden sich an einzelnen Stellen dichte, haufenförmige Ansammlungen von polynukleären Leukozyten, die als miliare Abszesse anzusprechen sind. Die Nekrosen finden sich an der Kuppe der Quaddeln und führen zu einer Perforation der Zysten nach außen. Aus einer solchen Perforation ragen anfgelockerte Hornschichtlamellen und Farbstoffmassen hervor. 
26. Versuch. Subkutane Injektion von GrünerlackOlivenöl $\left(3.0: 30^{\circ}\right)$ in die linke Ohrinnenfläche eines vier Monate alten Kaninchens (Nr. 267).

2./V. 1910. Injektion.

12./V. 1910. Die meisten Quaddeln zeigen Nekrose, die Farbemulsion kommt nach außen; einzelne Intiltrate erhalten.

20./V. 1910. Der gleiche Befund.

9./VI. 1910. Lahlreiche Knoten, in der Ungebung derselben kleinste follikulär angeordnete Knötchen (Keratosis follicularis). Die exzidierten Hautstücke werden in 10\% Formol fixiert. Versuchsdauer 38 Tage.

Bei diesem Versuche finden wir eine pathologische Proliferation des Rete Malpighii mit Epithelzysten, sowie Hohlräume, die durch die Injektion der Farbstoff-Emulsion entstanden sind, ferner ein dichtes Zellinfiltrat in der Kutis, in dem besonders die zahlreichen Fremdkörperzellen mit dem phagozytierten Farbstoffaufallen.

27. Versuch. Subkutane Injektion von Säuregrün. olivenöl (3:30) in die linke ohrinnenflächeeines jungen Kaninchens.

20 /I. 1910. Injektion.

28./1. 1900. Auf der linken Ohrinnenfläche mehrere Geschwüre, aus denen sich eine eiterähnliche Masse entleert, Auberdem Geschwüre, die zur Perforation des Ohrlappens geführt haben.

31./I 1910. Die Eiterung schreitet weiter vor.

10./II. 1910. An mehreren Stellen bricht der Eiter durch, Ulzera mit Krusten bedeckt.

17./II. 1910. Eine ovale, die ganze Dicke des Ohrlappens einnehmende Perforation mit kallösen Rändern. Auf der Ohrinnenfläche mehrere Öffnurgen, aus denen sich eine weiBlich-ölige Masse herauspressen läßt. Die Versuchsdauer beträgt 28 Tage. Die exzidierten Hautstücke wurden in $10 \%$ Formol fixiert.

Entsprechend dem makroskopischen Verhalten spielen sich die Veränderungen sowohl an der Ohran@en- als -innenfäche ab.

Das Resultat dieses Versuches mit subkutaner Injektion von Säuregrün-Olivenöl ist das gleiche wie bei Injektion yon Scbarlachöl und Brillantrot-Olivenöl, nur da sich im Zellinfiltrate im Gegensatz zu den früberen Versuchen, hier keine Fremdkörper-und Riesenzellen nachweisen ließen. Letztere Tatsache läßt sich wahrscheinlich auf den Umstand zurückführen, daß der Farbstoff Säuregrün (Triphenylmethanfarbstoff) keine Kristallbeimengungen, im Gegensatz zu Scharlachrot und Brillantrot, enthält.

28. Versuch. Subkutane Injektion von SäuregrünOlivenöl $(30: 30 \cdot 0)$ in die linke 0 hrinnenfläche eines jungen Kaninchens (Nr. 76).

17./II. 1910. Injektion.

28./I. 1910. An mehreren Stellen der Ohrinnen- und -AuBenfläche auf der Kuppe der quaddelähnlichen Gebilde grauverfärbte nekrotische Massen.

9./III. 1910. Status idem.

12./III. 1910. Exzision der Hautstücke und Fixierung in 10\% Formol. Versuchsdauer 23 Tage. 
Histologische Untersuchung: Die Veränderungen beziehen sich hier sowohl auf die Ohraußen- als auch Ohrinnenfläche. Die pathologischen Epithelproliferationen sind bei den Versuchen mit Säuregrün und Säuregelb (von Kristallen befreit) geringer als bei Scharlachrot und Brillantrot.

Bei diesem Versuche fällt außer der pathologischen Epithelproliferation und Epithelzystenbildung die reichliche Bildung von Fremdkörper- und Riesenzellen und ihre außerordentliche Größe besonders auf. Die histologische Untersuchung eines kallösen Randstückes von einem den Ohrlappen perforierten Ulkus ergab den gleichen Befund wie bei den Versuchen 2 und 22.

29. Versucb. Subkutane Injektion von Säuregrün 30 : $30^{\circ} 0$ Olivenöl in die linke Ohrinnenfläche eines älteren Kaninehens. (Nr. 18.)

19./III. 1910. Injektion.

22./III. 1910. Quaddeln zeigen keine Veränderungen.

5./IV. 1910. An einzelnen Quaddeln Nekrose, an anderen Stellen wiederum derbe Knoten. An der Ohraubenfläche eine einhellergroße nekrotische Stelle.

12./IV. 1910. Die nekrotischen Stellen sind in Ausheilung begriffen, an einer Stelle eine dieke Schwiele palpierbar.

25./IV. 1910. Exzision der Hautsticke und Fixierung in $10 \%$ igem Formol. Versuchsdaner 37 Tage.

Histologische Untersuchung: Die Ohraußenfläche weist keine Veränderungen auf. An der Ohrinnenfläche finden wir anch hier eine pathologische Proliferation und Verbreitung des Rete Malpighii mit Epithelzystenbildung, im Innern derselben aufgelockerte Hornschichtlamellen. Die Epithelzysten hängen mit dem gewucherten Rete Malpighii zusammen, in letzterem deutliche Vakuolenbildung nachweisbar, mit Farbstoffkristallen in und zwischen den Zellen.

An einer Stelle der Ohrinnenfläche findet sich ein im Ausheilen begriffenes Ulkus, das von einem jungen, dichten Granulationsgewebe ausgefüllt wird. In der Kutis, besonders in der Nähe der durch die Injektionsmasse gebildeten Hohlräume sind die entzündlichen Erscheinungen bereits im Abklingen begritten, das Gewebe zeigt bereits das Aussehen eines jungen Granulationsgewebes mit stark erweiterten Blat- and Lymphgefäßen. In letzteren sind die Endothelien gequollen. Im Gewebe lassen sich keine Fremdkörper-, keine Riesenzellen, keine Mastzellen, wohl aber in Haufen angeordnete Plasmazellen nachweisen. Unterhalb des Ulkus verlaufen stark erweiterte Gefäße, die strotzend mit Blat gefüllt sind; auBerdem zahlreiche Hämorrhagien in der Kutis nachweisbar.

30. Versuch. Subkutane Injektion von reinem, sterilisiertem Olivenöl in dierechte Ohrinnenflächeeinesälteren Kaninchens (Nr. 469) (vergl. Tafel - Fig. 9).

7./VI. 1910. Injektion.

28./VI. 1910. Einzelne Quaddeln erhalten, einzelne nekrotisch.

12. ViI. 1910. Status idem.

25.VII. 1910. Auf der Obrinnenfläche einzelne Quaddeln nekrotisch, anßerdem ein derber Strang fählbar; an der Ohraußjenfläche ein Knoten sichtbar. 
18./IX. 1910. Die exzidierten Hautstücke werden in $10 \%$ igem Formol fixiert. Versuchsdauer 3 Monate und 11 Tage.

Histologische Untersuchung: Block 1. Die hauptsächlichsten Veränderungen zeigt die Ohraußenfläche. In der Kutis finden wir Hohlräume (Ölzysten), die nach Injektion von Olivenöl entstanden sind und geringe, entzündliche Reaktionserscheinungen in den Maschen und übrig gebliebenen Bindegewebsbrücken aufweisen. Im Zellinfiltrat finden wir gewucherte, fixe Bindegewebszellen, polynukläere Leukozyten, Lymphozyten, Plasmazellen. Die Bindegewebsbündel sind gequollen und durch Ödem auseinander gedrängt. Im Zellinfiltrat oder auch in der Nähe desselben kommen spärliche Riesenzellen vor, die sich durch ein vakuolisiertes Protoplasma und randständige Kerne auszeichnen. Diese, sowie die in Haufen vorkommenden Fettkörnchenzellen sind von gran-gelblicher Farbe und zart granuliert, geben im Gefrierschnitt bei Färbung mit Osmium, Sudan III, deutliche Fettreaktion. An manchen Stellen finden wir Keratosis follikularis-ähnliche Bilder, ferner eine pathologische Proliferation des Rete Malpighii. Die Ohrinnenfläche weist gleichfalls eine Verbreiterung des Rete Malpighii mit geringer Zapfenbildung und Epithelzysten auf, sowie eine Vergrößerung der Talgdrüsen. Der Ohrknorpel ist an einzelnen Stellen in Form von Inseln gewuchert.

Block 2. An der OhrauBenfläche finden wir eine ganz mäßige Verbreiterung der Haarwurzelscheiden, Ölzysten im Zellinfiltrat, gleichfalls Fettkörnchen- und Riesenzellen und kleine Haufen von Plasmazellen.

Block 3. Hier lassen sich die wesentlichsten Veränderungen an der Ohrinnenfläche nachweisen. Im gewucherten Ohrknorpel findet sich eine Lücke. Entsprechend der makroskopisch sichtbaren papelartigen Erhebung ist das Rete Malpighii verbreitert und mit plumpen oder breiten Zapfen versehen. In der Basalschichte läßt sich viel Pigment in Form von Körnchen nachweisen. Das entzündliche Infiltrat in der Cutis macht den Eindruck eines jungen Granulationsgewebes, Fettkörnchennnd Riesenzellen finden sich in der Umgebung der durch Injektion entstandenen Hohlräume, sowie der Gewebsspalten.

Block 4. Die Ohrinnenfläche zeigt eine bedeutende Prolifera* tion des Rete Malpighii mit Zapfenbildung; in der Reteschicht Mitosen, ferner polynukleäre Leukozyten in Durchwanderung begriffen. Die Haarwurzelscheiden sind verbreitert. In der Tiefe der Kutis Epithelinseln, die ein epitheliomähnliches Bild vortäuschen. Talgdrüsen vergrößert. In der Kutis läßt sich wiederum ein junges Granulationsgewebe nachweisen. An der Ohraußenfläche fallen uns wiederum die durch die Olivenölinjektion entstandenen Hohlräume (Ölzysten) auf, ferner geringe Keratosis follikularis-ähnliche Bildangen.

Block 5. Die Ohrinnenfläche zeigt außer einer Verbreiterung und Proliferation des Rete Malpighii reichliche Epithelzystenbildung. Im entzündlichen Infiltrat der Kutis sind auBer Fettkörnchen- und Riesenzellen, Plasmazellen in geringer Menge nach- 
weisbar, Ohrknorpel gewachert; in der Ohraußenfläche Ölzysten mit mäßigem Zellinfiltrat, sowie Fettkörnchen- und Riesenzellen.

31. Versueh ( $a$ und $b$ ). Subkutane Injektion von reinem, nicht sterilisiertem 0livenol in die rechte und linke Ohrinnenfläche eines jungen Kaninchens (Nr. 6).

5./VII. 1911. Injektion.

31./VII. 1911. Quaddelbildung deutlich ausgesprochen. Exzision der Quaddeln und Fixierung in 10\% igem Formol. Versuchsdauer 26 Tage.

Die histologische Untersuchung je eines Knotens von der rechten (Block $a$ ) und linken (Block $b$ ) Ohrinnenfläche ergab den gleichen Befund, In der Ohraußenfläche sind mehrere Hohlräume maschenartig angeordnet, durch die Injektion von Olivenöl entstanden, vorbanden. Diese sind von endothelähnlichen Zellen ausgekleidet. Um diese Hohlräume (Ölzysten) lagert sich ein entzündliches Infiltrat, das eine verhältuismäßig "geringe Ausdehnung hat, mit spärlichen Fettkörnchenzellen. In diesen Präparaten läßt sich keine Verbreiterung des Rete Malpighii sowie keine Epithelzystenbildung konstatieren.

32. Versuch. Subkutane Injektion von reinem, nicht sterilisiertem Olivenöl in die rechte und linke Ohrinneafläche eines 8-10 Monate alten Kaninchens (Nr. 94).

29./VII. 1912. Injektion an mehreren Stellen.

31./VII. 1912. Die Obrinnenfäche zeigt außer Quaddeln geringes ÖRem.

5./VIII. 1912. Einzeine Quaddeln perforiert, einzelne erhalten, zum Teil in Knoten umgewandelt.

20./VIII. 1912. Kaninchen ist eingegangen, die exzidierten Quaddeln und Knoten werden in 10\%igem Formol fixiert. Versuchsdauer 23 Tage.

Die histologische Untersuchung mehrerer Knotenvon diesen ejn in Serienschnitte zerlegter - ergab die gleichen Bilder wie bei den Versuchen mit den Anilinfarbstoffen und beim Versuch Nr. 30.

Die wichtigsten Veränderungen spielen sich in der Ohrinnenfläche ab (mäßige Epithelproliferation mit Vakuolenbildung in der Basalschichte, Epithelzysten, Wucherung der Talgdräsen), während wir in der Ohraußenfläche nur Hohlräume (Ölzysten), die Depots der Olivenölinjektionen, vorfinden. In der Umgebung derselluen lassen sich Fettkörnchen- und Riesenzellen nachweisen. Das Zellinfiltrat der Kutis ist sehr spärlich, keine Plasma- und keine Mastzellen nachweisbar, außer einer geringen Vermehrung der fixen Bindegewebszellen. Die Bindegewebsbündel sind gequollen und auseinandergedrängt, der Ohrknorpel stark gewuchert. In der Lücke des Ohrknorpels befindet sich ein AbszeB. Bei Färbung von Gefrierschnitten mit Osmium, sowie mit Sudan III zeigen die Fettkörnchenzellen die charakteristische Reaktion, ebenso die im Gewebe vorhandenen spärlichen Riesenzellen. Die mit Sudan III rot gefärbten Öltröpfchen befinden sich nicht nur in den öldepots, sondern auch in den Spalten der Bindegewebsbündel. Die Nervenfasern, ebenso die Knorpelzellen sind gleichfalls rot gefärbt. Die Blut- und Lymphgefäße sind mit Bakterien, die postmortal gewachsen sind, vollgepfropft, insbesondere an den Wandungen. 
33. Versuch. Subkutane Injektion von reinem, nicht sterilisiertem Olivenöl in die rechte und linke Ohrinnenfläche eines 8-10 Monatealten Kaninchens (Nr. 15).

29./VII. 1912. Injektion an mehreren Stellen.

31. VII. 1912, Kein Ödem. Quaddelbildung gering.

5./VIII. 1912. An freien Stellen der Ohrinnenfläche werden weitere Injektionen vorgenommen.

26./VIII. 1912. Einige Quaddeln deutlich erhalten, einzelne zu Knötchen umgewandelt.

6./IX. 1912. Status idem.

7./X. 1912. Auf der Ohrinnenfläche stecknadelkopf- bis linsengroße derbe Knötchen, vereinzelte an der Ohraufienfläche. Die exzidierten Hautstücke werden in $10 \%$ igem Formol fixiert. Versuchsdauer 2 Monate acht Tage.

Die histologische Untersuchung ergibt folgenden Befund: Die Ohrinnenfläche zeigt die Epidermis als schmales Band, in der Kutis liegen mehrere langgestreckte Epithelzysten, die von einem mäßig dichten Zellinfiltrat (gewucherte, fixe Bindegewebszellen, Lymphozyten, vereinzelte Plasmazellen, spärliche Fettkörnchenzellen) umgeben sind. Die Bindegewebsbündel sind gequollen und auseinander gedrängt, anßerdem Hohlräume (Ölzysten).

34. Versuch. Subkatane Injektion von reinem, sterilisiertem Olivenöl in die rechte und linke Ohrinnenfläche eines 8-10 Monate alten Kaninchens (Nr. 93).

26./VII. 1912. Injektion an mehreren Stellen.

29./VII. 1912. Ohrlappen diffus ödematös, an einzelnen Quaddeln beginnende Perforation.

31./VII. 1912. Ödem besteht noch weiter, Quaddeln deutlich erhalten.

5./VIII. 1912. Ödem geringer, Quaddeln deutlich.

26./VIII. 1912. An der Ohraußen- und -lnnenfläche stecknadelkopf- bis linsen- bis zehnlellerstückgroße Knötchen, sowie einzelne Quaddeln noch gut erhalten. Odem geschwunden.

6./IX, 1912. Status idem.

7./X. 1912. Die exzidierten Hantstücke werden in $10 \%$ igem Formol fixiert. Versuchsdauer 2 Monate 11 Tage.

Die histologische Untersuchung je eines Krotens (Block a) von der rechten und (Biock c) von der linken Ohrinnenfläche ergibt das gleiche Resultat wie beim Versuch $31 a$ und $31 b$.

Ein dritter Knoten der rechten Ohrinnenfläche (Block b) zeigt histologisch die Epidermis schmal, in der Kutis eine langgestreckte Epithelzyste, die in Verfolgung von lückenlosen Serienschnitten mit den Haarbalgdrüsen resp. Haarwurzelseheiden zusammenhängt; ein vierter Knoten (Block $d$ ) an der linken Ohrinnenfläche zeigt außer einer mäßigen Epithelproliferation die Öffnung der Epithelzysten durch das Deckepithel nach außen einwandfrei an Serienschnitten. Das die Epithel- und Ölzysten umgebende Zellinfiltrat, darunter Fettkörnchen- und vereinzelte Riesenzellen ist spärlich. Das Bindegewebe der Kutis, die Blnt- und Lymphgefäße zeigen die gleichen Veränderungen wie in dem Versuch 30 ,

35. Versuch. Subkutane Injektion von reinem, sterili. siertem Olivenöl in die rechte und linke Ohrinnenfläche eines 8-10 Monate alten Kaninchens (Nr. 24). 
26./VII. 1912. Injektion an mehreren Stellen.

29./VII. 1912. Ohrlappen ödematös, Injektion an freien Stellen.

31./VII. 1912. Quaddeln deutlich.

5./VIII. 1912 bis $7 . / \mathrm{X}$. 1912. Status idem.

14./X. 1912. Das stark abgemagerte Tier ist eingegangen, die exzidierten Hautstücke werden in $10 \%$ igem Formol fixiert. Versuchsdauer 2 Monate 18 Tage.

Histologis ch ergibt die Untersuchung eines Knotens (Block a) das gleiche Resultat wie die Versuche $31 a$ and $31 b$, während Block $b$ in der Kutis mehrere Epithelzysten aufweist:

36. Versuch. Subkutane Injektion von reinem, sterilisiertem Olivenöl in die rechte und linke Ohrinnenfläche eines 8-10 Monate alten Kaninchens (Nr. 97).

26./VII. 1912. Injektion an mebreren Stellen.

29.VII. 1912. Ohrlappen odematös, Injektion an freien Stellen.

5./VIII. 1912. Zwei Quaddeln perforiert, die meisten Quaddeln deutlich erhalten.

26/VIII. 1912. Quaddeln kleiner als nach der Injektion.

6./IX. 1912. Auf der Ohrinnen- weniger der Außenfläche Quaddeln und derbe Knoten von Stecknadelkopf- bis Linsen- und Bohnengröße.

7./X. 1912. Status idem.

21./X. 1912. Tier stark abgemagert, die exzidierten Hautstücke werden in $10 \%$ igem Formol fixiert. Versuchsdauer 2 Monate 25 Tage.

Die histologische Untersuchung eines in Serien zerlegten Knotens bestätigte in der Ohrinnenfläche den Zusammenhang der in der Kutis gelegenen Epithelzysten mit den Talgdrüsen und dem Deckepithel, das Epithel selbst ist nicht verbreitert. Ohraußenfläche enthält Ölzysten mit spärlichen Fettköruchenzellen in der Umgebung.

37. Versueh. Subkutane Injektion von reinem, sterilisiertem Olivenöl in die rechte und linke Ohrinnenfläche eines 8-10 Monate alten Kaninchens (Nr. 54).

31./VII. 1912. Injektion an mehreren Stellen.

5/VIII. 1912. Quaddeln gut erhalten.

26./VIII. 1912. Quaddeln etwas kleiner.

9.IX. 1912. Status idem. Quaddeln gut erhalten, vereinzelte Knötchen vou Stecknadelkopf- bis Linsengröße.

9./X. 1912. Tier eingegangen. Versuchsdauer 2 Monate 9 Tage.

Histologisch finden wir in der Obrinnenfläche die gleichen Veränderungen wie beim Versuch 33, geringe Epithelproliferation des Rete, sowie eine in der Cutis eingelagerte, langgestreckte Epithelzyste, in der Ohraußenfläche Ölzysten mit in der Umgebung befindlichen spärlichen Riesenzellen.

38. Versuch. Subkutane Injektionvon reinem, sterilisiertem Olivenöl in die rechte und linke Ohrinnenfläche eines 8-10 Monate alten Kaninchens (Nr. 61).

31./VII. 1912. Injektion an mehreren Stellen.

5./VIII 1912. Quaddeln gut erhalten.

26./VIII. 1912. Quaddeln kleiner.

6./X 1912. Anf der Ohrinnenfäche Quaddeln gut erhalten, einzelne von diesen zu derben, kleinen Knoten umgewandelt, vereinzelte auf der Ohraußenfläche.

7./X. 1912. Status idem. 
15./X. 1912. Das stark abgemagerte Tier ist eingegangen. Versuchsdauer 2 Monate 15 Tage.

Die Untersuchung eines Knutens (Block a) ergab histologis ch das gleiche Resultat wie bei den Versuchen 33 nnd 37, eine in der Kutis gelegene, langgestreckte Epithelzyste, die Epidermis schmal und nicht proliferiert. Die Untersuchung eines zweiten Knotens (Block b) ergab das gleiche Resultat wie in den Versuchen $31 a$ und $31 b, 34 a, 34 c$.

\section{Epikrise.}

\section{Zusammenfassung meiner Versuchsresultate.}

Die Injektionsversuche mit Scharlachrot-Olivenöl (Scharlachöl) haben zu dem Ergebnisse geführt, daß nach subkutaner Injektion von Scharlachöl in die innere Obrfläche von Kaninchen histologisch sich eine pathologische Epithelproliferation des Rete Malpighii mit Epithelzysten und Vergrößerung der Talgdrüsen nachweisen läßt. Diese Veränderungen bieten jë nach dem Sitze der Farbstoff-Depots in der Ohraußen- und -innenfläche, je nach der Lage im Stratum papillare, subpapillare oder in den tieferen Schichten der Kutis oder in der Nähe der Haarwurzelscheiden, ein der Keratosis follikularis (Lichen pilaris) ähnliches Bild dar, das bei reichlicheren Epithelleisten von manchen Autoren auch als epitheliom-, trichoepitheliom-ähnlich beschrieben wird. In der Nähe der Zellinfiltrate, sowie der Epithelzysten lassen sich Riesen- und Fremdkörperzellen nachweisen. Mit Scharlachöl erzielte ich stets das gleiche Resultat in den Versuchen 1. 2, 3, 4, 5, 6, 7, mit Scharlachrot-Aqua destillata dasselbe Resultat wie in Versuch 8.

Die pathologischen Epithelproliferationen zeigten bei verschieden altrigen Tieren kaum einen nennenswerten quantitativen Unterschied; vielleicht waren die Reaktionserscheinungen in loco bei jüngeren Tieren etwas stärker als bei älteren. War das Scharlachrot in destilliertem Wasser suspendiert, so erhielt ich die gleichen Bilder wie bei einer Scharlachöl-Emulsion, nur daß bei letzterer die Veränderungen noch etwas stärker ausfielen. Nach Unterbindung der Arterie und Vene am Ohr und nachfolgender Injektion trat zunächst ein starkes Ödem des ganzen Ohres auf; die histologisch nachweisbaren Epithelwucherungen waren dabei 
bedeutend stärker als bei Tieren ohne Unterbindung der Gefäße.

Die mit Brillantrot-Olivenöl in gleicher Weise wie mit Scharlachöl ansgeführten Versuche $(9,10,11,12,13,14$, 15), sowie der Versuch 16 mit B rillantrot-A qu a dest. ergaben das gleiche Resultat wie die Scharlachölversuche, nur war die Proliferation im Versuch 16 quantitativ etwas geringer ausgesprochen. Ebenso zeigt der Versuch 15 nach Unterbindung der Gefäße am Ohr eine stärkere Proliferationstendenz des Epithels.

Die pathologischen Epithelwucherungen sind bei den Versuchen mit Brillantrot stärker akzentuiert als die in gleicher Weise ausgeführten Versuche mit Scharlachrot. Einen Unterschied im histologischen Bilde fand ich, außer der stärkeren epithelialen Wucherung bei Brillantrot, in dem massenhaften Auftreten von Fremdkörperzellen bei letzterem im Gegensatz zu Scharlachrot. Während nun bei Scharlachrot nur wenige Kristalle als Beimengungen nachzuweisen sind, so finden sich solche bei Brillantrot in außerordentlich großer Menge. Es scheint, daß das relative spärliche Auftreten von Fremdkörperzellen bei den Versuchen mit Scharlachölinjektionen und das gehäufte Auftreten von Fremdkörperzellen bei den Brillantrot-Versuchen damit zusammenhängt. Über das Aussehen, die Form und die sonstigen biologischen Eigenschaften habe ich bereits im histologischen Teile Erwähnung getan. Die Fremdkörperzellen bei Brillantrot unterscheiden sich von denen nach Scharlachrot durch die stärkere Phagozytose von Kristallen und verleihen dadurch dem Protoplasma ein granuliertes Aussehen.

Ebenso zeigten die Versuche mit Krapplack-Olivenöl (17 und 18) eine vollständige Übereinstimmung mit den Scharlachöl- und Brillantrot-Olivenöl-Versuchen.

Eine geringere epitheliale Proliferation mit Überwiegen der entzündlichen Erscheinungen in der Kutis (Abszeßbildung) ließen die Versuche 21 (Mennige-Olivenöl), sowie vollständiges Fehlen der Epithelwucherung in den Versuchen 19 (Azofarbe-Olivenöl) und 20 (Alizarin-Olivenöl) erkennen. 
Die Versuche mit Gelblicht-Olivenöl (22, 23, $24,25)$ ergaben ein positives Resultat, wie Versuch 27 (vgl. Tabelle II.)

Ein analoges Bild erzielte ich in Versuch 26 nach Injektion von Grünerlack-O livenöl. Ähnliche histologische Befunde ergaben sich bei den Versuchen 27 und 29 mit Säuregrün-Olivenöl, nur daß die Fremdkörper- und Riesenzellen fehlten, während ich beim Versuch 28 das gleiche Bild mit großen Fremdkörpern- und Riesenzellen erhielt. Das Auftreten von Fremdkörper- und Riesenzellen beim Versuch 28 ist wahrscheinlich auf das Vorhandensein von vereinzelten Kristallen oder größeren Farbstoffkörnchen zurückzuführen, die beim Versuch 27 und 29 nicht vorhanden waren, also keinen Anlaß zur Fremdkörper- und Riesenzellenbildung geben konnten.

Nach Injektion von reinem, nicht sterilisiertem Olivenöl erhielt ich in den Versuchen 30,32, 33, sowie nach Injektion von reinem, sterilisiertem Olivenöl (Versuche $34 b, 34 d, 35 b, 36,37,38 b$ ) mit gewissen quantitativen Unterschieden das gleiche Resultat wie nach Injektion von Farbstoffemulsionen: Epithelproliferation, Epithelzysten, Fettkörnchen- und Riesenzellen usw. bei einer Versuchsdauer von 23 Tagen bis 2 Monate 18 Tagen bis 3 Monate und 11 Tage. In den Versuchen $31 a, 31 b$, $34 a, 34 c, 35 a, 38 a$ hatte ich außer Ölzysten ein negatives Resultat in bezug auf die Epitelproliferation und Epithelzystenbildung zu verzeichnen. Außer dieser durch Olivenölinjektion bedingten epithelialen Wucherung wäre noch die Wucherung des Ohrknorpels, sowie das reichliche Auftreten von Fettkörnchen- und Riesenzellen in der Nähe der Epithel- und Ölzysten, sowie die Phagozytose von Öltröpfchen durch einzelne zellige Elemente (Lymphozyten, polynukleäre Leukozyten, Riesenzellen) besonders hervorzuheben.

\section{Versuchsresultate der anderen Autoren.}

Sämtliche Autoren, die sich mit der Frage der experimentellen Erzeugung von Epithelwucherungen beschäftigten, stimmen in der Tatsache überein, daß es sowohl mit Schar- 
lachöl, als auch mit chemisch dem Scharlach $\mathrm{R}$ verwandten, aber auch vollständig verschieden konstituierten Stoffen gelingt, solche Epithelproliferationen zu erzeugen. ${ }^{1}$ )

Nur in bezug auf die Ätiologie der Wucherung ist bisher kein einheitlicher Gesichtspunkt (W a cker und S chmincke) erzielt worden. B. Fis cher, Stoeber, Rutschinski, Benthin halten für den auslösenden Faktor der Wucherung chemische (chemotaktische) Reize der injizierten Substanzen, ohne jedoch diese Reize näher zu definieren (l. c. Wacker und Schmincke, Münchner med. Wochenschrift 1911, Nr. 30 und 31). Jores spricht ebenfalls nur von einer Reizung des Epithels. Stahr nimmt einen Komplex von Ursachen an, unter denen die anatomische Beschaffenheit des Injektionsortes eine große Rolle spielen soll. Stoeber und Wacker denken an eine Änderung des Zellchemismus des Epithels infolge der Injektion, welche die Wucherung im Gefolge haben soll. Nach $v$. W ys s beruht die wachstumsanregende Wirkung der Injektion in dem Ausschluf des Epithels ron der normalen Ernährung. A. W. Me yer spricht, wie bereits früher erwähnt wurde, Zirkulationsstörungen und nachfolgende Entzündung als Ursache der Wucherung an. Dieser Ansicht Mejers, daß Zirkulationsstörungen von ursächlicher Bedeutung für das Zustandekommen der Epithelwucherungen sind, schließen sich Wacker und Schmincke auf Grund der Versuche von Schmincke und Greischer nicht an. Nur bei venöser Hyperämie kann nach diesen Autoren von einer unterstützenden, nicht ursächlichen Wirkung derselben gesprochen werden.

Takeyoshi Mori, sowie Ishio Haga glauben auch, daß diese atypischen Epithelwucherungen als eine entzündliche Reaktion, die durch einen Reiz seitens des Scharlachsöl usw. ausgelöst würde, aufzufassen sei, weil nach den Versuchen Moris zuerst nach der Injektion zwischen der Epidermis und dem Knorpel eine starke Entzündung entsteht und die Keinschicht der Haarbälge, welche sich in diesem Entzündungsbezirk befindet, viele Kernteilungsfiguren aufweist.

1) Bay on, H. berichtet über epitheliale Wuchexungen durch Injektion von Teer. The Lancet. 7. Dec. 1912. 


\section{Bedeutung der Versuche für die Pathologie im allgemeinen und das Krebsproblem im besonderen. Vergleich meiner Ver- suche mit denen der anderen Autoren.}

Zur Pathogenese dieser Versuche möchte ich in bezug auf den zeitlichen Ablauf der einzelnen Entwicklungsstadien folgendes anführen:

Injiziert man subkutan eine gesättigte Scharlachöl-Emulsion, so diffundiert die Farbstoff-Emulsion von der Stelle ihres Depots und bringt zunächst das umliegende Bindegewebe zur Entzündung und zur Nekrose, während die Farbstoffkristalle zur Bildung von Fremdkörper- und Riesenzellen Veranlassung geben.

Nach einigen Tagen findet eine Vermehrung der Mitosen der Keimschicht und zwar sowohl am Deckepithel als auch an den Haarbälgen und Talgdrüsen statt. Auch atypische Mitosen finden sich. Die Epithelneubildung wird immer stärker, die Keimschicht proliferiert und bildet Zapfen. Diese in die Tiefe wuchernden Epithelzapfen wachsen nun in der unregelmäßigsten Weise. Außer dieser pathologischen Epithelproliferation ist die Entwicklung der Epithelzysten besonders $\mathrm{zu}$ besprechen.

Dieselben haben eine verschiedene Genese, das einemal entstehen dieselben aus $\mathrm{Abszedierungen,} \mathrm{das} \mathrm{anderemal}$ durch Erweiterung der Talgdrüsen, Follikel, Haarwurzelscheiden durch Anhäufung von Hornmassen, eine Art Retentionszysten.

Bei der einen Art von Epithelzysten entsteht durch Nekrose und Entzündung des Gewebes ein Abszeß, dessen Wand von in seinen Bereich gelangten Epithelien des Rete oder der Talgdrüsen oder der Haarwurzelscheiden ausgekleidet wird. Diese Epithelauskleidung hat in der Regel mehr minder die Form einer Flasche, wie man auf Serienschnitten sehen kann; der Bauch derselben entspricht der epithelisierten Abszeßhöhle, der Hals dem Epithelrohr.

Als Beweis für die Epithelialisierung des Abszesses kann angeführt werden, daß sich der ursprünglich in der Tiefe der Kutis befindliche AbszeB immer mehr dem Rete Malpighii nähert und dieses ganz nahe berührt. Die in der Nähe ron bereits 
epithelisierten Abszessen, fertigen Epithelzysten, befindlichen kleineren Abszesse werden sekundär von der Epithelzystenwand oder den in der Nähe befindlichen Anhangsgebilden der Haut epithelisiert. Man sieht an Serienschnitten, wie solche Epithelleisten aus der Zystenwand ausgehen und in Form einer Gabel die Abszeßhöhle einzusäumen beginnen.

Zum Unterschiede von diesen Epithelzysten mit abszeßähnlichem Inhalt müssen wir noch eine zweite Art von Epithelzysten unterscheiden, die in ihrem Innern gewucherte, konzentrisch angeordnete Hornschichtlamellen, abgestoßene Epithelien, Talg- und Farbstoffreste enthalten und ihren Ausgangspunkt von den Haarbalgdrüsen nehmen und gleichfalls nach außen münden. Wir begegnen sowohl solchen einkämmerigen Epithelzysten als auch mehrkämmerigen, die miteinander kommunizieren. Diese öffnen sich entweder mit einer oder mehreren Öffnungen nach außen, im letzteren Falle sieht man zwischen zwei Öffnungen ein sogenanntes $Z$ wischenstück.

An Serienschnitten kann man die Entwicklung solcher Epithelzysten genau verfolgen und den Nachweis erbringen, daß sie in die Follikel, in die Haarbalgdrüsen, in die Haarwurzelscheiden münden oder im Zusammenhang mit dem Rete sich nach außen öffnen. Es besteht also stets eine Kommunikation der Epithelzysten mit dem Deckepithel oder den Anhangsgebilden der Haut.

An Serienschnitten läßt sich ferner einwandfrei der Beweis erbringen, daß die Epithelwucherung nicht nur von den Anhangsgebilden der Haut sondern auch vom Deckepithel ihren Ausgang nimmt. Die Bildung von Epithelzysten dagegen geht erst nach Exfoliierung des Abszesses und Berührung mit der Reteschicht vor sich oder nimmt von dem Epithel der Anhangsgebilde der Haut (K a ufmann, Mori, Haga) ihren Ausgang. An Serienschnitten konnte ich jedoch in keinem Präparate das Zustreben eines proliferierten Retezapfens durch die Kutis zum Öltropfen (F ischer) beobachten, sondern stets nur die sich an die Nekrose anschließende Exfoliierung des Abszesses mit nachfolgender Epithelisierung.

Von diesen im Stratum papillare resp. subpapillare befindlichen Epithelzysten sind noch solche Zysten zu unter- 
scheiden, welche durch Injektion von Farbst off-Emulsion entstandene Abszess e darstellen, infolge der Nekrose des Deckepithels nach außen durchbrechen und bei welchen die Epithelisierung des Kavum von den Wundrändern her erfolgt.

Ferner sehen wir ganz nahe dem Rete Malpighii gelegene, vom Epithel umschlossene und mit Hornschichtlamellen erfüllte Hohlräume. In der Schnittserie bekommen wir Bilder mit nach außen sich öffnenden Zysten. Aus solchen ragen dann die aufgelockerten Hornschichtlamellen heraus und täuschen Epithelzysten vor, die in Wirklichkeit den erweiterten, mit konzentrisch geschichteten Hornschichtlamellen erfüllten Follikeln entsprechen, in welch letzteren wir im Zentrum oder auch in dessen seitlichen Anteilen ein oder mehrere Lanugohaare finden. Dieses Bild entspricht dem der Keratosis follicularis (Lichen pilaris).

Von a $\beta_{\text {en }}$ auf die Epidermis aufgepinselt, wirkt das Scharlachöl nicht. Die Injektion des Scharlachöls bewirkt nach B. Fischer zunächst eine Veränderung des Bindegewebes, und die chemischen Substanzen wirken vom Bindegewebe aus auf das Epithel ein. Der weitere Verlauf des Fischerschen Experimentes gestaltet sich dann so, daß das Scharlachöl langsam aus den Epithelzystchen verschwindet, und zwar zuerst das öl, während der Farbstoff in ein Epithelnest abgeschieden wird. Kommt nun kein Öl mehr hinzu, dann verhornt der Epithelbaufen (Hornperlen), und es entstehen cholesteatomähnliche Gebilde, die nach außen durchbrechen können, oder bereits vorher perforiert waren.

Wie ich bereits des öfteren erwähnte, zeigen die verschiedenen Anilinfarbstoffe in ihrer Wirkung auf das Epithel nur quantitative Unterschiede, die sich auch ergeben, wenn wir als Vehikel statt des Olivenöls das destillierte Wasser verwenden.

Im Gegensatze zu W. A. Meyer, Stöber und Wacker, Greischer, Wacker und Schmincke erzielte ich nach Injektion von reinem, nicht sterilisiertem und reinem, sterilisiertem Olivenöl in der Mehrzahl der Versuche ein positives Resultat, analog den Versuchen nach Injektion von Anilinfarbstoff-Emulsionen. Die Ursache der chemischen Reiz- 
wirkung auf das Epithel ist wohl nicht in dem längeren Liegenbleiben des Olivenöls am Orte der Injektion zu suchen, da ich bereits bei einer Versuchsdauer von 23 Tagen ein positives Resultat erzielte. Vielleicht wäre die Annahme gerechtfertigt, daB das Olivenöl ranzig geworden ist, d. h. einen gewissen Säuregrad erreicht und a uf diese Weise die Proliferation des Epithels angeregt hat.

Außer diesen positiven Resultaten habe ich auch bei längerer Versuchsdauer (2 Monate und 18 Tage) negative zu verzeichnen. Auf welche Momente das Ausbleiben der Proliferation bei ein und demselben Versuchstier, anf ein und derselben Ohrinnenfläche zurückzuführen ist, kann ich nicht beantworten. Nur die Tatsache als solche möchte ich hier feststellen.

Ich schließe mich der Ansicht Borsts an, nach der die zuerst von Wacker und Schmincke hervorgehobene Eigenschaft, daß eine ganze Reihe der verschiedenartigsten Substanzen teils mit positivem, teils mit negativem Resultat zur Erzeugung von Epithelproliferationen zur Verwendung gelangt, eine sehr bemerkenswerte Tatsache darstellt. Die mit positivem Resultat zur Injektion benutzten Stoffe zeigen nach diesen Autoren die gemeinsame physikalische Eigenschaft, die Li p o i d lö s li ch k e it.

Bei den zur Injektion benützten fettigen und öligen Substanzen spielt nach W a cker und Sch mincke der Säuregehalt (Ranziditätsgrad) eine Rolle. Die ron Wacker und Stöber mit Indol und Skatol in Kaninchenfett erhaltenen ausgiebigen Wucherungen sind nach den jetzigen Erfahrungen von Wacker und Schmincke als additionelle Wirkungen des Indols-Skatols und Kaninchenfetts aufzufassen. Will man eine Substanz auf ihre proliferationsanregende Wirkung prüfen, so muß man dieselbe nach den Ausführungen der genannten Autoren in Olivenöl einspritzen. $\mathrm{Nach}$ meinen Resultaten bezüglich der Proliferationsfähigkeit von reinem, sterilisiertem und reinem, nichtsterilisiertem Olivenöl ist es notwendig, die zu prüfendenStoffe, z. B. Farbstoffe etc., nichtin Olivenöl a ufulösen oderzu suspendieren, sondernin Wasser, 
da wir ja sonst durch die proliferierende Eigenschaft des Olivenöls eine additionelle Wirkung erzielen. Ich verweise hier nur auf meine Versuche 1 und 9 , bei denen als Vehikel Olivenöl, sowie auf die Versuche 8 und 16, bei denen als Vehikel Aq. destill. verwendet wurde. Bei letzteren sind die Proliferationen bedeutend schwächer ausgefallen als bei den Versuchen 1 und 9. W a cker und S c h m in cke geben ja selbst zu, daß epithelanregende Substanzen in fettiger oder öliger Lösung besser wirken als in wässeriger.

Nach Greis chers Untersuchungen aus dem Borstschen Institut kommt den injizierten Stoffen die ausschlaggebende Rolle zu; ihre Wirkungsweise ist an einen längeren Kontakt mit den Epithelien gebunden. Zirkulationsveränderungen spielen nur insofern bei der Epithelwucherung mit eine Rolle, als sie eine längere oder kürzere Einwirkungsdauer der injizierten Substanzen auf das Epithel des Injektionsortes ermöglichen. Bei venöser Hyperämie kann von einer unterstützenden, nicht ursächlichen Wirkung derselben gesprochen werden. Wenn auch A. W. Me yer in der Zirkulationsstörung ein ursächliches Moment für die Proliferation des Epithels sieht und nach dieser Richtung vielleicht zn einseitig diesen Faktor hervorhebt, so gebührt doch A. W. Meyer das Verdienst, auf die Bedeutung der Zirkulationsstörung zuerst hingewiesen zu haben.

Bei meinen Versuchen 7 und 15 erhielt ich nach Unterbindung der Arterie und Vene an der Ohrwurzel und nachfolgender Injektion von Scharlach- oder Brillantrotöl zuerst ein sehr starkes Ödem des ganzen Ohres, die Wucherungen waren bedeutend stärker als bei den Versuchen ohne Unterbindung der Gefäße. Für gewisse Fälle von Ulcus cruris mit schweren Zirkulationsstörungen und chronischen Entzündungen kommen manchmal hyperkeratotische und verruköse Plaques zur Beobachtung (Nobl). Für solche Formen dürfte die Meyersche Ansicht wohl noch am ehesten Geltung haben.

Meine eigenen Versuche haben mich gelehrt, dabzweifelsohne der chemische Reiz den wichtigsten Faktor abgibt, der das Epithel nach subkutaner Injektion von Anilinfarbstoffemulsionen zur Proliferation bringt, aberauch demals Vehikel 
ben̈̈tzten Olivenöl kann nach meinen Versuchsresultaten eine Einwirkung nicht abgesprochen werden. Dazu kommen noch eine Reihe anderer Faktoren, wie Zirkulationstörung und Entzündung (Meyer), anatomische Beschaffenheit der Injektionsstelle (Stahr), kurzum ein Komplex von Ursachen (Benthin), welcheman zur Erklärung der Wucherungen anzuführengenötigt ist.

Ich halte in Übereinstimmung mit Fischer, Stoeber, Rutschinski, Benthin, Mori Haga u. a. nach meinen Versuchen für den auslösenden Faktor den chemischen Reiz der injizierten Substanzen. Über die Wirkungsweise des ursächlichen Momentes, d. i. der primären Auslösung des Wachstums (Borst) kann ich auf Grund meiner Versuche keine präzise Erklärung abgeben.

Für das Krebsproblem bedeuten diese Versuche insoferne eine wertvolle Stütze, als sie uns zeigen, welche Rolle der chemische Reiz im allgemeinen spielt, ferner daß es gelingt, histologisch Bilder zu erzielen, welche dem Krebs ähnliche Bilder vortäuschen. Schon aus diesem Grunde, ohne aus den rorhin angeführten Tatsachen für das Krebsproblem irgendwelche Schlüsse zu ziehen, sind die Fischerschen Versuche als bedeutsame, biologische Experimente auf dem Gebiete der Chemotaxis aufzufassen (Wolf $\mathrm{f}$ ).

Im folgenden möchte ich einige Worte über den Begriff "atypische Epithelwucherung anfügen. Mit diesem Namen bezeichnet C. Friedländer (zit. nach Marchand) die an allen Oberflächen- und Drüsen-Epithelien, besonders häufig an der Epidermis vorkommende Bildung unregelmäBiger, oft verästelter Zapfen, welche sich in die Unterlage hinein erstrecken. Nach Wolff (l. cfr. II. Bd. p. 54) ist die atypische Epithelwucherung nur ein anatomischer Begriff und erklärt in keiner Weise die Krebsgenese, da atypische Epithelwucherungen bei den mannigfaehsten Reizzuständen vorkommen! Es fehlt eben noch ein unbekannter Faktor, der die atypische Epithelwucherung zur Kresbildung führt.

Bei meinen Beschreibungen habe ich die Bezeichnung "atypische Epitbelwucherung“ durch die nichts präjudizierende 
„pathologische" ersetzt. Besteht doch bei allen diesen Versuchen eine vermehrte Epithelproliferation, da darf es uns nicht wundernehmen, wenn wir bei den. unregelmäßig verbreiterten und verlängerten Epithelzapfen Bilder antreffen, welche durch das Vorkommen von Epithelinseln und Hornperlen als epitheliomähnliche anzusprechen wären. Das wichtigste Argument, das gegen die Bezeichnung "atypische Epithelproliferation", wie wir sie beim Epitheliom antreffen, ganz abgesehen von dem Fehlen der Malignität, anzufübren ist, besteht in dem Fehlen der Anaplasie der Zellen.

Bei dem von mir beobachteten Fall IV ron papillomähnlichen Knötchen an der Haut nach Finwirkung von pulverförmigen, trockenen Anilinfarbstoffen konnte ich keinen Übergang in Karzinom beobachten. Diese maulbeerähnlichen Gebilde können sich auch spontan oder unter wenig eingreifender Therapie zurückbilden. Letztere Tatsache stimmt auch mit den experimentell erzeugten Knötchen und epitheliomähnlichen Wucherungen nach Einreibungen und Injektion von Anilinfarbstoffen überein.

Bei den Injektionsversuchen mit Anilinfarbstoffen kann man nach meinen Versuchen schon durch den histologischen Befund zwei parallel verlaufende Vorgänge unterscheiden: 1. die Farbstoffemulsion allein veranlaßt die pathologische Epithelproliferation und die Vergrößerung der Talgdrüsen; 2. die den Farbstoffen beigemengten Kristalle, die nur in sehr geringem $\mathrm{Maße}$ chemisch (Tonerdehydrat, ${ }^{1}$ ) fast ausschließlich mechanisch (Tonerdehydrat, Bariumsulfat) wirken, rufen hauptsächlich entzündliche Erscheinungen hervor und stehen wahrscheinlich zur Bildung der Fremdkörper- und Riesenzellen in ursächlicher Beziehung. Zu gleichen Resultaten gelangte auch Rutschinski (1910).

Bei der proliferierenden Wirkung der Farbstoff-Emulsion sind wiederum $z$ wei Faktoren beteiligt: 1. die Wirkung des Anilinfarbstoffs, 2. die des Olivenöls. Daher ist es notwendig, wie ich bereits früher auseinandergesetzt habe, bei der Prüfung einer Substanz auf

1) Die Wirküng von Tonerdehydrat auf das Gewebe der Kutis ist ähnlich der des Aleuronats (chemisch und mechanisch). 
ihre proliferationsanregende Wirkung dieselbe nicht in Olivenöl, sondern in Wasser suspendiert zu injizieren. Nur unter der Bedingung, daß die in Olivenöl aufgelösten Farbstoffe nicht länger als zwei Wochen an Ort und Stelle liegen bleiben, können wir das Olivenöl als Vehikel benutzen, weil bei dieser kurzen Versuchsdauer das proliferierende Moment des Olivenöls nicht zur Entfaltung kommt.

Will man nun aus einem histologischen Bild einen Rückschluß auf die zur Prüfung verwendeten Stoffe ziehen, so muß man sich vor gewissen Irrtümern in acht nehmen. Finden wir z. B. in einem histologischen Präparat Epithelzysten, die je nach der Schnittserie mit dem verbreiterten und proliferierten Rete Malpighii zusammenhängen oder nicht, so sind folgende Momente zu überlegen:

Von einer traumatischen Epithelzystenbildung, bedingt durch Verschleppung von Epithelnestern in die Tiefe beim Einstich der Nadel, kann ich nicht gut sprechen, weil ich für diese Entstehungsart der Epithelzysten keine Beweise anführen kann. Nach meinen Versuchen ist es feststehend und zwar durch genaue Verfolgung der Schnittserien, daß sich die eine Art von Epithelzysten durch Exfoliierung des Abszesses bis zum Rete Malpighii und nachfolgender Epithelisierung entwickelt, die andere Art von Epithelzysten von den Haarbälgen oder Haarwurzelscheiden ihren Ausgang nimmt. Von solchen Zysten sind jene zu unterscheiden, die sich nach Durchbruch einer durch Injektion von Farbstoffemulsion entstandenen Quaddel oder eines Abszesses entwickeln, wobei es nachträglich zu einer Epithelisierung von den Wundrändern her gekommen war.

Außer der chemisch wirkenden Komponenteder Farbstoffe haben wir bei diesen auch noch die mechanische in Betracht zu ziehen. Zur Zeit bin ich mit einer Reihe von Untersuchungen beschäftigt, die sich auf die Größe der mechanischen Komponente verschiedener Agentien beziehen, über deren Resultate ich in einer besonderen Arbeit berichten werde. Diese Versuche mit Injektion von Glasstaub, Bolus alba, Carbo animalis, Tonerdehydrat, Bariumsulfat in verschiedenen Vehikeln, Öl, Wasser usw. suspen- 
diert, schließen sich den Untersuchungen ron Marchand, Ribbert, Podwyssozki, Alexander Fraenkel, Fuerst E., Werner, R., Rutschinski, Deton, Greischer u. a. an. Auch habe ich vor, über das Vorkommen sowie die Genese der Fremdkörper- und Riesenzellen in dieser Richtung Versuche anzustellen.

Hier sei nur kurz darauf hingewiesen, daß sich Fremdkörper- und Riesenzellen nach subkutaner Injektion von Scharlachöl in die innere Ohrfläche in der Kutis finden und letztere als Fremdkörper-Riesenzellen aufzufassen sind. Entsprechend dem geringeren Gehalte des Scharlachrots an beigemengten Kristallen ist auch die Zahl der Fremdkörperund Riesenzellen bei den Scharlachölversuchen geringer als bei Brillantrot. Bei letzterem finden sich entsprechend der großen Zahl von Kristallen massenhafte Fremdkörperzellen im Gewebe. Sie haben eine graugelbe Farbe, sind vakuolisiert, das Protoplasma erscheint bei Untersuchung mit der Immersionslinse granuliert infolge der phagozytierten Kristalle, außerdem findet sich ein großer randständiger Kern. Diese Zellen färben sich im Gefrierschnitt sowohl mit Hämatoxylin-Sudan als auch mit Osmium, geben also die charakteristische Fettreaktion.

Wir bekommen aber auch Riesenzellen im Gewebe nach Injektion ron reinem, sterilisiertem und reinem, nicht sterilisiertem Olivenöl; auch diese Riesenzellen- sowie die Fettkörnchenzellen geben die Fettfärbung mit Osmium, Sudan III usw. Die Frage, ob und durch welche Art von Reizen dieselben entstehen, sowie über die Genese der Riesenzellen, gehören gleichfalls in das Gebiet der in einer anderen Arbeit $\mathrm{zu}$ besprechenden Untersuchungen.

Sow ohl nach Einreibung von Anilinfarbstoffen auf die Ohrinnenfläche, als a uch durch subkutane Injektion von Farbstoffemulsion bekamen wir nahezu analoge Bilder in bezug auf die Epithelwucherung, die als epitheliom- resp. trichoepitheliom-ähnlicheVeränderungenzubezeichnen sind. Wenn man diese experimentell erzeugten Gebilde wie ich schon wiederholt und ausdrücklich bemerkte - nicht als maligne Neoplasmen, sondern lediglich als Gewebsprolife- 
rationen entzündlicher Natur, hervorgerufen durch einen chemischen Reiz, anspricht, so ist doch die Tatsache auffallend, daß sowohl bei Einwirkung von außen - Einreibung - als auch bei Einwirkung von innen - subkutane Injektion von der Kutis her - durch ein und denselben chemischen Reiz histologisch die gleichen Bilder erzeugt werden.

Ribbert konnte kleine, aber typische papilläre Auswüchse an der Innenfï̈che der Kaninchenlippe dadurch erzeugen, dah er an bestimmten Stellen wiederholt die sich immer wieder regenerierende Epitheldecke bis zum Bluten abkratzte und dann schließlich heilen liels. Stahr, der - wie bereits erwähnt - die Versuche Fischers und Ribberts einer Nachprüfung unterzog, kommt zuं dem Schlusse, daß nicht nur ein "Reiz", sondern ein Komplex von Ursachen, unter denen die anatomische Beschaffenheit der Gegend eine große Rolle spielt, das Plattenepithel zur Proliferation gebracht hat.

Bezüglich der Ätiologie der Proliferation äußert sich Fuerst dahin: „Die hypertrophischen und hyperplastischen Prozesse sind nicht sowohl bedingt durch die formative Wirksamkeit des thermischen oder chemischen Reizes, als vielmehr durch primäre Gewebsläsion, und gehören in das Gebiet der exzessiven Regeneration." Nach O. Hertwig sind die Untersuchungen über (positiven und negativen) Chemotropismus ron großer Bedeutung auch für das Verständnis vieler Vorgänge im Körper der Wirbeltiere und des Menschen. R. Werner, der die Angaben $F u$ ersts über die wachstumsbefördernde Wirkung des Äthersprays nachprüfte, kommt zu dem Ergebnis, daß das Kältetrauma auf die Gewebe als Entzündungsreiz wirkt.

Aus diesen Mitteilungen Ribberts, Stahrs usw. wie auch aus meinen Versuchsresultaten geht demnach hervor, daß Reize verschiedener Art die gleichen Veränderungen hervorrufen.

\section{Welche Ausblicke gewähren meine Versuche für die atiologische und klinische Auffassung einiger Dermatosen?}

Ich habe bei meinen Einreibungs- und Injektions-Versuchen bei Kaninchen auf die Ähnlichkeit des klinischen und histologischen Bildes mit dem bei Keratosis follicularis 
(Lichen pilaris) beim Menschen auftretenden Krankheitsbilde des öftern hingewiesen.

Bei der äußeren Einwirkung geben die Farbstoffe den Reiz für die starke Wucherung des Stratum corneum in den Follikeln ab. Aus diesen ragen dann die einzelnen Zapfen, die der Hautoberfläche ein reibeisenähnliches Aussehen verleihen, hervor. Außer dieser exogenen Entstehungsart der Keratosis follicularis-ähnlichen Veränderungen kommt experimentell noch die subkutane in Betracht, welche wahr. scheinlich durch die Diffundierung der Farbstoffemulsion vom Depot der Injektionsstelle zu den Follikeln entsteht. Kristalle ließen sich in der Nähe der Follikel nicht nachweisen.

Die in der Pubertätszeit bei beiden Geschlechtern sich entwickelnde Dermatose hat ihren Sitz an der hinteren und äußeren Fläche der Oberarme und an der vorderen und äußeren der Oberschenkel, an der Haut der Hinterbacken und der Waden. Es sind kleine, stecknadelkopfgroße, trockene, hornartige, über den Mündungen der Haarfollikel sitzende Knötchen, nach deren Abkratzen ein zusammengerolltes Lanugohaar zum Vorschein kommt, und welche der Haut eine eigentümlich rauhe, trockene Beschaffenheit verleihen.

Da Anilinfarbstoffe bei subkutaner Injektion dieselbe Wirkung auf das Epitbel ausüben wie Eiweißfäulnisprodukte (Indol, Skatol usw.) undwie fettige und ölige Substanzen, so wäre die Vermutung denkbar, daß die Ursache des Auftretens der Keratosis follicularis in der Pubertätszeitbeim Menschen jene Hormone sein dürtten, die wir vielleicht auf den protektiven EinfluB der Keimdrüse beziehen könnten.

Hier möchteich nur in Parenthese anführen, daß nach den Farbstoffrersuchen die Möglichkeit ins Auge zu fassen und durch entsprechende Versuchezu erhärten wäre, ob nicht auch das melanotische Naevuspigment $t^{1}$ ) die Fähigkeit hat, Zellwucherungen anzuregen.

1) v. $\mathrm{Zumbusch}$ hat in einer Arbeit aus dem chemischen Univ.Institut. in Wien (Hofrat E. Ludwig) „Beiträge zur Charakterisierung 
Sowohl bei den Einreibungs- als auch Injektions-Versuchen habe ich die Vergrößerung der Talgdrüsen besonders hervorgehoben und gleichzeitig erwähnt, daß die Talgdrüsen, die anfänglich noch gut zu erkennen sind, allmählich in der Epithelwucherung aufgehen (Stoeber). Zuerst werden die Ausführungsgänge durch Wucherung des dieselben auskleidenden Epithels zu verdickten, plumpen Epithelzapfen, an deren Ende noch gut erhaltene, körnige Zellen des Drüsenkörpers sitzen. Letztere schwinden auch und gehen in der allgemeinen Wucherung auf, darauf bildet sich in den zentralen Partien Verhornung der Zellen aus, und zuletzt kann eine mit Hornmasse erfüllte Zyste resultieren.

Meine Versuche mit reinem, sterilisiertem und nicht sterilisiertem Olivenöl, sowie die von $\mathrm{W}$ a cker und $\mathrm{S} \mathrm{ch} \mathrm{mincke}$ mit verschiedenen fettigen und öligen Stoffen ausgeführten Untersuchungen haben nun in eindeutiger Weise gezeigt, daß es mit diesen Stoffen zu analogen Proliferationen des Epithels, sowie zur Vergrößerung der Talgdrüsen kommt, wie nach Injektion von Farbstoffemulsion.

Diese Versuche ron Wacker und Schmincke sowie meine Versuche geben vielleicht für die ätiologische Auffassung des Rhinophyma einen Weg we is er a b. Die meisten Autoren nehmen in der Ätiologie des Rhinophyma einen Komplex von ursächlichen Momenten an.

Dohi hat im Jahre 1896 in einer histologischen und klinischen Studie aus dem Institute $\mathrm{P}$ a l t a u $\mathrm{f}$ darauf hingewiesen, daß das Rhinophyma eine Krankheitsform darstellt, die in Erweiterung und Neubildung der Gefäße, Neubildung des Bindegewebes, Hypertrophie der Talgdrüsen ihre wesentlichen Momente findet. Welcher von diesen Prozessen aber der primäre, welche die sekundären sind, oder was überhaupt die Ursachen des Leidens ausmacht, darüber scheinen die Ansichten nicht ganz einig zu sein. Nach Dohis histologischen Untersuchungen

des Sarkommelanins vom Menschen" geliefert. Sigmund Fränkel hat in seinem Vortrage "Zur Chemie des Karzinoms" auf die Untersuchungen H. Eppingers "Über Melanurie" hingewiesen. Diesem Autor gelang es bei einem Falle von Melanosarkom, welcher die Erscheinungen der Melanurie zeigte, das Melanogen, das sich als ein Abbauprodukt des Tryptophans darstellt, zu isolieren.

Hneck, Werner. Pigmenstudien. Ziegler Beiträge. Bd. LIV. 
betreffen die hauptsächlichsten Veränderungen die Gefäße, das Kutisgewebe und die Drüsen; sie sind teils regetativer und nutritiver Natur, teils sind es entzïndliche Prozesse akuten und chronischen Verlaufs.

Diese bistologischen Befunde stehen, wie Dohi ausführt, mit der von Kaposi vertretenen Anschaung von der primären Angioneurose (vegetative Störung) und den daraus hervorgehenden Ernährungsstörungen, die sich durch Hypersekretion und atypische Degeneration der Sekrete (verschieden fettige und keratinöse Umwandlung der Zellen), weiters in Hypersekretion und Hypertrophie der Talgdrüsen, in Zunahme des Bindegewebes durch Induration, in chronischem Ödem und endlich auch in Neubildung offenbaren, im Einklange.

Bekanntlich finden wir beim klinischen Bilde des Rhinophyma, der Pfundnase, die Acne rosacea als Vorstadium, die schon klinisch den Ausdruck der lokalen Entzündung und Zirkulationsstörung darstellt. Außer diesen beiden Momenten kommt auf Grund meiner Versuche mit reinem, nicht sterilisiertem und reinem sterilisiertem Olivenöl und auf Grund der Versuche von Wacker und Schmincke mit fettigen und öligen Substanzen die Proliferationsfähigkeit der Talgdrüsen bei Einwirkung der genannten Fette und Öle als veranlassendes Moment hinzu. Es wäre ja möglich, daß bei der Pathogenese des Rhinophyma die Sebummassen gleichfalls für die Vergrößerung sowie überhaupt für die Proliferation der Talgdrüsen einen Reiz abgeben. $\mathrm{Ob}$ nun die Sebummasen zersetzt werden oder nicht, ob die Flaschenbazillen hiebei eine Rolle spielen oder nicht, oder ob die gesteigerte Sekretion erst sekundär infolge der lokalen Entzündung und Zirkulationsstörung in die Erscheinung tritt, die Beantwortung dieser Frage soll meinen weiteren experimentellen Untersuchungen vorbehalten bleiben.

Weiters ist noch die Frage zu prüfen, ob vereiterte Atheromedurch ihren Inhalt tatsächlich für eine Epithelproliferation bis zur krebsigen Umwandlung verantwortlich zu machen sind (Fall Kerl aus der Klinik Riehl).

Haben Wacker und $\$ \mathrm{cbmincke}$ in der komplexen 
Ursache der Wachstumsanregung durch ihre verdienstvollen Experimente die Lipoidlöslichkeit der Substanzen, welche die Epithelproliferation anregen, gefunden, so mußte ich $\mathbf{n a c h}$ meinen Versuchen unabhängig von dengenannten Autoren dem reinen, nicht sterilisierten und reinen, sterilisierten 0livenöl gleichfalls eine ziemlich beträchtliche, proliferierende Wirkung auf das Epithel und die Talgdrüsen zu erkennen.

Erst wenn es gelungen ist, bemerken $W$ acker und Schmincke (l. c.), die Wirkung dieser Stoffe genauer zu ergründen, kann an eine Beantwortung der zweiten Frage, inwieweit solche Stoffe genetisch beim Karzinom beteiligt sind, und $o b$ so die experimentell erzeugten Epithelwucherungen mit Karzinomwucherungen Wesensgemeinschaft haben, herangegangen werden.

Die Hoffnung, diese komplizierten Fragen einer definitiven Klärung entgegenzuführen, ist nach W ack er und Sch mincke von vornherein sehr gering, da es schwer gelingen wird, die Verhältnisse, wie sie für die Karzinomgenese bei Menschen maßgebend sein mögen, im Tierexperiment auch nur annähernd nachzuahmen.

\section{Zusammenfassung.}

In dieser $z$ weiten $V$ ersuchsreihe wurden die Versuche B. Fischers mit subkutaner Injektion von Scharlachöl in das Kaninchenohr nachgeprüft und die Erzeugung pathologischer Epithelwucherungen durch Scharlachölinjektionen bestätigt. Die gleichen Resultate (epitheliom-, trichoepitheliom- oder Keratosis follikularis-ähnliche Bilder) erhielt ich mit chemisch dem Scharlachrot nicht analog konstituierten Anilinfarbstoffen, so daß ich, in Übereinstimmung mit anderen Autoren, dem Scharlachrot allein keine spezifische Wirkung auf das Epithel zuschreiben kann.

Stoeber und Wacker gelang es mit Eiweißfäulnisprodukten (Naphthylamin, Skatol, Indol usw.), Wacker und Schmincke mit verschiedenartigen öligen und fettigen Substanzen, Epithelwucherungen zu erzeugen, während ich mit Injektionen von reinem, nicht sterilisiertem 
und reinem, sterilisiertem Olivenöl - im Gegensatz zu Wacker und Schmincke - ein positives Resultat erzielte.

\section{L i t e r a t ur.}

1. Aschoff, L. Pathologische Anatomie, ein Lehrbuch für Stustierende und Ärzte. Gustav Fischer. Jena 1911. I. Bd. 2. Aufl. p. 557. 2. Askanazy, M. Die Resultate der experimentellen Forschung über teratoide Geschwülste. Wiener med. Wochenschr. 1909. Nr. 43. (Mit ansführlicher Literatur.) - 3. A u sp it z, H. Über die Verhältnisse der Oberhaut zur Papillarschicht, insbesondere bei pathologischen Zuständen der Haut. Arch. f. Derm, u. Syph 1870. p. 25 u. 57. - 4. Benthin, Walther. Erzeugung atypischer Epithelwucherungen. Zeitschr. für Krebsforschung. 1911. II. Bd. 2. Heft. p. 227. - 5. B o rst, Max. Die Lehre von den Geschwülsten mit einem mikroskopischen Atlas. 1902. Wiesbaden. Verlag von J. F. Bergmann. I. Band. p. 80. II. Band. p. 519. - 6. Derselbe. Atypische Epithelwucherungen. Physikal.-med. Ges. in Würzburg. Sitzung vom 27. Februar 1910. Ref. in der Deutschen med. Wochenschrift. 1910. Nr, 34. p. 1586. - 7. Bor is s ow, P. Über die chemotaktische Wirkung verschiedener Substanzen auf amöboide Zellen und ihren Einfluß auf die Zusammensetzung des entzündlichen Exsudates. Z i eg I ers Beiträge zur pathol. Anatomie und allgemeinen Pathologie. 1894, Bd. XVI. p. 432. 8. Brosch, Anton. Theoretische und experimentelle Untersuchungen zur Pathogenesis und Histogenesis der malignen Geschwälste. Virchow s Arch. f. path. Anatomie u. Phys. und f. klin. Medizin. 1900. Bd. CLXII. p. 32. - 9. Czerny, V. II. Pariser internationaler Krebs-Kongreß. Münchener med. Wochenschr. 1910. Nr. 44. - 10. Deton, Willy. Künstliche Riesenzellengranulome. Zeitschr. f. Krebsforschung. 1911. II. Bd. 2. Heft. p. 224. - 11. Dohi. Ein Beitrag zur Kenntnis des Rbinophyma. (Histologische u. klinische Studie.) Arch. f. Derm. u. Syph. 1896. Bd. XXXVII. p. 361. - 12. Epping er, Hans. Über Melanurie. Biochemische Zeitschr. 1910. Bd. XXVIII. p. 181. - 13. Fis c her, Bernhard. Die experimentelle Erzeugung atypischer Epithelwucherungen und die Entstehung bösartiger Geschwülste. Münch. med. Wochenschr. 1906. Nr. 42. - 14. Fraenkel, Alexander. Das Problem der Krebskrankbeit. Wiener klin. Wochenschr. 1911. Nr. 10. - 15. Fränkel, Sigmund. Zur Chemie des Karzinoms. Wiener klin. Woch. 1912. Nr. 27. p. 1041. - 16. Freund, Paula. Über experimentelle Erzengung teratoider Tumoren bei der weißen Ratte. Zieglers Beiträge. 1911. Bd. LI. p. 490. - 17. F ür st. Über die Veränderungen des Epithels durch leichte Wärme- und Kältewirkungen beim Menschen und Säugetier. Zugleich ein Beitrag zur Theorie der Riesenzellen. Z i eg lers Beiträge. Bd. XXIV. p. 415-457. - 18. Geipel. Demonstration mikroskopischer Präparate. Gesellschaft für Natur- und Heilkunde zu Dresden. Sítzung vom 9. März 1907. Ref. Münch̀. med. Woch. 1907. Nr. 20. p. 1057. - 19. Greis cher, S. Experimentelle atypische Epithelwucherungen auf dem Boden von Zirkulationsstörung. Zeitschr. f. Krebsforschung. 1911. Bd. I. H. 1. p. 11s. -20 . Herxheimer, G. und Reinke, F. Allgemeines zur Geschwulstlehre; insbesondere über Wesen und Genese des Karzinoms. In L u bars ch-O stertag. 1909. XIII. Jahrg. II. Abt. p. 356. (Mit ausführlicher Literatur.) - 21. Ja e g e r, Alfred. Die Ursache der Krebserkrankung. Wiener klin. Wochenschr. 1910. Nr. 50. 22. Jores, L. Über Art und Zustandekommen der von B. Fischer mittels "Scharlachöl“ erzengten Epithelwucherungen. Münch. med. Woch. 1907. Nr. 18. p. 879. - 23. K a u f mann, Eduard. Lehrbuch der speziellen pathologischen Anatomie für Studierende und Ärzte. IV. neu bearbeitete und vermehrte Auflage. Berlin. Verlag von Georg Reimer. 1907. 
p. 906. - 24. K a u fmann, E. Erzeugung atypischer Epithelwucherungen. Med. Gesellschaft in Göttingen. 8. 22. III. 1912. Ref. Deutsche medizin. Woch. 1912. Nr. 28. p. 1358. - 25. Kerl, W. Demonstration eines Falles von multiplen Atheromen (Plattenepithelkarzinom anf Grund eines erweichten Atheroms). Wiener derm. Gesellsch. Sitzung vom 17. Mai 1911. Wiener klin. Woch. 1911. Nr. 39. p. 1381. - 26. Kraus, R., Graff, E. von, Ranzi, E. Über neuere serologische Methoden zur Diagnose maligner Tumoren. Wiener klin. Woch. 1911. Nr. 28. - 27. L e b e r, Th. Über die Entstehung der Entzündung und die Wirkung der entzündungserregenden Schädlichkeiten. Fortschritte der Medizin. 1888. Nr. 12. p. 460. - 28. Lubarsch, 0. Allgemeine Biologie und Pathologie. Jahreskurse für ärztliche Fortbildung. Jahrg. 1910. 1. H. Januar. p. 37. - 29. Mar chand, F. Untersuchungen über die Einheilung von Fremdkörpern. Ein Beitrag zur Lehre von der entzündlichen Gewehsneubildung. Zieglers Beiträge zur pathol. Anatomie und zur allg. Pathologie. Gustav Fischer, Jena 1889. Bd. IV. p. 1. - 30. Derselbe. Der Prozeß der Wundheilung mit Einheilung der Transplantation. Stuttgart. Verlag von Ferd. Enke. Deutsche Chirurgie. 1901. Lieferung 16. p. 164. - 31. M a s a y a s u Miyahara. Zur Frage der atypischen Epithelwucherungen beim Lupus und ihre Beziehungen zum Karzinom. Frankfurter Zeitschr. f. Pathologie. 1911. IX. Band. 2. Heft. - 32. Maxim ow, Alexander. Experimentelle Untersuchungen über die entzündliche Neubildung von Bindegewebe. Zieglers Beiträge zur pathol. Anatomie und zur allg. Pathologie. 1902. V. Suppl.-Band. (Mit ausführlicher Literatur.) - 33. Mori, T ake y osh i. Experimentelle Untersuchungen über die Genese atypischer Epithelwucherungen. Virchows Arch. 1912. Bd. CCVIII. p. 333. - 34. O r th, Johannes. Rückblicke. Virchow s Arch. 1910. Bd. CC. p. 1. - 35. Paltauf, R. Die klinische Diagnostik des Krebses. Referat, erstattet auf der II. internationalen Krebskonferenz zu Paris. 1.-5. Oktober 1910. Wiener klin. Wochenschr. 1910. Nr. 46. p. 1623. - 36. Podwyss ozki, W. Zur Frage über die formativen Reize. Riesenzellengranulome durch Kieselguhr hervorgerufen. Zi eglers Beiträge.. 1909. Bd. XLVII. p. 270. 37. Ribbert, H. Geschwulstlehre für Ärzte und Studierende. Bonn, Verlag von Friedrich Cohen. 1904. p. 349. - 38. Derselbe. Lehrbuch der allgemeinen Pathologie und der allgemeinen pathologischen Anatomie. II. vermehrte und verbesserte Auflage, Leipzig 1905. p. 387. - 39. Der selbe. Das Karzinom des Menschen. Bonn 1911. - 40. Ritter. Atypische Epithelwucherungen, die durch Injektion von Scharlachöl am Kaninchenohr hervorgerufen sind. Medizinischer Verein Greifswald. Sitzung vom 10. Dez, 1906. Ref. Münch. med. Wochenschr. 1907. Nr. 11. p. 542. - 41. Roh rbach, R. Über eine hochgradige atypische Epithelwucherung bei Sypbilis. Berliner klin. Wochenschr, 1912. Nr. 13. - 42. Rokitansky, Carl. Lehrbuch der pathologischen Anatomie. 3. umgearbeitete Auflage. Wien 1855. Wilh. Braumüller. Bd. I. p. 170. - 43. Ruts chinski. Zur Frage über experimentelle Erzengung atypischer Epithelwucherungen. Russky Wratsch. 1910. Nr. 23. p. 794. Zit. nach Greischer. 44. Derselbe. Beitrag zur Frage von der Ätiologie der experimentellen Proliferation des Epithelgewebes. Ibid. 1910. Nr. 51. Zit. bei Greischer. - 45. Samuel, S. Entzündung. Lubarsch-Ostertag. Ergebnisse der allgem. Pathologie v. pathol. Anatomie. II. Abteil. p. 72 ff. (Mit ausführlicher Literatur.) - 46. S cheltema, J. J. Über die Veränderungen im Unterhautbindegewebe bei der Entzündung. Deutsche med. Wochenschr. 1886. Nr. 27. p. 461. - 47. S chmaus, H. Grundriß der path. Anatomie. VII. neu bearbeitete Aufiage. Wiesbaden, Verlag von J. F. Bergmann. 1904. p. 718. - 48. S chm in cke, A. Experimentelle Untersuchungen zum Geschwulstproblem. Ärztlicher Verein München. Sitzung vom 12. Juli 1911. Ref. Münch. med. Wochenschr. 1911. Nr. 48. p. 2586. - 49. S c h rei- 
ber, L. und Wengler. Über die Wirkungen des Scharlachöls auf die Netzhaut. Mitosenbildung der Ganglienzellen. Naturhistorisch-medizinischer Verein zu Heidelberg. Sitzung vom 28. Juli 1908. Ref. Münch. medizin. Wochenschr. 1908. Nr. 35. p. 1854. - 50. S e ckel. Über experimentell erzeugte atypische Epithelwucherungen. Naturwissenschaftl.-med. Ges. zu Jena. Sektion für Heilkunde. Sitzung vom 29. Novbr. 1907. Ref. Münch. med. Wochenschr. 1908. Nr. 4. p. 199. - 51. Stahr, Hermann. Atypische Epithelwucherung und Karzinom. Nachprüfung und Bewertung der Experimente von B. F is ch er, Bonn. Münch. med. Wochenschr. 1907. Nr. 24. p. 1178. - 52. S toe ber, Hans. Experimentelle Untersuchungen über die Erzeugung atypischer Epithelwucherungen. Münch. med. Wochenschrift. 1909. Nr. 3. - 53. Derselbe. Die Erzeugung atypischer Epithelwucherungen durch Injektion von Scharlachrot und Amidoazotoluolöl in das subkutane Gewebe des Menschen. Münch. med. Wochenschr. 1910. Nr. 14. - 54. Stoeber, H. und Wacker, L. Ein weiterer Beitrag zur Erzeugung atypischer Epithelwucherungen mit Eiweißfäulnisprodukten. Münch. medizin. Wochenschr. 1910. Nr. 18. - 55. Tietze, A. Epithelwachstum. Med. Sektion der schles. Ges. für vaterländ. Kultur zu Breslau. 16. Dezember 1910. Ref. Berliner klin. Wochenschr. 1911. Nr. 6. - 56. Un n a, P. G. Histopathologie der Hantkrankheiten. Berlin 1894. Veriag von Aug. Hirschwald. - 57. Wacker, L. und Schmincke. A. Experimentelle Untersuchungen zur kausalen Genese atypischer Epithelwucherungen, Münch. med. Wochenschr. 1911. Nr. 30 und 31. - 58. Werner, R. Experimentelle Epithelstudien. Über Wachstum, Regeneration, Amitosenund Riesenzellenbildung des Epithels. Beiträge zur klin. Chirurgie. 1902. Bd. XXXIV. p. 1. - 59. Derse lbe. Über den Einfluß des Scharlachrotes auf Mäusetumoren. Münch. med. Wochenschr. 1908. Nr. 44. p. 2267. - 60. Wessely, K. Über die Wirkung des Scharlachöls auf die menschliche Epidermis. (Selbstversuch.) Med. Klinik. 1910. Nr. 10. - 61. Ders elb e. Scharlachölversuche beim Affen. Sitzung der physik.-mediz. Ges. zu Würzburg vom 3. März 1910. Ref. Münch. mediz. Wochenschr. 1910. Nr. 13 und Deutsche medizinische Wochenschr. 1910. Nr. 35. p. 1640. 62. Wolff, J. Die Lehre von der Krebskrankheit von den ältesten Zeiten bis zur Gegenwart. G. Fischer, Jena. 1911. I. u. II. Teil. - 63. Wys s, M. Oskar. Zur Wirkungsweise der Scharlachöl-Injektionen B. Fischers bei Erzeugung karzinomähnlicher Epithelwucherungen. Münch. medizin. Wochenschr. 1907. Nr. 32. p. 1576. - 64. D erselbe. Zur Entstehung des Röntgenkarz̈inoms der Haut und zur Fntstehung des Karzinoms im allgemeinen. Beiträge z. klin. Chirurgie. Bd. XLIX. p. 185. - 65. Derselbe. Zur Entstehung primärer Karzinome. Deutsche Zeitschr. f. Chir. Bd. XCIII. p. 537. - 66. Zi egler, Ernst. Allgemeine Pathologie. Jena. Verlag von Gustav Fischer. 1895 und 1902. p. $336 \mathrm{ff}$ - - 67. D e rs elbe. Lehrbuch der speziellen path. Anatomie. $X$. neu bearbeitete Aufl. Jena. Verlag yon Gustav Fischer. 1902. p. 479. - 68. Z u mbu sch, L. v. Beiträge zur Charakterisierung des Sarkommelanins vom Menschen. HoppeSeylers Zeitschrift für physiolog. Cbemie. 1902. Bd. XXXVI. p. 511.

\section{Teil.}

\section{Therapeutische (externe) Anwendung von Anilinfarbstoffen.}

1. Bisherige therapeutische Mitteilungen aus der Literatur.

2. Therapeutische Anwendung von $10 \%$ Brillantrot-, Gelblicht-; Grünerlack-, Krapplack-Salbe und -Pulver zur Behandlung von granulierenden Wunden, Brandwunden II. und III. Grades, Ulcera crusis, skrophulösen Geschwüren, exulzerierten Gummen usw.

3. Zusammenfassung der Resultate.

4. Literatur.

Arch. f. Dermat. a. Syph. Bd. CXVI. 
Fische $r$ sprach schon 1906 den Gedanken aus, daß diese epithelproliferierende Eigenschaft des Scharlachrots sich ev. praktisch verwerten lassen könne.

Im Jahre 1908 berichtete als Erster Schmieden aus der Bierschen Klinik in Berlin über klinische Erfahrungen, die er, $\mathrm{F}$ is chers Anregung folgend, mit einer $8 \%$ Scharlachrot-Salbe $\left.{ }^{1}\right)^{2}$ ) bei der Überhäutung granulierender Flächen gemacht hatte. Das Scharlachrot wurde als $8 \%$ Salbe appliziert. Nach der von Kraj ča empfohlenen Bereitungsweise: Rp. Scharlachrot $0.8 \mathrm{~g}$, tere cum oleo chlorof. usque ad solut., adde vaseline $100.0 \mathrm{~g} . \mathrm{S} \mathrm{chmieden} \mathrm{konnte} \mathrm{nach} \mathrm{Anwendung} \mathrm{von}$ Scharlachrot-Salbe die Bildung von sehr dicken Epitheldecken beobachten. Auch im mikroskopischen Bilde konnte $\mathrm{Schmieden}$ das neugebildete Epithel besichtigen. Das Epitbel ist kräftig und sieht absolut wie die normale Oberhaut aus, alle Schichten sind darin nachweisbar. Das mikroskopische Bild bestätigt also die klinische Beobachtung, daß es sich um ein sehr lebensfähiges Epithel handelt. Schmieden ist der Ansicht, daß die Scharlachrot-Salbe ein nützliches Hilfsmittel ist, um gereinigte, granulierende Flächen fest za verschließen, wenn ans irgend einem Grunde die Transplantation nicht am Platze ist.

Bei Anwendung der Scharlachrot-Salbe ist zu beachten, daß die Salbe messerrückendick auf Mull aufgestrichen, auf das Geschwür aufgelegt und mit einer Kallikotbinde festgebunden wird. Die dem Geschwür unmittelbar benachbarten Hautanteile werden mit Zinkpaste bestrichen, um Reizungen dieser Zone möglichst zu vermeiden. Der ScharlachrotVerband soll nie länger als 24 Stunden liegen bleiben, da sonst leicht gangränöser Zerfall des neugebildeten Epithels, der Granulationen und der Randzone der Haut eintreten kann. Es ist gut, Scharlachrot-Salbe mit indifferenter Salbe ( $3 \%$ Bor-Lanolin-Salbe) abzuwechseln, namentlich wenn stärkere Reizung der Geschwürsfläche aufgetreten war. Oder es kann die entzündliche Rötung der Umgebung des Geschwürs so stark sein, daß nach Applikation der Scharlachrot-Salbe Umschläge mit Burrowscher Lösung (1 Teil Burrow zu 10 Teilen Wasser) indiziert sind. Nach Applikation der Scharlachrot-Salbe erhalten die Granulationen nach 24 Stunden ein grau-weißes Aussehen, als Zeichen der Reizung, während vom Rande her sich oft schon nach Ablauf der ersten 24 Stunden ein frischer Epithelsaum zu bilden beginnt. Während der periphere Epithel-

1) He n r y, H. M., Lyle-New - York, berichtet in Medical Record vom 16. Nov, 1912 über einen Fall von Scharlachrot-Intoxikation, der eine 50jährige Frau mit schweren Verbrennungen der Brust betrifft. Nach diesem Autor kann die Scharlachrotsalbe, wenn sie auf größere Partien epithelentblößter Hautoberfläche appliziert wird, resorbiert werden und Vergiftungserscheinungen machen, die sich in Erbrechen, krampfartigen Leibschmerzen, Kopfschmerzen, Schwindelgefühl, Zyanose, Herabsetzung der Pulsspannung, Temperatursteigerung usw. äußern können.

2) Dobrowolskaj a, Heilwirkung des Scharlachrots bei granulierenden Wunden. Russki Wratsch. 1912. Bd. LIV. p. 1869. Ref. Mediz. Klinik 1913. Nr. 12. p. 470. 
saum sich von einem Tage zum andern sichtlich verbreitert, treten nach Morawetz häufig im Zentrum der granulierenden Fläche Epithelinseln auf, die, rasch wachsend, sich mit der peripheren Epithelzone vereinigen. So kommt die vollkommene Deckung des Krankheitsherdes recht rasch zustande, wobei besonders hervorzuheben ist, daß das unter der Einwirkung des Scharlachrots neugebildete Epithel sich durch außerordentliche Festigkeit auszeichnet.

Die Resultate Schmiedens wurden später von zahlreichen Autoren bestätigt, so von $\mathrm{Ka}$ ehler, der die Scharlach-R-Salbe u. a. zur Überhäutung eines nicht gedeckten Defektes nach Radikal-Operation eines Mamma-Karzinoms verwendete, ferner von Krajča, welche die Verbindung der Thierschen Transplantation mit der Anwendung der Scharlach-R-Salbe empfiehlt, und von Enderlen, der gute Erfolge der Überhäutung granulierender Flächen sah. Bei Substanzverlusten der Kornea wurde die $5 \%$ Salbe mit überraschendem Erfolge von Wolfrum und Cords angewendet, nachdem Schreiber und Wengler den experimentellen Beweis für die Wirksamkeit im Auge erbracht hatten. Durch Verwendung einer $4 \%$ Scharlach-R-Salbe rermied Auerbach jede übermäßige Reizung, brauchte daher niemals auszusetzen und indifferente Salben anzuwenden wie alle anderen Beobachter. Hermann sah gute Erfolge bei Trommelfellperforationen.

Im Jahre 1909 folgen die Nachprüfungen von Morawetz, Davis, Scharetzky, Kritschewski, Sprecher und Hayward.

Nach Sprecher läßt sich die Wirkung des Scharlachrots in der Weise erklären, daß es eine energische Karyokinese in den im Substanzverlust noch vorhandenen Basalzellen hervorruft.

Hayward wirft in seiner Arbeit aus der Bierschen chirurgischen Klinik in Berlin zum Schlusse noch folgende zwei Fragen auf: 1. Geben dem Scharlach-R chemisch verwandte Stoffe die gleiche Wirkung? 2. Läßt sich in dem Scharlach-R von Fischer und Schmieden ein Stoff nachweisen, der die gleiche Wirkung wie das kompliziert aufgebaute Molekül hat und damit als das wirksame Agens aufzufassen ist?

Die Beantwortung der ersten Frage ist unbefriedigend ansgefallen (Sudan I., Sudan G. etc.).

Stoeber fand bei seinen experimentellen Untersuchungen über Geschwülste das $\alpha-N a p h t h y l a m i n$, eine Komponente von Scharlach-R, das die spezifische Wirkung in weitgehendstem Maße hervorruft. Nach Hay wards Versuchen irritiert das $\alpha$-Naphthylamin zu stark, erweist sich für die Therapie als unbrauchbar. Erfolgreicher waren die Versuche mit einer anderen Komponente des ursprünglichen Scharlach-Farbstoffes, dem Amidoazotoluol. ${ }^{1}$ ) Dieser Azofarbstoff, ein

1) In einer jüngst erschienenen Arbeit empfiehlt Bantlin das Pellidol und Azodolen zur Behandlung der Ekzeme bei exsadativer Diathese. Pellidol ist Diazethyl-o-Amidoazotoluol, ein in Fett und öl lösliches Präparat, Azodolen eine Verbindung desselben mit einem Jodeiweißpräparat. (1. c. Münch. med. Woch. 1912, Nr. 39). Ử Uer das 
Spaltungsprodukt des Scharlach-R (Sudan IV) hat sich als der wirksame Bestandteil des Scharlach-R gezeigt.

Da Amidoazotoluol medicinale "Agfa" das Scharlach-R an Wirksamkeit übertrifft und dabei frei von schädlichen Reizwirkungen ist, so empfiehlt Hayward, an Stelle der früheren "Scharlach-R"Salbe nur noch die aus Amidoazotoluol hergestellte "Scharlach-Salbe" zu benützen. Das Amidoazotoluol medicinale "Agfa“ bildet ein rotbraunes Kristallpulver, das beim Verreiben ein gelbes Pulver liefert, in Alkohol, Äther, Ölen und Fetten mit rotgelber Farbe sich löst, im Wasser dagegen kaum löslich ist.

Im folgenden Jahre 1910 erzielte Strauss mit der Scharlach-RSalbe gleichfalls günstige Resultate. Bei unreinen, jauchenden Wunden oder solchen mit eitrigen Belägen ist die Salbe wertlos. Nach den Beobachtungen von Strauss wirkt das Amidoazotoluol genau so wie das Scharlach-R.

Nach Katz übertrifft die Wirkang der AmidoazotoluolSalbedieder Scharlach-R-Salbe an Promptheit und Schnelligkeit. Den Nachteil der Färbekraft der Scharlach R-Salbe vermeidet mit Sicherheit die Amidoazotoluolsalbe. Irgendwelche sonstige Nebenerscheinungen hat $\mathrm{Katz}$ nie gefunden, insbesondere keine Nierenreizung. Zusammenfassend bemerkt $\mathrm{Katz}$, daß bei Beobachtung gewisser Kautelen sich granulierende Wunden ungemein schnell überhäuten, die neugebildete Haut ist fest und widerstandsfähig; die Salbe ist außerordentlieh billig.

Über gleich günstige Resultate berichtet Pein bei Behandlung von Ulcera cruris sowie anderer granulierender Wunden. Ulcera mollia, Wundflächen von operierten Bubonen, luetische Ulzerationen heilten nicht, so lange noch das spezifische Virus aktiv war. Waren jedoch die Flächen durch die spezifischen Mittel resp. die Allgemeinbehandlung gereinigt, so wurde die Epithelisierung durch das Scharlach-R wesentlich beschleunigt.

Michaelis findet in der Anwendung der Salbenform von Scharlach R und Amidoazotoluol verschiedene Nachtoile; die Salbe reizt die Haut und erzeugt Ekzem. Aus diesen Gründen verordnet Michaelis das Amidaazotoluol in Pulverform, und zwar in folgender Verschreibung: Rp. Amidoazotoluol 10*0, Zinkperhydrol 20.0, Bismuth. subnitric. ad $100^{\circ} 0$, M. f. pulvis. Ohne $Z$ weifel hat diese Form der Applikation infolge ihrer einfachen Technik viele Vorteile gegenüber der Salbenbehandlung.

Die Tatsache, daß die bereits im I. Teil der Arbeit erwähnten Anilinfarbstoffe: Brillantrot, Gelblicht

Scharlach-R. medicinale „Kalle" und seine Ersatzpräparate Pellidol und Azodolen berichtet kürzlich 0 . Retzlaff (l. c. Deutsche medizinische Wochensch. 1912, Nr. 42.).

(l. efr.) Decker C., Die Scharlachrot-Salbe und ihre Modifika. tionen. Mediz. Klinik 1912. Nr. 49. p. 1990. 
(Azofarbstoffe), Grünerlack (Triphenylmethanfarbstoff), Krapplack (Anthrazen-Alizarin-Farbe) eine die Haut - individuell natürlich in sehr verschiedenem Maße - reizende Wirkung ausüben, die auch beim Tierexperiment in einer Wucherung des Rete Malpighii analog dem Scharlach-R zum Ausdruck gelangt, veranlaßte mich, die oben erwähnten Farbstoffe als Salben und Wundstreupulver zur Epithelisierung granulierender Wunden zu applizieren. Die genannten Farbstoffe enthalten, wie bereits bekannt, außer dem Anilinfarbstoff das Tonerdehydrat als Beiz- und Bindemittel, das Blanc fixe (Bariumsulfat) als Beschwerungsmittel. Zur Epithelisierung von granulierenden Wunden, Ulcera cruris, Brandwunden II. und III. Grades, skrophulösen Geschwüren, exulzerierten Gummen usw. benützte ich aufer diesen genannten Farbstoffen den Anilinfarbstoff allein, und zwar das Litholrot (Azofarbe), das Säuregrün (Triphenylmethanfarbstoff), das Säuregelb (Azofarbe), und außerdem diese Farbstoffe als 10\% Salbe mit Vaselin.

Zunächst konnte ich bei Anwendung dieser 10\% Anilinfarbstoffsalben eine recht starke Granulationsbildung konstatieren, es wucherten die Granulationen recht üppig, so daß dieselben fast regelmäßig mit dem Lapisstift zerstört werden mußten, einerseits um der Bildung von Granulomen entgegenzuarbeiten, andererseits um der Epithelisierung der rein granulierenden Wunden keine großen Hindernisse in den Weg zu legen. Im Zentrum der granulierenden Fläche sah ich in meinen Fällen nie Epithelinseln auftreten, die Epithelisierung erfolgte stets rom Rande her. Der neugebildete Epithel zeichnete sich stets durch außerordentliche Festigkeit ans.

F all I. R. G., 61 J., Hilfsarbeiter, verh. (Prot.-Nr. 1957/09), suchte am 3. Dezember 1909 das Ambulatorium mit einem Ulcus cruris sin. von ungefähr 5-Kronengröße auf. Das Ulkus war schon vorher mit Lapissalbe, $3 \%$ Bor-Lanolinsalbe, $\mathrm{H}_{2} \mathrm{O}_{2}$, Einpinselungen mit Jodtinktur behandelt worden, ohne eine Tendenz zur Überhäutung zu zeigen. Lues ist auszuschlieben, Wassermann negativ.

Nach Anwendung einer $10 \%$ Säuregelbsalbe mit Vaselin heilte das Ulkas mit einer recht kräftigen Epitheldecke vollständig aus. Pat. wird am 15./II. 1910 geheilt entlassen.

Fall II. R. K., 40 J., Tischler, Uleus eruris sin. e varicibus (Prot.-Nr. 842/08), wurde vom 21. Februar 1910 an mit einer $10 \%$ Säuregelbsalbe behandelt und am 28./II. 1910 geheilt entlassen. 
Fall III. M. F., 31 J. alt, ledig, Kleinfuhrwerker (Prot.-Nr. 809/10), Verbrennung III. Grades der rechten Ach selfalte rückwärts und des rechten Handrückens, wurde anfangs, vom 22./VI. bis $26 / \mathrm{VI}$. 1910 mit $3 \%$ Borlanolinsalbe, nachher mit $10 \%$ Brillantrotsalbe behandelt. Pat. wird am 4./VII. 1910 geheilt entlassen.

Fall IV. St. J., 21 J., ledig, Schneider (Prot.-Nr. 61/10), Co mbastio II. Grades der linken Hohlhand und des Handrückens. Vom 7./VII. 1910 wurden die Brandwanden mit $3 \%$ Borlanolinsalbe, dann mit $10 \% \mathrm{Brillantrotsalbe}$ behandelt. Am 19./VII. 1910 wird Patient geheilt entlassen.

F a ll V. B. F., 22 J., ledig, Eisengießer (Prot.-Nr. 785/10), Combustio III. Grades an der linken kleinen Zehe. Die Wunde wird zunächst am 3./VII. 1910 mit $3 \%$ Bor-Lanolinsalbe behandelt, nachher abwechselnd mit 10\% Brillantrot- und $3 \%$ Bor-Lanolinsalbe. Die

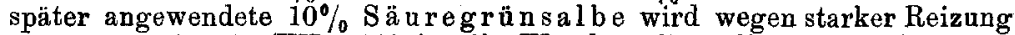
ausgesetzt. Am 27./VII. 1910 ist die Wunde vollständig epithelisiert.

Fall VI. F. J., 47 J., ledig, Schuhmacher (Prot.-Nr. 1095/09), Verbrennungen II. Grades am linken Handrücken. Vom 27./VI. 1910 wurde Pat. mit $10 \%$ Brillantrotsalbe und $3 \%$ Bor-Lanolinsalbe, dann mit Lapissalbe behandelt. Pat, wird am 19./VII. 1910 geheilt entlassen.

Fall VII. N. J., 31 J., ledig, Tischler (Prot.-Nr. 874/10). Verbrennung II. Grades an den Fingerrücken der linken Hand. Anfangs werden die Brandwunden mit Scharlachrotsalbe, nacher mit $10 \%$ SäuregeIb-, $10 \%$ Brillantrot- und schließlich mit $10 \%$ $\mathrm{Säuregrünsalbe} \mathrm{behandelt.} \mathrm{Letztere} \mathrm{mußte} \mathrm{wegen} \mathrm{zu} \mathrm{starker} \mathrm{Rei-}$ zung ausgesetzt werden. Pat. trat am 9./VII. 1910 in Behandlung und wurde am 23./VII. 1910 geheilt entlassen.

Aber nicht nur die $10 \%$ Brillantrotsalbe, auch das Brillantrotpulver (Litholrot R, Azofarbstoff) allein, auf verunreinigte oder gereinigte Wunden, wi e Ulcera cruris, Brandwunden III. Grades, skrophulöse Geschwüre, zerfallene Gummen, als Streupulver appliziert, zeigt außer einer austrocknenden eine a Berordentlichegranulationsbefördernde Wirkung, sowie, eine besondere Tendenz zur raschen Epithelisierung. Unter den von mir als Wnndstreupulver verwendeten Anilinfarbstoffen war die Wirkung des Brillantrotpulvers neben dem Scharlach- $R$ tatsäcblich so eklatant, daß ich zur Illustrierung des Heileffektes 5 Fälle anführe, die auch noch nach einer anderen Richtung hin bemerkenswert sind.

Es handelt sich um Patienten mit zerfallenen Gummen an den unteren Extremitäten usw. Trotzdem diese Patienten reichlich sowohl allgemein als auch lokal der Hg-Behandlung zugefïhrt wurden - ein Fall erhielt Salvarsan - war nach dieser kombinierten Behand- 
lung (Hg, Jod, Salvarsan) keine Heilungstendenz der zerfallenen Gummen zu verzeichnen, oder es traten nach Beendigung der Kur neue Knoten auf, die rasch zum Zerfall kamen. Nach Applikation von Brillantrotpulver, das abwechselnd jeden zweiten Tag mit $3 \%$ Bor-Lanolinsalbe angewendet wurde, kames in 2-3 Wochen zur vollständigen Epithelisierung der zerfallenen Gummen, welche bisher jeder Behandlung getrotzt hatten.

F all I. K. M., 28 J., ledig, Anstreicher, kam am 29./10. 1909 sub Prot.-Nr. 290/07 mit Scleroses erosae Nr. 2 in sulco coronario und Skleradenitis inguinal. bilat. modica in ambulatorische Behandlung. Die Injektionshehandlung mit $\mathrm{Hg}$ salicyl. I. Kur: (20/2 Injektionen) wird als $A$ bortivbehandlung vorgenommen.

30./I. 1910. Papulae madid. ad scrotum.

14. X. 1910. Uleus cruris dextr. nach Trauma (in luetico) Therapie: Burrow.

15./X. 1910. II. Kur: 1/2 Hg salicyl. Injektion, lokal graue Salbe. 11./XI. 1910. Ulcera gereinigt nach Lapissalbe, nach 10/2 $\mathrm{Hg}$ salicyl. Inj. keine Tendenz zur Ưberbäutung. Behandlung mit grauer Salbe ohne Erfolg, ebenso zeigt sich kein Heilungseffekt, wenn Lapissalbe mit Borsalbe abgewechselt wird. Ein staubendes Ulcus mit BrillantrotPulver.

16./XI. 1910. Das Olkusffbeginnt sich vom Rand her zu epithelisieren. 19./XII. 1910. Das Olkus ist fast vollständig epithelisiert.

Fall II. S. W., 26 J., ledig, Feinzeugsehmied (Prot.-Nr. 1067/09), kam am 8./VI. 1910 mit Sklerosis erosa, Exanthema crustos. und Papul. exulc. palati in ambulatorische Behandlung. Therapie: 6 Hg salicyl. Injektionen, nachber Einreibungen mit grauer Salbe. (10).

18/IX. 1910. Akne artefic. antibrachii utr. (Schmieröl, Petroleum).

19./IX. 1910. Wiedener Spital Injektion mit Salvarsan.

18./XI. 1910. Ulzeriertes Gumma, 5-Kronen groß, unterhalb der linken Kniescheibe (Rezidiv nach Ehrlichscher Injektion).

24./XI. 1910. Das Ulcus gummosum wird mit Brillantratpulver behandelt.

12./XII. 1910 Das Ulkus ist nach Behandlung mit Brillantrotpulver bedeutend kleiner, beginnt sich zu epithelisieren.

10./I. 1911. Das U1kus ist vollständig überhäutet.

Fall III. K. W., 30 J. alt, verh., Hilfsarbeiter (Prot.-Nr. 224/10). Lues seit 1905, wurde auf der Abteilung Lang mit grauen Ölinjektionen bebandelt.

17./II. 1910. Tubero-serpiginöses Syphilid am Stamm. Therapie: $20 / 2 \mathrm{Hg}$ sali cyl. Injektionen.

24./VII. 1910. Ulzeriertes Gumma am rechten Unters chenkel. Pat. blieb von der Behandlung aus.

27./XI. 1910. Ulzeröses Syphilid am rechten Unterschenkel (Gummata cutanea). Graue Salbe wird ohne Erfolg angewendet. Beginn der Behandlung mit Brillantrot. 23./XII. 1910. Das Ulcus gummosum ist vollständig überhäutet.

21./I. 1911. Die Narbe des Ulkus ist rollständig intakt und fest. 
Fall IV. H. J., 50 J. alt, verh., Schuhmacher (Prot.-Nr. 1119/11). Gummata exulaerata regionis coceygis et trochanter. major. femor. dextr. Unbehandelte Syphilis. $10 \cdot 0: 200 \cdot 0$

2./IX. 1911. Lokal 5\% weiße Präzipitatsalbe, intern Jodnatrium

7./X. 1911. Nach 9/2 Hg. salicyl. Injektionen und lokaler Behandlung mit grauer Salbe, intern Jodnatrium, sind die Ulzera noch nicht, überhäutet, Lokale Behandlung mit Brillantrotpulver. Hg salicyl.-Injektionen werden ausgesetzt.

9./X. 1911. Ulzera in Reinigung begriffen, zeigen vom Rand her Tendenz zur Überhäutung.

5./XII. 1911. Die Ulzera sind bis a uf einen kleinen zentralen Anteil nach lokaler Behandlung mit Brillantrot fast vollständig überhäutet.

Fall V. T. K., 16 J. alt, Weißgerberlehrling (Prot.-Nr. 1519/10). Skrophuloderma cruris dextr. Wassermann negativ. Therapie: Burrow, 3\% Bor-Lanolinsalbe, werden während 4 Wochen ohne jeden Effekt angewendet. Nach 14 tägiger Behandlung mit Brillantrotpulver ist das Uleus scrophulosum vollständig überhä ut et.

Das Brillantrot als Wundstreupulver zeigt seine rasch epithelisierende Wirkung nicht nur bei Ulcera cruris und Verbrennungen III. Grades, sondern auch bei ulzerierten Gummen (5 Fälle), sowie bei skrophulösen Geschwüren (1 Fall).

Bemerkenswert ist der Heilerfolg in den $5 \mathrm{~F}$ äll en $v$ o n zerfallenen Gummen nach Anwendung ron Brillantrotpulver. Die rasche epithelisierende, granulationsbefördernde Wirkung kommt in besonderem Maße dem Azofarbstoff Brillantrot $z u$, ohne daß für ihn eine spezifische Wirkung für die ulzerösen Prozesse der Syphilis oder Tuberkulose in Betracht gezogen werden soll.

Zusammenfassend können wir auf Grund unserer therapeutischen Beobachtungen bestätigen, daß.dem Scharlach R, sowie dem Amidoazotoluol eine stark granulationsbefördernde und epithelisierende Wirkung zukommt, müssen aber hinzufügen, daß die gleiche Wirkung auch den Anilinfarbstoffen Brillantrot, Krapplack, Säuregelb und Säuregrün, als Pulver oder Salbe appliziert, zuzuerkennen ist. DerScharlachsalbeallein ist also nach dieser Richtung hin keine spezifische Wirkung zuzuschreiben, weil eine grobe Reihe von chemisch nicht analog konstituierten Körpern analoge Wirkungen wie das Scharlach $R$ 
auf granulierende Flächen zur Epithelisierung derselben auszüuben imstande ist.

Die Wirkung aller dieser Stoffe hängt, abgesehen von der Natur derselben, auch noch von der Intensität des chemischen Reizes - eines sicherlich spezifischen - den sie auf die Wundflächen ausüben, ab. Aber auch die Intensität desselben ist an eine bestimmte obere Grenze gebunden, soll nicht durch den allzu starken chemischen Reiz eine Nekrose des Gewebes eintreten. Säuregrün (Grünerlack-Triphenylmethanfarbstoff) hat stark die Gewebe irritierende Eigenschaften, in derselben Konzentration wie Scharlach $\mathrm{R}$ oder Brillantrot angewendet. Hier wie dort handelt es sich um einen sowohl auf das Epithel, als auch das Bindegewebe chemisch wirkenden Reiz. Jedenfalls möchte ich glauben, daß die den verschiedenen chemischen Agentien inhärenten Reize zum Teil analoge Wirkungen, zum Teil einen ganz spezifisch chemischen Reiz entfalten können. Auf dieser Supposition würde sich die Wirkung vieler chemischer Agentien, die denselben therapeutischen Effekt erzielen, erklären lassen. Als Beispiel wähle ich die von allen Chirurgen geschätzte Billrothsche Lapis-Perubalsam-Salbe und die dem gleichen Zwecke dienende Scharlach $R$ - oder Brillantrot-Salbe. Der therapeutische leffekt wird sicherlich in vielen Fällen der gleiche sein; es kommt vor, daß manchmal die Lapis-Perubalsam-Salbe in ihrer Wirkung versagt, oder auch die Scharlachrot-Brillantrot-Salbe. Bes onders möchte ich noch einmal hervorheben, dab in beiden Fällen chemische Komponenten in Aktion treten, daß aber von den Anilinfarbstoffen spezifische chemische Reize ausgehen.

Gleichzeitig mit der Einführung der Scharlach R-Salbe in die Therapie macht sich wiederum das Bestreben geltend, ältere Wundheilmittel der Vergessenheit zu entreißen und auf ihre Wirksamkeit durch den chemischen Reiz auf Wundflächen hinzuweisen. Daß auch eine große Reihe anderer, von den älteren Chirurgen gebrauchter Wundstreupulve ${ }^{1}$ ) sehr gute Dienste leistet, ist ja allgemein bekannt.

1) In jüngster Zeit wird von Chirurgen und Gynäkologen bas Almateïn als Wundstreupulver vielfach empfohlen. Dasselbe ist ein 
Besitzen wir doch in der Billrothschen Perubalsam-Lapissalbe eine schon seit langem bekannte Wundsalbe, in dem Lapispuiver nach $B$ a ruch ein altbewährtes, rasch epithelisierendes, granulationsbeförderndes Wundheilmittel.

B aruch behandelt in einer aus der Bierschen Klinik in Berlin erschienenen Arbeit die Frage: „Über deh̀ Einflub des gepulverten Argentum nitricumauf as Wachstum der Granulationen und des Epithels".

Es ist auffällig, daß wir unter den Ersatzmitteln des Jodoforms kein einziges reizendes Wundpulver besitzen. Die Ersatzmittel desselben üben teilweise keinen Wundreiz aus, teils sind sie sogar, wie das Alumnol und Dermatol, Adstringentien, d. h. sie unterdrücken die Lebenstätigkeit der Zellen und halten also die Wundheilung anf.

Aus diesem Gruade hält es Baruch für berechtigt, ein Gemenge zu empfehlen, das sich duroh einen exquisiten Reiz auf die Zellneubildnng auszeichnet, und zwar sowohl im Sinne einer Granulationswucherung, als besonders auch einer raschen Epithelisierung. Baruch verwendet das Arg. nitr. als Basis mit Bolus alba als Ronstituens.

Rp. Argent. nitric. $1 \cdot 0$

Bolus alba steril. ad $100 \cdot 0$

M. subtile $f$. pulv.

D. in vitro nigro.

Die Möglichkeit, das Silberpulver auf infizierten, unsauberen Wundflächen anwenden zu können, ist nach Baruchs Ansicht ein besonderer Vorzug vor der Scharlachsalbe, die sich bekanntlich nur auf ganz gereinigten Wunden bewährt hat. "Der Versuch," sagt Schmieden, „noch unreine granulierende Flächen, z. B. chronische Beingeschwüre mit der Scharlachsalbe zu behandeln, erwies sich als ganz zwecklos." Aber auch anf gereinigten Wunden hat das Silberpulver vor der Salbenbehandlung den Vorzug, die Wundsekrete gut abzusaugen und ihnen ungehinderte Passage in den Verband zu gestatten.

Wie ich bereits erwähnte, darf bei der Beurteilung der Wirkungsweise eines Wundheilmittels (Wundsalbe, Streupulver) neben der chemischen Reiz-

geruchfreies, ungiftiges, reizloses Wund-Antiseptikum, das dem Jodoform und den Jodoform-Ersatzmitteln an Wirkung überlegen ist und ein Reaktionsprodukt vom Formaldehyd und Hämatoxylin darstellt. Die Wirkung dieses Almateïn ist wahrscheinlich auf den Reiz der chemischen Komponente des Formaldehyd und insbesondere des Hämatoxylin zu beziehen. Ich selbst habe das Almatein mit sehr gutem Erfolge als Wundstreupulver angewendet. Über die proliferationsfähige Wirkung des Almateïns werde ich gelegentlich, nach Abschluß einschlägiger Versuche, berichten. 
wirkung die mechanische Komponente nicht außer acht gelassen werden. Diesem letzten Gedanken hat Alexander Fränkel (1900) in seiner Arbeit über „Jodoformwirkung und Jod oformersatz Ausdruck gegeben:

„Die Untersuchung der Wirkung des Jodoformpulvers auf das $\mathrm{Gewebe}$ sehen wir unter nahezu gleichen histologischen Bildern ablaufen, wie sie sich bei der Einverleibung chemiseh indifferenter, aber nicht vorher sterilisierter Pulver darbieten; da entfällt wohl von selbst die Annahme einer spezifischen Beeinflussung der Gewebe durch das Jodoform. Es kann ihm lediglich die allen anderen, gleichzeitig und vergleichsweise angewendeten, nicht aseptischen Pulvern zukommende Wirkung der exsudativen und fibroplastischen Gewebsreizung durch Fremdkörpereinheilung zugesprochen werden."

Die bemerkenswerten Arbeiten von Stumpf und Lier$\operatorname{mann}$ (1911) lenken neuerdings die Aufmerksamkeit auf die Wundbehandlung mit Bolus alba, ebenso mit der aseptischen Boluswundpaste, die aus chemisch indifferenten Stoffen besteht, ungiftig und reizlos ist, auch keine Färbekraft besitzt, und die Maßnahmen der mechanischen Antiseptik unterstützt.

Weitere Versuche werden zu beweisen haben, in welchem Verhältnisse für die in Gebrauch stehenden Wundheilmittel chemische und mechanische Komponente zu einander stehen, und welche in dem einen oder anderen Falle die wirksameren sind.

\section{Zusammenfassung.}

Die wenigen Fälle zeigen zur Genüge, daß die von mir angewendeten Anilinfarbstoffsalben oder -Pulver der ScharlachR-Salbe in ibrem therapentischen Effekt der Epithelisierung in keiner Weise nachstehen, sondern ihr ebenbürtig an die Seite zu stellen sind. Kontrolluntersuchungen mit $3 \%$ iger BorLanolinsalbe, $8 \%$ iger Scharlach-R-Salbe und den genannten $10 \%$ igen Anilinfarbsoffsalben haben ergeben, daß die $10 \%$ ige Brillantrotsalbe nach meinen Erfahrungen die Scharlach-R-Salbe an Promptheit und Raschheit der Wirkung übertrifft, während die 10\%ige Säuregrünsalbe (Triphenylmethanfarbstoff) zu stark irritierend wirkt.

Es stimmen also die klinischen Beobachtungen mit den experimentellen Untersuchungen, sowie den therapeutischen Resultaten der genanten 
Anilinfarbstoffe Brillantrot, Krapplack, Gelblicht, Grünerlack überein, indem diesen eine starke granulationsfördernde und epithelisierende Wirkung zukommt, so daß sie für das Scharlach-R sowie das Amidoazotoluol nichtspezifisch ist.

\section{Literatur.}

1. Auerbach, Paul. Über den therapeutischen Wert der Scharlach-Salbe bei Haut- und Geschlechtskrankheiten. Klinisch-therapentische Wochenschr. 1909, Nr. 24, p. 594, - 2. Baruch, M. Über den EinfluB des gepulverten Argent. nitric. auf das Wachstum der Granulationen and des Epithels. Münch. med. Wochenschr. 1910, Nr. 35, p. 1829. 3. Davis, The effect of scarlat red in various combination upon the epithelisation of granulating surfaces. John Hopkins Hosp. Bull. Juni 1909, Nr. 219. Ref. Dermatol. Zeitschr., 1910, Bd. XVII, p. 115. - 4. E hrlich, P. und Hata, S. Die experimentelle Chemotherapie der Spirillosen. Berlin 1910. Verlag von Julius Springer. p. 154. - 5. Enderlen. Empfehlung der Scharlach R-Salbe zur Beschleunigung der Epithelisierung granulierender Flächen. Würzburger Ärzteabend, Sitzung vom 20. Febr. 1908. Ref. Münch. med. Wochenschr., 1908, Nr. 39, p. 2066. - 6. Fraenkel, Alexander. Über Jodoformwirkung und Jodoformersatz. Wiener klin. Wochenschr. 1900, Nr. 47, p. 1085. - 7. H a y w a rd, E. Weitere klinische Erfahrungen über die Anwendung der Scharlachfarbstoffe und deren Komponenten zur beschleunigten Epithelisierung granulierender Flächen. Münch. med. Wochenschr. 1909, Nr. 36 (mit ausführlicher Literatur). 8. Hermann. Scharlachrot bei Trommelfellperforationen. Deutsche med. Wochenschr. 1909, Nr. 22. - 9. Kaehler, M. Epithelisierung von Wundflächen unter Scharlachrotsalbe (nach Fischer.Schmieden). Mediz. Klinik 1908, Nr. 22, p. 836. - 10. Katz, W. Über die Behandlung granalierender Wunden mit Amidoazotoluolsalbe. Deutsche med. Wochenschrift 1910, Nr. 36, p. 1665. - 11. Kr ajŏ a, Clementine. Zur Epithelisierung granulierender Flächen durch Scharlachrot. Kombination mit inselförmiger Hauttransplantation. Münch. med. Wochenschr. 1908, Nr. 38. p. 1969. - 12. Kritschewski. Diskussionsbemerkung. Charkowsche medizin. Ges. v. 17. April 1909. Ref. Wiener klin.-therap. Wochenschr., 1909, Nr. 42. - 13. Lierman n, W. Beiträge zur Wundbehandlung mit Bolus alba. (Deutsche medizin. Wochenschrift, 1911, Nr. 40). - 14. M ich aelis, Paul. Fine neue Anwendungsart des Amidoazotoluols, des wirksamen Bestandteiles der Scharlachrotsalbe. Medizin. Klinik, 1911, Nr. 4. 15. Moraw etz, Gustav. Erfahrungen über die Behandlung granulierender Wundflächen mit Scharlachrotsalbe. Therap. Monatshefte, 1909, 23. Jahrg., H. 9. - 16. Pein, K. Über die Behandlang des Ulcus cruris mit Scharlachrot. Therapie d. Gegenwart, 1910, H. 3, p. 121. - 17. Scharetzky. Über Deckung der Hautdefekte mit Scharlachrot. Charkowsche medizin. Ges. v. 17. April 1909. Ref. Klin.-therap. Wochenschr. 1909, Nr. 42, p. 1072. - 18. Schmieden, V. EpitheJwachstum unter Einwirkung von Scharlach R. Zentralbl. f. Chir, 1908, Nr. 6, p. 153. 19. Schmieden, V. und Hayward, E. Der heutige Stand der experimentellen und therapeutischen Verwertung der Scharlachfarbstoffe. Zeitschr. f. Chir. 1911, Bd. CXII, p. 467 (mit ausführlicher Literatur). 20. Sprecher (Genua). Über den therapeutischen Wert des Scharlachrot. Gaz. degli osped. 1909, Nr. 23. Ref. Klin.-Ther. Wochenschr. 1909, Nr. 13 , p. 325. - 21. Straus s, M. Beitrag zur Kenntnis der Wirkung des Scharlach R. auf das Epithelwachstum. Ein neues Wundheilmittel. 
Deutsche medizin. Wochenschr. 1910, Nr. 19. - 22. Stumpf, J. Der Bolusverband, ein neuer steriler Wundverband. Münchner med. Wochenschrift 1911, Nr. 11. - 23. Wolfrum, M. und Cords, R. Tíber die Anwendung von Scharlachrot bei Augenaffektionen. Münchner med. Wochenschr. 1909, Nr. 5, p. 242.

\section{Erklärung der Abbildungen auf Taf. XXIX-XXXII.}

Fig. 1. Schnitt durch den papillomähnlichen Tumor von der Beugefläche des rechten Vorderarmes (Fall IV. Einwirkung von trockenen, pulverförmigen Anilinfarbstoffen a uf die menschliche Haut). Fixierung und Härtung in Alkohol, Färbung mit Haemalaun-Eosin. 72fache Vergrößerung. - Aus dem Niveau der Haut erhebt sich ein etwa linsengroßes $K n o ̈ t c h e n$ von papillom. ähnlicher Struktur, mit mäBiger Hyperkeratose und. stark ausgesprochener Akanthose. An den Randpartien ist das Rete Malpighii bandartig schmal, das sich entsprechend dem Tumor mit verbreiterten und verlängerten Reteleisten in die Kutis senkt. In den Vertiefungen, Buchten und Falten des maulbeerähnlichen Knötchens lassen sich schmutzig-grünlich-gelbe, staubförmige Farbstoffpartikel und Kristalle (Tonerdehydrat und Bariumsulfat) nachweisen. In den erweiterten Interspinalräumen der Reteschicht finden sich außer Farbstoffpartikeln spindelig ausgezogene Leukozyten in Durchwanderung begriffen. Blasige Abhebung des Stratum comeum allein oder des Stratum corneum mit der obersten Reteschicht sind als intraepidermoidale Zysten (ein- und mehrkämmerige) anzusprechen. Im Rete Malpighii zahlreiche Mitosen nachweisbar. Der Papillarkörper ist der Hauptsitz der entzündlichen Veränderungen, das Zellinfiltrat im Stratum papillare und subpapillare setz' sich aus gewucherten fixen Bindegewebszellen, polynukeären Leukozyten, Lymphozyten, Mast- und Plasmazellen zusammen. Die Bindegewebsfasern, sowie die Zellen des Infiltrats sind mit Farbstoffkristallen imprägniert. Blut- und Lymphgefäße erweitert, ibre Endothelien gequollen. In den tiefsten Schichten des Papillarkörpers, oft auch im subkutanen Fettgewebe spärliche Farbstoffkristalle nachweisbar. An den infiltratfreien Stellen sind die elastischen Fasern qualitativ and quantitativ gut erhalten. Der in seiner Länge getroffene Schweißdrüsenausführungsgang ist in seinen Wandungen verdickt und erweitert.

Fig. 2. Schnitt durch ein mit Scharlachrot bedecktes, den Follikeln entsprechendes Knötchen, entstanden nach acht Einreibungen von Scharlachrot auf die Ohrinnenfläche eines zwei Jahrealten Kaninchens. (7. Versuch; Versuchsdauer 60 Tage.) Fixierung in 10\% igem Formol, Härtung in Alkohol. Färbung mit Haemalaun-Eosin. 85fache Vergrößerung. Das Stratum corneum ist ein wenig verbreitert, auf demselben kein Farbstoff nachweisbar. Die Proliferation und Verbreiterung des Rete Malpighii dokumentiert sich in verschieden langen und breiten Epithelzapfen, Abschnürung von Epithelinseln mit Hornperlen. Dadurch entsteht ein epitheliomähnliches Bild. Außerdem findet sich eine Vergrößerung der Talgdrüsen. In der Kutis die entzündlichen Erscheinungen gleichfalls im Abklingen begriffen. (Fortsetzung der Tafelerklärung s. p. 682). 
I. Einreibungs-

\begin{tabular}{|c|c|c|c|c|c|}
\hline $\begin{array}{l}\text { Prot.- } \\
\mathrm{Nr} \text {. }\end{array}$ & $\begin{array}{l}\text { Daner } \\
\text { des Versuches }\end{array}$ & $\begin{array}{c}\text { Ungefähres } \\
\text { Alter des } \\
\text { Versuchstieres }\end{array}$ & $\begin{array}{c}\text { Ort der } \\
\text { Einreibung } \\
\text { Ohrinnen- } \\
\text { fläehe }\end{array}$ & $\begin{array}{l}\text { Eingeriebene } \\
\text { Substmuz }\end{array}$ & $\begin{array}{l}\text { Anzahl der } \\
\text { Einreibungen }\end{array}$ \\
\hline 1 & $\begin{array}{l}\text { 4./VII.-- } \\
\text { 24./VII. 1908 }\end{array}$ & $\begin{array}{l}\text { Junges } \\
\text { Kaninchen }\end{array}$ & rechte & Bleiweiß & 6 \\
\hline 2 & $"$ & $\begin{array}{c}\text { Junges } \\
\text { Kaninchen } \\
\text { (Albino) }\end{array}$ & linke & Miloriblau & 6 \\
\hline 3 & $\Rightarrow$ & $n$ & rechte & Sienna & 6 \\
\hline 4 & $\begin{array}{r}4 . / \text { VII - } \\
\text { 14./VII. 1908 }\end{array}$ & $\pi$ & linke & Zinnober & 3 \\
\hline 5 & $\begin{array}{c}4 . / \text { VII.-- } \\
24 . / \text { VII. 1908 }\end{array}$ & $\begin{array}{l}\text { Junges } \\
\text { Kaninchen }\end{array}$ & $\mid \begin{array}{c}\text { linke und } \\
\text { rechte }\end{array}$ & $n$ & 2 \\
\hline $6 a$ & $\begin{array}{l}\text { 16./XII.- } \\
20 . / I .1909\end{array}$ & $\begin{array}{l}6 \text { Monate } \\
\text { altes } \\
\text { Kaninchen }\end{array}$ & rechte & Scharlachrot & 10 \\
\hline $6 b$ & $\eta$ & $n$ & linke & $\eta$ & 9 \\
\hline 7 & $\begin{array}{l}\text { 17./XII.- } \\
\text { 15./II. } 1909\end{array}$ & $\begin{array}{l}2 \text { Jahre altes } \\
\text { Kaninchen }\end{array}$ & $\begin{array}{l}\text { rechte } \\
\text { und } \\
\text { linke }\end{array}$ & $n$ & 8 \\
\hline 8 & $\begin{array}{l}12 . / \mathrm{V} \\
15 . / \mathrm{IX} \\
1910\end{array}$ & $\begin{array}{c}\text { Ālteres } \\
\text { Kaninchen }\end{array}$ & $n$ & $n$ & 8 \\
\hline 9 & \begin{tabular}{|}
$4 . / \mathrm{VII} \cdot \overline{-}$ \\
$25 . / \mathrm{VII} .1908$
\end{tabular} & $\begin{array}{l}\text { Junges } \\
\text { Kaninchen }\end{array}$ & rechte & Brillantrot & 7 \\
\hline
\end{tabular}


Klinische und experimentelle Untersuchungen etc.

Versuche.

\begin{tabular}{|c|c|c|c|}
\hline $\begin{array}{l}\text { Resultate } \\
\text { der Versuche }\end{array}$ & $\begin{array}{c}\text { Axzision } \\
\text { nach }\end{array}$ & $\begin{array}{l}\text { Fixierungs- } \\
\text { flitssigkeit }\end{array}$ & $\begin{array}{c}\text { Ergebnisse der } \\
\text { hi stologiachen Ontersuchung }\end{array}$ \\
\hline- & - & - & - \\
\hline- & - & - & - \\
\hline- & - & - & - \\
\hline- & - & - & - \\
\hline- & - & - & - \\
\hline $\begin{array}{l}\text { Dermatitis, außer- } \\
\text { dem stark vorsprin- } \\
\text { gende, den Follikeln } \\
\text { entsprechende } \\
\text { Knötchen; innere } \\
\text { Ohrfläche vom } \\
\text { reibeisenähnlichem } \\
\text { Aussehen }\end{array}$ & 5 Tagen nach & $\begin{array}{l}10 \% \\
\text { Formol }\end{array}$ & $\begin{array}{l}\text { Proliferation des Rete } \\
\text { Malpighil, Epithelprolife- } \\
\text { ration mit Epithelzapfen } \\
\text { und Hornperlen (epithe- } \\
\text { liomähnliches Bild). } \\
\text { Vergrößerung der Talg- } \\
\text { drüsen; entzündliche } \\
\text { Erscheinungen in der } \\
\text { Kutis im Abklingen } \\
\text { begriffen }\end{array}$ \\
\hline$\pi$ & $n$ & $\eta$ & 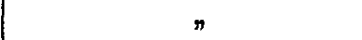 \\
\hline$n$ & $\mid \begin{array}{c}5 \text { Tagen nach } \\
\text { der } 8 . \mathrm{E} .\end{array}$ & 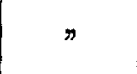 & $\pi$ \\
\hline $\begin{array}{c}\text { Dermatitis und } \\
\text { follikuläre } \\
\text { Knötchen; spontane } \\
\text { Involution } \\
\text { der Knötchen }\end{array}$ & - & - & - \\
\hline $\begin{array}{c}\text { Zirkumskripte } \\
\text { Dermatitis } \\
\text { (Knötchen mit } \\
\text { Farbstoff bedeckt) }\end{array}$ & $\begin{array}{c}3 \text { Tagen nach } \\
\text { der } 7 . \text { E. }\end{array}$ & $\begin{array}{l}10 \% \\
\text { Formol }\end{array}$ & $\begin{array}{l}\text { Proliferation d. Rete Malp. } \\
\text { in Form von verlängerten } \\
\text { and verbreiterten Zapfen, } \\
\text { Wucherung der Talgdrüs., } \\
\text { das Strat. corn. durch die } \\
\text { Exsudatmasse blasig abge- } \\
\text { hoben, entzündliche Ersch. } \\
\text { in der Kutis mit Epithel- } \\
\text { inseln(epitheliomähnl.Bild) }\end{array}$ \\
\hline
\end{tabular}

1) Die innere Ohrfläche zeigt makroskopisch bei den Versuchen 1-5 keine Veränderangen, daher wurden keine histologischen Untersuchungen durchgeführt. 
Sachs.

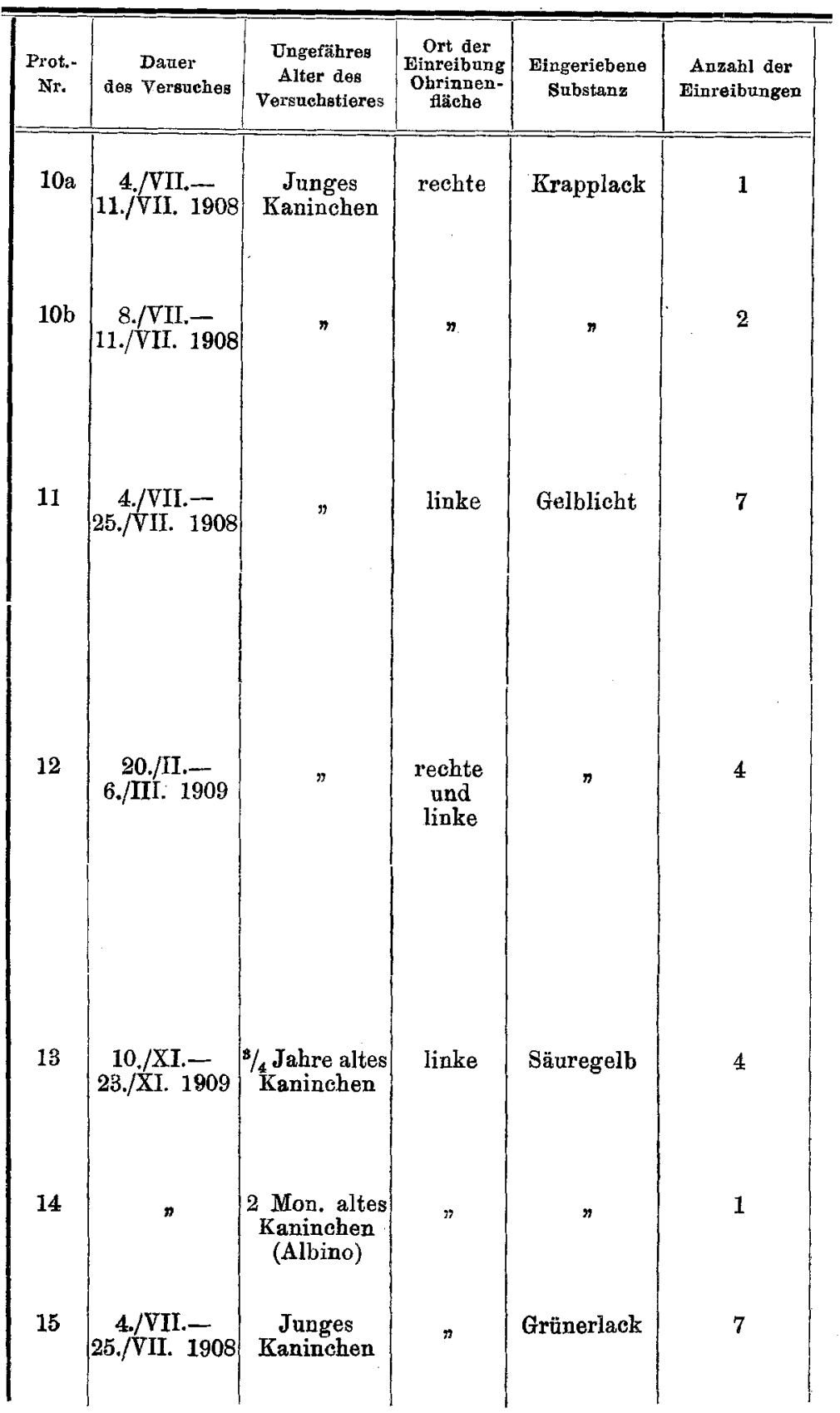




\begin{tabular}{|c|c|c|c|}
\hline $\begin{array}{l}\text { Resultate } \\
\text { der Versuche }\end{array}$ & $\begin{array}{l}\text { Exzision } \\
\text { nach }\end{array}$ & $\begin{array}{l}\text { Fixierungs- } \\
\text { fllissigkeit }\end{array}$ & $\begin{array}{c}\text { Ergebnisse der } \\
\text { histologischen Untersuchung }\end{array}$ \\
\hline $\begin{array}{c}\text { Ein mit rotem } \\
\text { Farbstoff bedecktes } \\
\text { Knötchen }\end{array}$ & 3 Tagen & $\begin{array}{l}10 \% \\
\text { Formol }\end{array}$ & $\begin{array}{l}\text { Entsprechend der Farb- } \\
\text { stoffauflagerung findet } \\
\text { sich ein die ganze Epi- } \\
\text { dermis und die obersten } \\
\text { Schichten der Kutis ein- } \\
\text { nehmender Substanzver- } \\
\text { lust, der durch eine } \\
\text { Exsudatmasse ansgefüllt } \\
\text { ist, in der Kutis alle } \\
\text { Stadien der Entzündung } \\
\text { bis zur Bildung eines } \\
\text { Granulationsgewebes }\end{array}$ \\
\hline $\begin{array}{c}\text { Zirkumskripte } \\
\text { Dermatitis } \\
\text { (Knötchen mit } \\
\text { Farbstoff bedeckt) }\end{array}$ & $\begin{array}{l}3 \text { Tagen nach } \\
\text { der } 7 . \mathrm{E} .\end{array}$ & $\eta$ & $\begin{array}{l}\text { Proliferation des Rete } \\
\text { Malpighii in Form von } \\
\text { verlängerten und verbrei- } \\
\text { terten Zapfen, Wucherung } \\
\text { der Talgdrüsen, das Strat. } \\
\text { corn. durch die Exsudat- } \\
\text { masse blasig abgehoben, } \\
\text { entzündl. Erschein. in der } \\
\text { Kutis mit Epithelinseln } \\
\text { (epitheliomähnliches Bild) }\end{array}$ \\
\hline $\begin{array}{l}\text { Dermatitis in Form } \\
\text { von Knötchen oder } \\
\text { warzigen, mit } \\
\text { Farbstoff bedeckten } \\
\text { Effloreszenzen }\end{array}$ & $\begin{array}{l}3 \text { Tagen nach } \\
\text { der } 4 . \mathrm{W} .\end{array}$ & $\begin{array}{l}10 \% \\
\text { Formol }\end{array}$ & $\begin{array}{l}\text { Das mit Farbstoff bedeckte } \\
\text { Strat. corn. wird durch } \\
\text { eine Exsudatmasse ilasig } \\
\text { abgehoben, ziemlich starke } \\
\text { Wucherung des Rete Malp. } \\
\text { sowie der Talgdrüsen, } \\
\text { entzündl. Erschein. in der } \\
\text { Kutis im Abklingen be- } \\
\text { griffen, mit vereinzelten } \\
\text { Epithelinseln } \\
\text { (epitheliomähnliches Bild) }\end{array}$ \\
\hline \begin{tabular}{|c|} 
Kleinste, mit \\
Farbstoff bedeckte, \\
stecknadelkopf- \\
große Knötchen
\end{tabular} & $\begin{array}{l}\text { 4 Tagen nach } \\
\text { der 4. E. }\end{array}$ & $\begin{array}{l}10 \% \\
\text { Formol }\end{array}$ & $\begin{array}{l}\text { Eine der Epidermis auf- } \\
\text { gelagerte Exsudatmasse } \\
\text { ohne Gewebszerstörung, } \\
\text { in der Kutis geringe } \\
\text { entzündl. Erscheinungen }\end{array}$ \\
\hline $\begin{array}{l}\text { Oberflächliche } \\
\text { Dermatitis }\end{array}$ & $\begin{array}{c}4 \text { Tagen nach } \\
\text { der } 1 . \mathrm{E} .\end{array}$ & $\eta$ & $\begin{array}{l}\text { Oberfiächl. Substanzver- } \\
\text { lust mit einer Exsudat- } \\
\text { masse ausgefüllt, im Kori- } \\
\text { um ein entzündl. Infiltrat }\end{array}$ \\
\hline $\begin{array}{c}\text { Zirkumskripte } \\
\text { Dermatitis } \\
\text { (Knötchen mit } \\
\text { Farbstoft bedeckt) }\end{array}$ & $\mid \begin{array}{c}3 \text { Tagen nach } \\
\text { der } 7 . \mathbf{E} .\end{array}$ & $n$ & $\begin{array}{l}\text { Derselbe Befund wie bei } \\
\text { Versuch } 10\end{array}$ \\
\hline
\end{tabular}




\begin{tabular}{|c|c|c|c|c|c|}
\hline $\begin{array}{l}\text { Prot.- } \\
\text { Nr. }\end{array}$ & $\begin{array}{c}\text { Dauer } \\
\text { des Versuches }\end{array}$ & $\begin{array}{c}\text { Ungefähres } \\
\text { Alter des } \\
\text { Versuehstieres }\end{array}$ & $\begin{array}{l}\text { Ort der } \\
\text { Einreibung } \\
\text { Ohrinnen- } \\
\text { fläche }\end{array}$ & $\begin{array}{l}\text { Eingeriebene } \\
\text { Substanz }\end{array}$ & $\begin{array}{l}\text { Anzahl der } \\
\text { Einreibungen }\end{array}$ \\
\hline 16 & $\begin{array}{c}5 . / \mathrm{I} .-3 . / \mathrm{II} . \\
1909\end{array}$ & $\begin{array}{c}\text { Älteres } \\
\text { Kaninchen }\end{array}$ & $\begin{array}{l}\text { rechte } \\
\text { und } \\
\text { linke }\end{array}$ & Grünerlack & 2 \\
\hline 17 & $\begin{array}{c}8 . / \mathrm{I} .-20 . / \mathrm{II} . \\
1909\end{array}$ & $"$ & $n$ & $n$ & 6 \\
\hline 18 & $\begin{array}{l}\text { 12./II.-- } \\
\text { 23./II. } 1909\end{array}$ & $\begin{array}{l}\text { Junges } \\
\text { Kaninchen }\end{array}$ & $"$ & $n$ & 3 \\
\hline 19 & $\begin{array}{l}\text { 24./II.- } \\
\text { 1.J.V. } 1909\end{array}$ & $\begin{array}{c}\text { Ältéres } \\
\text { Kaninchen }\end{array}$ & $n$ & $n$ & 13 \\
\hline 20 & $\begin{array}{l}26 . / \mathrm{III} .- \\
\text { 1./IV. } 1909\end{array}$ & $\begin{array}{l}\text { Jüngeres } \\
\text { Kaninchen }\end{array}$ & $n$ & $n$ & 2 \\
\hline 21 & $\begin{array}{c}\text { 10./XI. } \\
\text { 10./XII. 1909 }\end{array}$ & $\begin{array}{c}3 / 4 \text { Jahre altes } \\
\text { Kaninchen }\end{array}$ & linke & Säuregrün & 10 \\
\hline 22 & $\begin{array}{c}\text { 10./XI,- } \\
\text { 23./XI. } 1909\end{array}$ & $\begin{array}{c}\text { 2 Mon. altes } \\
\text { Kaninchen } \\
\text { (Albino) }\end{array}$ & $\pi$ & $"$ & 1 \\
\hline $23 a$ & $\begin{array}{c}26 . / \mathrm{X} .- \\
\text { 16./XI. } 1908\end{array}$ & 3 Monate & rechte & $\begin{array}{l}10 \% \text { Grüner- } \\
\text { lack-Lano- } \\
\text { linsalbe }\end{array}$ & 7 \\
\hline $23 \mathrm{~b}$ & $n$ & $n$ & linke & $\begin{array}{l}10 \% \text { Gelb- } \\
\text { licht-Lano- } \\
\text { linsalbe }\end{array}$ & 7 \\
\hline 24 & $\begin{array}{c}\text { 10./XI.- } \\
\text { 10./XII. 1909 }\end{array}$ & $\begin{array}{c}3 / 4 \mathrm{Jahre} \text { altes } \\
\text { Kaninchen }\end{array}$ & rechte & $\begin{array}{c}\text { Tonerdehy- } \\
\text { drat }\end{array}$ & 10 \\
\hline
\end{tabular}

1) Krusten abgestoßen, makroskopisch keine Veränderungen nachweisbar, innere Ohrfläche glatt und glänzend.

2) Außer den 3 E. Einlegen eines mit dem Farbstoff imprägnierten Wattebausches, die Ohrränder werden mit 2 Nähten vereinigt. Das in seiner Ernährung stark herabgekommene Tier ist eingegangen. 
Klinische und experimentelle Untersuchungen etc.

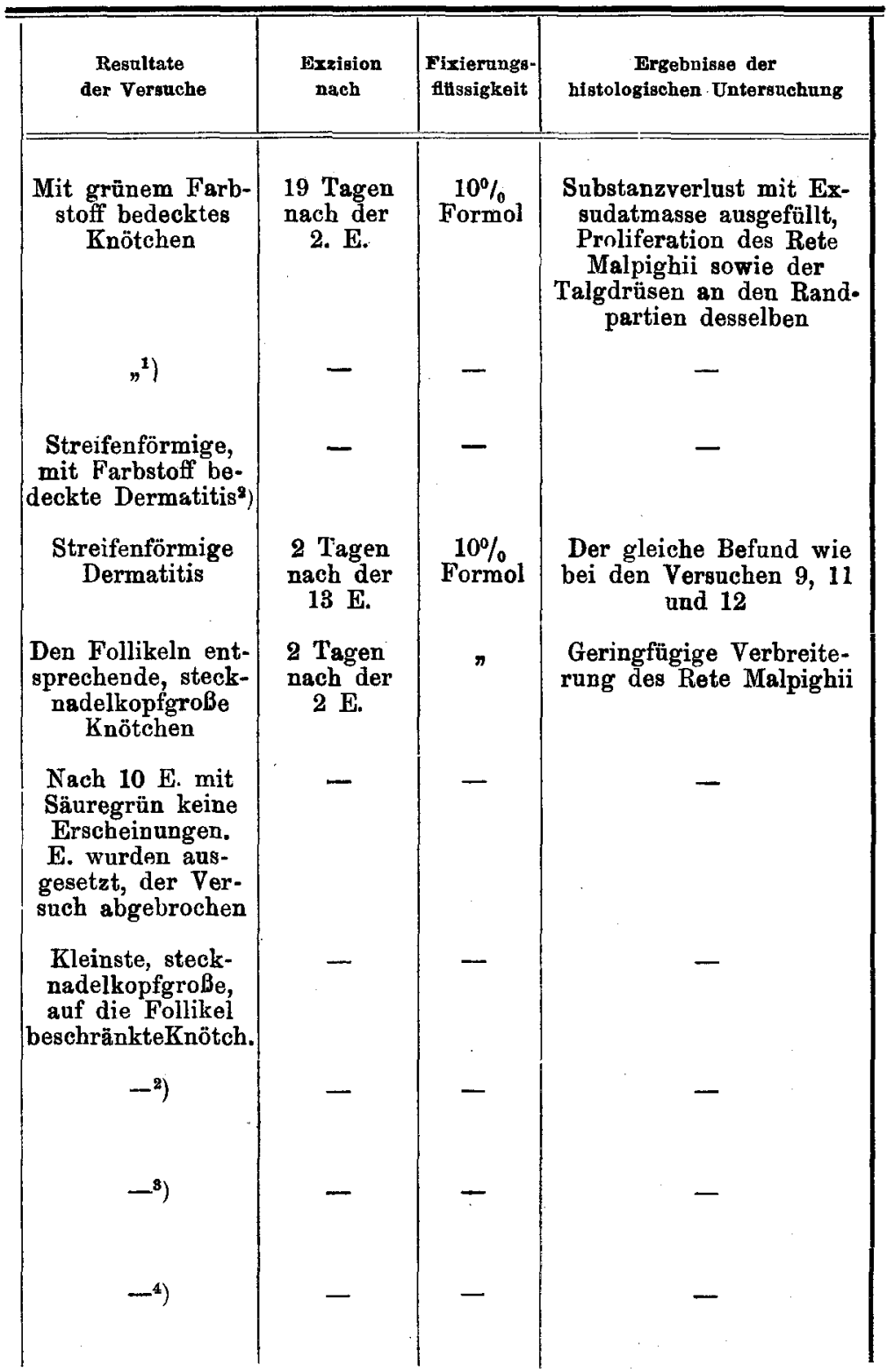

3) Makroskopisch keine Veränderungen nachweisbar; Ohrinnenfiäche vollständig intakt.

$\left.{ }^{4}\right)$ Nach Beendigung der 10. Einreibung mit Tonerdebydrat heilte die Exkoriation vollständig ab, daher erfolgte keine histologische Untersuchung. 


\begin{tabular}{|c|c|c|c|c|c|}
\hline $\begin{array}{l}\text { Prot.. } \\
\text { Nr. }\end{array}$ & $\begin{array}{c}\text { Dauer } \\
\text { des Versuches }\end{array}$ & $\begin{array}{c}\text { Ungefähres } \\
\text { Alter dos } \\
\text { Versuchstieres }\end{array}$ & $\begin{array}{l}\text { Ort der } \\
\text { Einreibung } \\
\text { Ohrinen- } \\
\text { fläche }\end{array}$ & $\begin{array}{l}\text { Fingeriebene } \\
\text { Substanz }\end{array}$ & $\begin{array}{c}\text { Anzahl der } \\
\text { Einreibungen }\end{array}$ \\
\hline 25 & $\begin{array}{c}\text { 10./XI.- } \\
\text { 23./XI. } 1909\end{array}$ & $\begin{array}{c}2 \text { Mon. altes } \\
\text { Kaninchen } \\
\text { (Albino) }\end{array}$ & rechte & $\begin{array}{l}\text { Tonerde- } \\
\text { hydrat }\end{array}$ & 1 \\
\hline 26 & $n$ & $\begin{array}{c}3 / 4 \text { Jahre altes } \\
\text { Kaninchen }\end{array}$ & $n$ & $\begin{array}{l}\text { Bariumsulfat } \\
\text { (Blane fixe) }\end{array}$ & 4 \\
\hline 27 & $"$ & $\begin{array}{c}2 \text { Mon. altes } \\
\text { Kaninchen }\end{array}$ & $n$ & Bariumsulfat & 1 \\
\hline
\end{tabular}

II. Injektions-

\begin{tabular}{|c|c|c|c|c|c|}
\hline $\begin{array}{l}\text { Prot.- } \\
\text { Nr. }\end{array}$ & $\begin{array}{c}\text { Dauer } \\
\text { des Versuches }\end{array}$ & $\begin{array}{c}\text { Ungefähres } \\
\text { Alter des } \\
\text { Versuchstieres }\end{array}$ & $\begin{array}{c}\text { Ort der } \\
\text { Injektion } \\
\text { Ohr: } \\
\text { innenfläehe }\end{array}$ & $\begin{array}{l}\text { Tnjizierte } \\
\text { Substanz }\end{array}$ & $\begin{array}{l}\text { Quantität der } \\
\text { injizierten } \\
\text { Substanz }\end{array}$ \\
\hline 1 & $\begin{array}{c}\text { 13./I.-17./II. } \\
1910\end{array}$ & $\begin{array}{l}\text { Junges } \\
\text { Kaninchen }\end{array}$ & rechte & $\begin{array}{l}\text { Scharlach- } \\
\text { rot-0livenöl } \\
(1 \cdot 0: 30 \cdot 0)\end{array}$ & $\begin{array}{c}\text { An zwei } \\
\text { Stellen zu je } \\
3 \mathrm{ccm}\end{array}$ \\
\hline 2 & $\mid \begin{array}{c}20 . / \mathrm{I}-17 . / \mathrm{II} . \\
1910\end{array}$ & $n$ & $n$ & $\begin{array}{c}\text { Soharlachöl } \\
(1 \cdot 0: 30 \cdot 0)\end{array}$ & $\begin{array}{l}\text { Im ganzen } \\
6 \mathrm{ccm}\end{array}$ \\
\hline 3 & \begin{tabular}{|c|} 
17./II.- \\
12./III. 1910
\end{tabular} & $n$ & $"$ & Scharlachöl & \begin{tabular}{|c|} 
Keine bestimmte \\
Quantität füir \\
die einzelnen \\
Quaddeln
\end{tabular} \\
\hline
\end{tabular}


Klinische und experimentelle Untersuchungen etc.

\begin{tabular}{|c|c|c|c|}
\hline $\begin{array}{c}\text { Resultate } \\
\text { der Versuche }\end{array}$ & $\begin{array}{l}\text { Exzision } \\
\text { nach }\end{array}$ & $\begin{array}{l}\text { Fixierungs- } \\
\text { flitissigkeit }\end{array}$ & $\begin{array}{c}\text { Ergebnisse der } \\
\text { histologischen Untersuchung }\end{array}$ \\
\hline $\begin{array}{l}\text { Im Abheilen be- } \\
\text { griffene oberfläch- } \\
\text { liche Exkoriation }\end{array}$ & $\begin{array}{l}4 \text { Tagen } \\
\text { nach der } \\
\text { 1. E. }\end{array}$ & $\begin{array}{l}10 \% \\
\text { Formol }\end{array}$ & $\begin{array}{l}\text { Eine durch geringe } \\
\text { Exsudatmasse ausgefüllte } \\
\text { Exkoriation, mit geringen } \\
\text { entzündlichen Erschei- } \\
\text { nungen in der Kutis }\end{array}$ \\
\hline $\begin{array}{l}\text { Keine } \\
\text { Erscheinungen }\end{array}$ & - & - & - \\
\hline$n$ & - & - & - \\
\hline
\end{tabular}

Versuche.

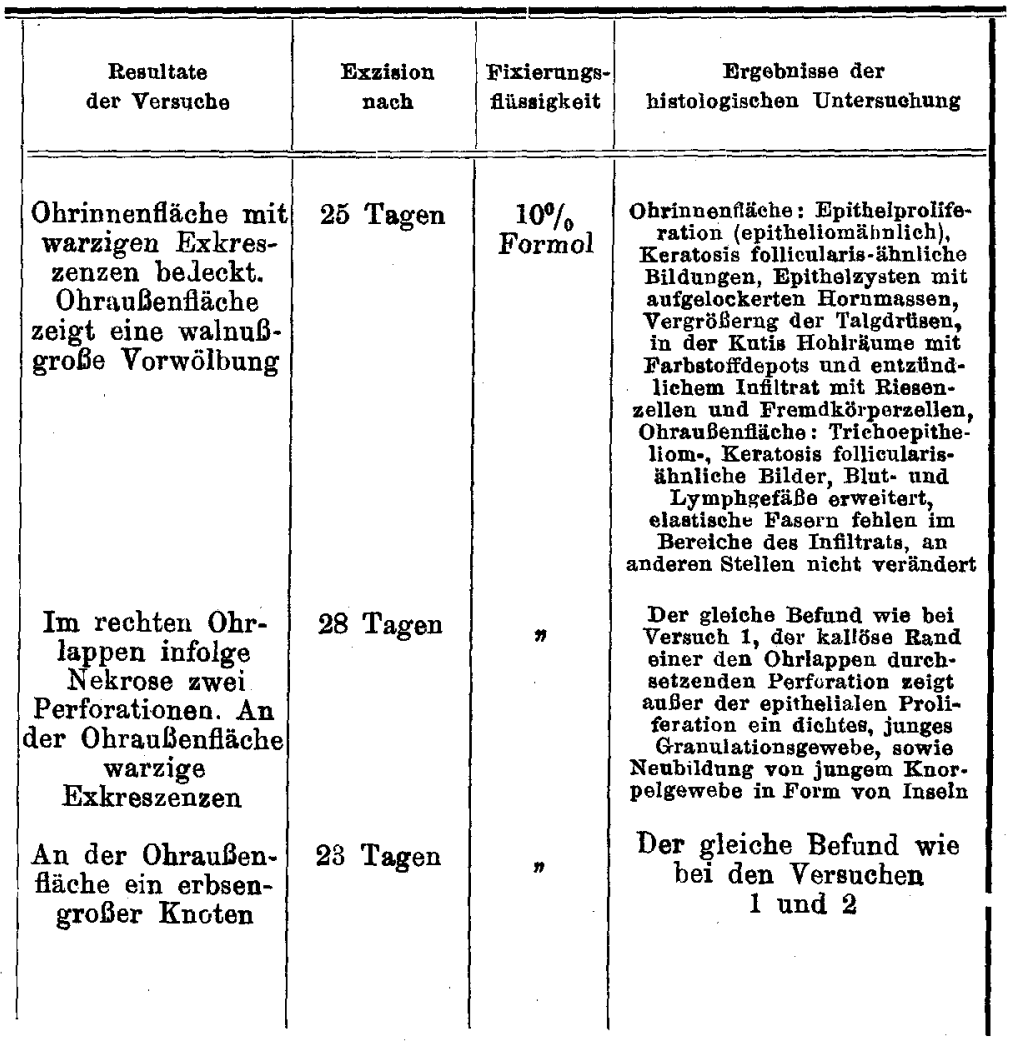




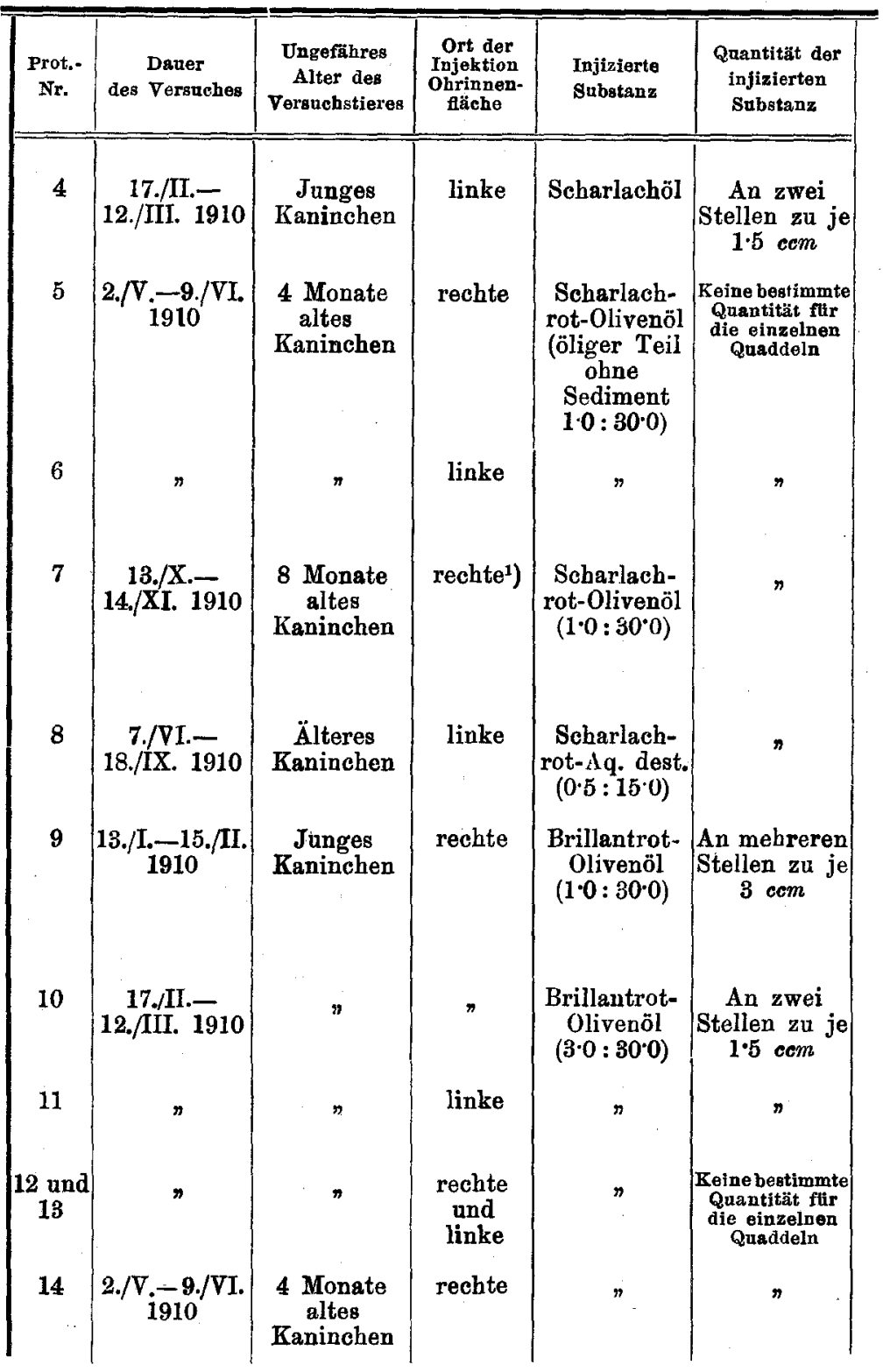

1) Die Injektion in das rechte Ohr fand nach Unterbindang der Arterie und Vene statt. 
Klinische und experimentelle Untersuchungen etc.

\begin{tabular}{|c|c|c|c|}
\hline $\begin{array}{l}\text { Resultate } \\
\text { der Versuche }\end{array}$ & $\begin{array}{l}\text { Exzision } \\
\text { nach }\end{array}$ & $\begin{array}{l}\text { Fixierungs- } \\
\text { filtssigkeit }\end{array}$ & $\begin{array}{c}\text { Ergebniase der } \\
\text { histologischen Untersuchung }\end{array}$ \\
\hline $\begin{array}{c}\text { An zwei Stellen } \\
\text { Nekrose }\end{array}$ & 23 Tagen & $\begin{array}{l}10 \% \\
\text { Formol }\end{array}$ & $\begin{array}{c}\text { Der gleiche Befund wie } \\
\text { bei den Versuchen } 1 \text {, } \\
2 \text { and } 3 .\end{array}$ \\
\hline $\begin{array}{l}\text { Um die nekrotischen } \\
\text { Stellen kleine waraige } \\
\text { Exkreszenzen, ebenso } \\
\text { um die Quaddeln und } \\
\text { auf dendelben }\end{array}$ & 38 Tagen & $"$ & $\begin{array}{l}\text { Ähnliche histologisehe } \\
\text { Veränderungen wie bei } \\
\text { den Versuchen } 1 \text { und } 2 \text {, } \\
\text { besonders bemerkenswert } \\
\text { sind die Keratosis foll.- } \\
\text { ähnlichen Bildungen }\end{array}$ \\
\hline $\begin{array}{l}\text { Ohrinnenfiäche mit } \\
\text { follikulären Exkres- } \\
\text { zenzen von reibeisen- } \\
\text { ahnlichem Aussehen }\end{array}$ & \# & $n$ & $\begin{array}{l}\text { Der gleiche Befund wie } \\
\text { beim Versuch } 5\end{array}$ \\
\hline \begin{tabular}{|l} 
In den Quaddeln \\
Perforationen, aus denen \\
kloine, warzige, \\
epithelisierte Erkres- \\
zenzen bervorragen, \\
diege haben das Aus- \\
sehen Beniler Wargen
\end{tabular} & 32 Tagen & $n$ & $\begin{array}{c}\text { Der gleiche Befund wie } \\
\text { bei Versuch 1, etwas } \\
\text { stärkere epitheliale } \\
\text { Proliferation }\end{array}$ \\
\hline $\begin{array}{l}\text { An einzelnen Quaddeln } \\
\text { Nekrosen mit in } \\
\text { Durchbruch begriffenen } \\
\text { Wucherungen }\end{array}$ & $\begin{array}{l}3 \text { Monaten } \\
\text { und } 13 \text { Tagen }\end{array}$ & $n$ & $\begin{array}{l}\text { Der gleiche Befund wie } \\
\text { bei Versuch } 1\end{array}$ \\
\hline 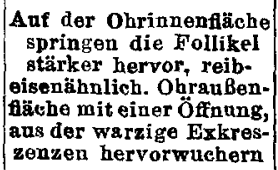 & 33 Tagen & $n$ & $\begin{array}{l}\text { Der gleiche Befund wie } \\
\text { bei Versuch 1, nur ist } \\
\text { die Fremdkörperzellen- } \\
\text { bildung eine reichlichere) }\end{array}$ \\
\hline \begin{tabular}{|c|} 
An der Injektionsstelle \\
oberfä̈chliche Nekrose
\end{tabular} \mid & 23 Tagen & $n$ & $\begin{array}{l}\text { Das gleiche Resultat wie } \\
\text { beim Versuch } 9\end{array}$ \\
\hline $\begin{array}{l}\text { Zwei einkronengrobe } \\
\text { Ulzerationen mit } \\
\text { warziger Oberfläche }\end{array}$ & $n$ & $n$ & $\begin{array}{l}\text { Das gleiche Resultat wie } \\
\text { bei den Versuchen } 9 \text { und } \\
\text { 10 }\end{array}$ \\
\hline $\begin{array}{l}\text { Quaddeln und } \\
\text { Ulzerationen }\end{array}$ & $n$ & $n$ & $\begin{array}{l}\text { Das gleiche Resultat } \\
\text { wie beim Versuch } 9\end{array}$ \\
\hline $\begin{array}{l}\text { Auf i. Obrinnenf. zahlr. } \\
\text { derbelnfiltr, nekr.Stellen } \\
\text { und anBerdem warzige, } \\
\text { follik. angeord. Exkres- } \\
\text { zenzen (Keratosis foll.- } \\
\text { annniiche Bildungen) }\end{array}$ & - & - & - \\
\hline
\end{tabular}

2) Eine Quaddel wurde in Serienschnitte zerlegt. 


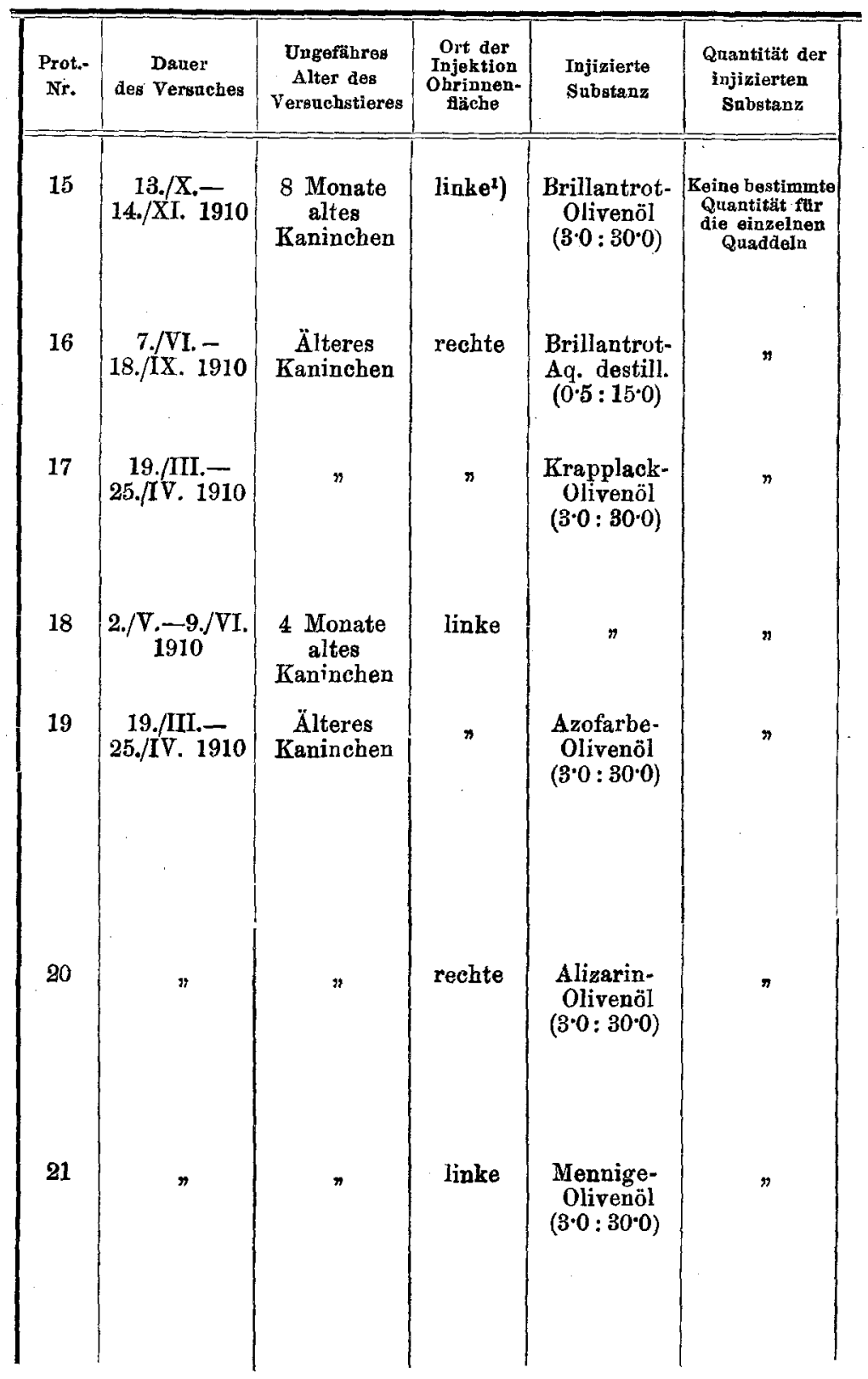

1) Unterbindung der Arterie und Vene des linken Ohres. 


\begin{tabular}{|c|c|c|c|}
\hline $\begin{array}{c}\text { Resultate } \\
\text { der Versuch } \theta\end{array}$ & $\begin{array}{c}\text { Exzision } \\
\text { nach }\end{array}$ & $\begin{array}{l}\text { Fixierungs- } \\
\text { fitissigkeit }\end{array}$ & $\begin{array}{c}\text { Ergebnisse der } \\
\text { histologischen Untersuchung }\end{array}$ \\
\hline $\begin{array}{l}\text { In den Quaddeln } \\
\text { Perforationen, aus } \\
\text { denen kleine, warzige, } \\
\text { epithelisierte Exkres- } \\
\text { zenzen hervorragen. } \\
\text { Diese haben das Aus- } \\
\text { sehen seniler Warzen }\end{array}$ & 32 Tagen & $\begin{array}{l}10 \% \\
\text { Eormol }\end{array}$ & $\begin{array}{c}\text { Der gleiche Befund wie } \\
\text { beim Versuch } 9 \text {; etwas } \\
\text { stärkere epitheliale } \\
\text { Proliferation }\end{array}$ \\
\hline $\begin{array}{l}\text { Einzelne Quaddeln } \\
\text { gut erhalten, eine } \\
\text { mit Perforation }\end{array}$ & $\begin{array}{l}3 \text { Monaten } \\
\text { und } \\
13 \text { Tagen }\end{array}$ & $\eta$ & $\begin{array}{l}\text { Der gleiche Befund wie } \\
\text { beim Versuch 9, nur sind } \\
\text { die Epithelproliferationen } \\
\text { etwas geringer }\end{array}$ \\
\hline $\begin{array}{c}\text { An der Ohrinnen- } \\
\text { fläche Infiltrate } \\
\text { und nekrotische } \\
\text { Stellen }\end{array}$ & 37 Tagen & $\eta$ & $\begin{array}{c}\text { Proliferation des Rete Mal- } \\
\text { pighii ist nicht so stark wie } \\
\text { bei Injektion von Scharlachrot } \\
\text { und Brillantrot-Olivenöl, } \\
\text { starke entzündliche Erschei- } \\
\text { nungen mit Fremdkörper- nnd } \\
\text { Riesenzellembildung }\end{array}$ \\
\hline $\begin{array}{l}\text { Einzelne Quaddeln gut } \\
\text { erhalten, einzelne } \\
\text { infolge Nekrose zu } \\
\text { Ulzera umgewandelt }\end{array}$ & 38 Tagen & $n$ & $\begin{array}{c}\text { Das gleiche Resultat } \\
\text { wie beim Versuch 17.2) }\end{array}$ \\
\hline $\begin{array}{l}\text { Ein kleiner Teil } \\
\text { der Injektions- } \\
\text { füssigkeit an der } \\
\text { Ohrinnenfläche, der } \\
\text { größte Teil an der } \\
\text { Ohraußenfläche, } \\
\text { außerdem ein } \\
\text { kleiner derber } \\
\text { Knoten fühlbar }\end{array}$ & 37 Tagen & 》 & $\begin{array}{l}\text { Fehlen der epithelialen Pro- } \\
\text { liferation, geringe Verbreite- } \\
\text { rung der Haarwurzelscheiden } \\
\text { und Talgdrisen, in der Kutis } \\
\text { hat das entzündliche Infiltrat } \\
\text { den Charakter eines jungen } \\
\text { Granulationsgewebes mit zahl- } \\
\text { reichen Fremdkörper- und } \\
\text { Riesenzellen und phago- } \\
\text { zytiertem Farbstoff }\end{array}$ \\
\hline $\begin{array}{l}\text { Auf der Ohrinnenfläche } \\
\text { Quaddeln. Der gröbte } \\
\text { Teil der Injektions- } \\
\text { masse befindet gich an } \\
\text { der Ohraaßenfläche. } \\
\text { Keine Nekrose }\end{array}$ & $n$ & $n$ & $\begin{array}{l}\text { Fehlen der epithelialen } \\
\text { Proliferation, starke ent- } \\
\text { zündliche Erscheinungen } \\
\text { in der Kutis mit Abszeß- } \\
\text { bildung und reichlicher } \\
\text { Fremdkörper- und } \\
\text { Riesenzellenanhänfung }\end{array}$ \\
\hline $\begin{array}{l}\text { Auf der Ohrinnen- } \\
\text { fläche nekrotische } \\
\text { Stellen und Infil- } \\
\text { trate, anf der Ohr- } \\
\text { auBenfläche drei } \\
\text { Infiltrate }\end{array}$ & $n$ & $n$ & $\begin{array}{l}\text { Geriigere Proliferation } \\
\text { des Rete Malpighii als } \\
\text { bei Injektion von Anilin- } \\
\text { farbstoffen, Epithelzysten, } \\
\text { starke entzüdl. Erschein. } \\
\text { in der Kutis mit beträcht- } \\
\text { licher Fremdkörper- nnd } \\
\text { Riesenzellenbildung }\end{array}$ \\
\hline
\end{tabular}

2) Eine Quaddel wurde in Serienschnitte zerlegt. 


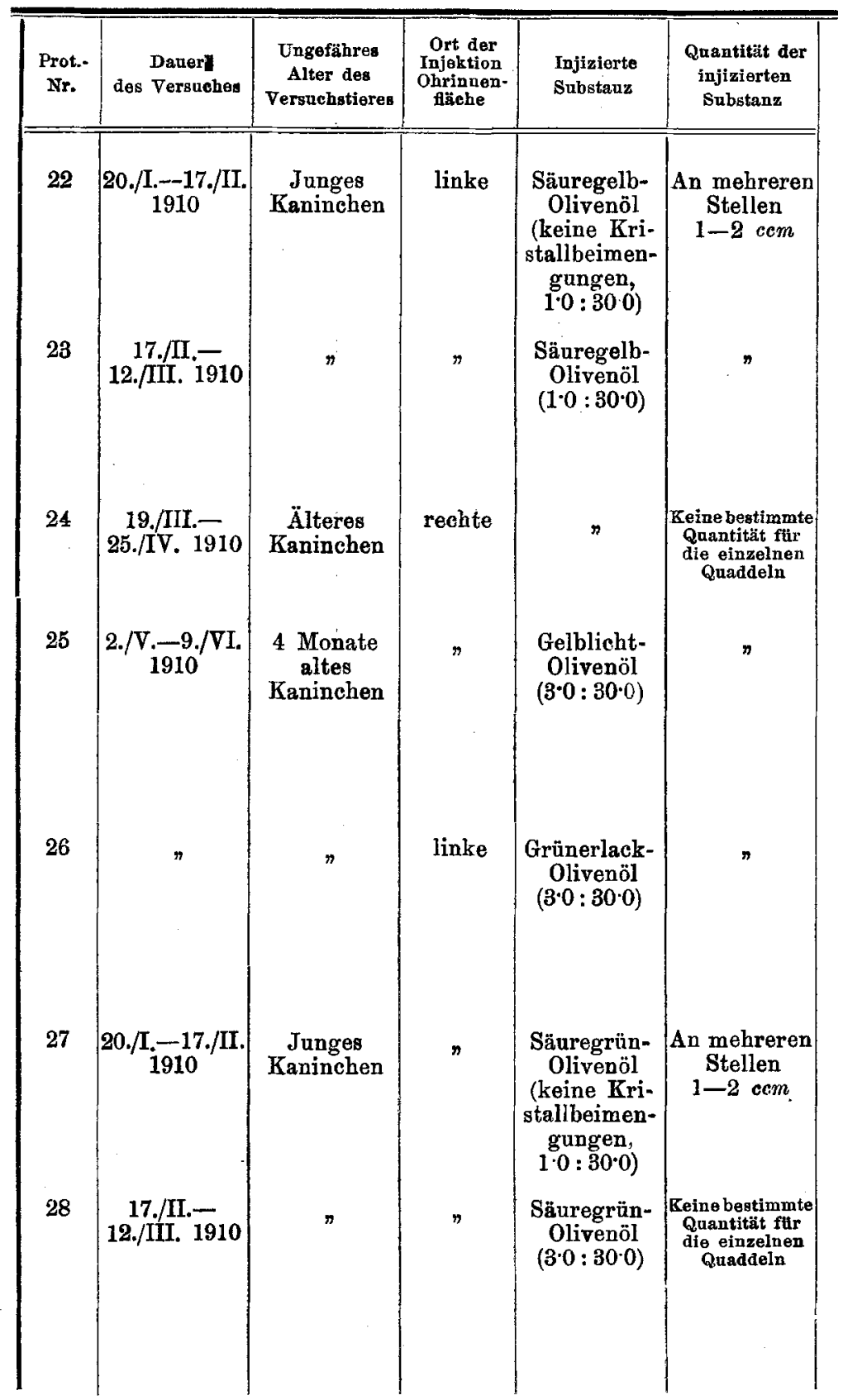




\begin{tabular}{|c|c|c|c|}
\hline $\begin{array}{c}\text { Resultate } \\
\text { der Versuche }\end{array}$ & $\begin{array}{l}\text { Exzision } \\
\text { nach }\end{array}$ & $\begin{array}{l}\text { Fixierungs- } \\
\text { fltsaigkeit }\end{array}$ & $\begin{array}{c}\text { Ergebnisse der } \\
\text { histologisehen Untersuchung }\end{array}$ \\
\hline $\begin{array}{l}\text { Nekrose an Stelle } \\
\text { der Quaddeln, } \\
\text { Perforationsulkus } \\
\text { mit kallösen } \\
\text { Rändern }\end{array}$ & - & - & $\begin{array}{l}\text { Der gleiche Befund wie } \\
\text { beim Versuch } 2\end{array}$ \\
\hline $\begin{array}{l}\text { An Stelle der } \\
\text { Quaddeln zwei } \\
\text { Ulzerationen }\end{array}$ & 23 Tagen & $\begin{array}{l}10 \% \\
\text { Formol }\end{array}$ & $\begin{array}{l}\text { Der gleiche Befund wie } \\
\text { bei Versuch } 1 \text { und } 9, \\
\text { Fehlen von Riesen- und } \\
\text { Fremdkörperzellen und } \\
\text { etwas geringere Prolife- } \\
\text { ration des Rete Malp. }\end{array}$ \\
\hline $\begin{array}{l}\text { Quaddeln, Nekrosen } \\
\text { und Ulzera }\end{array}$ & 37 Tagen & n & $\begin{array}{l}\text { Der gleiche Befund wie } \\
\text { bei Versuch 23, nur } \\
\text { geringere Riesen- und } \\
\text { Fremdkörperzellenbildung }\end{array}$ \\
\hline $\begin{array}{c}\text { Die meisten Quad- } \\
\text { deln nekrotisch, } \\
\text { außerdem in der } \\
\text { Umgebung } \\
\text { follikuläre warzige } \\
\text { Exkreszenzen }\end{array}$ & 38 Tagen & $n$ & $\begin{array}{c}\text { Ähnliche Resultate wie bei } \\
\text { Versuch 1 nnd 9, etwas } \\
\text { geringere Epithelproliferation, } \\
\text { starkere entzindliche } \\
\text { Erscheinungen in der Kutis } \\
\text { mit beträchtlicher Riesen- und } \\
\text { Fremdkôrperzellenbildung, } \\
\text { einzelne Quaddeln mit } \\
\text { Perforationöffnungen infolge } \\
\text { Nekrose }\end{array}$ \\
\hline \begin{tabular}{|} 
Auf der Ohrinnen- \\
fläche zahlreiche \\
derbe Infiltrate, \\
außerdem follikulär \\
angeordneteKnötch.
\end{tabular} & $n$ & $n$ & $\begin{array}{l}\text { Proliferation des Rete } \\
\text { Malp. mit Epithelzysten, } \\
\text { in der Kutis dichtes } \\
\text { Zellinfiltrat mit zahl- } \\
\text { reichen Fremdkörper- } \\
\text { und Riesenzellen und } \\
\text { phagozytierten Kristallen }\end{array}$ \\
\hline 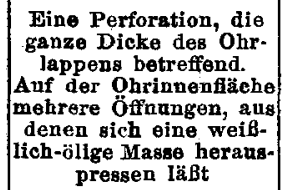 & 28 Tagen & $\begin{array}{l}10 \% \\
\text { Formol }\end{array}$ & $\begin{array}{l}\text { Ähnliche Befunde wie } \\
\text { bei Versuch 1,9 und } 23 \text {, } \\
\text { nur etwas geringere } \\
\text { Proliferation des Rete } \\
\text { Malp., Fehlen der Fremd- } \\
\text { körper- und Riesenzellen }\end{array}$ \\
\hline $\begin{array}{c}\text { An mehreren } \\
\text { Stellen Nekrose }\end{array}$ & 23 Tagen & $\begin{array}{l}10 \% \\
\text { Formol }\end{array}$ & $\begin{array}{l}\text { Das gleiche Resultat wie beim } \\
\text { Versueh 27, nur reichliche } \\
\text { Fremdkörper- und Riesenzellen } \\
\text { von besonderer Grö Be, der } \\
\text { kallöse Rand ergab histologisech } \\
\text { den gleichen Befund wie bei } \\
\text { den Versuchen } 2 \text { und } 22\end{array}$ \\
\hline
\end{tabular}




\begin{tabular}{|c|c|c|c|c|c|}
\hline $\begin{array}{l}\text { Prot.- } \\
\text { Nr. }\end{array}$ & $\begin{array}{c}\text { Daner } \\
\text { des Versuches }\end{array}$ & $\begin{array}{l}\text { Ungefähres } \\
\text { Alter des } \\
\text { Versuchstieres }\end{array}$ & $\begin{array}{c}\text { Ort der } \\
\text { Injektion } \\
\text { Ohrinnen- } \\
\text { fäche }\end{array}$ & $\begin{array}{l}\text { Injizierte } \\
\text { Substanz }\end{array}$ & $\begin{array}{l}\text { Quantität der } \\
\text { injizierten } \\
\text { Substanz }\end{array}$ \\
\hline 29 & $\begin{array}{l}\text { 19./III.- } \\
\text { 25./IV. } 1910\end{array}$ & $\begin{array}{c}\text { Älteres } \\
\text { Kaninchen }\end{array}$ & linke & $\begin{array}{c}\text { Säuregrün- } \\
\text { Olivenöl } \\
\left(3 \cdot 0: 30^{\circ} 0\right)\end{array}$ & $\begin{array}{l}\text { Keine bestimmte } \\
\text { Quantität für } \\
\text { die einzelnen } \\
\text { Quaddeln }\end{array}$ \\
\hline 30 & $\begin{array}{l}\text { 7./VI. }- \\
\text { 18./IX. } 1910\end{array}$ & $\pi$ & rechte & $\begin{array}{l}\text { Reines, nicht } \\
\text { sterilisiertes } \\
\text { Olivenöl }\end{array}$ & 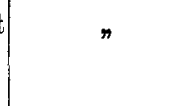 \\
\hline $31 a$ & \begin{tabular}{|} 
5./VII.- \\
31./VII. 1911
\end{tabular} & $\begin{array}{c}\text { Junges } \\
\text { Kaninchen }\end{array}$ & $n$ & $n$ & $"$ \\
\hline $31 b$ & $"$ & $n$ & linke & $n$ & $n$ \\
\hline 32 & $\begin{array}{c}29 . / \text { VII. }-\overline{\text { III. }} \\
\text { 20./VIII }\end{array}$ & $\begin{array}{c}8-10 \text { Monate } \\
\text { altes } \\
\text { Kaninchen }\end{array}$ & $\begin{array}{l}\text { rechte } \\
\text { und } \\
\text { linke }\end{array}$ & $n$ & " \\
\hline 33 & $\begin{array}{l}29 . / \text { VII.- } \\
7 . / \text { X. } 1912\end{array}$ & $"$ & $n$ & $n$ & $n$ \\
\hline 34 & $\begin{array}{l}\text { 26./VII.-- } \\
7 . / \text { X. } 1912\end{array}$ & $"$ & $"$ & $\begin{array}{c}\text { Reines, } \\
\text { sterilisiertes } \\
\text { Olivenöl }\end{array}$ & $n$ \\
\hline 35 & $\begin{array}{l}\text { 26./VII.- } \\
\text { 14./X. } 1912\end{array}$ & $"$ & $n$ & $"$ & $n$ \\
\hline
\end{tabular}




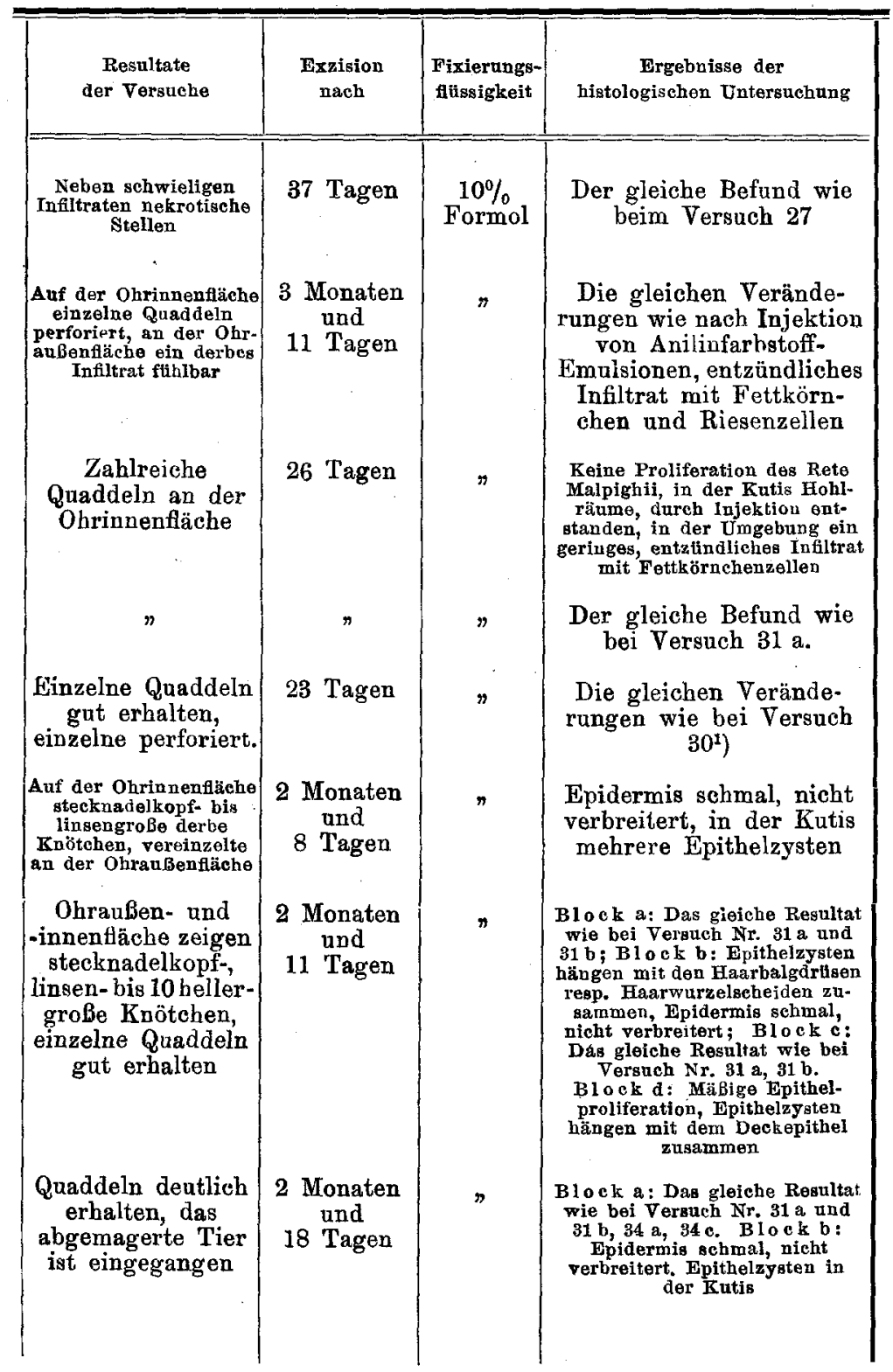

1) Ein Knoten wurde in Serienschnitte zerlegt. 


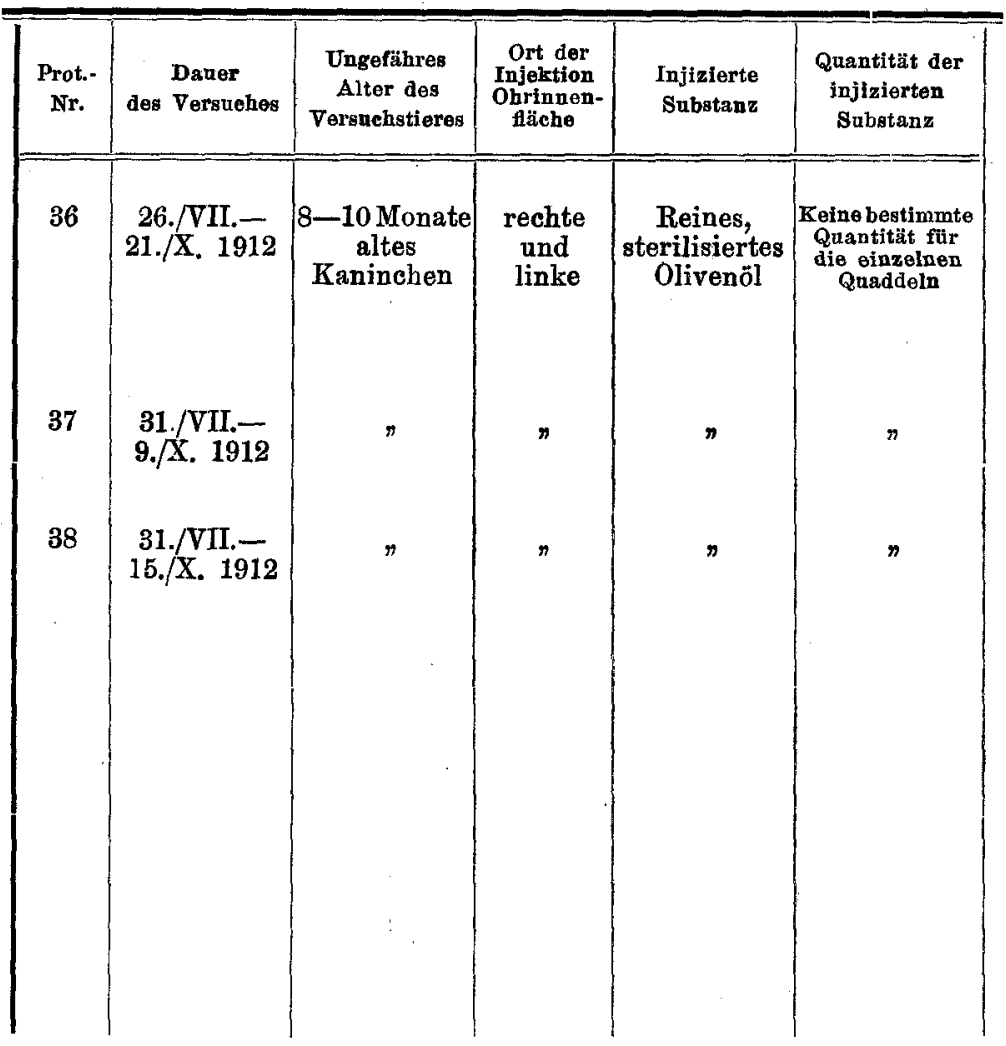

Fig. 3. Schnitt durch ein mit Brillantrot bedecktes Knötchen, entstanden nach acht Einreibungen von Brillantrot a die Ohrinnenfläche eines jungen Kaninchens. (9. Versuch; Versuchsdauer 22 Tage.) Fixierung in 10\%igem Formol, Härtung in Alkohol. Färbung mit Haemalaun-Eosin. 85fache Vergrößerung. - Entsprechend der Farbstoffauflagerung findet sich das Stratum corneum vom Rete Malpighii duch eine Exsadatmasse blasig abgehoben. Die Verbreiterung und pathologische Proliferation des Rete Malpighii, mit Zapfenbildung, Epithelinseln, Hornperlen in den Epithelzapfen, veranlabtein epitheli o mähnliches Bild. Außerdem sind die Talgdrüsen vergrößert, jn der Kutis die entzündlichen Erscheinungen im Abklingen begriffen und an Stelle des entzündlichen Infiltrats ein junges Granulationsgewebe.

Fig. 4. Schnitt durch ein mit Gelblicht bedecktes Knötchen, entstanden nach vier Einreibungen von Gelblicht auf die Ohrinnenfläche eines jungen Kaninchens. (12. Versuch; Versuchsdauer $14 \mathrm{Tage.}$ ) Fixierung in $10 \%$ igem 


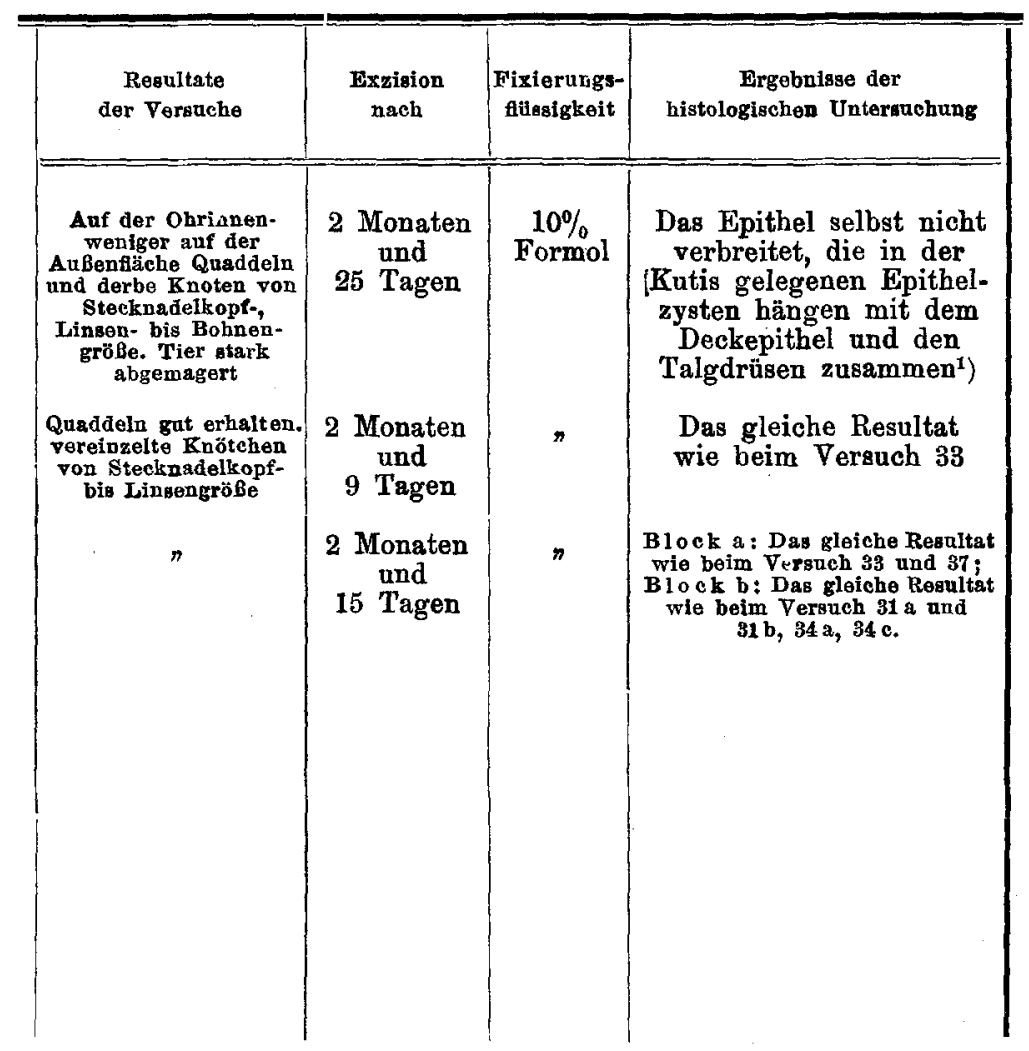

1) Ein Knoten wurde in Serien zeriegt.

Formol und Härtung in Alkohol. Färbung mit Haemalaun-Eosin. 62fache Vergrößerung. - Das mit dem Farbstoff Gelblicht bedeckte Knötchen besteht aus einer Exsudatmasse, welche das Stratum cornenm blasig vom Rete Malpighii abhebt. Durcb die ziemlich starke Verbreiterung und pathologische Proliferation des Rete Malpighii, mit Zapfenbildung und Epithelinseln in der Kutis entsteht ein epitheliomähnliches Bild. In den erweiterten Follikeln finden sich aufgelockerte und konzentrisch angeordnete Hornschichtlamellen. Die Talgdrüsen beträchtlich vergröBert, stehen mit den verbreiterten Zapfen in Verbindung. In der Kutis sind die entzündliche Erscheinung im Abklingen begriffen.

Fig. 5. Schnitt durcheinen Knoten, entstanden nach subkutaner Injektion von Brillantrot-0livenöl (1.0: 300$)$ in die rechte Ohrinnenfläche eines jungen Kaninchens. (9. Versuch; Versuchsdauer 33 Tage.) Fixierung in $10 \%$ igem Formol. Härtung in Alkohol. Färbung mit Haemalaun-Eosin. - Epitheliomähnliche Bildungen. 75fache Vergrößerung. An der Ohrinnenfläche konstatiert man eine Verbreiterung und pathologische Proli- 
feration des Rete Malpighii mit Zapfenbildung und Epithelinseln, wodurch das epitheliomähnliche Bild entsteht. Die erweiterten Follikel mit den vermehrten, aufgelockerten, konzentrisch geschichteten, das Hautniveau überragenden Hornschichtlamellen, sowie den eingepflanzten Lanugohaaren zeigen ein der Keratosis follicularis ähnliches Bild. Die Talgdrüsen sınd vergrößert, Blut- und Lymphgefäße erweitert.

Fig. 6. Derselbe Schnitt. Trichoepitheliomähnliche Bildungen. 48fache Vergrößerung. An der Ohraußentläche ist das Rete Malpighii etwas verbreitert. Die Follikel sind erweitert und bieten mit den Hornschichtlamellen ein der Keratosis follicularis älntiches Bild dar. Mit dem Rete Malpighii hängen kleinere Epithelzysten zusammen, von denen einige geschlossen sind und einige sich nach außen öffuen. Im Stratum papillare und subpapillare sind die Haarwurzelscheiden, die quer oder schräg getroffen erscheinen, bedeutend verbreitert, lassen in ihrem zentralen Anteile stets den Querschnitt eines Haares erkennen. Einige dieser verbreiterten Haarwurzelscheiden stehen wiederum mit dem verbreiterten Rete Malpighii in Verbíndung. Dieses Bild der verbreiterten Haarwurzelscheiden hat eine gewisse Ähnlichkeit mit dem von Jarisch beschriebenen Trichoepithelioma pa pillosum. BJut- und Lymphgefäße erweitert. In der Nähe dieser, sowie der durch die Farbstoffemulsion entstandenen Hohlräume, die mit endothelähnlichen Zellen ausgekleidet sind, finden sich Fremdkö r perzellen in Gruppen angeordnet. In beiden unteren Quadranten dieses Bildes sind Teile der Epithelzystenwand za sehen. Die entzündlichen Erscheinungen in der Kutis im Abklingen begriffen.

Fig. 7. Derselbe Schnitt. Keratosis follicularis-ähnliche Bildungen. 75fache Vergrößerung. Díe Ohraußenfläche zeigt gleichfalls eine Verbreiterung des Rete Malpighii mit Zapfenbildung. Die Follikel sind erweitert und mit aufgelockerten, konzentrisch geschichteten Hornschichtlamellen, welche zapfen- oder kegelartig hervorragen, erfüllt und enthalten ein oder mehrere Lanugohaare. Histologisch sowie klinisch entspricht dieses Bild der Keratosis follicularis.

Fig. 8. Derselbe Schnitt. Fremdkörperzellen. 310fache Vergrößerung. $Z$ wischen den Bindegewebszellen lagern sich Fremdkörperzellen in Haufen. Diese Lellen sind von runder, ovaler oder auch polygonaler Form, von graugelber Farbe, granuliert mit einem großen randständigen Kern. Bei Untersuchung mit der Immersionsłinse kann man die Granula als Farbstoffkristalle dentlich erkennen und außerdem eine honigwabenähnliche (vakuolisierte) Struktur. Diese Zellen färben sich im Gefrierschnitt mit Sudan III, geben mit Osmium die charakteristische Fettreaktion. In der Nähe dieser Zellen ist eine Arterie quer getroffen, die Gefäßwand ein wenig kontrahiert, die Endothelien nur wenig gequollen. Fig. 9. Schnitt durch einen Knoten, entstanden nach subkutaner Injektion von reinem, sterilisiertem Olivenöl in die Ohrinnenfläche eines älteren Kaninchens. (30. Versuch; Versuchsdauer 3 Monate und 13 Tage.) Fixierung in $10 \%$ igem Formol and Härtung in Alkohol. Färbung mit HaemalaunEosin. 48fache Vergrößerung. Verbreiterung und pathologische Proliferation des Rete Malpighii mit Zapfenbildung und Epithelinseln in der Kutis veranlassen ein epitheliomähnliches Bild. In der Kutis sind nebeneinander eine Epithelzyste, sowie ein mit endothelähnlichen Zellen ausgekleideter Hohlraum, der durch Injektion von Olivenöl entstanden ist, zu sehen. In der Kutis selbst läßt sich als Residuam derentzündlichen Erscheinungen ein junges Gronulationsgewebe nachweisen.

Eingelaufen am 3. März 1913. 


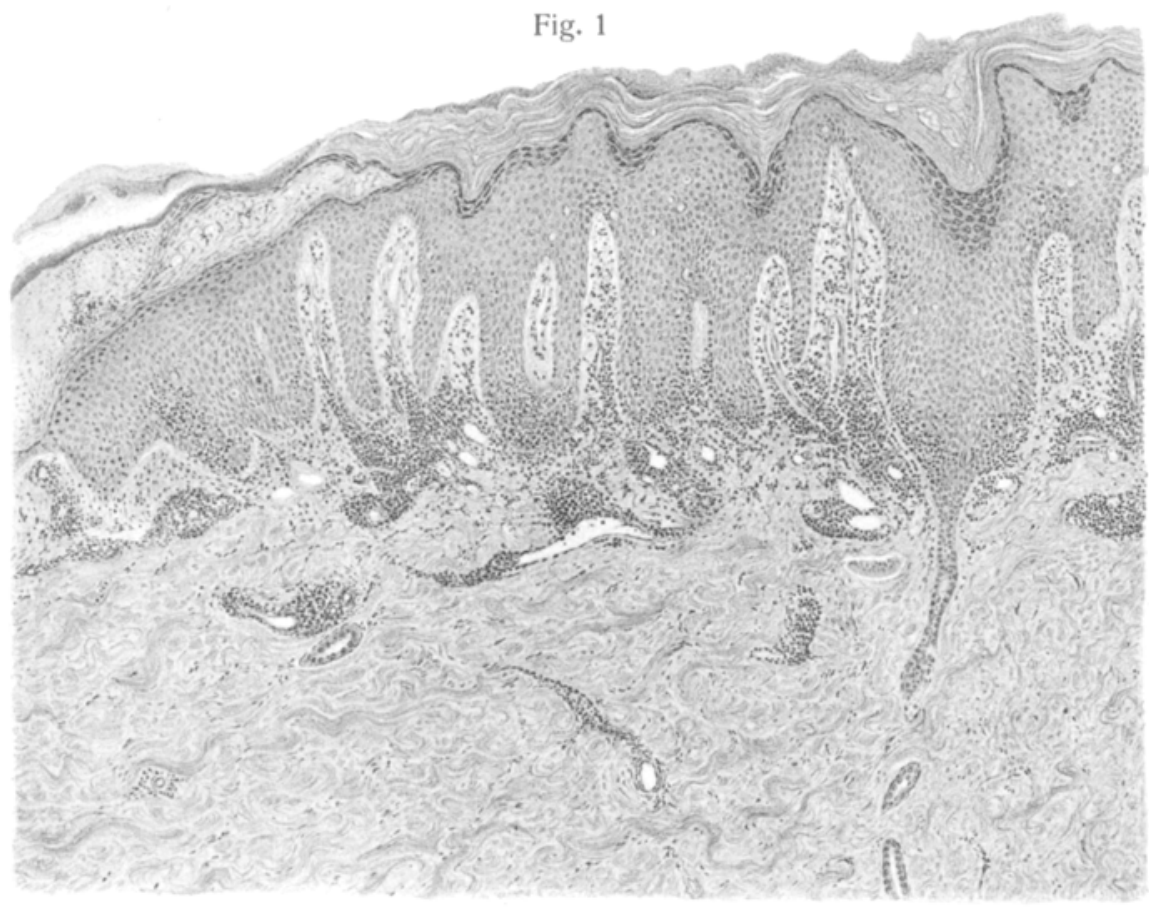

Fig. 2

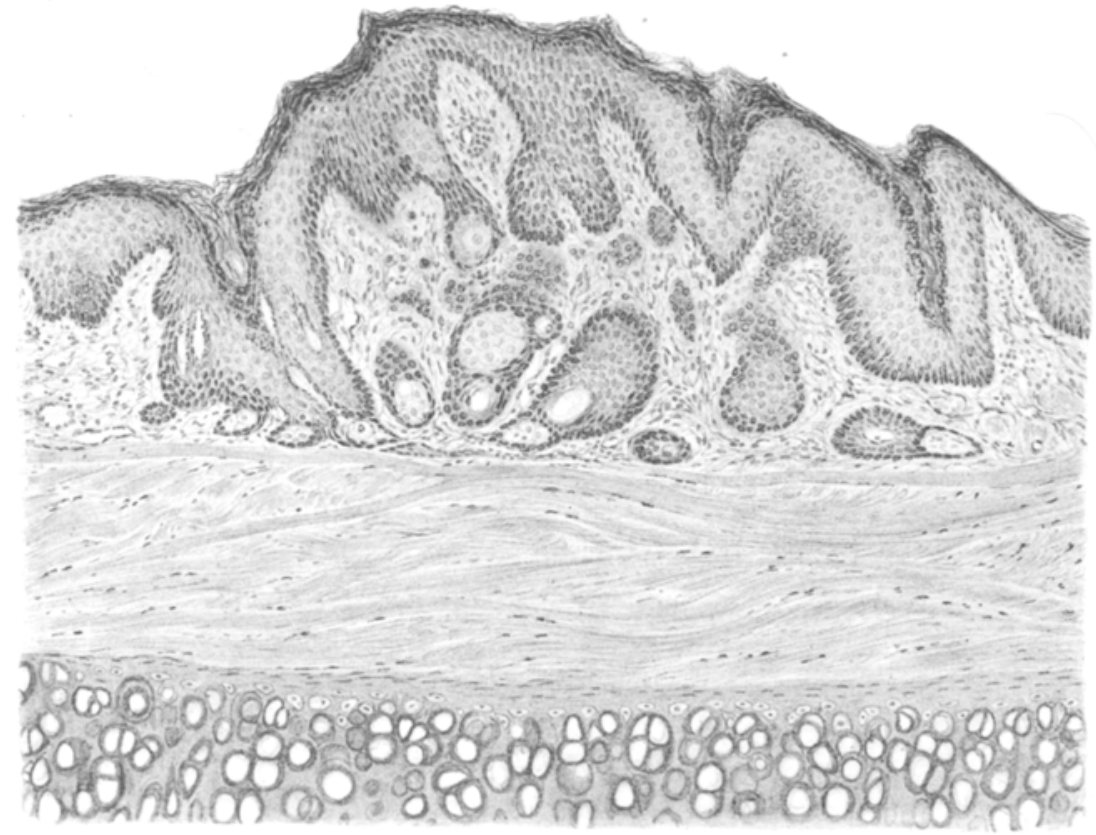

Sachs: Wirkung von Anilinfarbstoffen aufdie Haut. 
Fig. 3

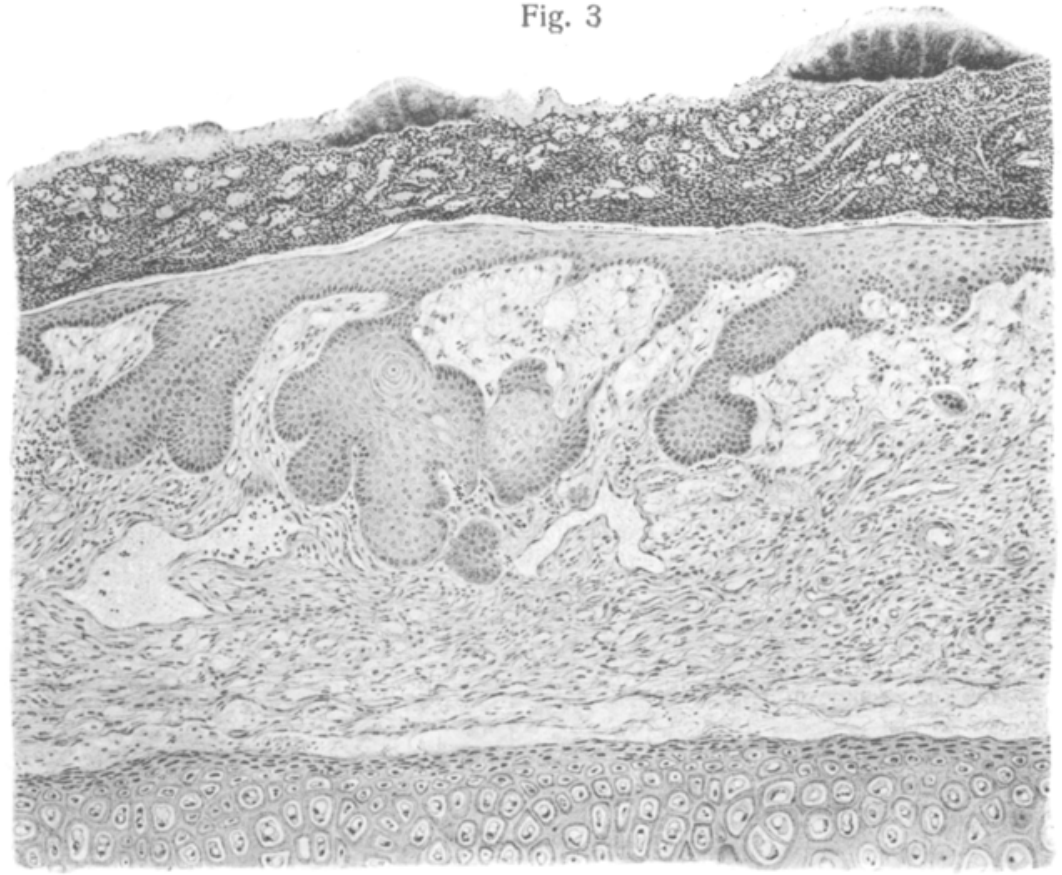

Fig. 4

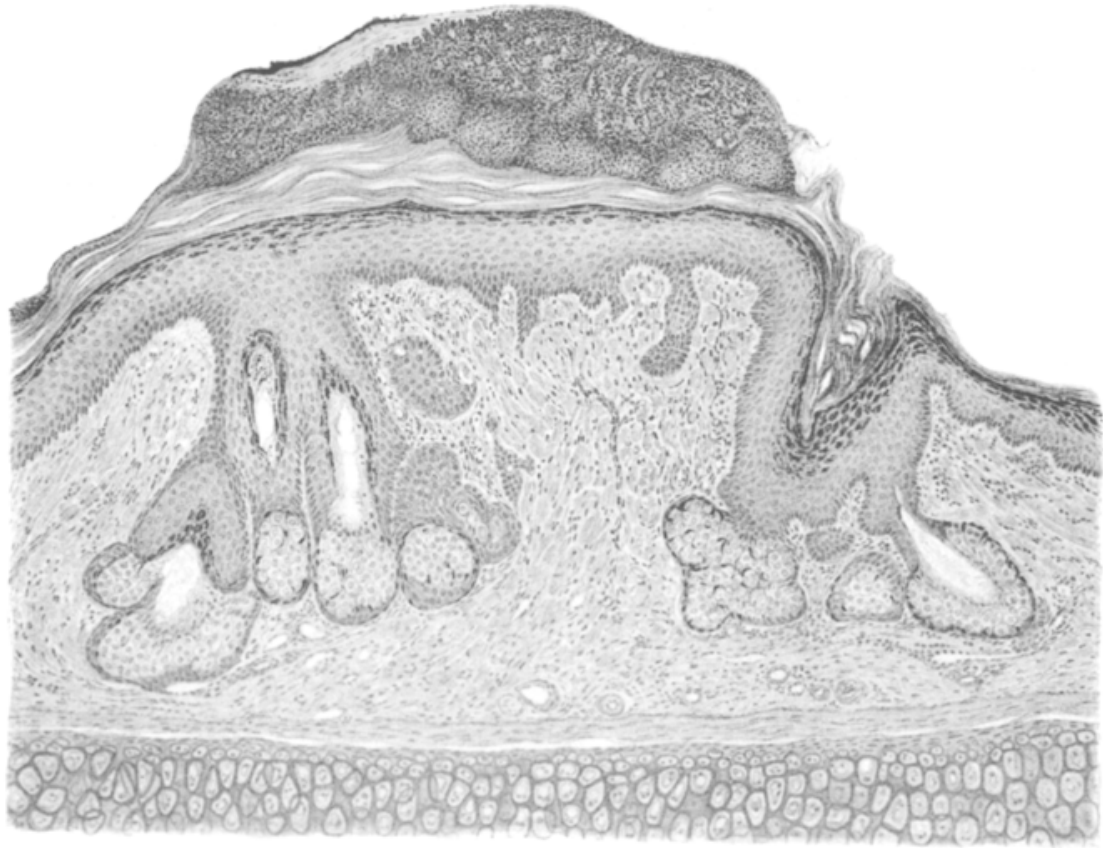

Sachs: Wirkung von Anilinfarbstoffen auf die Haut. 
Fig. 5
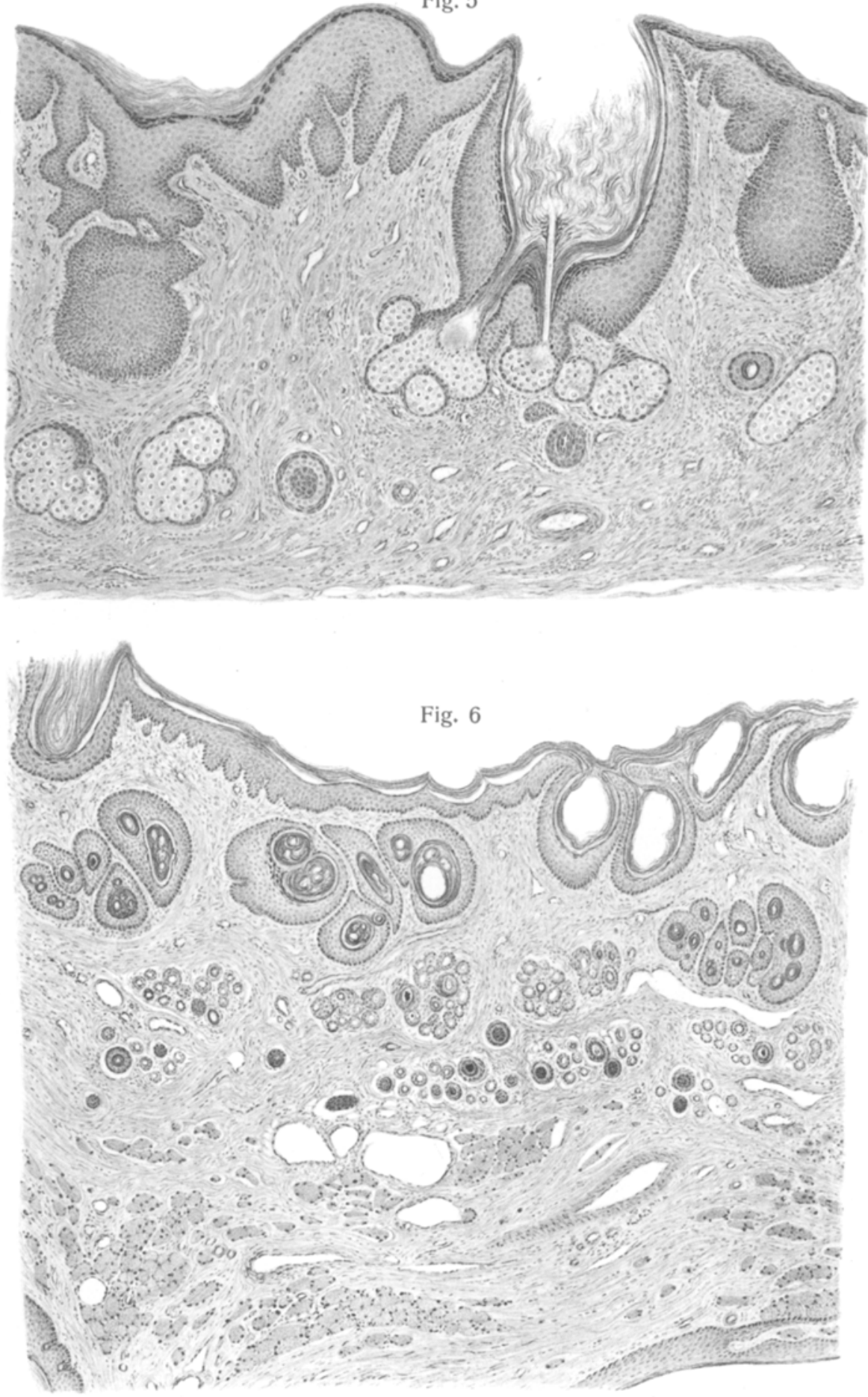

Sachs: Wirkung von Anilinfarbstoffen auf die Haut. 


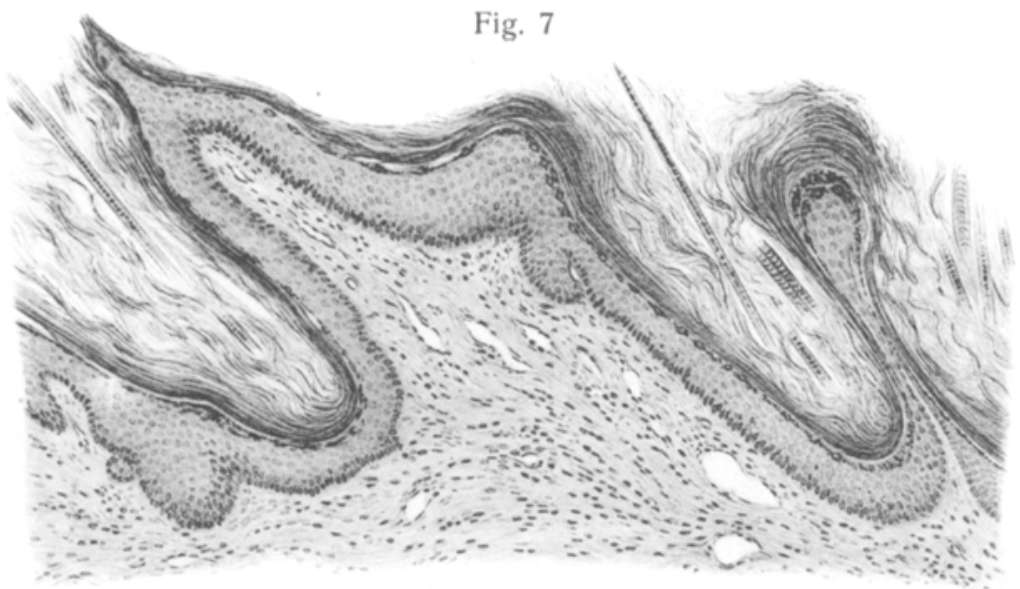

Fig. 8

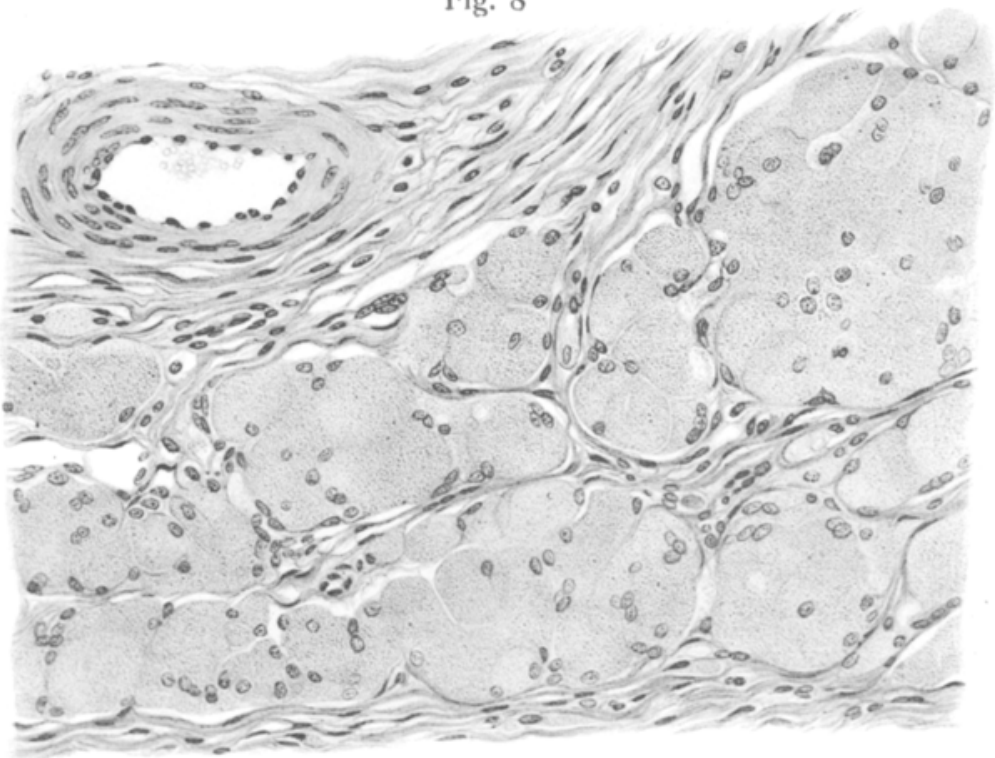

Fig. 9

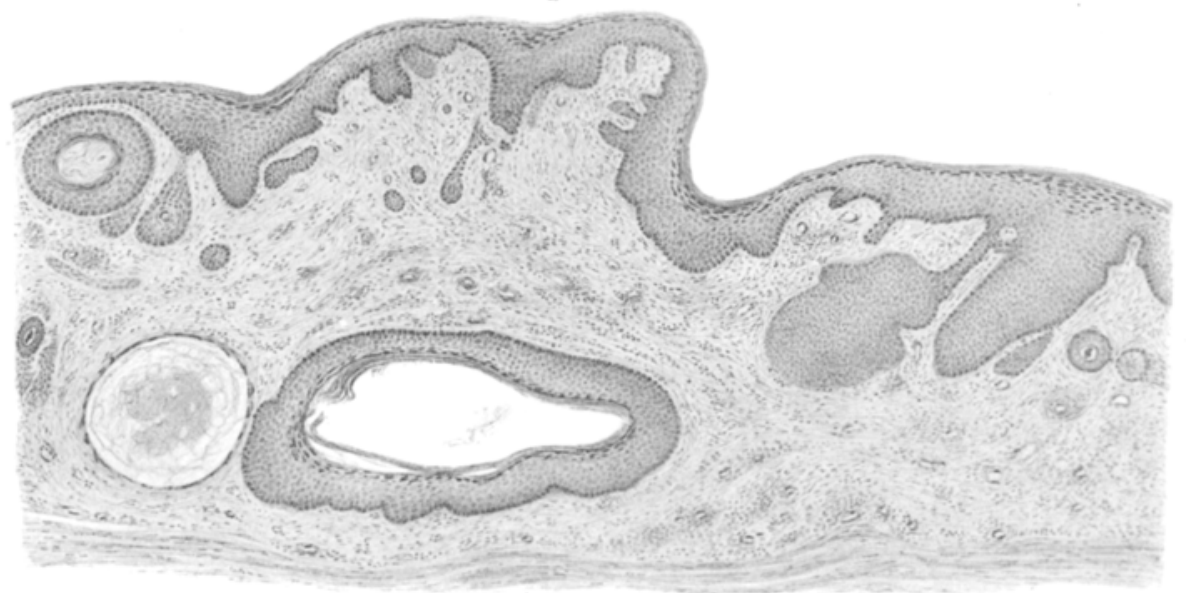

Sachs: Wirkung von Anilinfarbstoffen auf die Haut. 